TECHNICAL REPORT STANDARD TITLE PAGE

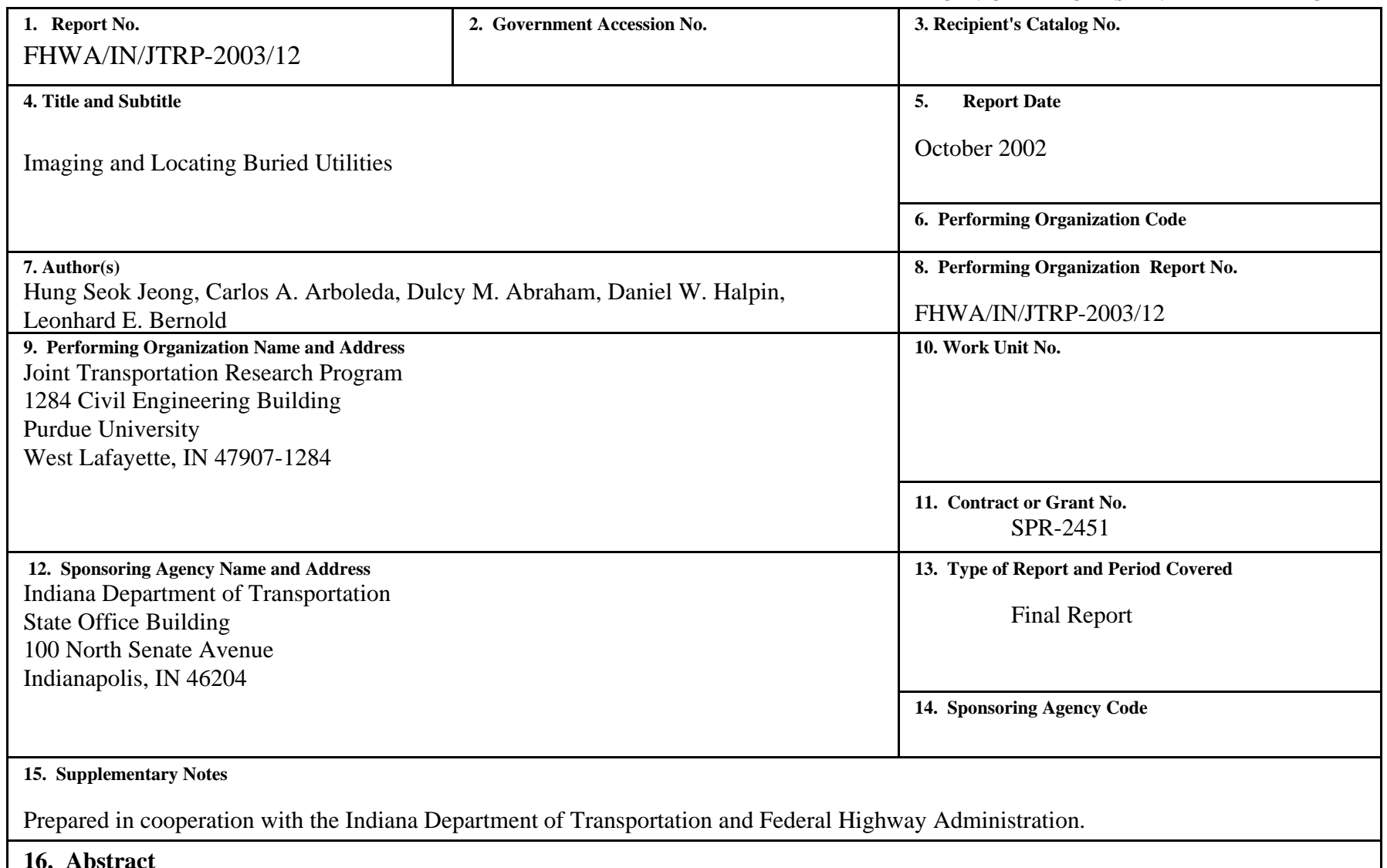

The urban underground has become a spider's web of utility lines, including phones, electricity, gas, cable TV, fiber optics, traffic signals, street lighting circuits, drainage and sanitary sewers and water mains. Utility damages during construction are very significant and on the rise, resulting in construction delays, design changes, claims, property damages, service breakdowns, disruption of neighboring businesses and even injuries and lost lives. The American Institute of Constructors (AIC) reported that damage to utility lines is the third most significant crisis for contractors.

The state-of-the-art and the state-of-the-practice imaging technologies that have potential for being applied in locating underground utilities were identified through literature review and case studies and the conditions under which use of these technologies are most appropriate were analyzed. Based on the characterizations of imaging technologies, a decision tool named IMAGTECH was developed in order to provide site engineers/technicians with a user-friendly tool in selecting appropriate imaging technologies. Quantitative data based on questionnaire surveys to State Department of Transportations (DOTs) and Subsurface Utility Engineering (SUE) providers was used to present comprehensive insight into the various aspects of the rapidly growing market in SUE. A multimedia educational tool was also developed to facilitate a better understanding of underground utility locating systems by the many in the construction domain, particularly entry-level engineers who are relatively unfamiliar with these technologies.

17. Key Words

Subsurface Utility Engineering, One-Call System, Pipe and Cable Locators, Metal Detectors, Electronic Marker Systems, Terrain Conductivity Meter, Ground Penetrating Radar, Acoustic Emission Method, Resistivity Method, Infrared Thermography Method, Micro-gravitational Method, IMAGTECH, Decision Support System, Multimedia Educational Tool. 19. Security Classif. (of this report) Unclassified

\section{Distribution Statement}

No restrictions. This document is available to the public through the National Technical Information Service, Springfield, VA 22161 


\section{TECHNICAL Summary}

INDOT Research

Technology Transfer and Project Implementation Information

TRB Subject Code:21-4 Utilities Accommodation

Publication No.: FHWA/IN/JTRP-2003/12, SPR-2451

October 2003

Final Report

\section{IMAGING AND LOCATING BURIED UTILITIES}

\section{Introduction}

Population growth and industrial expansion since World War II have resulted in increased infrastructure spending particularly in the United States (U.S). The urban underground has become a spider's web of utility lines, including phones, electricity, gas, cable TV, fiber optics, traffic signals, street lighting circuits, drainage and sanitary sewers and water mains. The deregulation of utility services has been adding to the problem of utility congestion as multiple service providers seek to place their networks underground.

New construction in urban areas and a growing number of rehabilitation and replacement projects undertaken to maintain and improve the aging infrastructure have often resulted in increased instances of damages to underground utilities, and undesirable consequences to contractors, project owners and citizens. These consequences include construction delays, design changes, claims, property damages, service breakdowns, disruption of neighboring business and even injuries and lost lives.

The costs of utility damages are very significant and on the rise. Generally, the total cost of damages is underreported because only the direct costs of the emergency response and of repairing the damage are included. The American Institute of Constructors (AIC) reported that damage to utility lines is the third most important crisis for contractors, the other two issues being on-thejob accident requiring hospitalization and contractual dispute with a client resulting in litigation

The major objectives of this study were:

a) to identify, through literature review and case studies, the state-of-the-art and the state-of-the-practice imaging technologies that have potential for being applied in locating underground utilities, and

b) to analyze the conditions under which the use of these technologies is most appropriate because not all technologies can locate all types of utilities, or be used in all types of soil or at all depths.

\section{Findings}

This report evaluated and compared currently available systems for locating underground utilities. The synergistic use of the One-Call system and Subsurface Utility Engineering (SUE) is recommended to improve the safety of the underground pipelines and project efficiency in construction projects.

The report presents a comprehensive overview of various aspects of the new and rapidly growing SUE market. The cost-benefit analysis, based on seventy one (71) actual construction projects where SUE was employed, revealed that more than four times the funds invested in the SUE service were returned to project owners, in the form of savings. The highest cost savings factor was the reduced number of utility relocations. This provides a strong indication that SUE is a promising tool for cost savings in highway construction projects particularly where utilities are congested.

The questionnaire surveys of State DOTs revealed an average increase of $17 \%$ in the 
annual SUE program budget during the 19992001 period, high satisfaction with the use of SUE (>90\%), and an increasing number of states that have initiated the use of SUE for their highway construction projects. The questionnaire survey of the SUE industry revealed various aspects of SUE practices in the private sector. It revealed a rapid growth rate of SUE business (173\%) in the past five years. The major clients are currently State DOTs (>50\%). SUE firms are highly dependent on pipe and cable locators for the designating process and vacuum excavation system for the locating process.

The study examined a variety of underground utility imaging methods, interpretation of the results obtained from each imaging method and application of the method. Based on this analysis, ten criteria were chosen to assist in the selection of the most appropriate imaging technology. The criteria include type of utility, material of utility, joint type of metallic pipe, special material for detection, access point to utility, surface condition, inner state of utility, soil type, the depth of utility and the diameter of utility. A multimedia educational tool was developed to facilitate a better understanding of underground utility locating systems by the many in the construction domain, particularly entry-level engineers who are relatively unfamiliar with these technologies. This tool also contains video streaming files for different imaging technologies recorded during the site visits by the research team. The video clips enable the users to observe the different steps in each of the major imaging technologies.

\section{Implementation}

A Decision Support System named IMAGTECH was developed, in order to provide a tool for the selection of appropriate imaging methods. When a user selects or inputs data that best matches the conditions at the proposed site, the application provides the most appropriate imaging method and two other alternatives with a level of reliability assigned to each imaging method. The application can be used as a training tool to simulate utility locating operations. A multimedia education tool was also developed to facilitate better understanding of the underground utility locating systems for entrylevel civil and construction engineers.

\section{Contacts}

For more information:

Prof. Dulcy Abraham

Principal Investigator

School of Civil Engineering

Purdue University

West Lafayette IN 47907

Phone: (765) 494-2239

Fax: (765) 494-0644

Prof. Daniel Halpin

Principal Investigator

School of Civil Engineering

Purdue University

West Lafayette IN 47907

Phone: (765) 494-2244

Fax: (765) 494-0644

\author{
Indiana Department of Transportation \\ Division of Research \\ 1205 Montgomery Street \\ P.O. Box 2279 \\ West Lafayette, IN 47906 \\ Phone: (765) 463-1521 \\ Fax: (765) 497-1665
}

\section{Purdue University}

Joint Transportation Research Program

School of Civil Engineering

West Lafayette, IN 47907-1284

Phone: (765) 494-9310

Fax: (765) 496-1105 
Final Report

FHWA/IN/JTRP-2003/12

\title{
IMAGING AND LOCATING BURIED UTILITIES
}

\author{
By \\ Hyung Seok Jeong \\ Graduate Research Assistant \\ Carlos A. Arboleda \\ Graduate Research Assistant \\ Dulcy M. Abraham \\ Associate Professor \\ and \\ Daniel W. Halpin \\ Professor \\ School of Civil Engineering \\ Purdue University \\ West Lafayette, Indiana \\ and \\ Leonhard E. Bernold \\ Associate Professor \\ Department of Civil, Construction, and Environmental Engineering \\ North Carolina State University \\ Raleigh, North Carolina \\ Joint Transportation Research Program \\ Project No: C-36-67III \\ File No: 9-10-60 \\ SPR- 2451 \\ Conducted in Cooperation with the \\ Indiana Department of Transportation \\ and the U.S. Department of Transportation \\ Federal Highway Administration
}

The contents of this report reflect the views of the authors, who are responsible for the facts and the accuracy of the data presented herein. The contents do not necessarily reflect the official views or policies of the Indiana Department of Transportation or the Federal Highway Administration at the time of publication. The report does not constitute a standard, specification, or regulation.

Purdue University

West Lafayette, IN 47907

October 2003 


\section{Acknowledgements}

The writers gratefully acknowledge the contribution of DOT utility managers and SUE providers who participated in this study. Special thanks and appreciations are due to Paul Scott (FHWA), James H. Anspach (SO-DEEP Inc.), Nick Zembillas and John Harter (TBE group Inc.) and John Midyette (Accurate Locating Inc.). Without their valuable insight, this research would not have been possible. We are indebted to the members of the Study Advisory Committee (SAC) - Jeffrey Lew (Purdue University); Dave Ward, Dwane Myers, Dwayne Harris, Matt Thomas, James Harrell, James Ude, Victor Trowbridge (INDOT); Paul Berebitsky (Indiana Constructors), and Ed Ratulowski (FHWA) for their commitment to this project, and for their guidance throughout the course of this study.

The financial support of the Joint Transportation Research Program of the Indiana Department of Transportation and Purdue University under grant SPR-2451 is also hereby acknowledged. The contents of this paper reflect the views of the authors, who are responsible for the facts and the accuracy of the data presented herein, and do not necessarily reflect the official views or policies of the Federal Highway Administration and the Indiana Department of Transportation, nor do the contents constitute a standard, specification, or regulation. 


\section{TABLE OF CONTENTS}

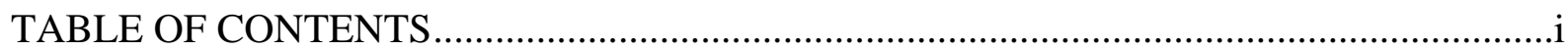

LIST OF FIGURES ……………………..................................................................... viii

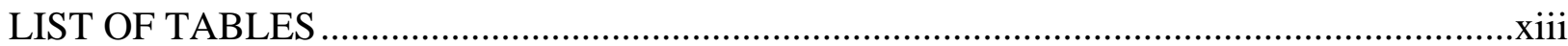

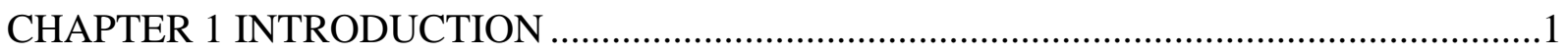

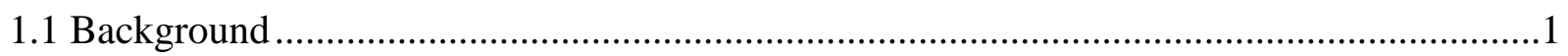

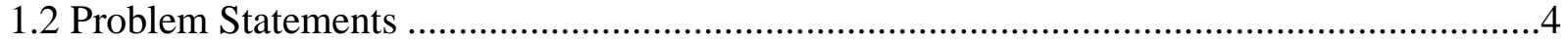

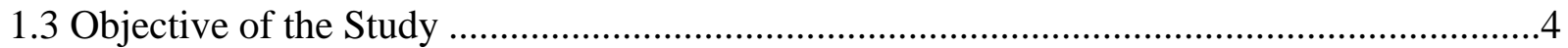

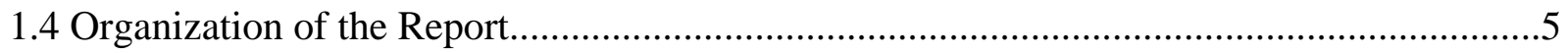

CHAPTER 2 STATE-OF-THE-ART IN MAPPING AND MODELING .....................................6

2.1 Implementing Light Detection and Ranging (LIDAR)......................................................6

2.2 Implementing Side Scan Sonar....................................................................................

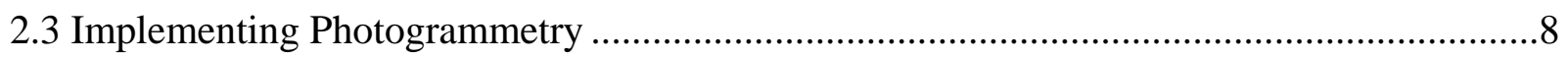

2.4 Implementing Drilling and Sampling Method..................................................................

2.5 CAD-Integrated Excavation and Pipe Laying ……….........................................................10

2.6 Robotic Subsurface Mapping Using Ground Penetrating Radar ............................................12

CHAPTER 3 STATE-OF-THE-PRACTICE IN POSITIONING SYSTEMS AND STATE-OFTHE-ART IN INTEGRATION APPLICATIONS....................................................................

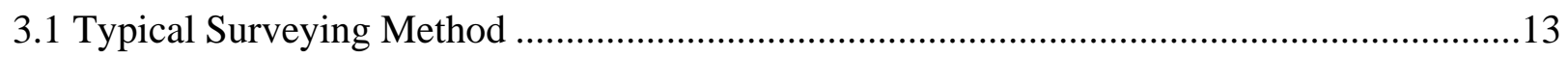

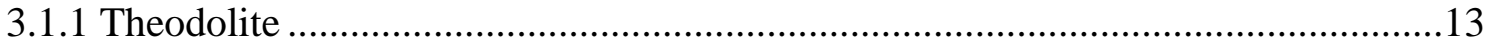

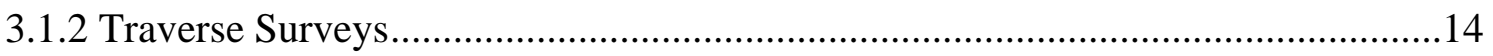


3.2 Geographical Positioning System.....................................................................................

3.2.1 GPS Fundamentals.......................................................................................

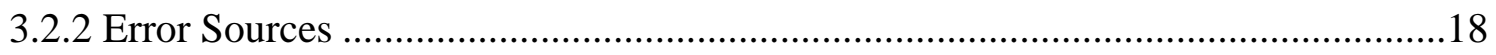

3.2.3 Differential Correction......................................................................................19

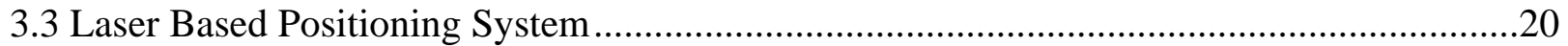

3.3.1 Computer Aided Positioning System (CAPSY ${ }^{\mathrm{TM}}$ ) ..............................................20

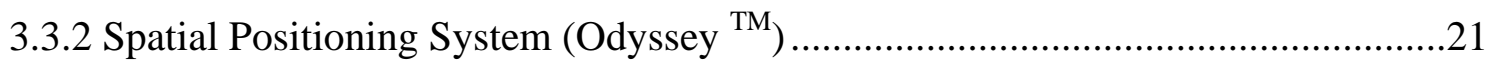

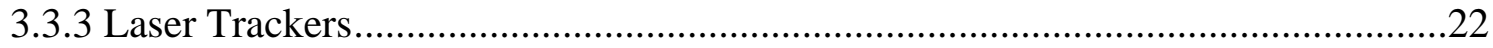

3.3.4 Terrestrial Lidar Mapping Units (CYRAX System)..............................................23

3.3.5 Robotic Total Stations..........................................................................................25

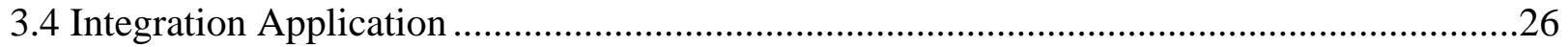

3.4.1 Low-Cost Automatic Yield Mapping In Hand-Harvested Citrus ............................26

3.4.2 Mobile Mapping System for Roadway Data Collection...........................................28

3.4.3 Electronic Navigation for Support Vessels.............................................................30

CHAPTER 4 UNDERGROUND UTILITY LOCATING SYSTEMS .....................................32

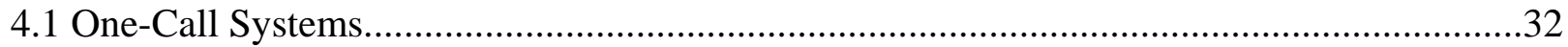

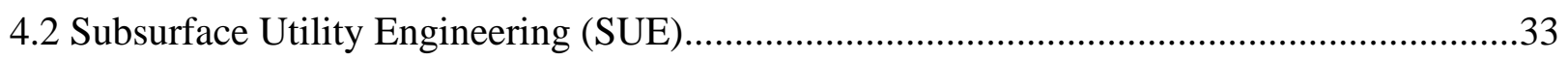

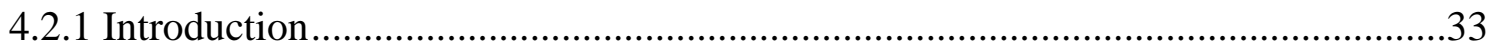

4.2.2 Overview of Subsurface Utility Engineering..........................................................34

4.2.2.1 Quality Levels in SUE ............................................................................34

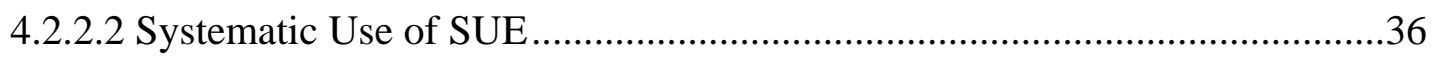

4.2.2.3 Major Activities in SUE.............................................................................

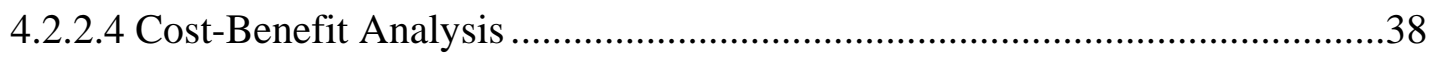

4.2.3 Current SUE Practice in State DOTs ...................................................................42

4.2.4 Current SUE Practice in Industry ..........................................................................45

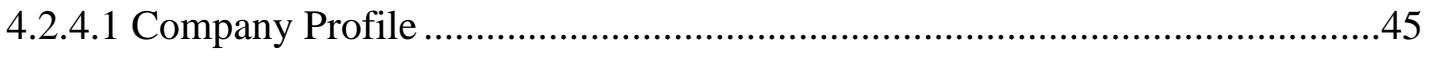

4.2.4.2 The Clients and Types of Contracts...............................................................48

4.2.4.3 Project Practices and Control of Operations ...................................................52

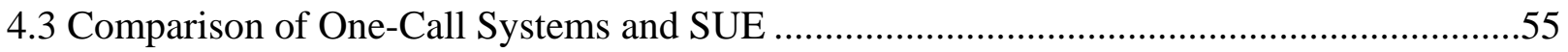


CHAPTER 5 SURFACE UTILITY IMAGING (DESIGNATING) \& LOCATING

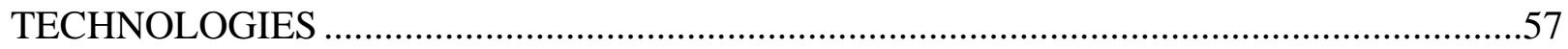

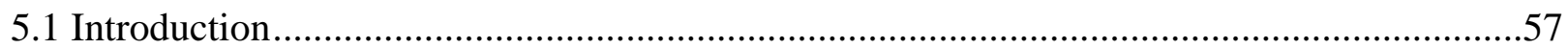

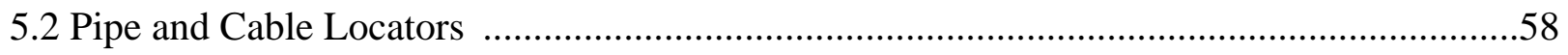

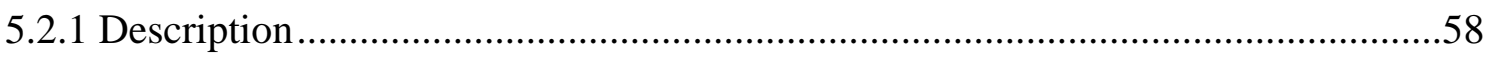

5.2.2 Main Features and Application Ranges ...........................................................61

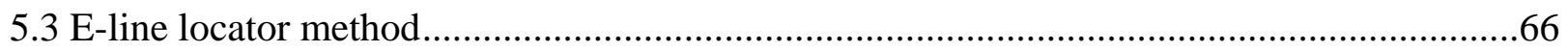

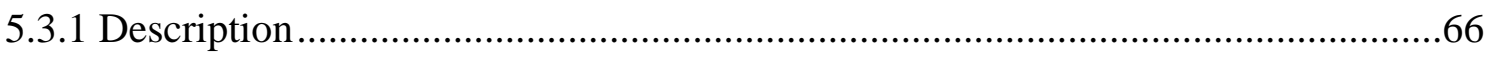

5.3.2 Main Features and Application Ranges ......................................................67

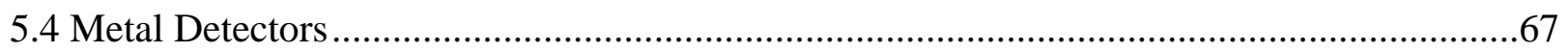

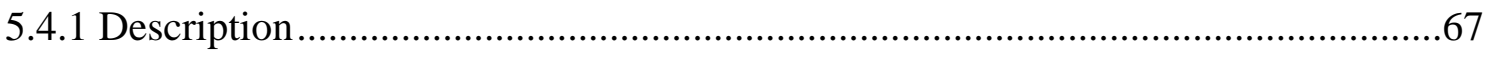

5.4.2 Main Features and Application Ranges ......................................................68

5.5 Electronic Marker System (EMS) ........................................................................69

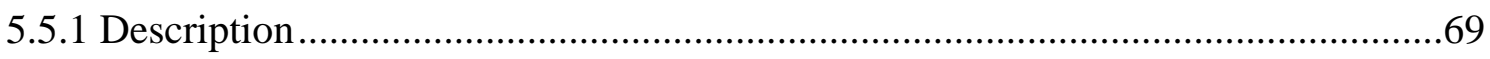

5.5.2 Main Features and Application Ranges ..........................................................69

5.6 Terrain Conductivity Method - Electromagnetic Method ................................................70

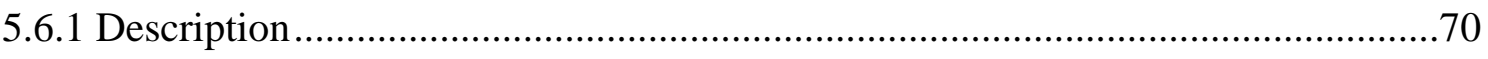

5.6.2 Main Features and Application Ranges ........................................................71

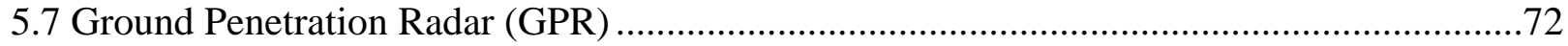

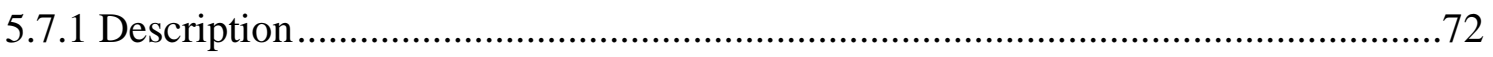

5.7.2 Main Features and Application Ranges ........................................................74

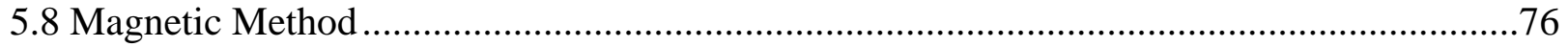

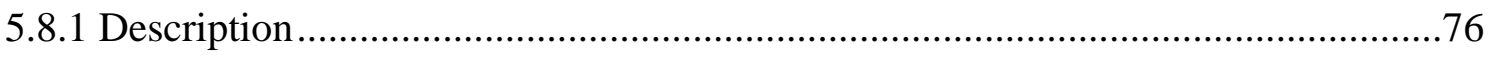

5.8.2 Main Features and Application Ranges ......................................................77

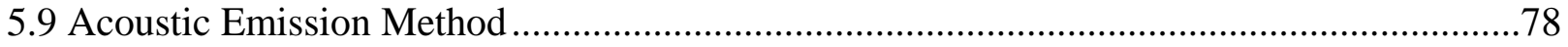

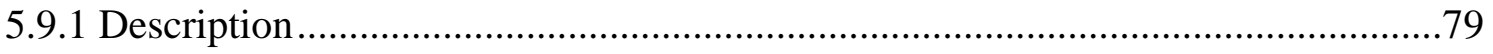

5.9.2 Main Features and Application Ranges .....................................................79

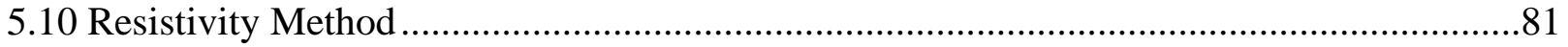

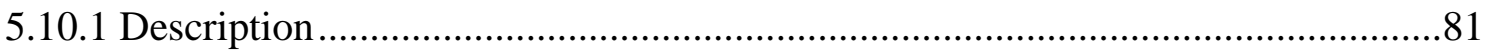


5.10.2 Main Features and Application Ranges ..............................................................82

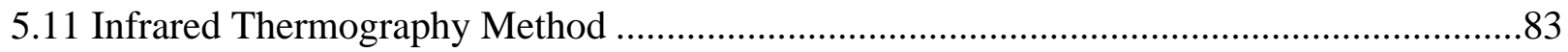

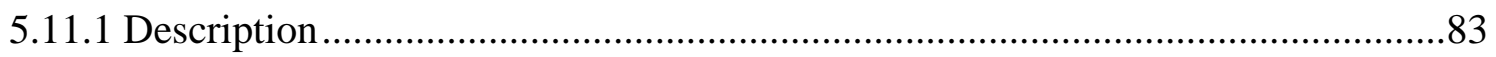

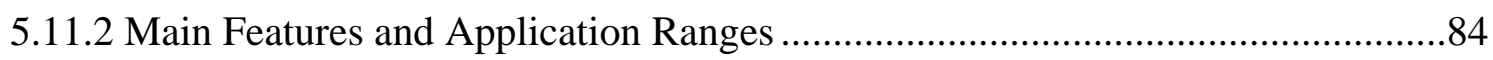

5.12 Microgravitational Techniques .........................................................................................

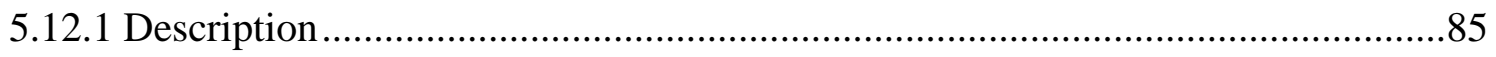

5.12.2 Main Features and Application Ranges ............................................................87

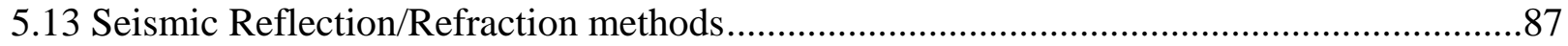

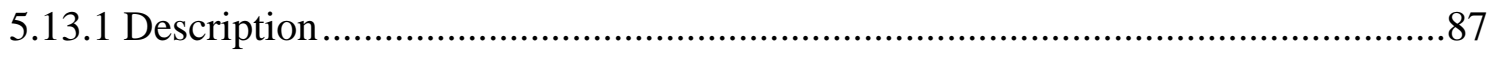

5.13.2 Main Features and Application Ranges ............................................................8

5.14 Vacuum Excavation System (Locating Technology) ...........................................................89

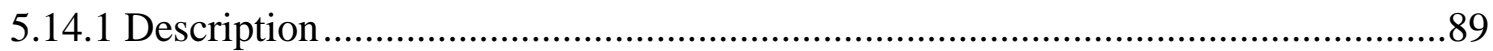

5.14.2 Main Features and Application Ranges .................................................................91

5.15 Summary Table of Subsurface Utility Designating Methods ................................................93

CHAPTER 6 PERFORMANCE CRITERIA FOR IMAGING AND LOCATING

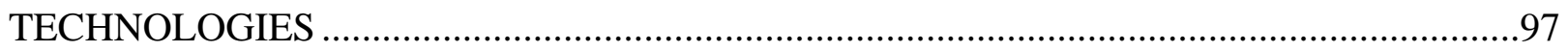

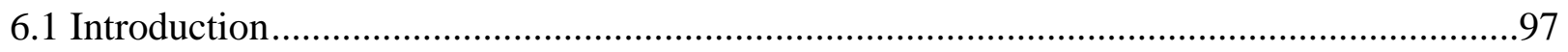

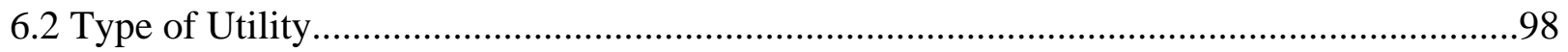

6.3 Material of Utility …………………........................................................................100

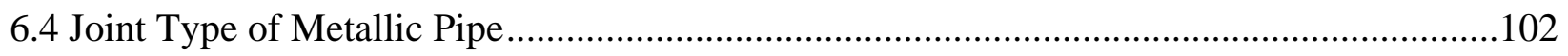

6.5 Special Materials for Detection of Underground Utility ..................................................107

6.6 Access Point to Utility ........................................................................................................108

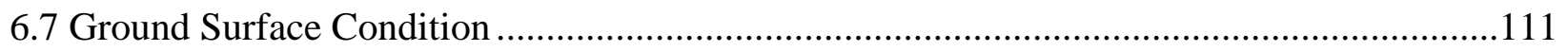

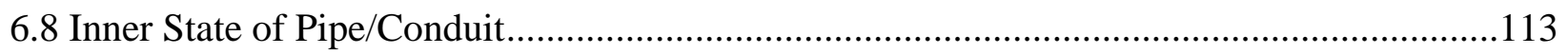

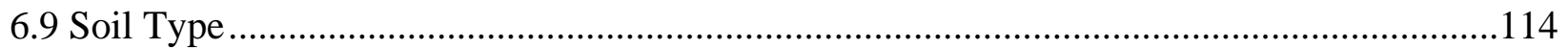

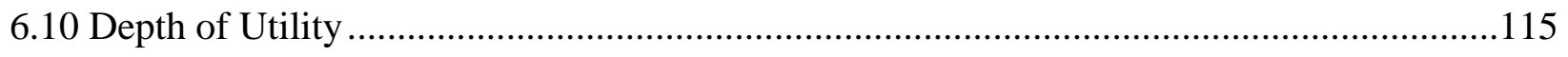

6.11 Utility Diameter/Depth Ratio..........................................................................................117

6.12 Summary Table ...............................................................................................................118 


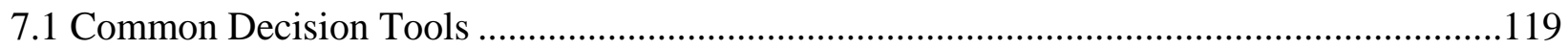

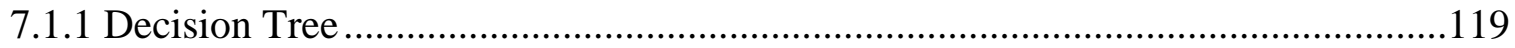

7.1.2 Analytical Hierarchy Process (AHP) ....................................................................120

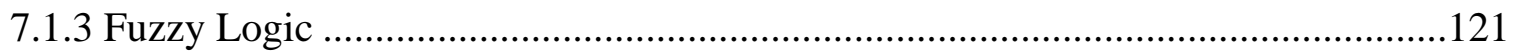

7.1.4 Artificial Neural Network (ANN) ......................................................................122

7.1.5 Genetic Algorithm (GA) .................................................................................123

7.2 Features Required for a Decision Tool in the DSS ...........................................................124

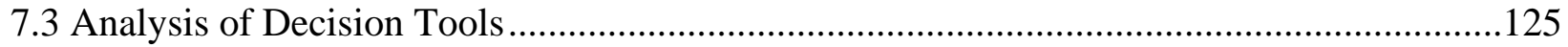

7.4 Deterministic Parallel Selection Technique (DPST) …….......................................................125

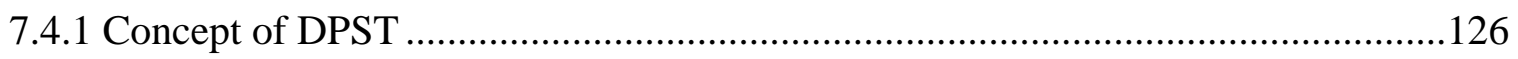

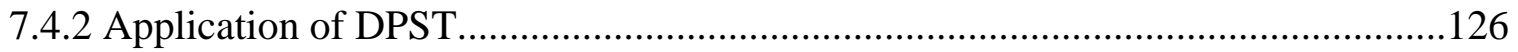

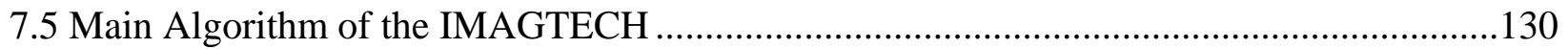

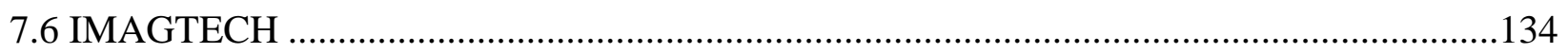

7.6.1 The Initial Screen and Pre-Stage............................................................................134

7.6.2 Step 1: Type of Utility \& Material of Utility ...........................................................137

7.6.3 Step 1: Type of Utility \& Material of Utility ...........................................................139

7.6.4 Step 3: Access Point to Utility \& Ground Surface Condition ..................................140

7.6.5 Step 4: Inner State of the Pipe and Soil Type ........................................................137

7.6.6 Step 5: The Depth of Utility \& Diameter of Utility ....................................................142

7.6.7 Step 6: Summary of the Input Data..........................................................................143

7.6.8 Final Result: Recommended Designating Methods.................................................145

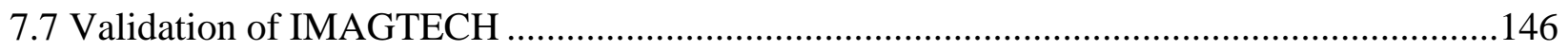

7.7.1 Mira Vista St./Vista Del Sol Dr. Bridges Project, Las Vegas, NV ...........................142

7.7.2 INDOT- SUE on SR27 in Richmond, IN127 ........................................................150

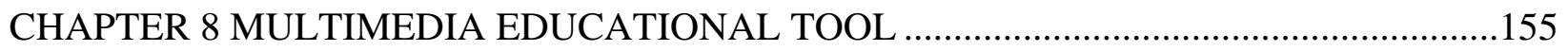

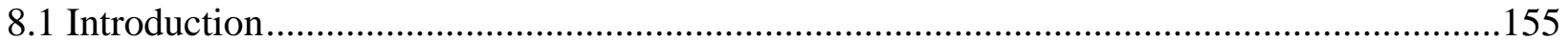


8.2 Main Page 155

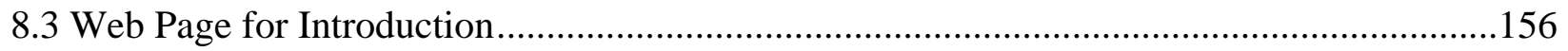

8.4 Web Pages for Underground Utility Locating Systems........................................................157

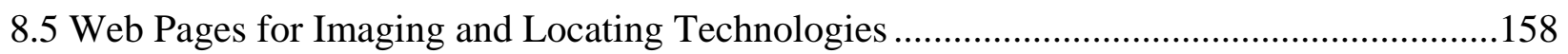

8.6 Web Pages for IMAGTECH............................................................................................160

8.7 Web Pages for Related Links...........................................................................................161

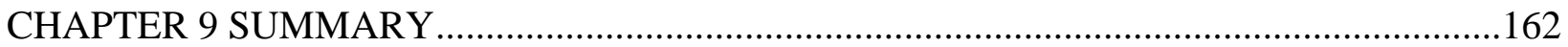

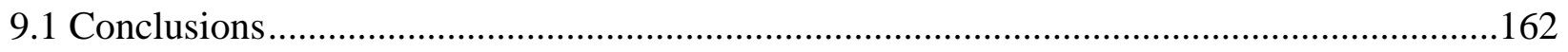

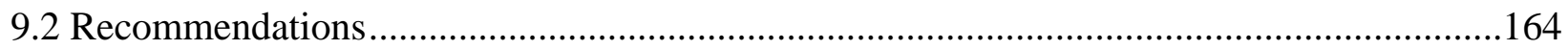

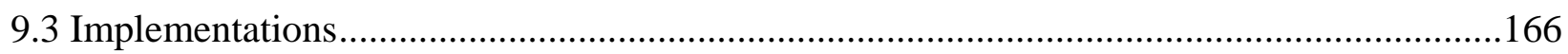

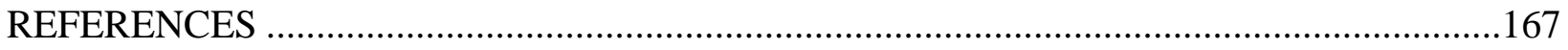

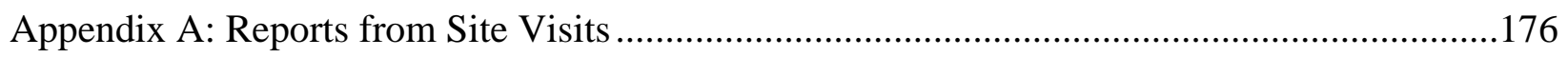

Appendix B: Questionnaire used for Field Data Collection ..........................................................197

Appendix C: Questionnaire (STATE DOT) …………........................................................199

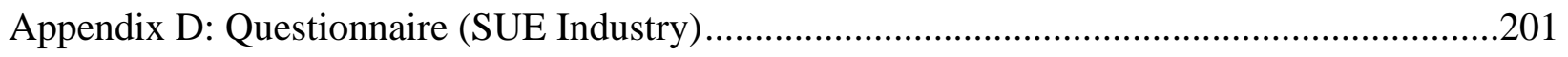

Appendix E: Accident and Damage Prevention Model...............................................................209

E1: Accident and Damage Prevention Modeling and Concepts .......................................209

E1.1 Current Model and Problems........................................................................209

E1.2 Proposed Model...................................................................................210

E2: System Prototype Design .......................................................................................212

E2.1 Utility Location Assessment...................................................................212

E2.1.1 System Platform ....................................................................212

E2.2 Proposed Prototypes ............................................................................216

E2.2.1 Prototype1 Implementing Auto-Tracking Station ..........................218

E2.2.2 Prototype 2 Implementing GPS ..................................................218

E2.2.3 Prototype 3 Implementing a Laser Based Positioning System.....220

E3: Field Experiments and the Analysis of Field Data....................................................222 
E3.1 SPS-CAD and Additional Calculation Formula......................................222

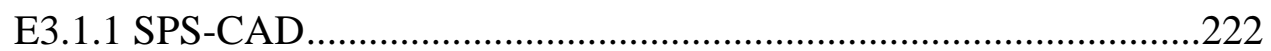

E3.1.2 Algorithm for TCAP (Trench Calculated Point) ........................224

E3.1.3 TCAP Depth Adjustment .....................................................225

E3.2 The Initial Field Experiment ..............................................................226

E3.2.1 Setting Up the Reference Points and Odyssey .........................226

E3.2.2 Data Collection................................................................222

E3.2.3 Analysis of Initial Field Experiment .......................................229

E3.2.4 Questions to the Final Experiment ...........................................231

E3.3 The Final Field Experiment.............................................................232

E3.3.1 Setting up the reference Points and Odyssey .............................232

E3.3.2 Data Collection and Analysis of the Final Field Experiment.......234

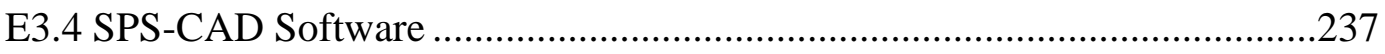

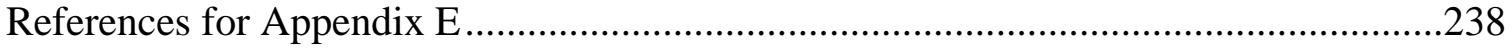

Appendix F: Diskette (IMAGTECH and Source Codes) 


\section{LIST OF TABLES}

Table 3.1 Traverse Specifications - United States (Kavanagh 2001) .....................................15

Table 3.2 Positional Tolerances for Land Title Surveys......................................................15

Table 3.3 American Congress on Surveying and Mapping Minimum Angle, Distance, and Closure Requirements for Survey Measurements That Control Land Boundaries for ALTA-ACSM LAND TITLE SURVEY (1)................................................16

Table 3.4 GPS errors from all sources before and after Differential Correction .......................19

Table 4.1 Categories for Quantification of SUE Cost Savings (Lew 2000) .............................39

Table 4.2 Summary of Cost-Benefit Analysis of SUE ......................................................41

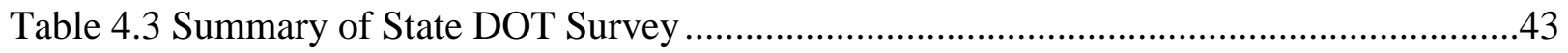

Table 4.4 Annual Sales, Geographical Domain \& Number of Employees ..............................46

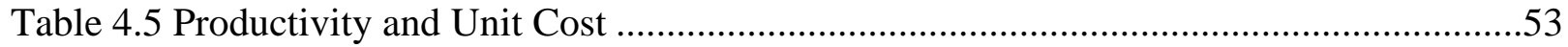

Table 4.6 Factors Challenging SUE Projects...............................................................54

Table 4.7 Comparison of One-Call System and SUE in Construction Project..........................56

Table 5.1 Operating Frequencies of Electronic Markers .......................................................70

Table 5.2 Factors Affecting Result of Infrared Thermography ............................................84

Table 6.1 Applicability of the Type of Utility to Designating Methods...................................100

Table 6.2 Classification of Materials of Underground Utilities .............................................101

Table 6.3 Classification of Designating Methods by Detectable Material Type.......................101

Table 6.4 Applicability of Material of Utility to Designating Methods ...................................102

Table 6.5 Applicable Joints of Metallic Pipe to Designating Methods ....................................107

Table 6.6 Applicability of Special Materials for Detection to Designating Methods .................107

Table 6.7 Physical Access Points to Underground Utilities ....................................................108

Table 6.8 Classification of Subsurface Utility Designating Methods

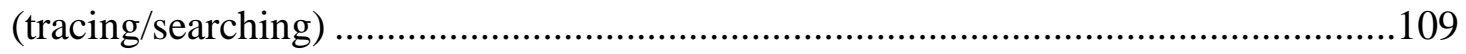

Table 6.9 Applicability of Access Point of Utility to Designating Methods .............................111

Table 6.10 Applicability of Ground Surface Condition to Designating Methods ......................112 
Table 6.11 Applicability of Inner State of Pipe and Conduit to designating methods .114

Table 6.12 Relationship Between Soil Type and Designating Methods .115

Table 6.13 Detectable Range of Depth of Designating Methods

Table 7.1 Analysis of Five Decision Tools .125

Table 7.2 Identification of Applicability of Entries to Each Designating Method.....................128

Table 7.3 Summary of Project Data (Mira Vista St./Vista Del Sol Dr. Bridges) .......................148

Table 7.4 Comparison of Actually Applied Method and Recommended Methods....................149

Table 7.5 Summary of the Site Condition (INDOT- SUE on SR27 in Richmond, IN)...............152

Table 7.6 Comparison of Actually Applied Method and Recommended Methods. .154

Table E2.1 Position-Measuring Instruments and Their Compared Features..... .216

Table E3.1. Coordinates of Four Reference Points...............................................................226

Table E3.2 Receiver Position, ATP, and CTP Data ...........................................................228

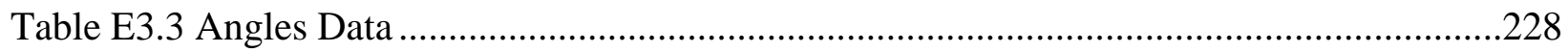

Table E3.4 Coordinates of Four Reference Points.................................................................233 


\section{LIST OF FIGURES}

Figure 1.1 Cause and Effect Diagram of Subsurface Facilities Damage.....................................2

Figure 1.2 Key Elements to Damage Prevention...........................................................................

Figure 2.1. An Image Generated by LIDAR application..........................................................6

Figure 2.2 Side-Scan Sonar application and signal interpretation .............................................

Figure 2.3 Single Point Triangulation and Multiple Points Triangulation ...................................8

Figure 2.4 CSIRO’s photogrammetry Implementation (left) and Sirojoint Application

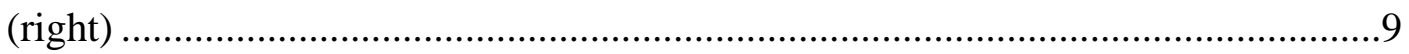

Figure 2.5 Geosoft's Wholeplot ${ }^{\mathrm{TM}}$ Drillhole Plotting application.............................................10

Figure 2.6 Concept of Trench Excavation Using Laser Guidance ...............................................11

Figure 3.1 The Seventeenth Century Theodolite (Left) and The Successor (Right) ....................14

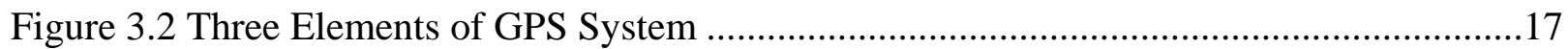

Figure 3.3 CASPY and Its Applications ............................................................................20

Figure 3.4 Odyssey Transmitters, Receiver, and Control Station Terminal ................................22

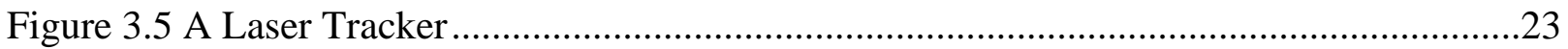

Figure 3.6 The CYRAX Laser-Mapping and Imaging System .................................................24

Figure 3.7 Robotic Total Stations ........................................................................................25

Figure 3.8 General Schematic Diagram of the CHTS ..........................................................27

Figure 3.9 Georeferenced Aerial Photograph of 3.5-ha Block Overlaid with Harvested

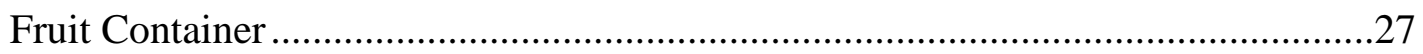

Figure 3.10 Weighing systems for measuring weight for citrus yield .......................................28

Figure 3.11 The MMS basic process of collecting digital measurements ..................................29

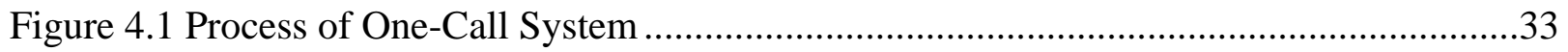

Figure 4.2 Quality Levels in SUE..........................................................................................35

Figure 4.3 Systematic Use of SUE in a Construction Project.......................................................37

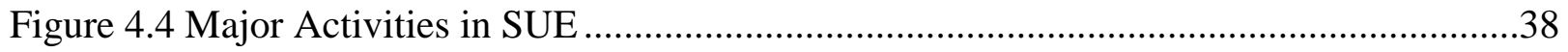

Figure 4.5 Degree of Impact of Different Categories to Cost Savings .........................................42

Figure 4.6 Business Growth of SUE Providers .........................................................................4 
Figure 4.7 Breakdown of Contract Methods in SUE

Figure 5.1 Various Designating Methods for Underground Utilities ..........................................58

Figure 5.2 Principle of Pipe and Cable Locators .......................................................................59

Figure 5.3 Frequency and Length of Radio Frequency Travel..................................................60

Figure 5.4 Frequencies and Coupling to Adjacent Pipes................................................................60

Figure 5.5 Examples of Hook-up to Physical Access Point to Utility............................................61

Figure 5.6 Designating Subsurface Utility Using a Receiver .......................................................62

Figure 5.7 Inductive Mode Designating ............................................................................63

Figure 5.8 Condition of Passive Mode Designating ..................................................................64

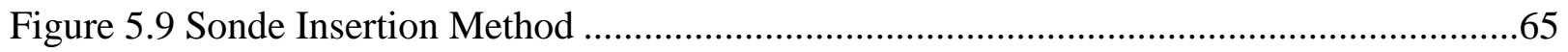

Figure 5.10 Installation of Metallic Tape …………………….............................................65

Figure 5.11 E-line Locator ...........................................................................................66

Figure 5.12 Detection of Ferromagnetic Object ......................................................................67

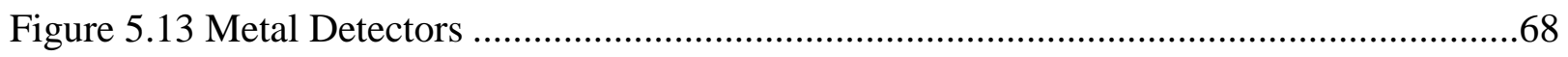

Figure 5.14 Electronic Markers \& Electronic Marker Locator......................................................69

Figure 5.15 Principle of Terrain Conductivity Method .................................................................70

Figure 5.16 Application of Terrain Conductivity Method...........................................................72

Figure 5.17 Principle of GPR Method .......................................................................................72

Figure 5.18 GPR Application by Hand and by Truck ……………………...............................73

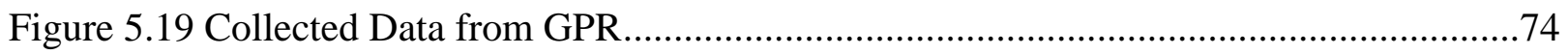

Figure 5.20 Principle of Magnetic Method...........................................................................76

Figure 5.21 Application of magnetic method ..............................................................................77

Figure 5.22 Principle of Acoustic Emission Method................................................................79

Figure 5.23 Acoustic Pipe Tracers (for Gas pipe (left) and for water pipe (right)) ......................80

Figure 5.24 Principle of Resistivity Method...............................................................................81

Figure 5.25 2-D Resistivity Imaging for Detection of a Buried Sewer Pipe .................................82

Figure 5.26 Application of resistivity method ............................................................................82

Figure 5.27 Infrared Thermography Equipment and Image Taken (Steam pipe)........................85

Figure 5.28 Application of Microgravitational Techniques and the Microgravimeter..................86 
Figure 5.29 Sketch of Seismic Reflection and Seismic Refraction Methods .88

Figure 5.30 Removal Process …………………………….................................................90

Figure 5.31 Reduction Process with High-Pressure Air ...............................................................90

Figure 5.32 Self-Contained Vacuum Excavation Truck Systems ................................................91

Figure 6.1 Breakdown of Estimated Pipeline Replacement and New Pipeline Installation in the North America by Responsible Agencies .................................................................98

Figure 6.2 Sonde Inserted to a Pipe through a Special Canopy .......................................................99

Figure 6.4 Various Joints for Steel Pipes ..................................................................................103

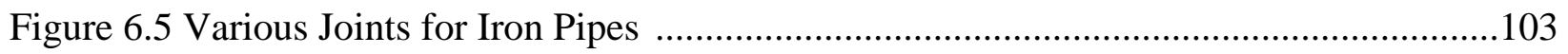

Figure 6.6 Cathodic Protection System ...............................................................................104

Figure 6.7 Joint Types of Metallic Pipe .................................................................................105

Figure 6.8 Electrical Continuity of Pipe Versus Frequency .......................................................106

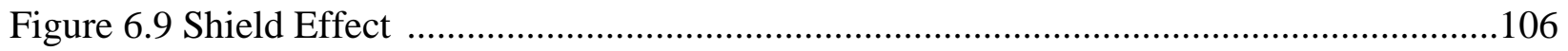

Figure 6.10 Common Physical Access Points to Urban Utilities ...............................................109

Figure 6.11 Soil Conductivity ...............................................................................................115

Figure 7.1 Research and Development Decision Tree................................................................120

Figure 7.2 Architecture of Artificial Neural Network ..................................................................122

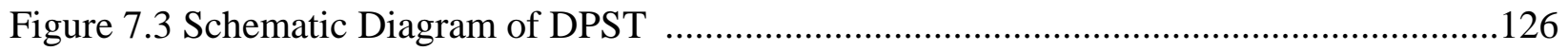

Figure 7.4 Simplified Example for Application of DPST ……………..................................127

Figure 7.5 Numeric Conversion of Linguistic Applicability ......................................................128

Figure 7.6 Step1 and Step2 Matrices ...................................................................................129

Figure 7.7 Step 4: Selection of Appropriate Imaging Technologies ...........................................130

Figure 7.8 Main Algorithm of the Computer Application ...........................................................133

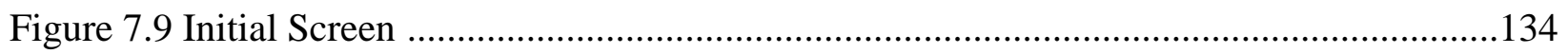

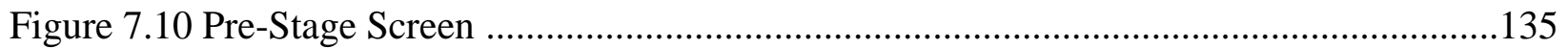

Figure 7.11 Connected Internet Page (Terrain Conductivity Method) ..........................................136

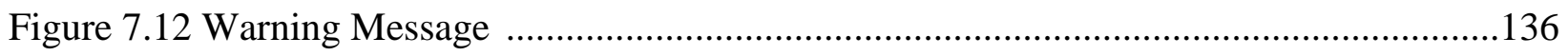

Figure 7.13 Step 1 Screen: Type of Utility \& Material of Utility ................................................137

Figure 7.14 Help Screen for Material of Utility ……….............................................................138 
Figure 7.15 Step 2 Screen: Joint Type of Metallic Pipe \& Special Material for Detection 139

Figure 7.16 Step 3 Screen: Access Point to Utility \& Ground Surface Condition .140

Figure 7.17 Step 4 Screen: Inner State of the Pipe and Soil Type..........................................142

Figure 7.18 Step 5 Screen: The Depth of Utility \& Diameter of Utility ..................................143

Figure 7.19 Step 6 Screen: Summary of the Input Data ......................................................144

Figure 7.20 The Final Screen: Recommended Designating Methods .....................................145

Figure 7.21 Project Location: Mira Vista St./Vista Del Sol Dr. Bridges..................................147

Figure 7.22 Application of Acoustic Pipe Tracer (RD 500) ................................................148

Figure 7.23 Results of the Computerized Decision Tool for the Mira Vista Street Area............149

Figure 7.24 Project Location: INDOT- SUE on SR27 in Richmond, IN ................................150

Figure 7.25 Applications of Pipe and Cable Locator -Inductive Mode ...................................151

Figure 7.26 Result Screen for INDOT-SUE on SR27 in Richmond, IN project.......................153

Figure 8.1 Structure of Multimedia Web Pages.................................................................155

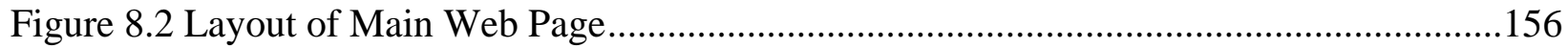

Figure 8.3 Layout of Introduction Page .........................................................................157

Figure 8.4 Layout of Underground Utility Locating Systems Web Page.................................158

Figure 8.5 Designating and Locating Technologies Described in Web Pages ...........................158

Figure 8.6 Layout of Imaging and Locating Technologies Web Pages....................................159

Figure 8.7 Captured Image of Video Clips ...........................................................................160

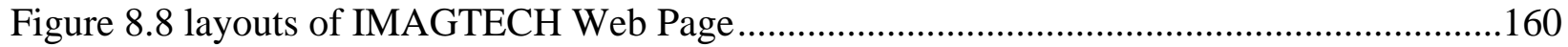

Figure 8.9 Layout of Links Web Page ............................................................................161

Figure E1.1 Proactive Accident Preventions Model, Prevention stage, and Reactive Litigation

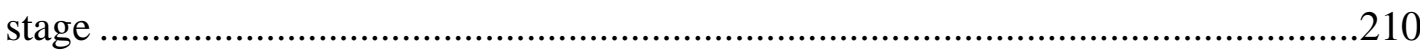

Figure E1.2 AMM Information and Layers ..................................................................211

Figure E1.3 The Proactive Damage Prevention Concept ......................................................211

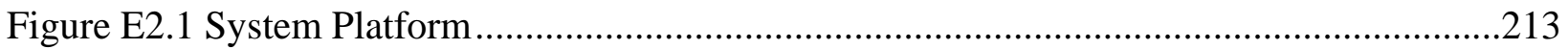

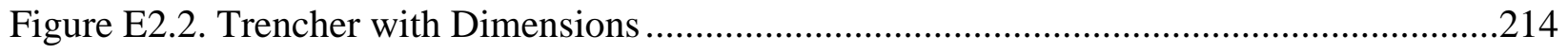

Figure E2.3 Simplifying Diagram for Determining Utility Location When $\theta_{X}=0 \theta_{Y}=0 \ldots \ldots . .214$

Figure E2.4 Simplifying Diagram for Determining Utility Location When $\theta_{\mathrm{X}}=0 \theta_{\mathrm{Y}} \neq 0 \ldots \ldots . .215$ 
Figure E2.5 Simplifying Diagram for Determining Utility Location When $\theta_{X} \neq 0 \theta_{Y} \neq 0 \ldots \ldots . .215$

Figure E2.6 Prototype 1 Implementing Auto-Tracking Total Station ....................................217

Figure E2.7 Analysis of Two Strategies in the Prototype 1...............................................218

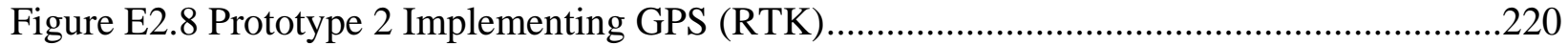

Figure E2.9 The Prototype 3 Implementing a Laser Based Positioning...................................221

Figure E2.10 The Top View Picture of The Prototype 3 Set-up ............................................221

Figure E3.1. The Reading Screen of SPSi or Odyssey ….................................................222

Figure E3.2. T2-7200 Inclinometer and USB1 Data Acquisition from US Digital....................223

Figure E3.3. The Locations of Three Inclinometers on the Trencher.......................................223

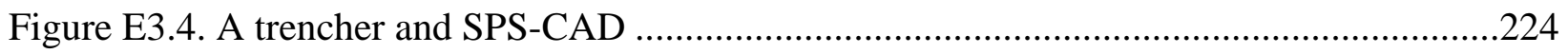

Figure E3.5. The Algorithm of Direction Correction .......................................................225

Figure E3.6. Depth Adjustment of TCAP.........................................................................225

Figure E3.7. Reference Points and Transmitters Location ...................................................226

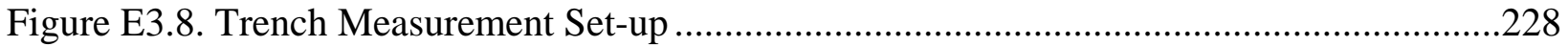

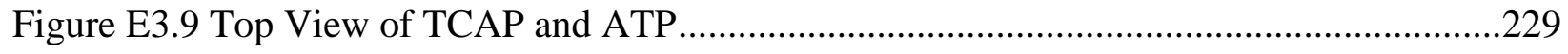

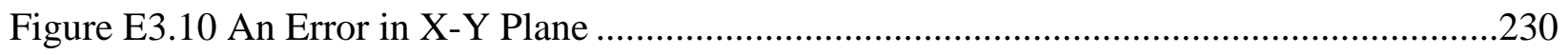

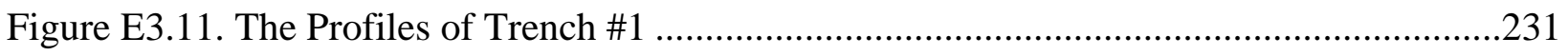

Figure E3.12. The Advantages of Real-time Data Collection ..............................................231

Figure E3.13. Reference Points and Transmitters Location ................................................232

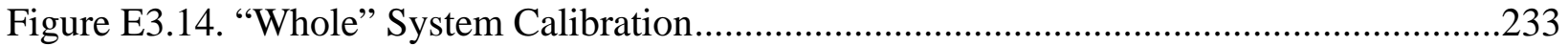

Figure E3.15. Coordinate-Correction Values .................................................................234

Figure E3.16. Locations of a Receiver, TCAP, and ATP ....................................................234

Figure E3.17. Locations While Hitting Objects.................................................................235

Figure E3.18. An Error in XY Plane...........................................................................236

Figure E3.19. The Scenario Showing Self-Correcting Direction ..........................................236

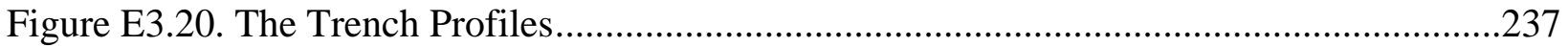

Figure E3.21 Data Flow Diagram of SPS-CAD Software .................................................238 


\section{CHAPTER 1 INTRODUCTION}

\subsection{Background}

Population growth and industrial expansion since World War II have resulted in increased infrastructure spending particularly in the United States (U.S). (Lew et al. 2000). Approximately 14 million miles of subsurface utilities make American infrastructure the envy of the world (GeoSpec LLC, 2002). However, the urban underground has become a spider's web of utility lines, including phones, electricity, gas, cable TV, fiber optics, traffic signals, street lighting circuits, drainage and sanitary sewers and water mains. The deregulation of utility services has been adding to the problem of utility congestion as multiple service providers seek to place their networks underground.

New construction in urban areas and the growing number of rehabilitation and replacement projects undertaken to maintain and improve the aging infrastructure have often resulted in increased instances of damages to underground utilities, and undesirable consequences to contractors, project owners and citizens. These consequences include construction delays, design changes, claims, property damages, service breakdowns, disruption of neighboring businesses and even injuries and lost lives.

The costs of utility damages are very significant and on the rise. In 1993, there were more than 104,000 hits or third party damage to gas pipelines with a total cost exceeding $\$ 83$ million (Doctor et al. 1995). A 1996 survey in Kansas reported that the total cost of the reported damages was $\$ 4,663,544$, and that 1.2 million locates were requested from members of OneCall. In 1997, Memphis Light, Gas and Water paid damages of \$515,000 and collected damages of $\$ 793,000$ for utility damage (Stinson 1998). Damage to underground utilities can cause vital facility outages for homes, businesses, hospitals, air and ground traffic control operations, and emergency service providers. Generally, the total cost of damages is underreported because only the direct costs of the emergency response and of repairing the damage are included (Lorenc and Bernold 1998). Heinrich (1996) revealed that the total costs associated with an accident reported 
in the media to cost $\$ 15,000$ were actually closer to $\$ 313,000$, which was almost twenty times higher than the originally expected cost of the damage. The American Institute of Constructors (AIC) reported that damage to utility lines is the third most important crisis for contractors, the other two issues being on-the-job accident requiring hospitalization and contractual dispute with a client resulting in litigation (Reid 1999).

In August 1999, Common Ground published the study of One-Call Systems and Damage Prevention Best Practice. It defines that all of parties relating to subsurface utilities placement can be the cause of the accident. There are Facility Owners/Operators, Excavators, One-Call Centers, and Locators. The cause and effect diagram of subsurface facilities damage is summarized in Figure 1.

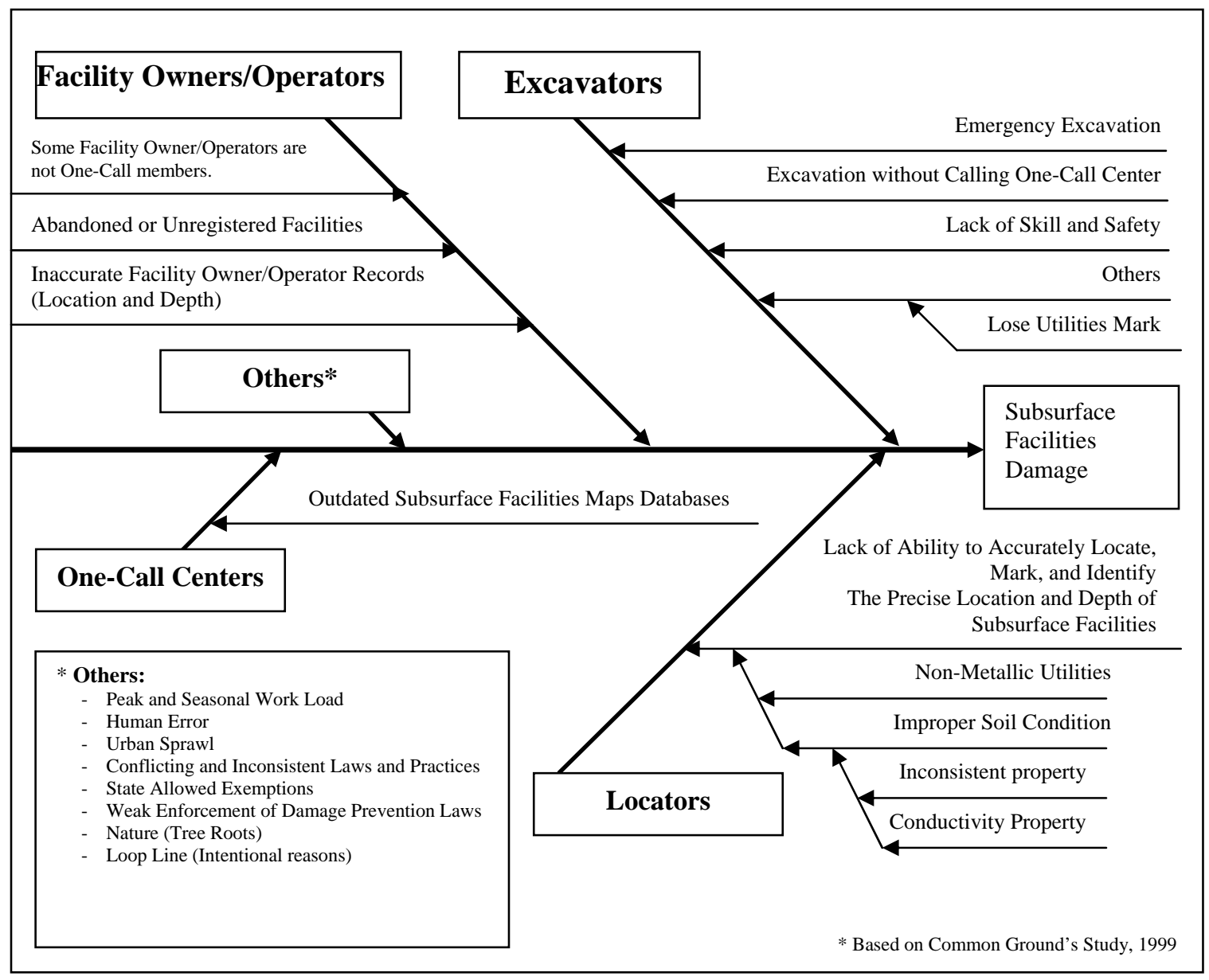

Figure 1.1 Cause and Effect Diagram of Subsurface Facilities Damage 
Figure 2 shows the damage prevention strategies suggested by Common Ground. It is clear that determining the location of subsurface facilities, and maintaining accurate mapping files is essential in preventing damage to utilities and the communities they serve.

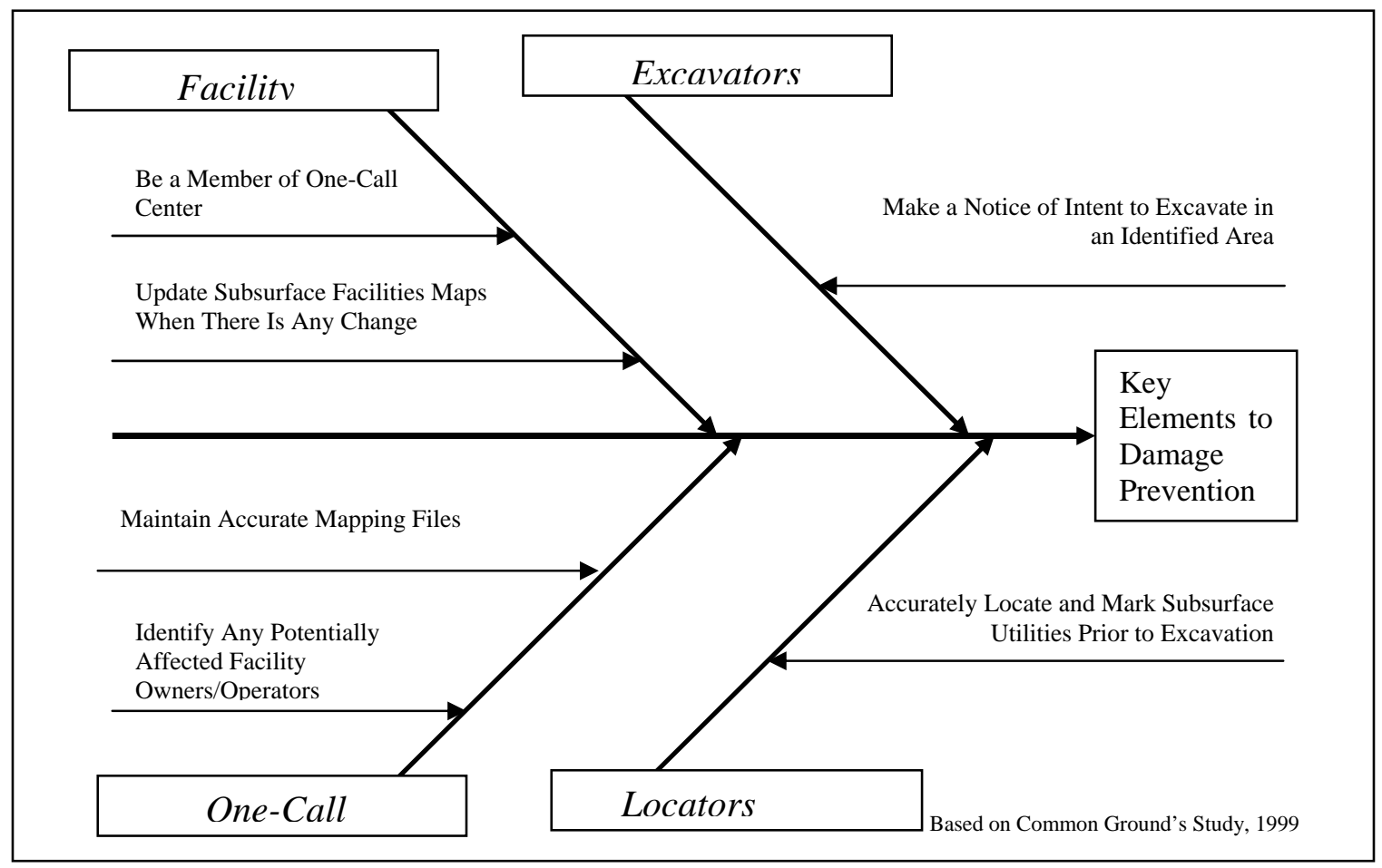

Figure 1.2 Key Elements to Damage Prevention

Subsurface utility mapping is becoming an essential process to reduce the adverse effect of damages to utilities, before construction starts. Since records about utility positions are virtually nonexistent, or often incomplete and inaccurate with errors as high as 15-30\% (Stevens and Anspach 1993), the ability to physically determine on-site the location, nature and depth of underground utility services is critical. One of the organized efforts to diminish the risk of utility hits and subsequent damage is the One-Call system, which is a state-regulated program that requires utility owners to mark the location of known active facilities on the ground surface prior to construction (Lew 2001). The involvement of the One-Call system in the construction stage, however, limits its benefits to mere avoidance of utility hits. Subsurface Utility Engineering (SUE) which has emerged in the past two decades characterizes the quality of subsurface utility information utilizing surface geophysical imaging technologies, civil engineering, surveying and 
data management skills during the design phase of a construction project. The employment of SUE in the design stage allows not only the prevention of utility damage but also minimizes the costs of utility relocates, design changes and utility related construction delays.

\subsection{Problem Statement}

The success of both One-Call system and SUE system is initialized by correct identification of underground utility. However, a wide variety of geophysical imaging technologies and different application conditions pose challenges in selecting appropriate imaging technologies. Fifty six percent of the damages in 1995 for gas pipelines was caused when the One-Call system was used and 25 percent of hits on located facilities were due to mislocates (Sterling 2000). Selection of appropriate imaging methods requires specific considerations such as knowledge of existing site environmental conditions, utility size and composition, and cost (Anspach and Wilson 1994). Furthermore, the advent of new materials, congested rights-of-way, and new construction methods such as horizontal directional drilling trigger a challenge to the successful identification of horizontal location of underground utility (ASCE 2002).

\subsection{Objectives of the Study}

The primary objectives of this study are:

(1) To identify, through literature review and case studies, the state-of-the-art and the state-ofthe-practice imaging technologies that have potential for being applied in locating underground utilities.

(2) To analyze the conditions under which use of these technologies are most appropriate. Not all technologies can locate all types of utilities, or be used in all types of soil or at all depths. Some technologies may be affected by interference from nearby objects.

(3) To develop the boundary conditions that affect current instrumentation used in imaging technologies.

(4) To organize demonstration projects for INDOT personnel to view the proper application of the imaging technologies 
Based on the results from objectives (2) \& (3), a decision support system named IMAGTECH was developed. The tool can provide a method to determine the most appropriate imaging (designating) technologies and application guidelines when the site conditions are provided to the program as input values. A multimedia educational tool (Web pages) was developed to provide information about the imaging technologies. It includes pictures and video clips which were obtained from site visits. Current underground utility locating systems were analyzed, with the primary focus on Subsurface Utility Engineering (SUE).

\subsection{Organization of the Report}

This report consists of nine chapters. The second chapter of the report describes the state-of-theart in mapping and modeling, while Chapter 3 provides an overview of positioning systems and integration applications. Chapter 4 provides an overview of two underground utility locating systems, which are the One-Call system and Subsurface Utility Engineering (SUE). A detailed analysis of SUE including cost-benefit analysis, current trends in State DOTs and business practices of SUE providers is described in this chapter. The fifth chapter presents the theories and applications of various types of designating and locating technologies. Chapter Six deals with key criteria and their applicability to each designating method based on the literature review and expert opinion. Based on the established key criteria, Chapter Seven describe the key features of IMAGTECH, which is a decision support system, developed for selecting the most appropriate designating methods for given site conditions. In Chapter Eight, a multimedia educational tool is described. This web-based tool provides information about the underground utility locating systems, designating technologies and photographs and movie clips taken at the site visits. Chapter Nine summarizes the findings of this report and concludes with the contributions of this study and recommendations for future work. 


\section{CHAPTER 2}

\section{STATE-OF-THE-ART IN MAPPING AND MODELING}

This chapter presents literature reviews on mapping and modeling in other areas such as geotechnical engineering, transportation engineering, and mining engineering.

\subsection{Implementing Light Detection and Ranging (LIDAR)}

LIDAR stands for Light Detection And Ranging that uses the same principle as RADAR. The LIDAR instrument transmits light out to the actual surface of the target. The transmitted light interacts with and is changed by the characteristics of the target. Some of this light is reflected back to the instrument where it is analyzed. The change in the properties of the light enables some property of the target to be determined. Moreover, measuring the time for the light to travel out to the target and back to the LIDAR allows distance to the target to be determined. There are three basic generic types of LIDAR: Range finder, DIAL, and Doppler LIDAR (Arnold 2001).

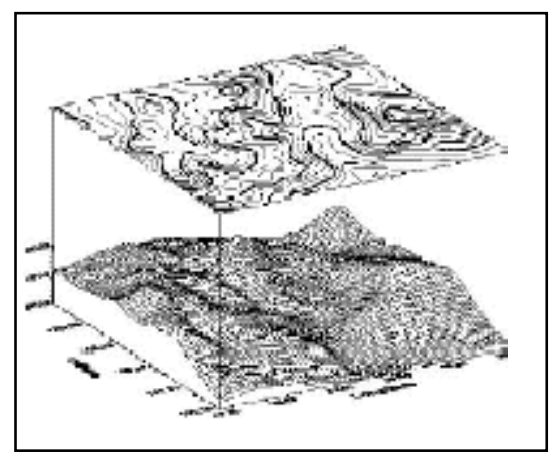

Figure 2.1. Image Generated by LIDAR Application (Arnold 2001)

Range finder LIDAR is the simplest LIDAR. They are used to measure the distance from the LIDAR instrument to a target. The elevation of an object can be calculated since we know the plane altitude and the distance from the plane to the object. The location can be obtained by knowing the position of the plane, possible by GPS. By displaying the elevation and the property 
of the object, three-dimensional surface map can be generated. Figure 2.1 shows the image generated by using LIDAR.

\subsection{Implementing Side Scan Sonar}

In geological engineering, side scan sonar has been used to map the surface of underwater ridges. The sound transmitted by an instrument mounted on a ship travels to the seafloor and bounces off of the seafloor. Then, it returns to the instrument and is recorded.

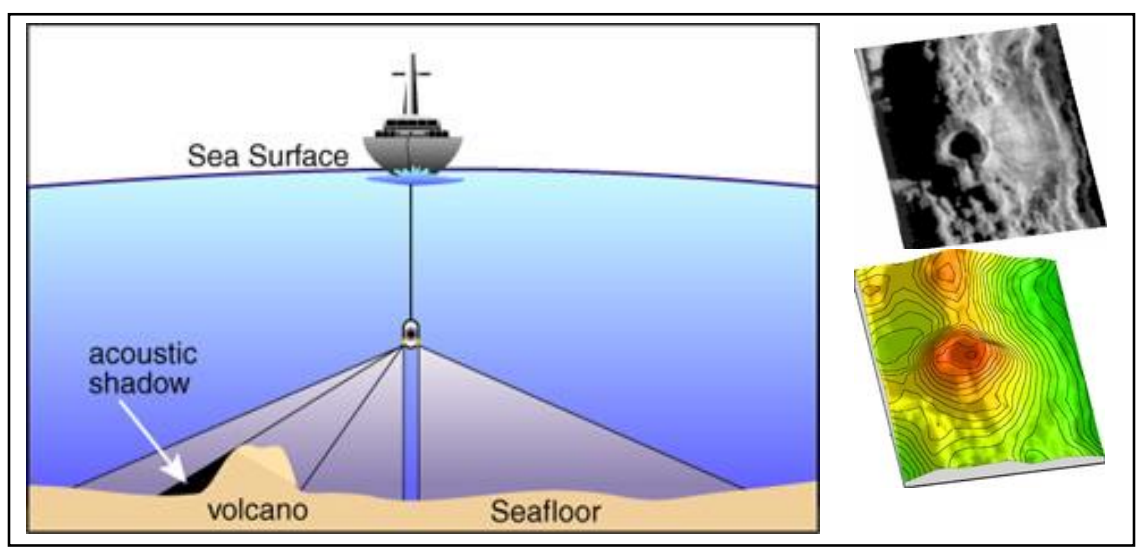

Figure 2.2. Side-Scan Sonar Application and Signal Interpretation (“Side-Scan" 2002)

The intensity of the returning signal is primarily controlled by the slope of the seafloor and the material property of the seafloor. A stronger return is received if the seafloor slopes toward the instrument. Also, the return is stronger if the seafloor is made of bare rock. The strength of the return is much lower if the seafloor is covered by mud or sand. The strength of the sound is converted to the shades of gray. A strong return is white, and a weak return is black. Two figures on the right in Figure 2.3 show a seafloor volcano that has a large crater on its top. The contours are lines of equal water depth; the color also represents water depth with reds being the shallowest and dark greens the deepest. 


\subsection{Implementing Photogrammetry}

Photogrammetry is the art and science of obtaining reliable measurements by means of images. Triangulation is the principle used by both photogrammetry and theodolites to produce 3dimensional point measurements. By mathematically intersecting converging lines in space, the precise location of the point can be determined. However, unlike theodolites, photogrammetry can measure multiple points at a time with virtually no limit on the number of simultaneously triangulated points. Figure 2.3 shows the single point triangulation and multiple point triangulation.

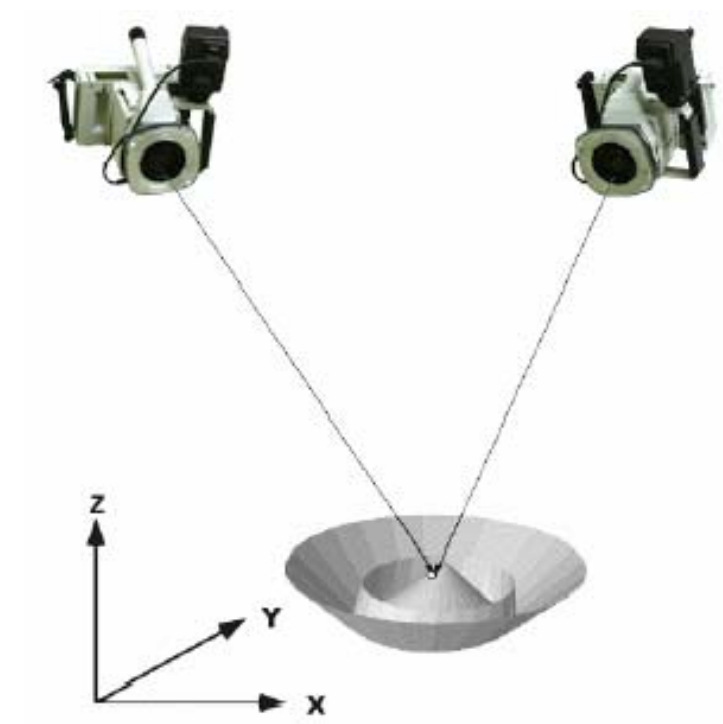

Single Point Triangulation (Theodolites)

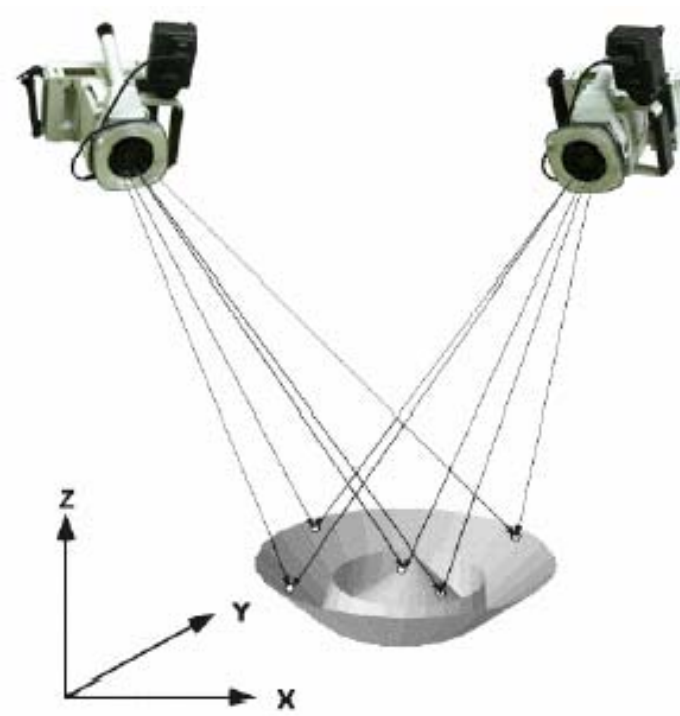

Multiple Point Triangulation (Photogrammetry)

Figure 2.3. Single Point Triangulation and Multiple Points Triangulation

In multiple points triangulation, two pictures are taken from at least two different locations, and a target is measured in each picture to develop a line of sight from each camera location to the target. If the camera location and aiming direction are known, the lines can be mathematically intersected to produce the XYZ coordinates of each targeted point. 
3D imaging is an extension of photography into a domain where the data acquired include spatial data and visual data. To produce a true 3D image, the spatial data are combined with visual data. A 3D image can be displayed using a computer. The computer can recreate a perspective view of the image from any view orientation and display the spatial data fused with the visual to data to provide a realistic lifelike image that can be manipulated and analyzed. 3D Imaging is unlike visualization of computer generated 3D data in that the images are representations of real world objects and are not simply displayed as computer rendered 3D models of a scene (CSIRO 2001). CSIRO has applied 3D imaging to aid rock mining in Australia. 3D imaging is used to identify and characterize discontinuities in rock masses. The data acquired can then be used to visualize the true structure of the rock mass and analyze the stability of a rock slope.

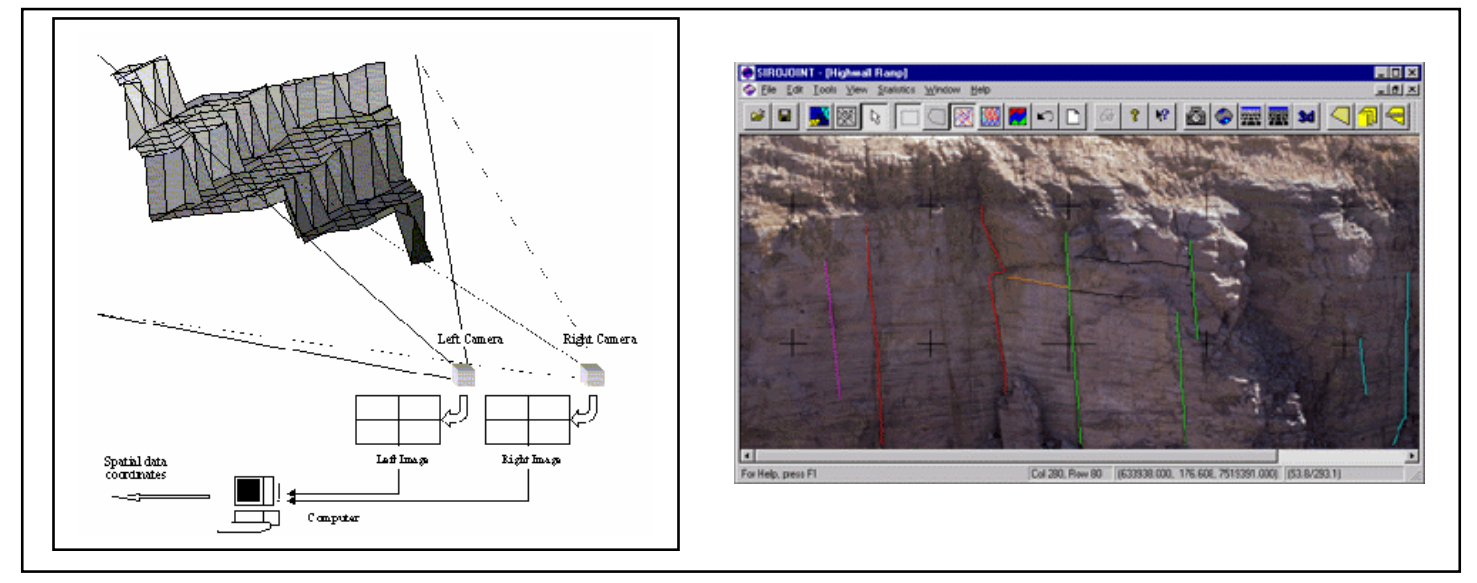

Figure 2.4. CSIRO's Photogrammetry Implementation (left) and Sirojoint Application (right) (CSIRO 2001)

Sirojoint is a software application for 3-D joint set analysis of rock slopes. Sirojoint allows geologists to rapidly measure rock face attributes such as joint orientations, trace lengths and block surface areas. Figure 2.4 shows how CSIRO implemented photogrammetry and Sirojoint software application.

\subsection{Implementing Drilling and Sampling Method}

A drilling and sampling technique has been used in geological engineering. Construction also uses this technique to predict the underground layers that have a potential effect on the foundation of the structure and excavation. Moreover, the drilling and sampling technique 
provides information regarding moisture content in the samples. Therefore, underground water flow direction that has a great impact on trenching and foundation excavation can be predicted.

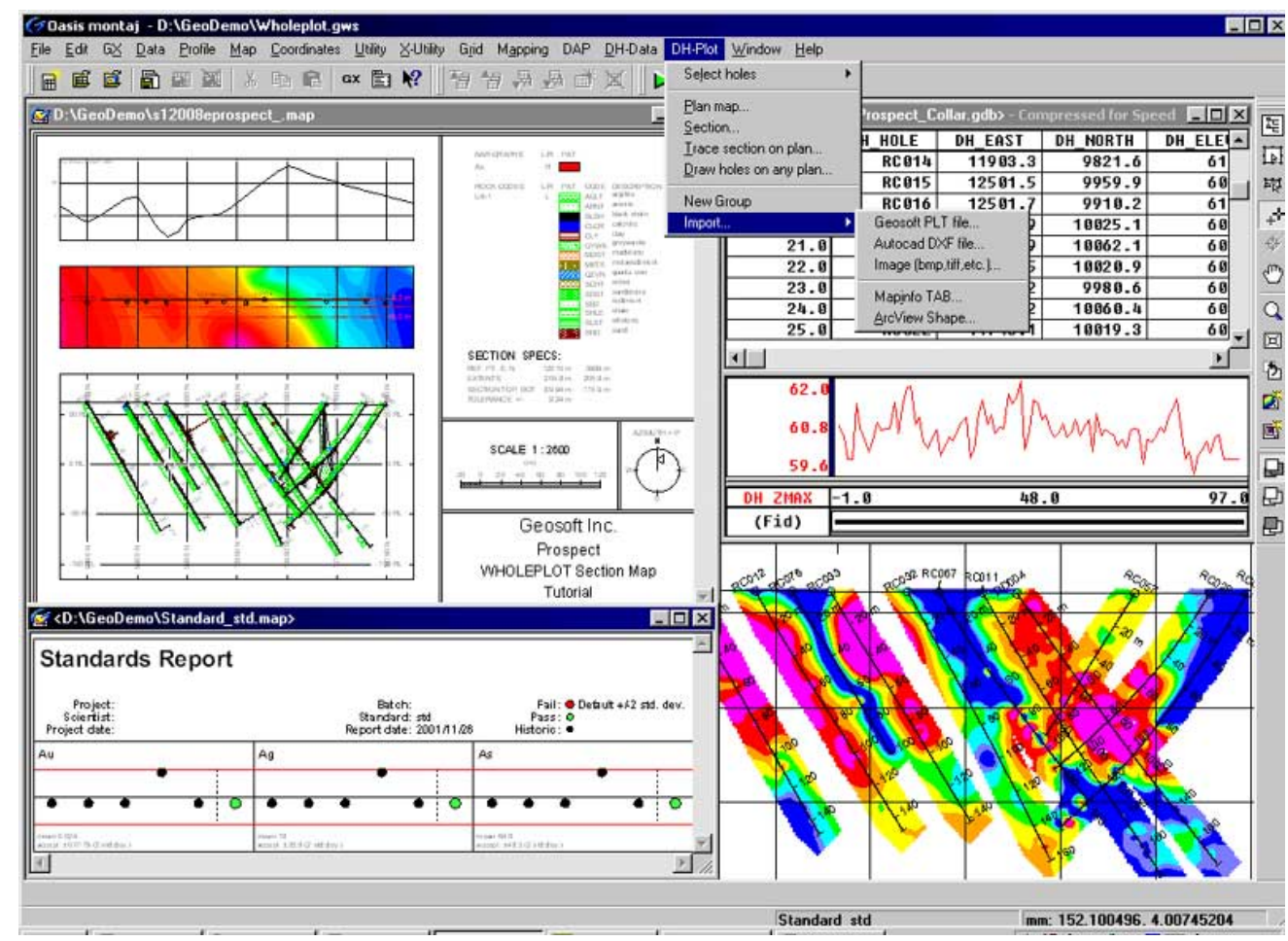

Figure 2.5. Geosoft's Wholeplot ${ }^{\mathrm{TM}}$ Drillhole Plotting application (http://www.geosoft.com)

Mineral exploration also uses the technique to predict the location of minerals. Several holes on site are simply drilled and sampled at several depths. A software application, such as GIS and Wholeplot ${ }^{\mathrm{TM}}$, that has the ability to handle a large volume of spatial data is needed. Wholeplot ${ }^{\mathrm{TM}}$ application is shown in Figure 2.5.

\subsection{CAD-Integrated Excavation and Pipe Laying}

Bernold introduced CAD-Integrated Excavation and Pipe Laying in a 1997 paper. The paper presented the concept and development of a spatially integrated excavation and pipe-laying system. Four important components are an excavator, electronic transducers for measuring the angles of the excavator arm, a laptop computer with data-acquisition board and touch screen, and the Odyssey (a laser based position measurement tool) (Huang and Bernold 1997). All of these 
components were integrated into one system termed the Excavator Mounted Spatial Position Measurement System or EM-SPS. All of these technologies are considered key components of a safe and economical robotic excavation system of the future (Huang and Bernold 1997).

The availability of real-time spatial position information at the digging machine has three main implications (Huang and Bernold 1997). First an operator is allowed to acquire accurate data about the actual path and speed needed for the control and planning of future actions when in an autonomous mode. Second, position and force data from the robotic system can be established. Third, since the relevant spatial position data are available, an as-built database can be created automatically.

Figure 2.6 shows the concept of trench excavation using laser guidance. Two laser receivers are mounted high up on the back of the excavator to eliminate the obstruction of the line of sight to both transmitters. A link of angle encoders mounted on the boom and stick of the arm create twodimensional coordinates of the bucket within the framework of the equipment.

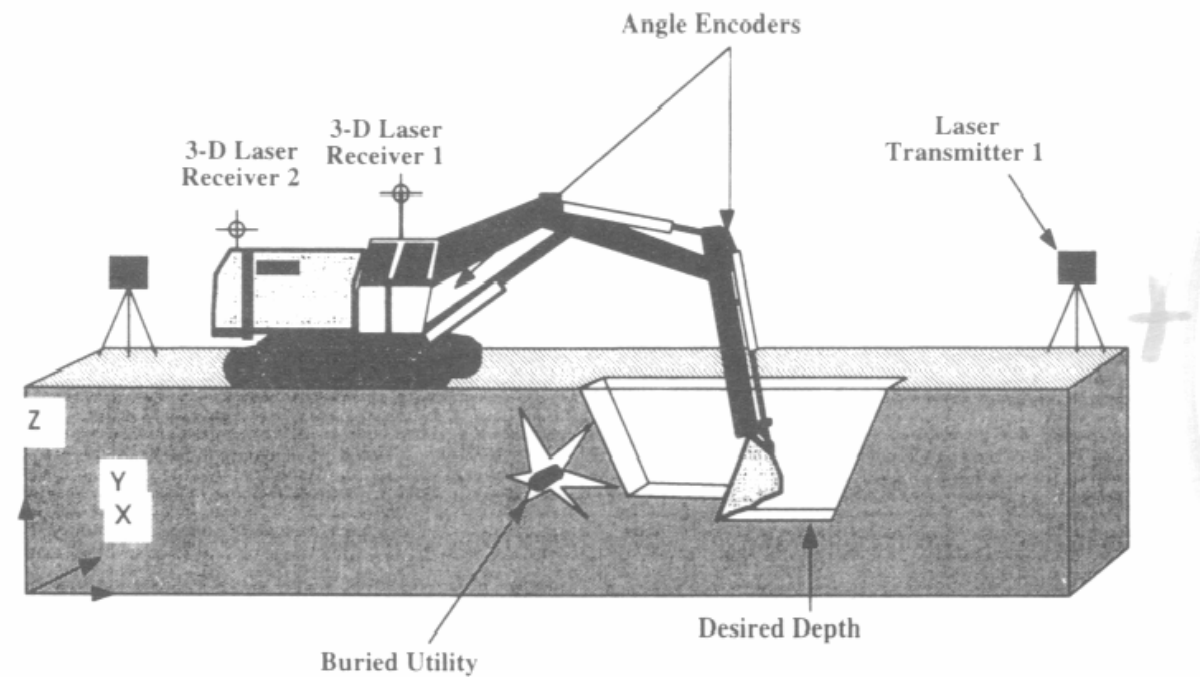

Figure 2.6 Concept of Trench Excavation Using Laser Guidance (Huang and Bernold 1997)

To assist the operator in visualizing the location of the excavator, a display system using AutoCAD software was developed. It integrates the 3D data from EM-SPS with joint encoders mounted on the excavator. The needed interface program written in QuickBasic handles all data 
collection and processing tasks. AutoLISP program in AutoCAD software updates the location and orientation of the excavator and its trenching operation.

\subsection{Robotic Subsurface Mapping Using Ground Penetrating Radar}

In 1997 Herman, a member of Robotic Institute at Carnegie Mellon University, worked on the doctoral dissertation topic: Robotic Subsurface Mapping Using Ground Penetrating Radar. Herman developed a robotic system that can autonomously gather and process Ground Penetrating Radar (GPR) data. The system uses a scanning laser rangefinder to construct an elevation map of an area. By using the elevation map, a robotic manipulator can follow the contour of the terrain when it moves the GPR antenna during the scanning process. The collected data are then processed to detect and locate buried objects. Three new processing methods were developed. Two are volume based processing methods, and one is a surface based processing method.

In volume based processing, the 3-D data are directly processed to find the buried objects, while in surface based processing, the 3-D data are first reduced to a series of 2.5-D surfaces before further processing. Each of these methods can be made very fast using parallel processing techniques, but they require an accurate propagation velocity of the GPR signal in the soil. On

the other hand, the surface based processing method uses 3-D segmentation to recognize the shape of the buried objects, which does not require an accurate propagation velocity estimate. Both approaches are quite efficient and well suited for online data processing. 


\section{CHAPTER 3}

\section{STATE-OF-THE-PRACTICE IN POSITIONING SYSTEMS AND STATE-OF-THE-ART IN INTEGRATION APPLICATIONS}

Positioning systems and integration concepts are key elements in order to map geographic information. This chapter describes the key features of typical surveying method, Geographical Positioning Systems, and laser based positioning systems.

\subsection{Typical Surveying Method}

\subsubsection{Theodolite}

The evolution of the theodolite first began with the description of the instrument in the book Pantometria, by Leonard Diggs in 1571. In 1775 Jesse Ramsden, (1735-1800) a most innovative London instrument maker, completed his circular dividing engine. This engine enabled much more accurate divisions than the previous laborious and tedious means of manually dividing circles. And so, in approximately 1782 Jesse Ramsden commenced construction on his Great Theodolite, incorporating a 3-foot diameter horizontal circle and weighing approximately 200 pounds. Since that time, the theodolite has been developed to achieve great functionality and accuracy in a smaller and lighter body.

With today's technology, the total station has been replacing the old model of the theodolite. The total station is the surveying instrument composed of the theodolite with electronic-reading-scale and EDM, Electronic Distance Measurement. Therefore, the total station eliminates the need for a measuring tape, and EDM also allows much more accuracy. Figure 3.1 shows the seventeenth century theodolite (left) and its smart successor (right). 


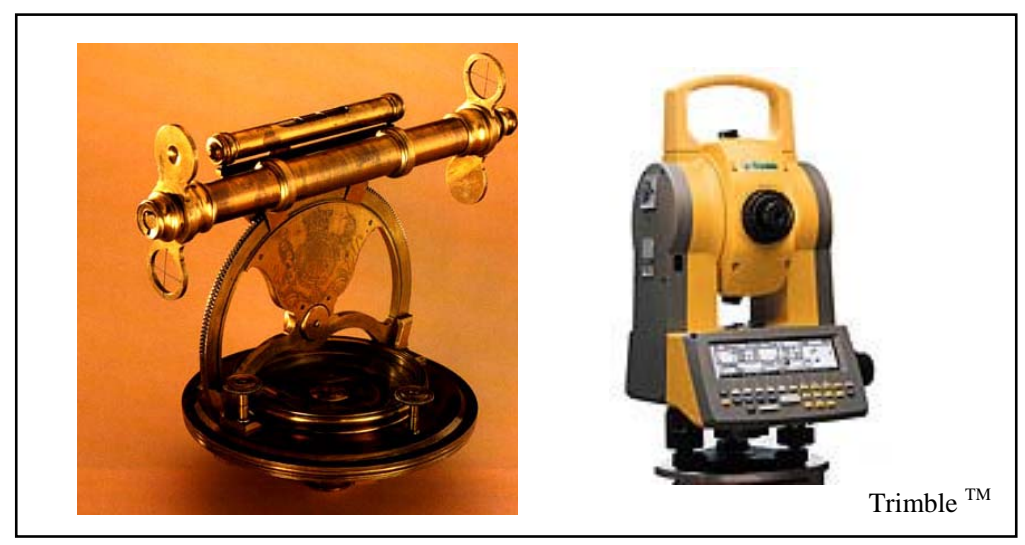

Figure 3.1 The Seventeenth Century Theodolite (Left) and The Successor (Right) (http://www.trimble.com)

\subsubsection{Traverse Surveys}

A traverse is a form of control survey that comprises a series of established stations. The stations are related to each other by distance and deflection angle. The angle can be measured by theodolites; the distance between stations can be measured by steel tape or EDMI. There are two types of traverses: open traverse and closed traverse.

An open traverse is particularly useful as control for preliminary survey. Open traverses may extend for long distances but without opportunity to check the accuracy of the ongoing work. A closed traverse is one that either begins and ends at the same point or begins and ends at points whose positions have been previously determined; in both cases, the angles can be closed geometrically, and the position closure can be determined mathematically (Kavanagh 2001).

The accuracy issue in surveying is very critical. However, it is too expensive and unreasonable to require the highest accuracy for all types of surveying jobs. Moreover, surveying instruments have different levels of accuracy. With regard to typical surveying instrumentation, there is an accuracy standard for conventional field control surveys, as shown in table 3.1. For cadastral surveys, The American Congress on Surveying and Mapping (ACSM) and the American Land Title Association (ALTA) collaborated to produce new classifications based on present 
technology and land use. These 1992 classifications (subject to state regulations) are shown in Table 3.3 (Kavanagh 2001). In 1997 ACSM and ALTA published positional tolerances for different classes of surveys in table 3.2 (Kavanagh 2001).

Table 3.1 Traverse Specifications - United States (Kavanagh 2001)

\begin{tabular}{|c|c|c|c|c|c|}
\hline \multirow{2}{*}{ Classification } & \multirow{2}{*}{ First Order } & \multicolumn{2}{|c|}{ Second Order } & \multicolumn{2}{|c|}{ Third Order } \\
\hline & & Class I & Class II & Class I & Class II \\
\hline $\begin{array}{c}\text { Recommended } \\
\text { spacing of } \\
\text { principal stations }\end{array}$ & $\begin{array}{c}\text { Network } \\
\text { stations; other } \\
\text { surveys seldom } \\
\text { less than } 3 \mathrm{~km}\end{array}$ & $\begin{array}{l}\text { Principal stations } \\
\text { seldom less than } 4 \\
\text { km except in } \\
\text { metropolitan area } \\
\text { surveys, where the } \\
\text { limitation is } 0.3 \mathrm{~km}\end{array}$ & $\begin{array}{l}\text { Principal stations } \\
\text { seldom less than } 2 \\
\text { km except in } \\
\text { metropolitan area } \\
\text { surveys, where the } \\
\text { limitation is } 0.2 \mathrm{~km}\end{array}$ & \multicolumn{2}{|c|}{$\begin{array}{l}\text { Seldom less than } 0.1 \mathrm{~km} \text { in } \\
\text { tertiary surveys in } \\
\text { metropolitan area surveys; } \\
\text { as required for other } \\
\text { surveys }\end{array}$} \\
\hline $\begin{array}{c}\text { Position closure } \\
\text { After azimuth } \\
\text { adjustment }\end{array}$ & $\begin{array}{c}0.04 \mathrm{~m} \sqrt{ } \mathrm{k} \text { or } \\
1: 100,000\end{array}$ & $\begin{array}{c}0.08 \mathrm{~m} \sqrt{ } \mathrm{k} \text { or } \\
1: 50,000\end{array}$ & $\begin{array}{c}0.2 \mathrm{~m} \sqrt{\mathrm{k}} \text { or } \\
1: 20,000\end{array}$ & $\begin{array}{c}0.4 \mathrm{~m} \sqrt{ } \mathrm{k} \text { or } \\
1: 10,000\end{array}$ & $\begin{array}{c}0.8 \mathrm{~m} \sqrt{ } \mathrm{k} \text { or } \\
1: 5,000\end{array}$ \\
\hline
\end{tabular}

Table 3.2 Positional Tolerances for Land Title Surveys

\begin{tabular}{|l|l|}
\hline \multicolumn{1}{|c|}{ Survey Class } & \\
\hline Urban & $0.07 \mathrm{ft}($ or $20 \mathrm{~mm})+50 \mathrm{ppm}$ \\
\hline Suburban & $0.13 \mathrm{ft}($ or $40 \mathrm{~mm})+100 \mathrm{ppm}$ \\
\hline Rural & $0.26 \mathrm{ft}($ or $80 \mathrm{~mm})+200 \mathrm{ppm}$ \\
\hline Mountain / Marshland & $0.66 \mathrm{ft}($ or $200 \mathrm{~mm})+200 \mathrm{ppm}$ \\
\hline
\end{tabular}


Table 3.3 American Congress on Surveying and Mapping Minimum Angle, Distance, and Closure Requirements for Survey Measurements That Control Land Boundaries for ALTA-ACSM LAND TITLE SURVEY (1)

\begin{tabular}{|c|c|c|c|c|c|c|c|}
\hline $\begin{array}{l}\text { Dir. Reading of } \\
\text { Instrument } \\
\text { (2) }\end{array}$ & $\begin{array}{c}\text { Instrument } \\
\text { Reading } \\
\text { Estimated } \\
\text { (3) }\end{array}$ & $\begin{array}{c}\text { Number of } \\
\text { Observations } \\
\text { per station } \\
\text { (4) }\end{array}$ & $\begin{array}{c}\text { Spread from } \\
\text { Mean of D\&R } \\
\text { Not to Exceed } \\
\text { (5) }\end{array}$ & $\begin{array}{c}\text { Angle Closure } \\
\text { Where N = No. of } \\
\text { Stations Not to } \\
\text { Exceed } \\
\text { (3) }\end{array}$ & $\begin{array}{c}\text { Linear } \\
\text { Closure } \\
(6)\end{array}$ & $\begin{array}{c}\text { Distance } \\
\text { Measurement } \\
\text { (7) }\end{array}$ & $\begin{array}{l}\text { Minimum Length of } \\
\text { Measurements } \\
\text { (8), (9), (10) }\end{array}$ \\
\hline $20 ”<1$ '> 10" & 5” $<0.1>$ N.A. & 2D\&R & 5 ” > 0.1 '> 5’ & $10 " \sqrt{ } \mathrm{N}$ & $1: 15,000$ & $\begin{array}{c}\text { EDM or double tape } \\
\text { with steel tape }\end{array}$ & $\begin{array}{c}\text { (8) } 81 \text { m., (9) } 153 \text { m., } \\
\text { (10) } 20 \mathrm{~m} .\end{array}$ \\
\hline
\end{tabular}

Note (1) All requirements of each class must be satisfied in order to qualify for that particular class of survey. The use of more precise instrument does not change other requirements, such as the number of angle turned, etc.

Note (2) Instrument must have a direct reading of at least amount specified (not an estimated reading), ie.: 20” = Micrometer reading theodolite, <1'> = scale reading theodolite, 10" = Electronic reading theodolite.

Note (3) Instrument must have the capability of allowing an estimated reading to specific reading.

Note (4) D \& R means the Direct and Reverse positions of instrument telescope; i.e., urban surveys require that two angles in the direct and two angles in the reverse position be measured and meaned.

Note (5) Any angle measured that exceeds the specified amount from the mean must be rejected and the set of angles remeasured.

Note (6) Ratio of closure after angles are balanced and closure calculated.

Note (7) All distance measurements must be made with a properly calibrated EDM or steel tape, applying atmospheric temperature, sag, tension, slope, scale factor, and sea level corrections as necessary.

Note (8) EDM having an error of $5 \mathrm{~mm}$, independent of distance measured (manufacturer's specification).

Note (9) EDM having an error of $10 \mathrm{~mm}$, independent of distance measured (manufacturer's specification).

Note (10) Calibrated steel tape. 


\subsection{Geographical Positioning System}

\subsubsection{GPS Fundamentals}

Global Positioning System (GPS) is the positioning system instrument that identifies an exact position on the earth anytime, in any weather, anywhere. GPS satellites, 24 in all, orbit 11,000 nautical miles about the earth, taking 12 hours to go around the Earth. They are continuously monitored by ground stations located worldwide. The signal transmitted from the satellite can be detected by any GPS receiver.

GPS has 3 parts: the space segment, the user segment, and the control segment (Figure 3.2). The space segment consists of 24 satellites as described before. The user segment consists of GPS receivers. The control segment consists of 5 ground stations located around the world that make sure the satellites are working properly.

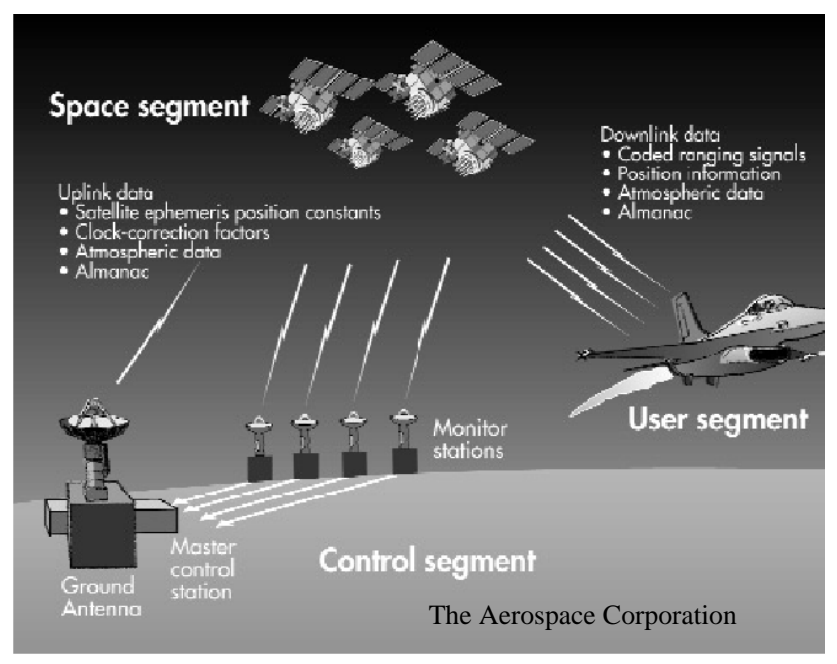

Figure 3.2 Three Elements of GPS System (http://www.aero.org)

Each satellite is equipped with very precise clock to let it broadcast signals with precise time. The precise clock keeps time to within three nanoseconds. The ground unit will receive the satellite signal and the time it was sent. The difference between the times the signal is sent and 
the time it is received, multiplied by the speed of light, enables the receiver to calculate the distance to the satellite.

The ground control segment consists of unmanned monitor stations located around the world (Hawaii and Kwajalein in the Pacific Ocean; Diego Garcia in the Indian Ocean; Ascension Island in the Atlantic Ocean; and Colorado Springs, Colorado); a master station at Falcon Air Force Base in Colorado Springs, Colorado; and four large ground antenna stations that broadcast signals to the satellites. The stations also track and monitor the GPS satellites.

The basic theory of GPS is "trilateration" from satellites. Trilateration is a basic geometric principle that determines one location if the distance from another is known. The geometry behind this is very easy to understand in two-dimensional space. This same concept works in three-dimensional space as well, but dealing with spheres instead of circles. Four spheres instead of three circles are required to find the exact location. The heart of a GPS receiver is the ability to find the receiver's distance from four (or more) GPS satellites. Once it determines its distance from the four satellites, the receiver can calculate its exact location and altitude on Earth. If the receiver can only find three satellites, then it can use an imaginary sphere to represent the Earth and can produce location information but no altitude information.

\subsubsection{Error Sources}

Since the satellites are very far from the Earth, six error sources affect the accuracy of readingposition: ephemeris data, satellite clock, Ionosphere, Troposphere, multipath, and receiver (Parkinson and Spilker 1996).

Ephemeris data is an error in transmitted location of the satellite. Satellite clock is an error in the transmitted clock on signal. Ionosphere and Troposphere are errors caused by distortion of the signals moving through ionospheric layer and tropospheric layer. Multipath is an error caused by reflected signals entering the receiver GPS antenna. The receiver itself can create an error by thermal noise, software accuracy, and inter-channel biases. Moreover, there is another error source called Select Availability or Man-Made error. The US Department Of Defense has 
determined that providing this level of precision to the general public is against the US national interest. Therefore, DOD has introduced man-made intentional errors to degrade the position accuracy of GPS to about 100 meters. This intentional degradation is called Selective Availability (SA) and is implemented by tethering the satellite clocks and reporting the orbit of the satellites inaccurately. Military receivers are equipped with special hardware and codes that can mitigate the effect of SA. SA can be turned ON or OFF through ground commands by the GPS system administrators. Table 3.4 shows GPS errors from all sources.

\section{Table 3.4 GPS Errors from All Sources Before and After Differential Correction}

\begin{tabular}{|l|c|c|}
\hline \multicolumn{1}{|c|}{ Source } & $\begin{array}{c}\text { Uncorrected Error Level } \\
\text { (Meter) }\end{array}$ & $\begin{array}{c}\text { Corrected Error Level } \\
\text { (Differential GPS) } \\
\text { (Meter) }\end{array}$ \\
\hline Ionosphere & $0-30$ & Mostly removed \\
\hline Troposphere & $0-30$ & All removed \\
\hline Receiver & $0-10$ & All removed \\
\hline Ephemeris & $1-5$ & All removed \\
\hline Clock & $0-1.5$ & All removed \\
\hline Multipath & $0-1$ & Not removed \\
\hline Selective Availability & $0-70$ & All Removed \\
\hline
\end{tabular}

\subsubsection{Differential Correction}

A technique called differential correction is necessary to get accuracies within $1-5$ meters, or even better, with advanced equipment. Differential correction requires a second GPS receiver, a base station, collecting data at a stationary position on a precisely known point (typically it is a surveyed benchmark). Because the physical location of the base station is known, a correction factor can be computed by comparing the known location with the GPS location determined by using the satellites.

The differential correction process takes this correction factor and applies it to the GPS data collected by a GPS receiver in the field. Differential correction eliminates most of the errors listed in the GPS Error Budget discussed earlier. After differential correction, the GPS Errors change as Table 2.4 . 


\subsection{Laser Based Positioning System}

\subsubsection{Computer Aided Positioning System (CAPSY ${ }^{\mathrm{TM}}$ )}

In June 1989 CAPSY, shown in Figure 3.3, was first introduced at the ISARC' 89 in San Francisco, the United States. CAPSY is based on triangulation to calculate its current position. Therefore, it needs to know the exact angles in between three known points as a reference. The rotating laser beam inside CAPSY is capable of scanning the environment for three reference points. These three reference points are made of retro-reflective material, called 'reflector'. A reflector is made unique in order to distinguish them from others.

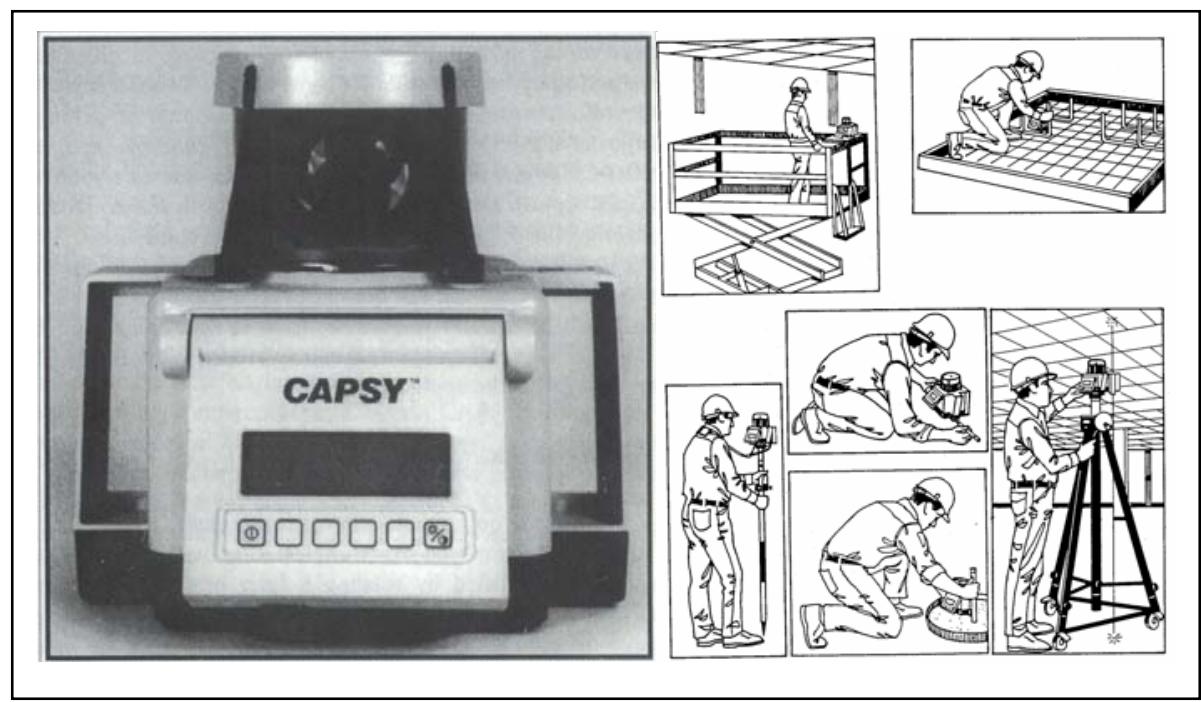

Figure 3.3 CASPY and Its Applications

When the laser beam hits the reflector, the laser light is reflected back into the unit and analyzed by internal computer. This will provide two essential pieces of information. First it will measure the exact angle of this reflector in respect to an internal index; second it will recognize the specific bar code of this reflector so it knows which target is scanned (DeVos 1993).

The CAPSY basic function is calculating XY-position. The actual position is updated 5 times a second and can be considered a real time position (DeVos 1993). The angle is measured with an accuracy of $0.001-0.003$ of a degree. Before CAPSY can be used as a one-man survey 
instrument, calibration is needed. First, three or more reflectors need to be placed in appropriate positions that are in the lines of sight to the CAPSY processing unit. After that the processing unit needs to be placed on 2 known-position points for calibration. After calibration has been done, CAPSY will be capable of displaying the real time XY-position of any point within the line of sight to at least three reflectors. CPASY applications are shown on figure 2.3.

At a 1995 conference of the American Society of Civil Engineering, CAPSY application was introduced for site material handling and layout control. An author, I.D. Tommelein, presented her integrating system called MoveCapPlan. The MoveCapPlan system integrated two pieces of hardware and custom software, namely MovePlan and CAPSY (Tommelein 1995).

The MovePlan model aided in planning the reuse of site space over time (Tommelein and Zouein 1993, Tommelein 1994). Therefore, a user must have provided the material and project schedules over the graphical layout as a planed layout. CAPSY performed as a data entry when material was loaded at the warehouse or storage area. Since CAPSY is capable of giving XY-position, an actual layout over time frame can be created and compared to a planned layout and a future planned layout.

\subsubsection{Spatial Positioning System (Odyssey $\left.{ }^{\mathrm{TM}}\right)$}

Odyssey is another real time positioning system, but it can provide accurate three-dimensional position measurements. There are two primary components in an Odyssey system: transmitters and receivers. More transmitters would cover a larger area of space and would allow for redundant position determination to be made as each pair of transmitters provides a position measurement (Yvan et al. 1995). Each transmitter is set at a location to scatter light about the site. The set-up of transmitters is very easy because it can be set at any point. The receiver includes a computer and screen, two optical lenses, a battery, and a data entry and retrieval system (Yvan et al. 1995). “ Two optical lenses form the line. The position of lenses and the known geometry of the pole allow the point of position definition to be projected to the end of the pole. Therefore, the position of the tip of the pole does not change if the pole is slanted, rotated, upside down or sideways (Yvan et al. 1995).” Odyssey currently provides 1:10,000 
accuracies, 5 updates per second, and has a working range of 130 meters (Yvan et al. 1995). If higher accuracies are required, staying stable over a point for a longer period of time will significantly improve accuracy. Moreover, the less distance between transmitters the greater the accuracy.

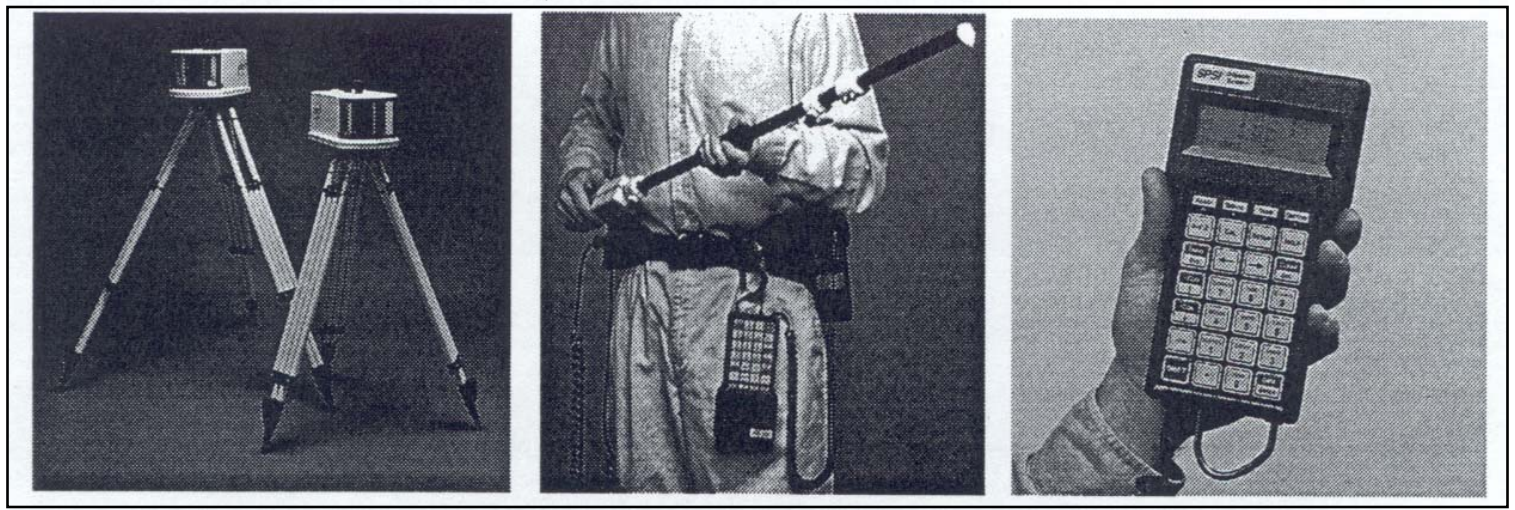

Figure 3.4 Odyssey Transmitters, Receiver, and Control Station Terminal

Calibration prior to first using is required. After at least two transmitters are placed, a receiver unit has to be placed and calibrated on four reference points; four are for calibration, and the last one is for validating first 4 points. If calibration has been successful, a receiver can provide a three-dimensional coordinate on any point within the system's range. Figure 3.4 shows Odyssey transmitters, receiver, and control station terminal.

\subsubsection{Laser Trackers}

Laser trackers are portable Coordinate Measuring Machines (CMM) that measure coordinates by tracking a laser beam to a retro-reflective target (Bridges 2001). Introduced in the late 1980s, they can make measurements of objects ranging in size from a few inches ( 2 inches) to about 30 ft. Trackers provide accuracy, speed, and versatility, can collect coordinate data at up to 1,000 samples/sec, and usually require one operator.

A basic laser- tracker system (Figure 3.5) consists of a tracker, control unit, personal or laptop computer, and software. The tracker determines coordinates by measuring two angles and the 
distance to the object. It sends a laser beam to a retro-reflective target glued to, or held by hand against, the object or surface being measured. The beam reflects off the target and retraces its path, reentering the tracker at the same location it left. Laser trackers collect three dimensional coordinate data, which software can convert to geometrical entities such as points, planes, spheres, and cylinders. Usually, the data are displayed within a local-coordinate system tied to features of the object

Laser trackers have penetrated deeply into the automotive and aerospace industries, and their use continues to grow elsewhere. Applications for trackers include inspection of tools and equipment components to compare actual dimensions with design values; stock verification to ensure desirable tolerances; measurements of tools, fixtures, and assemblies during fabrication; alignment of equipment such as precision rollers; dynamic measurement of components such as robot arms in motion; and reverse engineering of computer-aided design models from prototypes.

The major challenges to apply this technology are associated with the increased demand for precision in the measurement systems (Leica 2003). Given that the instrument is portable and light, it can be easily moved to different locations in order to obtain accurate surface inspection on construction job sites.

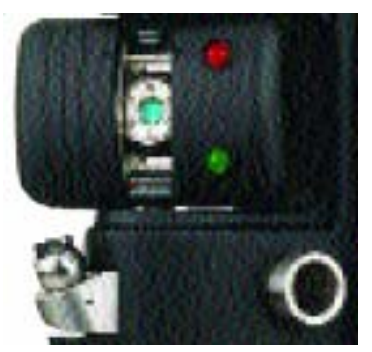

Figure 3.5. A laser Tracker (Bridges 2001)

\subsubsection{Terrestrial Lidar Mapping Units (CYRAX System)}

CYRAX is a completely integrated laser radar and 3-D modeling system that produces a digital model of an object or surface, like that of a digital camera but with added range information that provides the accurate 3-D geometry of the scanned structure (Figure 3.6). CYRAX eliminates the 
human error inherent in labor-intensive digitization processes like photogrammetry (in which large numbers of photographs must be taken, scanned, and organized by hand) by automatically gathering and processing data on the entire structure (Wilson et.al., 1998). Using this stored data, accurate 3-D CAD models of any portion of the scanned structure can be produced. CYRAX is therefore the only technology that can collect accurate 3-D data and create 3-D digital representations and models of large objects such as oil refineries, buildings, mines, and ships (Wilson et.al., 1998).

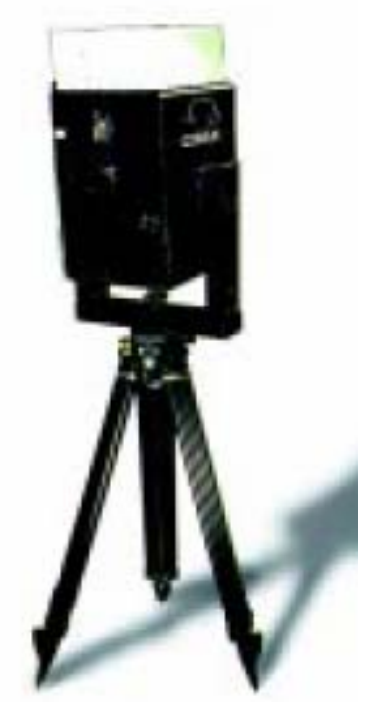

Figure 3.6. The CYRAX Laser-Mapping and Imaging System (Wilson et al. 1998)

Development of CYRAX was a joint effort between Cyra Technologies, Los Alamos National Laboratory, and the Massachusetts Institute of Technology (MIT) Lincoln Laboratory. Researchers from the Los Alamos Physics Division developed the time-interval interpolator integrated circuit, a precise time measuring innovation that makes CYRAX possible (Wilson et al. 1998). To model complex structures such as a battleship structure, CYRAX sends out laser pulses that interpret the object as a cloud of points in 3D space. Using a time-interval interpolator, CYRAX determines the location of each point by measuring the time it takes a light pulse to travel from the laser to the surface and back again. The time-interval interpolator measures this interval to within 10-ps, which translates to 2-mm precision. CYRAX instantaneously creates a digital representation of the object. Computer graphics perception software then translates the cloud of points to create a 3D surface model. This model can then be exported to CAD to create accurate 2D drawings. 
CYRAX's primary application is in the architecture, engineering, and construction industry, but it has many other possible uses, including producing accurate geologic contour maps for the mining industry, capturing detailed archival images of accident and crime scenes for law enforcement, generating parts lists for complex structures such as oil refineries, and even creating realistic cinematic special effects (Los Alamos 2003). For instance, to plan for expansions and renovations, owners rely heavily on accurate computer aided design (CAD) models of the as-built condition of their facilities. CAD models require considerable investment to ensure that they are updated as the facility is modified. Using conventional methods to create or update models is slow, costly, and often impossible when accessibility is limited. These conditions are appropriate to use CYRAX as a technology to create accurate three-dimensional (3-D) models of large and complex structures.

\subsubsection{Robotic Total Stations}

Robotic Total Stations are systems that provide optical communications for radio-free operation, an instant lock/remote location system and reflectorless distance measurements (Figure 3.7). Robotic total stations rely on a communications link between the robotic instrument and the operator at the rover. The radios carry commands from the rover to the instrument, and measurements and data from the instrument to the rover (Leica 2003).

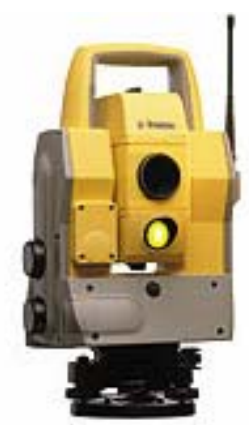

Figure 3.7 Robotic Total Stations (Survey Solutions 2003)

Robotic Total Stations differ from Total Stations in that they do not require a field technician to operate the Robotic Total Station once it is set up and running. The instrument will lock onto the target prism reflector and follow the prism as the rod operator moves. After the initial location of 
the prism, the instrument tracks the reflector automatically - even if there are brief interruptions in the line-of-sight (i.e., vehicles or people crossing the line-of-sight) and intelligent software routines assure reliable tracking. In the Robotic Total Station, all data collection is handled at the rod, rather than at the total station, which makes it possible to run a "one-man field crew" on simple jobs without losing productivity.

Robotic Total Stations are ideal for both survey and stakeout work. When surveying in robotic mode, the operator takes the control unit to the prism to record measurements and collect other data. For stakeout, the operator uses the control unit to navigate to the point. Robotic operation ensures higher data quality, because the operator is taking the measurements at the point being measured, where errors can be quickly identified and corrected.

\subsection{Integration Application}

\subsubsection{Low-Cost Automatic Yield Mapping in Hand-Harvested Citrus}

A simple system has been developed to generate yield maps of hand-harvested citrus implementing a GPS recorder. The technology may also be applied to other hand-harvested fruit and vegetable crops as well. The yield measurement and mapping cannot interfere with the harvest (Schueller 1999). The method of yield measurement used here was to map the location of each container as it was picked up by the goat truck. One advantage of the designed measurement is there is no need for changes in practice by many field workers, who may be untrained and uneducated. Only the goat truck operators have to use the yield measurement equipment, and one of their current jobs is actually the picker's production (Schueller 1999).

The Crop Harvest Tracking System (CHTS) developed by GeoFocus, of Gainesville, FL, was used for this task. The GPS signal from satellites is received from the antenna by the GPS board and stored by the computer in RAM memory. Flash memory and real-time differential GPS are also available as options on the CHTS. The CHTS schematic diagram is shown in Figure 3.8. 


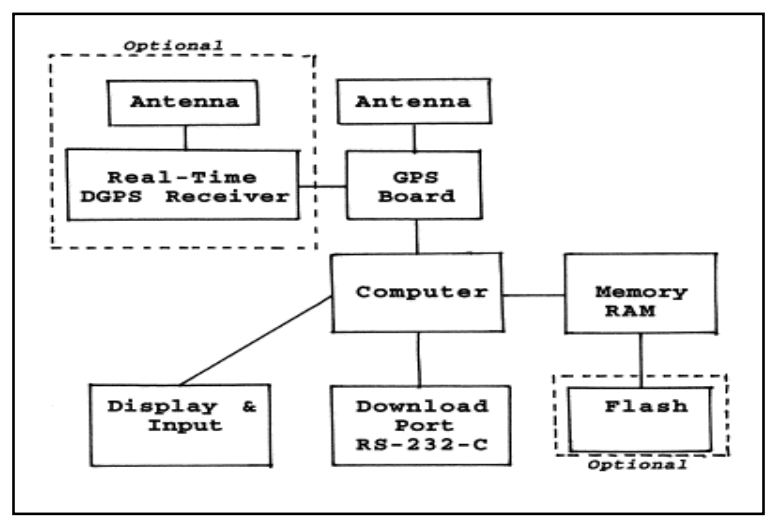

Figure 3.8 General Schematic Diagram of the CHTS (Schueller 1999)

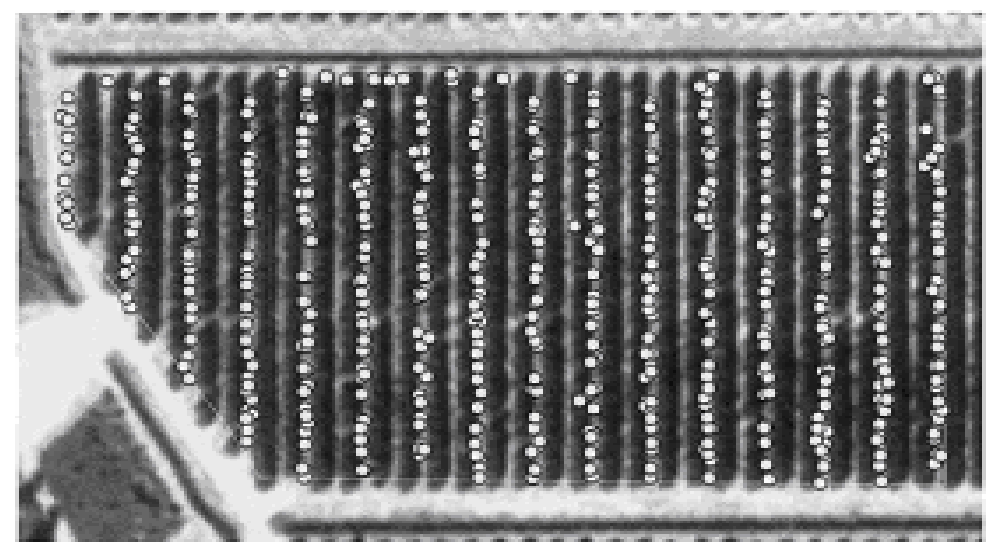

Figure 3.9 Georeferenced Aerial Photograph of 3.5-ha Block Overlaid with Harvested Fruit Container (Schueller 1999)

The data from CHTS are downloaded into a PC for post-processing to correct the GPS location data. Because of the radio link requirement in real-time mode, the post-processing mode is cheaper and therefore chosen. After processing, the accuracy will be improved from 100 meters to 1 - 3 meters accuracy. The corrected location data will later be overlaid on a georeferenced aerial photograph, as shown in Figure 3.9. The greater densities of containers correspond to larger trees. Low production in a region of large trees would indicate the need of management intervention to determine if there was a problem with water, pests, nutrition, or tree health.

Therefore, the concepts to automatically detect loading are currently researched by the author. The goal is to improve the accuracy and usefulness of the yield mapping system. Real-time differential GPS is an available CHTS option that would allow the differential post-processing to 
be eliminated. Removable flash memory is also available, as an option to simplify data transfer to PCs. Weighing the containers would provide more accuracy in measuring the fruit harvested. The field weighing system is shown in Figure 3.10. Load cells in the bed of the goat truck and a pressure sensor in the hydraulic bed lift cylinder are being evaluated in field trials. CHTS units include built-in analog-to-digital converters that can automatically record weight measurements together with the GPS data.

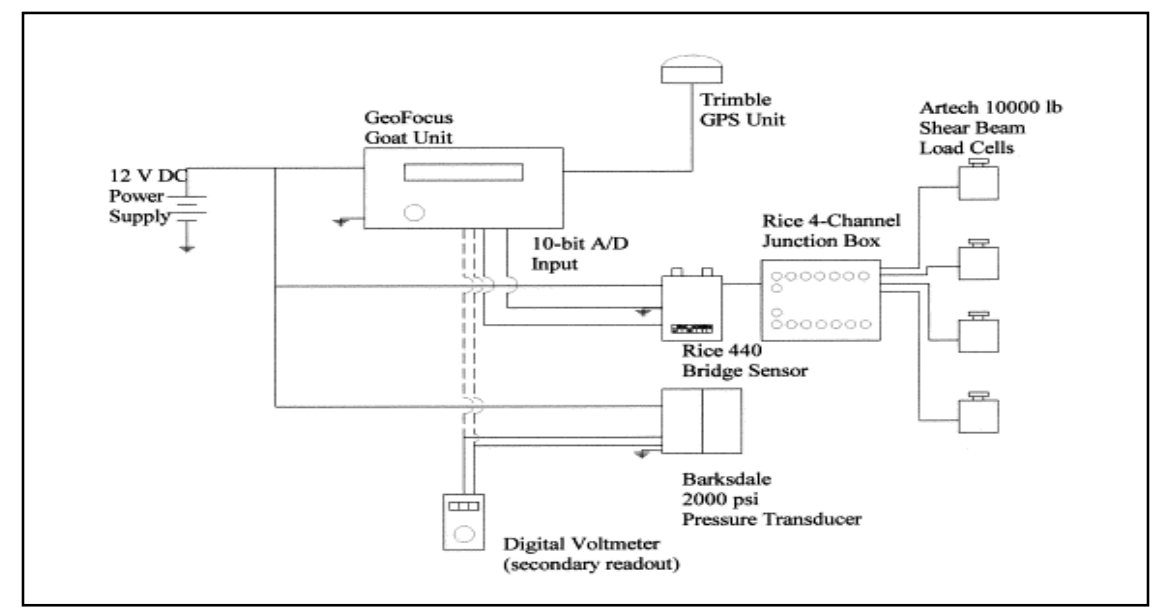

\section{Figure 3.10 Weighing Systems for Measuring Weight for Citrus Yield (Schueller, 1999)}

\subsubsection{Mobile Mapping System for Roadway Data Collection}

Mobile Mapping Systems (MMS) have been developed for automatically collecting roadway inventory data (Karimi et al. 2000). Advanced technologies are used, such as GPS for collecting geo-referencing data and digital cameras for collecting roadway data, are used. An MMS is driven on a subject roadway, collecting positioning data and digital images of the roadway. The results of an evaluation of accuracy of descriptive inventory data collected by three different MMSs are discussed. Each system was tested in three different road environments, and five different types of inventory elements were included in each test (Hassan et al. 2000).

A GPS receiver, a DMI, an INS, and digital cameras are common technologies used in an MMS. Differential GPS techniques are used to obtain high positional accuracy. The DMI and INS provide backups for positional data during the absence of GPS signal. The DMI triggers data 
capture activities at regular distance intervals, and the INS provides data on vehicle body roll, pitch, and heading (Hassan et al. 2000).

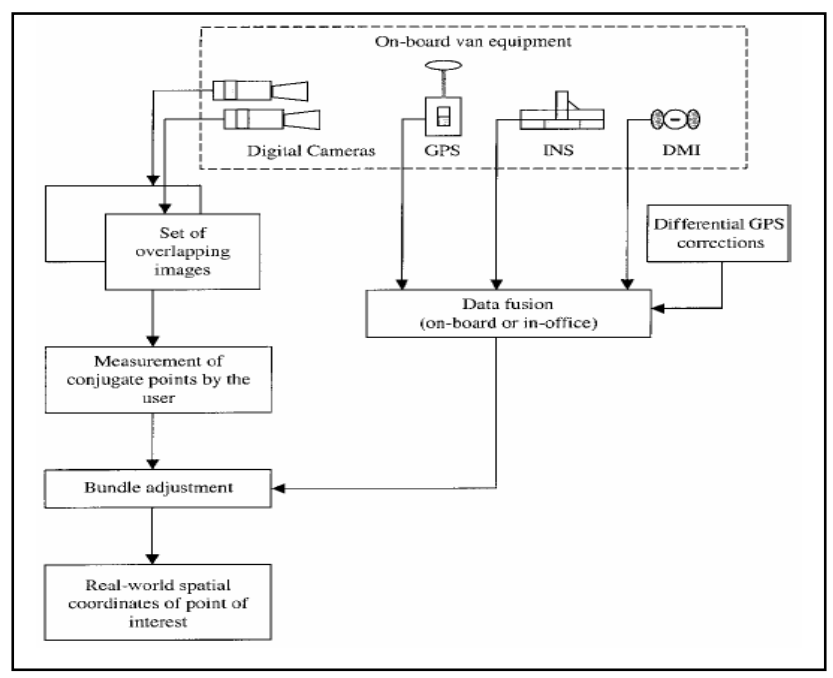

Figure 3.11 MMS Basic Process of Collecting Digital Measurements (Hassan et al. 2000)

The GPS data positioning data also correct the growth of the INS errors, whereas the INS high frequency measures are essential to detect and correct cycle slips. The digital cameras mounted on the van and pointed in different directions record images at regular distance intervals. Because the images are georeferenced, operators use photogrammetric software packages to make digital measurements of features and extract descriptive data from the image. By doing so, the location of objects with respect to the location of the van can be measured. Figure 3.11 shows the MMS basic process of collecting digital measurements.

Three different MMSs available on the US commercial market as of mid-1998 were used in the evaluation. The MMSs had similar technologies but different integration strategies, photogrammetric software, and input data. To measure the accuracy of data collected, the Percent Measurement Element (PME) is used and can be defined (Hassan et al. 2000)

$$
\text { PMEi }=\left[\frac{\text { MMSi }-\mathrm{GTi}}{\mathrm{GTi}}\right] \cdot 100
$$


where PMEi = percent error in the $\mathrm{i}$ th observation on an inventory element; MMSi $=\mathrm{I}$ th observation on a particular type of inventory element using MMSs; and GTi = I th ground truth observation on that particular type of inventory element.

"As the measure of descriptive data accuracy for data collected by an MMS, the PME has several useful properties. Its sign (positive or negative) allows the evaluator to determine if a particular method of data collection is overestimating (positive sign) or underestimating (negative sign) the true dimension of the inventory element. The use of ground truth observation in denominator of (1) normalizes for the size of an inventory element. Thus, errors in measurement of inventory elements of different sizes are comparable. Furthermore, the use of the PME is simple and straightforward.”

(Hassan et al. 2000)

\subsubsection{Electronic Navigation for Support Vessels}

A support vessel, operating a remotely operated vehicle (ROV), can only work efficiently if the crew can see the vessel and ROV in relation to one another and the ROV target (Sea Tech., July 1999). The need of ROV use has been increased for undersea platform and pipeline inspection and all kinds of undersea-related activities. While operating ROV, the vessel position is derived from DGPS, and the ROV position from the vessel position can be determined by using Hydroacoustic Positioning Reference (HPR).

The operation was cumbersome at a certain spot on the seabed because the systems were not integrated. Therefore, the project funded by Phillip Petroleum Company Norway (PPCoN) was conducted. The goal is to integrate the ship and the ROV navigation systems into one system with digital displays of the vessel and the ROV on the appropriate area map.

The integrated system has been used in anchored offloading buoys around Ekofisk field. To accomplish the removal, a 20-ton anchor and 50 tons of chain were pulled up. Because the 
mooring system was dumped on the seabed 20 years ago, the exact location was unknown, and the mooring system can be buried. Extensive seabed mapping with an ROV was necessary to find the locations where to grapple the anchor and chain and to stay from nearby pipelines. The system has shown the ship time saving compared to a nonintegrated system and the success of producing an accurate seabed map. Moreover, when minor oil leaks are reported, the integrated system can track the source of the oil leak faster and more reliably. 


\section{CHAPTER 4}

\section{UNDERGROUND UTILITY LOCATING SYSTEMS}

\subsection{One-Call Systems}

The One-Call system is a state regulated program, which is primarily designed to prevent underground pipeline damages during excavation. One-Call centers serve all fifty states and the District of Columbia. While laws vary by state, they all require excavators to contact the OneCall center responsible for that area before any digging begins.

The One-Call system starts with a call from an excavating contractor who calls the One-Call center regarding the proposed excavation with the information of the specific location of the excavation, the start date and time of excavation, and the description of the excavation activity. By law, the call should be made typically at least two working days before the planned excavation. Personnel in the One-Call center search spatial databases in order to identify possible conflicts with nearby facilities, process the information, and notify affected facility owners/operators.

When the facility owners/operators receive the notification (called a "ticket") from the One-Call center, they determine if there is a need to send their locating crews or their contracted locate company to the site. Once the locating team is sent to the site, the location of the underground pipelines is marked on the surface with above-ground APWA (American Public Works Association) color-coded markings and the completion of the work is reported to the One-Call center. The process of One-Call system is shown in Figure 4.1.

Due to the nature of the One-Call system, there are some inherent challenges in its sole use for improving the safety of the existing underground pipelines during excavation. Suppose the call from an excavator is made about 48 hours before the excavation as usual, then the locating team typically has less than 24 hours to do the marking of the underground pipelines on the surface because of the preprocessing time. 


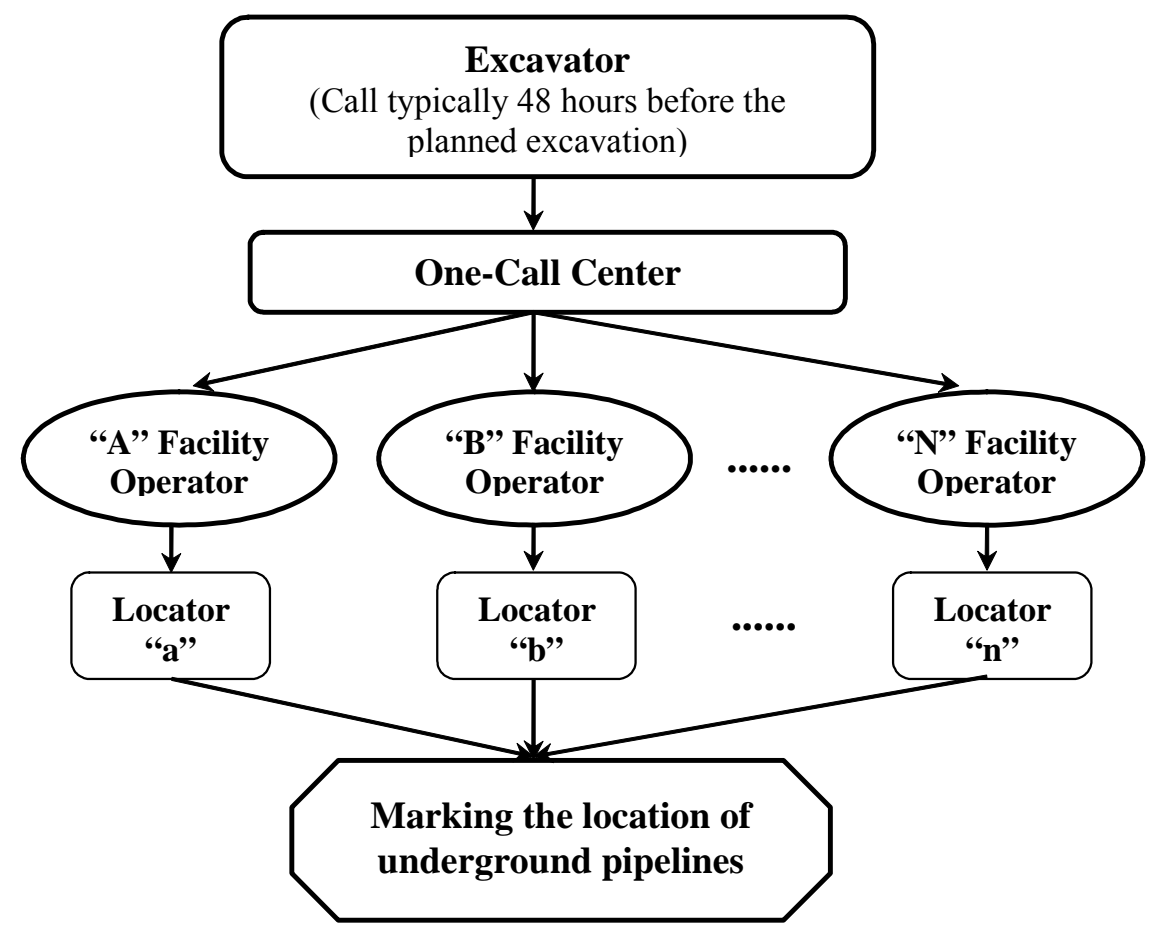

Figure 4.1. Process of One-Call System

This time constraint hinders thorough consideration of given information and careful selection of the most appropriate utility detecting technique based on site conditions, consequently increasing the probability of mislocates of the underground facility. In addition, the One-Call system can only work with the information based on the existence of buried facilities that the members of the One-Call network provide and the information of the proposed worksite provided by the excavator. The facilities of non-members are not located, and if information from the members and the excavator is not sufficient, the locating results can in incorrect.

\subsection{Subsurface Utility Engineering (SUE)}

\subsubsection{Introduction}

SUE is an emerging engineering process that has been proved to be an effective tool to reduce underground utility accidents and damage. This process aims to accurately locate and depict utilities and disseminate the information prior to commencing construction so that conflicts and 
disasters can be minimized. The practice of SUE has been developed and refined over many years and was systematically put into professional practice in the 1980s (Lew and Anspach 2000). A state utility engineer in the Virginia Department of Transportation (VDOT) sensed the potential of SUE and allocated $\$ 10,000$ for a trial project in late 1983. This was the first official SUE contract by a State DOT. VDOT reported to the Federal Highway Administration (FHWA) that over $\$ 1$ million in savings to the taxpayer were realized from this project (FHWA 2002). State DOTs and FHWA since then have taken a leading role in the promotion of SUE, and the term Subsurface Utility Engineering was coined at the 1989 FHWA National Highway Utility Conference. Today, in addition to FHWA and state DOTs, SUE is officially utilized in many state agencies, such as the Federal Aviation Agency (FAA), the Department of Defense (DOD), the Department of Energy (DOE), the General Service Administration (GSA) and the Network Reliability Council (NRC), as well as many municipalities and engineering firms.

This section evaluates various aspects of SUE. The first part of this paper presents an overview of SUE, including issues such as quality levels in SUE, incorporating SUE at different stages in the construction project, and major activities related to SUE. The second part presents a costbenefit analysis based on 71 actual construction projects with a combined construction value in excess of $\$ 1$ billion. The third part illustrates the trend of State DOTs in the use of SUE based on questionnaire surveys, and the last part presents the various aspects of SUE practice in the private sector.

\subsubsection{Overview of Subsurface Utility Engineering (SUE)}

\subsubsection{Quality Levels in SUE}

Stutzman and Anspach defined the four quality levels of underground utility information that are available to the design engineer, constructor, and project manager (Anspach 1995). These are quality level D, C, B, and A. The quality levels represent different combinations of traditional records research, site surveys, geophysical imaging techniques and locating techniques. As the quality level advances from D to A, superior technologies and processes are involved, increasing the accuracy and reliability of the collected data. The cost for obtaining underground utility data 
varies greatly as a factor of climate, soil, project specifications, geography, etc., however, in general, the higher the quality level desired, the higher the costs will be to obtain data. The increased accuracy and reliability of the data typically result in lower probabilities of utilityrelated damages. The conceptual relationship between quality levels associated with risk of utility damage and cost of SUE service is illustrated in Figure 4.2.

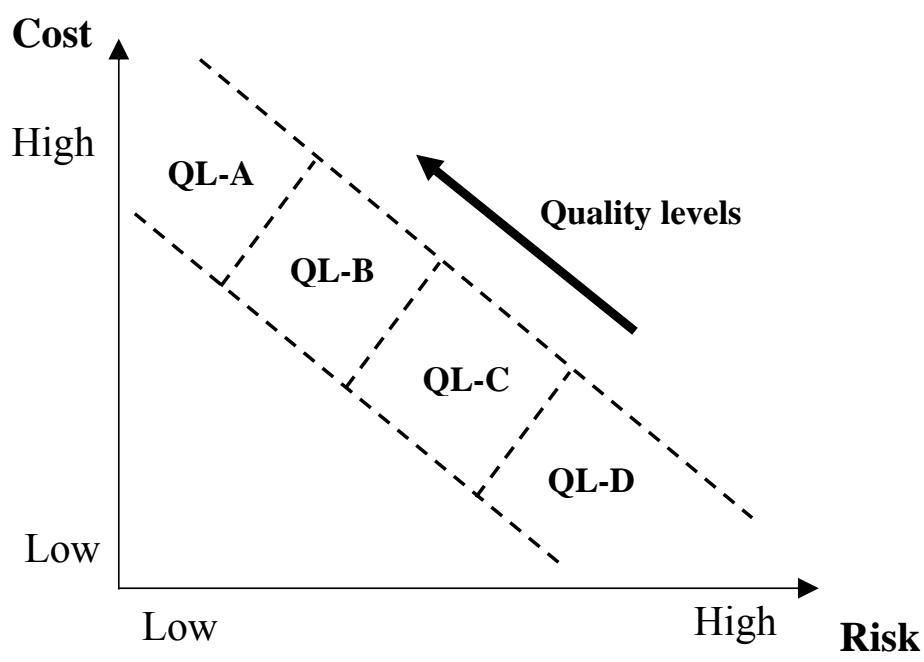

Figure 4.2. Quality Levels in SUE

In practice, the highest quality level may be needed at those points where utility conflicts may occur in a project. In contrast, a lower level of quality may be adequate in those areas where little to no conflict is anticipated (Zembillas 2002). Therefore, in a project, all types of quality level information can be found in the final deliverables. The generally accepted definitions of quality levels are as follows (Stevens and Anspach 1993; Lew 1996; ASCE 2002).

Quality Level D (QL-D) consists of information derived from existing records or oral recollection. It is often limited in terms of the comprehensiveness and accuracy required to eliminate the risks and dangers of conflict with underground infrastructure. This quality level is used for planning purposes such as route selection and utility relocation costs.

Quality Level C (QL-C) consists of information obtained by surveying and plotting visible above-ground utility features and by using professional judgment in correlating this information to QL-D information. This level has been traditionally used for design purposes. 
Quality Level B (QL-B) consists of information obtained through the application of appropriate surface geophysical methods to determine the existence and approximate horizontal position of subsurface utilities. QL-B data should be reproducible by surface geophysics at any point of their depiction. This information is surveyed to applicable tolerances defined by the project and reduced onto plan documents.

Quality Level A (QL-A) provides precise horizontal and vertical location of utilities obtained by the actual exposure (or verification of previously exposed and surveyed utilities) and subsequent measurement of subsurface utilities, usually at a specific point. The three-dimensional data of location, as well as other utility attributes, are shown on plan documents. Accuracy is typically set at $15 \mathrm{~mm}$ vertical and set at applicable horizontal survey and mapping accuracy levels as defined or expected by the project owner.

\subsubsection{Systematic Use of SUE}

The advantages of SUE can be fully realized when it is systematically incorporated during different construction stages in the project cycle as shown in Figure 4.3. During the planning stage of a construction project, all recorded utility information (QL-D) and visual indications (QL-C) are collected from utility owners, state government and the site survey. The recorded information is depicted on a base topographic plan prepared by the project surveyor and is used by the project engineer to locate the proposed construction facilities.

The use of SUE in the preliminary design stage involves all existing utilities designated at the proposed areas of work. This is an approximate horizontal location performed using the surface geophysical methods (QL-B). The acquired data is transferred onto preliminary plans for the project through a Computer Aided Design and Drafting (CADD) system or Geographic Information Systems (GIS). The location of proposed work can be optimized with respect to the horizontal location of the existing utilities. 


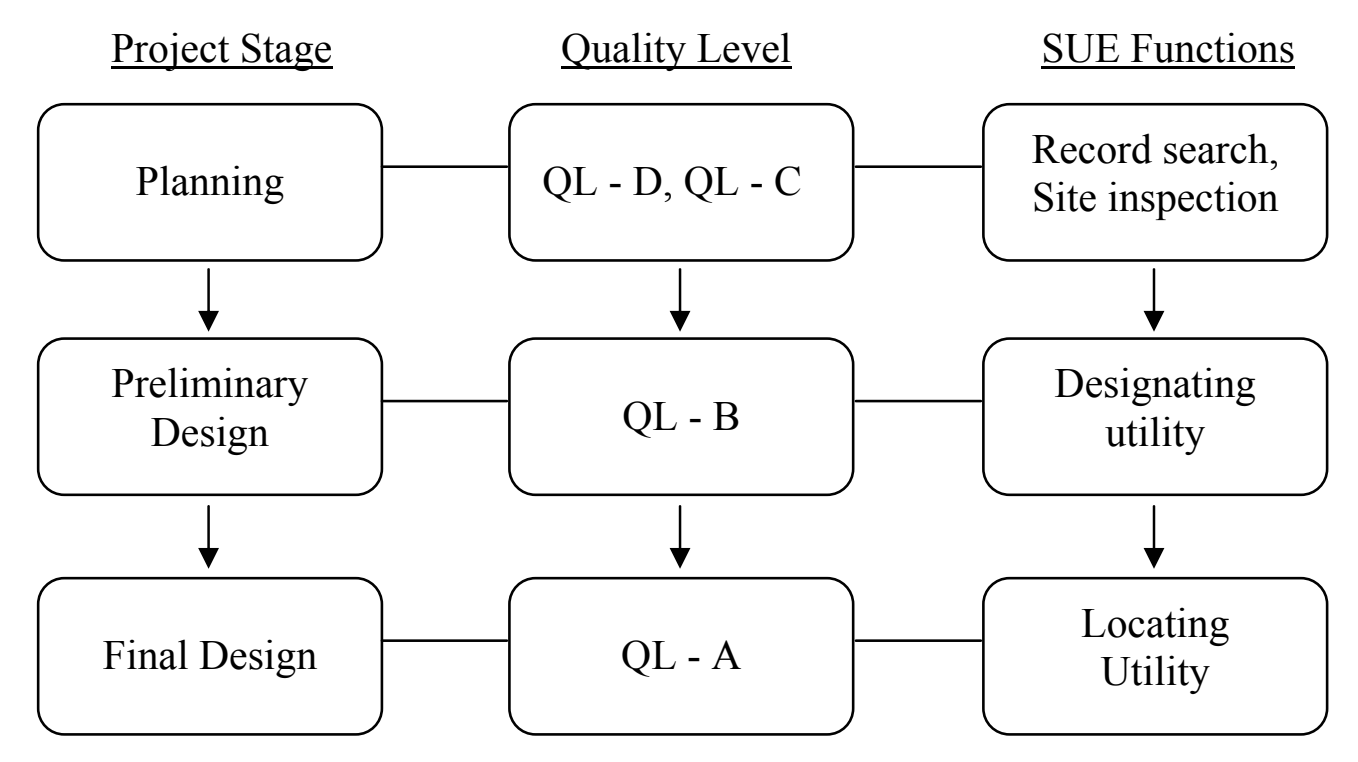

Figure 4.3. Systematic Use of SUE in a Construction Project

At the final design stage, locations, where conflicts with existing utilities may occur, can be identified. At these locations, QL-A data obtained from non-destructive locating methods or typically the vacuum excavation system can be used to adjust the final location of the proposed work. This systematic approach allows SUE engineers to narrow down the geographic region where upper quality level information is required as the construction project advances to a higher stage. This approach is an optimized SUE strategy using minimal budget.

\subsubsection{Major Activities in SUE}

The SUE process can be categorized into the five distinctive activities as shown in Figure 4.4. It is a combination of geophysics, surveying, civil engineering, and data management. Fieldwork involves three different activities, i.e., subsurface utility designating, subsurface utility locating and surveying. Subsurface utility designating determines the existence and approximate horizontal position of underground utilities using surface geophysical techniques, which include pipe and cable locators, magnetic methods, metal detectors, Ground Penetrating Radar (GPR), acoustic emission methods, etc. In the subsurface utility locating activity, minimally intrusive methods of excavation are used such as vacuum excavation, allowing the determination of the 
precise horizontal and vertical position of the underground utility line to be documented. This activity is to obtain the QL-A data.

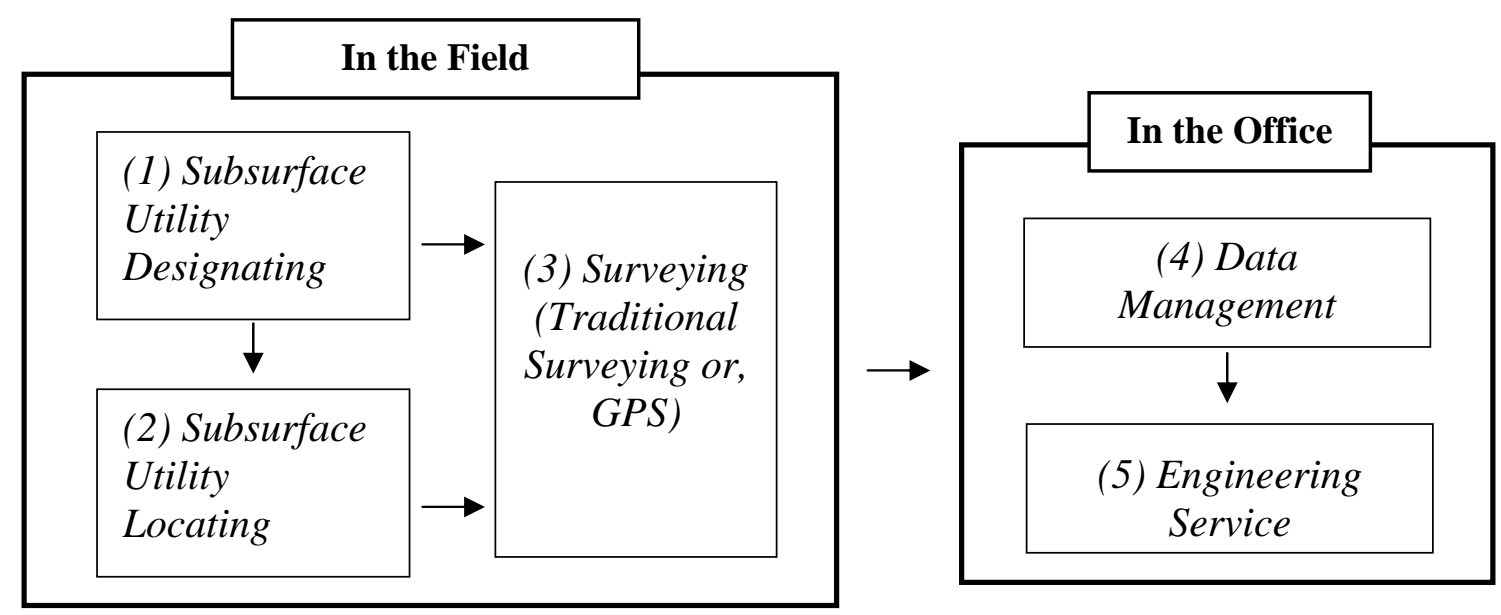

Figure 4.4. Major Activities in SUE

Surveying instruments such as levels, staffs and theodolites are typically used for the surveying activities. The Global Positioning System (GPS) is now widely accepted for surveying purposes. Its improved accuracy, e.g., when using Real Time Kinematic (RTK) technology, and the ease of data transfer to CADD and GIS environments have accelerated its use. The data management activity ranges from updating information on existing utility drawings or construction plans to the production of completely new utility maps. In the final engineering service activity, the SUE engineer provides consultation, conflict determinations, and utility coordination and design.

\subsubsection{Cost-Benefit Analysis}

The cost savings generated by SUE application in 71 highway construction projects in Virginia, North Carolina, Texas, and Ohio were examined by Lew (2000). The total construction costs of these projects were in excess of $\$ 1$ billion. For this study, the raw data on each project were recollected and analyzed to evaluate the quantitative benefits of SUE in various aspects.

The projects analyzed in this study, involved a mixture of interstate, arterial, and collector roads in urban, suburban, and rural settings. In terms of construction budget, various sizes of projects 
were examined with the construction cost ranging from $\$ 0.3$ million to $\$ 238$ million. The cost of using SUE for each project ranged from $\$ 2,200$ to $\$ 500,000$. It was determined that the ratio of the cost of SUE to the total construction cost (SUE cost ratio) ranged from $0.02 \%$ to $10.76 \%$, and the average ratio was $1.39 \%$ with the standard deviation of $1.86 \%$. This result was close to the predicted value (1\%) by Noone (1997).

In order to measure the SUE cost savings in the construction projects, 21 categories were developed to quantify the savings in terms of time, direct cost, user savings, and risk management aspects as shown in Table 4.1. These categories were derived from extensive interviews with DOTs, utility companies, SUE consultants, and contractors. The cost savings in each category were measured using two different methods - estimated cost and projected cost. Estimated costs include additional design and construction costs which can be reasonably estimated in each category in cases where SUE is not employed. These costs include utility relocation costs, project delay costs due to utility cuts, etc. Projected costs include items that may be difficult to quantify completely but can be with an acceptable degree of certainty. These costs were approximated by analyzing the projects in detail, interviewing the personnel involved in the project and applying historical cost data. Examples of these costs include contingency fees from all parties, damage to existing site facilities and damage to existing pavements.

\section{Table 4.1. Categories for Quantification of SUE Cost Savings (Lew 2000)}

\begin{tabular}{|l|l|}
\hline \hline 1) Reduced the number of utility line relocations & 12) Reduced the cost of project design \\
2) Reduced project delays due to utility relocations & 13) Reduced the damage to existing pavements \\
3) Reduced construction delay due to utility cuts & 14) Reduced damage to existing site facilities \\
4) Reduced contractor's claims and change orders & 15) Reduced the cost of needed utility relocates \\
5) Reduced delays caused by conflict redesign & 16) Minimized disruption to traffic and emergency \\
6) Reduced accidents and injuries due to line cuts & 17) Facilitated electronic map accuracy, as-built \\
7) Reduced travel delays to the motoring public & 18) Minimized chance of environmental damage \\
8) Reduced loss of service to utility customers & 19) Induced savings in risk management and \\
9) Improved contractor productivity \& methods & insurance \\
10) Increased the possibility of reduced bids & 20) Introduced concept of SUE \\
11) Reduced contingency fees from all parties & 21) Reduced right-of-ways acquisition costs \\
\hline
\end{tabular}

The measured project cost savings ranged from $\$ 6,000$ to $\$ 3,000,000$. In order to evaluate the total savings on a typical project using SUE when compared with costs from a project utilizing traditional utility data (QL-D \& QL-C), the following equation was used. 


$$
\text { Construction Cost Savings }(\mathrm{CCS})_{i}(\%)=\left(\frac{S_{i}-C S_{i}}{C_{i}+S_{i}}\right) \times 100
$$

where $C_{i}={\text { construction cost of the } \text { project }_{i}, S_{i}=\text { SUE savings from the project }}_{i}$ (additional costs that would have been expected if SUE were not implemented) and $C S_{i}=$ the amount of money spent on SUE for project $_{i}$. The average savings was $4.6 \%$ of the total construction cost with standard deviation of $6.38 \%$. This figure is less than the predicted value by Stevens (1993) who stated that the total savings on a typical project using SUE might range from $10 \%$ to $15 \%$.

Return on Investment (ROI) was calculated using equation (2).

$$
\operatorname{ROI}_{i}(\%)=\frac{S_{i}}{C S_{i}}
$$

Here, ROI is the amount of money saved by the expenditure of one dollar for SUE activity. In an analysis of the ROI on the 71 projects showed that only three projects had negative ROI. The average \$12.23 ROI for every $\$ 1.00$ spent on SUE was quantified with the standard deviation of \$29.04. The high standard deviation in this case implies the high volatility of ROI. The ROI of the 71 projects ranged from $\$ 0.59$ to $\$ 206.67$, which can be attributed to the different characteristics of the project, including the degree of the congestion of underground utilities in the project area, the location of the project (rural or urban), the type of the project (bridge or new road construction), the presence of new underground utility construction, the area covering the project, etc. For instance, urban road construction with a heavy presence of new underground utility construction in a utility-congested area can benefit greatly through the use of SUE. The data of the cost-benefit analysis is summarized in Table 4.2. 
Table 4.2. Summary of Cost-Benefit Analysis of SUE

\begin{tabular}{|l|r|r|r|r|r|r|}
\hline \multicolumn{1}{|c|}{ Items } & $N$ & \multicolumn{1}{c|}{ Mean } & \multicolumn{1}{c|}{ SD } & \multicolumn{1}{c|}{ SE } & \multicolumn{1}{c|}{ Min } & \multicolumn{1}{c|}{ Max } \\
\hline Construction Cost & 71 & $\$ 16,028,648$ & $\$ 31,717,159$ & $\$ 3,764,134$ & $\$ 275,333$ & $\$ 238,000,000$ \\
Cost of SUE & 71 & $\$ 86,156$ & $\$ 111,443$ & $\$ 13,226$ & $\$ 2,279$ & $\$ 545,907$ \\
SUE cost ratio & 71 & $1.39 \%$ & $1.86 \%$ & $0.22 \%$ & $0.02 \%$ & $10.76 \%$ \\
SUE savings & 71 & $\$ 398,920$ & $\$ 546,688$ & $\$ 64,880$ & $\$ 6,000$ & $\$ 3,136,000$ \\
\% of CCS & 71 & $4.26 \%$ & $6.38 \%$ & $0.76 \%$ & $-4.11 \%$ & $34.17 \%$ \\
ROI & 71 & $\$ 12.23$ & $\$ 29.25$ & $\$ 3.47$ & $\$ 0.59$ & $\$ 206.67$ \\
\hline CCS: construction cost savings, SD: Standard deviation, SE: Standard Error \\
\hline
\end{tabular}

A cost savings analysis of each individual category was also performed. In order to evaluate the degree of impact of each category (DI) to cost savings, the equation (3) was employed.

$$
\text { DI of the category }=\frac{\sum\left(\text { CSC }_{i}\right)}{\sum\left(\text { TCPS }_{i}\right)} \times 100
$$

where $\operatorname{CSC}_{i}=$ cost savings in each category for the project ${ }_{i}$, and $\operatorname{TCPS}_{i}=$ total cost savings in the project ${ }_{i}$. As shown in Figure 4.5, reduced number of utility relocations is the category that contributes most significantly to the cost savings (37.1\%). The use of SUE enables the early identification of conflicts between existing utilities and new utilities. This can lead to a significant reduction of the amount and length of utility relocations. Reduced contractor's claims $\&$ change orders is the second most significant contributor to cost savings (19.3\%). Incorrect utility information on the as-built drawings often leads to additional construction work and in some cases, claims and design change as project owners are typically responsible for unknown or differing site conditions. Precise information about utilities assists in quick and reliable decisionmaking in the negotiating and permitting process with municipalities and utility companies. Besides, the reduced likelihood of claims also decreases the level of contingency that has to be set aside to deal with uncertainties in the construction phase. 


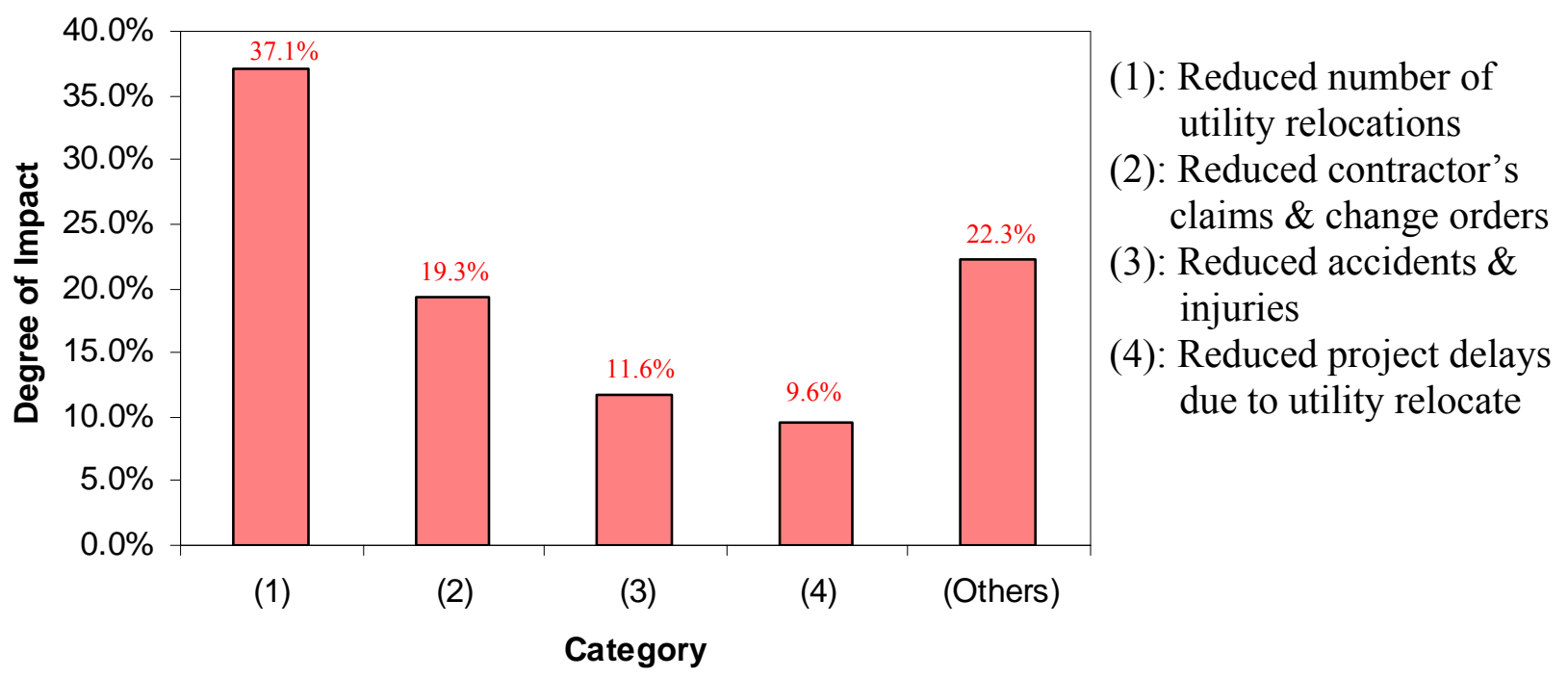

Figure 4.5. Degree of Impact of Different Categories to Cost Savings

Reduced accidents \& injuries due to utility line cuts is the third significant cost savings factor in the use of SUE (11.6\%). SUE upgrades the accuracy and the reliability of the location of existing utility lines, lessening the probability of hitting utilities during the excavation stage. Reduced project delays due to utility relocates is the fourth significant cost saving factor (9.6\%). Other cost savings categories that comprise a total of $22.3 \%$ include reduced right-of-way acquisition costs (3.5\%), induced savings in risk management \& insurance (3.3\%), reduced delays caused by conflict redesign $(2.8 \%)$, etc.

\subsubsection{Current Sue Practice in State Dot's}

For the purpose of evaluating the current SUE practices in state DOTs, questionnaire surveys were distributed to all 50 states in 2000, 2001 and 2002. Forty questionnaires were returned in the year 2000 survey (a response rate of 80\%), 29 questionnaires were collected in 2001 (a response rate of $58 \%$ ), and 35 states responded in 2002, representing a response rate of $70 \%$. The statistics quoted in this paper are primarily based on the 2002 survey unless noted otherwise. The summary of the finding is shown in Table 4.3. 
Table 4.3. Summary of State DOT Survey

\begin{tabular}{|c|c|c|c|c|c|c|}
\hline \hline Year & $\begin{array}{c}\text { Survey } \\
\text { Response }\end{array}$ & $\begin{array}{c}\text { SUE } \\
\text { Program }\end{array}$ & $\begin{array}{c}\text { Average } \\
\text { SUE Budget } \\
\text { (in 1,000's) }\end{array}$ & $\begin{array}{c}\text { Effective } \\
\text { tool for cost } \\
\text { reduction }\end{array}$ & $\begin{array}{c}\text { Effective } \\
\text { procedure for } \\
\text { reducing } \\
\text { delays }\end{array}$ & $\begin{array}{c}\text { Meet your } \\
\text { state } \\
\text { expectations }\end{array}$ \\
\hline 2000 & $40(80.0 \%)$ & $23(57.5 \%)$ & $\$ 1,501.1^{*}$ & $85.0 \%$ & $72.5 \%$ & $91.7 \%$ \\
2001 & $29(58.0 \%)$ & $16(55.2 \%)$ & $\$ 1,686.6^{*}$ & $72.4 \%$ & $75.9 \%$ & $87.5 \%$ \\
2002 & $35(70.0 \%)$ & $22(62.9 \%)$ & $\$ 2,020.9 *$ & $* *$ & $* *$ & $90.9 \%$ \\
\hline$*$ Converted in dollars of 2001 by Engineering News Record (ENR)'s Construction Cost Index \\
$* *:$ The item was not included in the 2002 survey \\
\hline
\end{tabular}

Twenty-two states, or $63 \%$ of respondents, reported that they have utilized SUE on their highway projects. Four states had initiated the SUE program in 2002 while two states started the use of SUE in 2001. Eight states, or $62 \%$ of the respondents that had not used SUE reported, that they were considering a pilot project for the use of SUE in five years. The average annual amount of budget spent on the SUE program in the states was about $\$ 1.5$ million in 2000 , about $\$ 1.7$ million in 2001, and \$ 2 million in 2002. The average annual budget for the SUE program grew as much as $135 \%$ higher during this period. No states reported a decrease in their SUE budget. The most active state in promoting SUE application in highway projects was Texas, spending more than $\$ 6$ million annually.

Virginia, which has the longest history of use of SUE, is mandated by state regulation to apply SUE to every highway project. Delaware, Maine, Maryland, North Carolina, and Pennsylvania reported that all or most of their highway projects currently involved the use of SUE. The other states typically employ SUE based on its usefulness in highway projects. The common criteria for choosing SUE for a project are (1) a urban highway construction project with a high potential for anticipated utility conflicts, (2) projects with complex utility networks - either aging or of significantly high potential for expensive utility relocations, (3) limited, narrow, and congested existing right-of-way, and (4) high-profile highway projects that have critical schedules.

State DOTs have different decision-making agencies to select projects for implementing SUE. More than $90 \%$ of respondents that have a SUE program reported that a design project manager made the decision to employ SUE or district utility agents were involved in the decision. Other responses include direct decision made by the state DOT central office or involvement by SUE 
consulting firms. States performing pilot projects indicated that the decision was made at the central office.

The survey indicated that more than $90 \%$ of state utility managers who responded are aware of SUE and they stated that SUE is an effective tool for cost reduction in a project $(85 \%$ in 2000 and $72 \%$ in 2001). Seventy-five percent of states surveyed in 2001 (73\% in 2000) reported that SUE is an effective procedure for reducing construction delays when it is used in the design stage. Decreased construction delays are based on a substantially positive increase in utility coordination and fewer anticipated utility conflicts when SUE is used. More than $90 \%$ of the states who have used a SUE program reported that SUE satisfactorily met their needs, emphasizing that SUE also benefits other groups, including utilities, contractors, engineers and the highway department by removing significantly additional workloads due to reduction of utility conflicts, delays and safety hazards which are expected unless SUE is utilized and consequently providing more clear predictable project schedule.

Regardless of the obvious benefits of SUE, some disappointing results from the use of SUE were reported mainly due to lack of professional SUE providers. Qualification guidelines for the selection of SUE providers were not strongly established nor rigorously enforced in the states. The survey revealed that a SUE provider for state highway projects was typically selected based on the SUE firm's past experience, availability of key personnel, ability to perform the project, quality assurance or quality program, and prior work experience with the DOT. Based on FHWA recommendations (FHWA 2002), SUE firms must be able to provide the following: a thorough understanding and knowledge of designating, locating, surveying, and data management activities; well trained and experienced engineers in accordance with state professional registration requirements; adequate resources including wide range of equipment and systems for each SUE activity; and the financial capacity to provide the required services. The ability to provide the required accuracy of SUE services and adequate insurance covering all aspects of work are also key ingredients of successful SUE providers. 


\subsubsection{Current SUE Practice in Private Sectors}

In order to evaluate the nature of SUE business in the private sector, a questionnaire was developed and distributed to 45 SUE companies that currently provide SUE services in the U. S. Twenty-three questionnaires were returned, representing a response rate of $51 \%$. Two of the respondents failed to complete the survey completely, thus 21 surveys were used in the analysis. The questionnaire consisted of three sections: (1) company profile; (2) clients and types of contracts; and (3) project practice and control of operations. The first section was intended to gather background information on the company and to measure the business growth in this industry. The second section was used to analyze the composition of clients using SUE and contract methods used on SUE projects. The third sections of the survey contained questions seeking information about technologies used in each SUE process, average productivity, unit price, man power and SUE operation challenges.

\subsubsection{Company Profile}

The majority of responding SUE providers (67\% of the respondents) had been in business less than 10 years. Nineteen percent of participants had greater than 10 years and less than 15 years of experience while 14 percent had more than 15 years of experience. SUE providers are in a young industry as SUE was initiated in the early 1980's and spread mainly through the effort of Federal Highway Administration (FHWA) and state DOTs. There has been relatively slow acceptance of the technology thus far as there are a few established companies offering this specialized service.

Approximately $79 \%$ of the respondents reported annual sales in the year 2001 of less than $\$ 5$ million. These companies can be characterized as small SUE providers. They employ less than 50 people, and their geographical domain is normally regional. Sixteen percent of the respondents indicated sales between $\$ 6$ million and $\$ 10$ million, while 5\% of the respondents had annual sales in excess of $\$ 10$ million. Typically, large firms involved in nationwide SUE business have more than 100 employees. The annual sales per employee increase as the size of company increases as shown in Table 4.4. Small companies generate an average of $\$ 60,063$ per 
employee in a year. In contrast, the large firms create sales of more than $\$ 100,000$ per employee. The difference can be partially attributed to the following factors:

- A SUE project lasts for a couple of days or at most several weeks. This implies that a waiting period (no work period) between projects can be a significant factor affecting the sales volume of the company. The flow of SUE projects for small firms tends to be low due to the nature of their localized business.

- Even small companies need to maintain a consistent staffing level for full SUE service irrespective of the number of projects since a typical SUE project consists of five different stages (which were shown in Figure 2.4) with different engineers. Subsequently manpower is not maximized, resulting in lower productivity in small companies.

Table 4.4. Annual Sales, Geographical Domain \& Number of Employees

\begin{tabular}{|c|c|c|c|c|c|c|}
\hline \hline $\begin{array}{c}\text { Annual } \\
\text { Sales } \\
\text { (millions) }\end{array}$ & Percentage & $\begin{array}{c}\text { Number of } \\
\text { employees }\end{array}$ & $\begin{array}{c}\text { Average } \\
\text { number of } \\
\text { employees }\end{array}$ & $\begin{array}{c}\text { Geographical } \\
\text { domain }\end{array}$ & $\begin{array}{c}\text { Average } \\
\text { annual } \\
\text { sales per } \\
\text { employee }\end{array}$ & $\begin{array}{c}\text { Company } \\
\text { Size }\end{array}$ \\
\hline$>10$ & $5 \%$ & $>150$ & 172 & Nationwide & $\$ 104,651$ & Large \\
\hline $6-10$ & $16 \%$ & $50-100$ & 82 & $\begin{array}{c}\text { Nationwide } \\
\text { Regional }\end{array}$ & $\$ 85,622$ & Medium \\
\hline$<5$ & $79 \%$ & $<50$ & 16 & Regional & $\$ 60,063$ & Small \\
\hline \hline
\end{tabular}

In the analysis of the employee composition of SUE firms, technicians for fieldwork comprise $69 \%$ of the total, and are in charge of designating, locating and surveying tasks and collecting data for utility properties. Project engineers, who typically manage all the SUE projects in a specific region, comprise $16 \%$. Others engineers for data management system form $13 \%$ of the employee group. Only $3 \%$ of employees are geophysicists. The survey revealed that middle and large companies hire geophysicists, and small firms do SUE business without employing geophysicists. The essential element for a successful SUE project is the correct identification of underground utilities. Different site environments, including soil conditions, pipe material, joint type of pipe, depth of utility, etc., commonly require the expertise of a geophysicist in the proper use of geophysical equipment for the detection of subsurface utilities. The low number of geophysicists employed in SUE firms is a growing concern in the industry particularly when it is necessary to provide high quality SUE deliverables. 
The growth rate in SUE business during the past five years is plotted based on the annual sales of SUE companies as shown in Figure 4.6. The annual sales in each year were converted in dollars of 2001 using ENR's Construction Cost Index, which is widely employed to incorporate inflation factors in construction industry. The growth rate was based on 1997 sales. Three criteria were utilized in the selection of appropriate respondents for this analysis.

a) The companies had annual sales in 2001 of more than $\$ 1$ million.

b) They have been in SUE business for more than 5 years.

c) These companies have not been involved in merge and acquisition activities (since these activities may distort the magnitude of sales of SUE business during that period).

Growth Rate

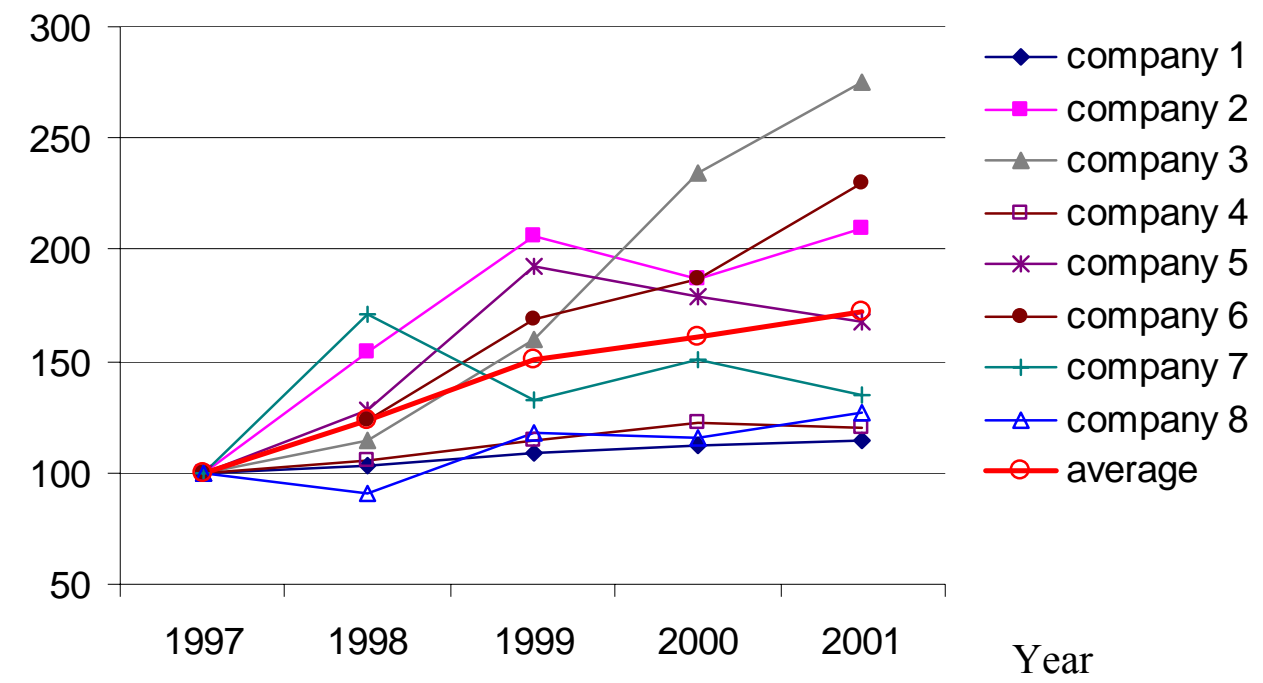

\begin{tabular}{|c|ccccc|}
\hline \multirow{2}{*}{ Company } & \multicolumn{5}{|c|}{ Year } \\
\cline { 2 - 6 } & 1997 & 1998 & 1999 & 2000 & 2001 \\
\hline Company 1 & $100.0 \%$ & $103.3 \%$ & $109.3 \%$ & $112.4 \%$ & $114.8 \%$ \\
Company 2 & $100.0 \%$ & $154.6 \%$ & $206.0 \%$ & $187.3 \%$ & $209.9 \%$ \\
Company 3 & $100.0 \%$ & $114.8 \%$ & $160.2 \%$ & $234.1 \%$ & $275.5 \%$ \\
Company 4 & $100.0 \%$ & $105.4 \%$ & $114.4 \%$ & $122.6 \%$ & $120.3 \%$ \\
Company 5 & $100.0 \%$ & $128.3 \%$ & $192.2 \%$ & $179.1 \%$ & $167.7 \%$ \\
Company 6 & $100.0 \%$ & $123.0 \%$ & $168.2 \%$ & $187.3 \%$ & $229.6 \%$ \\
Company 7 & $100.0 \%$ & $171.6 \%$ & $132.7 \%$ & $150.2 \%$ & $135.3 \%$ \\
Company 8 & $100.0 \%$ & $90.8 \%$ & $118.3 \%$ & $115.2 \%$ & $127.2 \%$ \\
\hline Average & $100 \%$ & $124.0 \%$ & $150.2 \%$ & $161.0 \%$ & $172.6 \%$ \\
\hline ENR's Construction & 5825 & 5920 & 6060 & 6221 \\
Cost Index & \multicolumn{5}{|c|}{ Base: year 1913=100 } \\
\hline \hline
\end{tabular}

Figure 4.6. Business Growth of SUE Providers 
The growth rate of the SUE business of selected companies ranged from $115 \%$ to $276 \%$, averaging $173 \%$. No company showed a decline in sales during the period. This rapid growth can be attributed to increasing consensus among project owners of the benefits of SUE such as cost savings and damage prevention, as well as growth of underground construction in urban areas, utility rehabilitation and replacement. It also strongly indicates that the SUE marketplace has just entered a robust adolescence period, but has yet to achieve the status of a mature industry.

\subsubsection{The Clients and Types of Contracts}

\section{The Clients}

FHWA and several DOTs were early proponents and advocates for the use of SUE. They primarily promoted the use of SUE in highway construction projects as a cost reduction tool. More than half of the projects undertaken by SUE providers were State DOT and federal agency projects $(55 \%)$. Sixteen percent of the projects were for institutions, military and industrial facility projects. Engineering firms comprised $11 \%$ of the clients and the other clients were municipalities (11\%), utility companies (4\%), and construction companies (3\%).

\section{Type of Contract}

SUE projects are typically obtained through negotiated contracts. Even though there are some projects performed under the competitive bidding, the bidding is avoided in this industry because it triggers the service to fall behind the necessary quality level. It is common for owners to approach SUE providers and negotiate the terms of a contract. Strategic alliances, typically in state DOT contracts, are a growing trend. These relationships are usually defined by a contract and extend over a period of two or three years (open-end method). Under such an arrangement, the owner can obtain a consistent level of underground utility information and consultation from a qualified SUE provider. The owner can eliminate a repetitive selection process during that period while securing the services of qualified provider.

The survey revealed that the most common type of contract used in the SUE industry is a costplus-fee contract method (42\%). Per Diem, or daily rate, contracts comprise $14 \%$. The wide use 
of cost-plus-fee, which is the typical contract method for engineering services, is based on the characteristics of SUE services. In 1989, a court of competent jurisdiction recognized SUE services are professional services rather than contractor services since information placed on plans that are relied upon by the public clearly fell into the professional services category (FHWA 2002). The type of contract for SUE operations is also highly related to the type of project owner. States DOTs and Federal agencies, which comprise more than half of the SUE clients, prefer a cost-plus-fee method because they have the resources to audit and do cost analyses. This type of contract also enables SUE firms to earn reasonable profits while recovering all costs expended on the project. The major disadvantage of cost-plus-fee and Per Diem method is the difficulty in proper budgeting and the provision of fewer incentives for SUE providers to work efficiently.

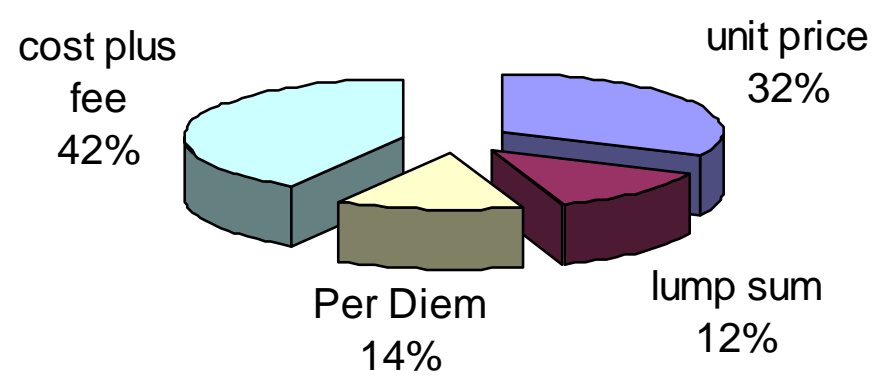

Figure 4.7. Breakdown of Contract Methods in SUE

Thirty-two percent of the contracts were made based on unit price contracts while $12 \%$ of the contracts used the lump sum contracting method. When only quality level A and B mapping are required, these types of contracts can be easily adapted since the fees for engineering service are not included. In unit price contracts, clients typically have the best control over budget and meeting the budget expectations, and SUE providers are encouraged to optimize their available resources to provide highly efficient and productive services. However, if the site environment is not favorable for the SUE firms, this method may negatively impact the profit of the SUE firm or the quality of the final deliverables. The primary advantage of the lump sum contract method is the ease in budgeting for project owners. However, it may be difficult to obtain the final deliverables at the exact level of effort anticipated by the SUE provider. 


\subsubsection{Project Practices and Control of Operations}

\section{Designating Methods and Locating Methods}

There are various designating methods available in industry to acquire data regarding twodimensional location of underground utilities. It is crucial for a SUE provider to be equipped with different kinds of instruments for successful designation of an underground utility and reliable SUE service because no single technology currently available can function in all soil conditions and at all depths. The participants in the survey were asked to identify the availability of different designating equipment and to evaluate the use of different designating equipment on typical highway projects for all utilities.

Pipe and cable locators, ground penetrating radar (GPR), and metal detectors were found to be the main designating equipment for SUE projects as most of the responding companies are equipped with those systems. Acoustic pipe tracers (APT) (62\%), magnetometers (48\%), terrain conductivity meters (TCM) (33\%), and electronic marker systems (EMS) (29\%) were also available for use. An E-line locator system, which is utilized for designating plastic gas pipe without tracing wires or electronic markers installed above the pipe, was not commonly available $(10 \%)$.

Eighty-two percent of designating operations on highway projects were performed using pipe and cable locators. Typically, this method is used to detect metallic utilities or tracing wire installed pipes. But non-metallic pipes can also be designated by inserting a sonde (a type of transmitter) through an access point to the underground utility, such as a manhole. Acoustic pipe tracers ( $6 \%$ of use), whose operation is based on elastic wave theory, are primarily designed for detecting plastic gas or water pipes. A low tracing length (typically less than $300 \mathrm{~m}$ ) and low accuracy due to noise in an urban area limit the use of this method. GPR is currently the third most common method for designating purposes (5\%). The major advantage of GPR is that it can image different types of materials buried underground. The drawbacks of using this equipment include inapplicability to high conductive soils (clay and saturated soils), practical limitation of imaging objects located $2 \mathrm{~m}$ below the surface, and high operating costs compared to pipe and cable locators. 


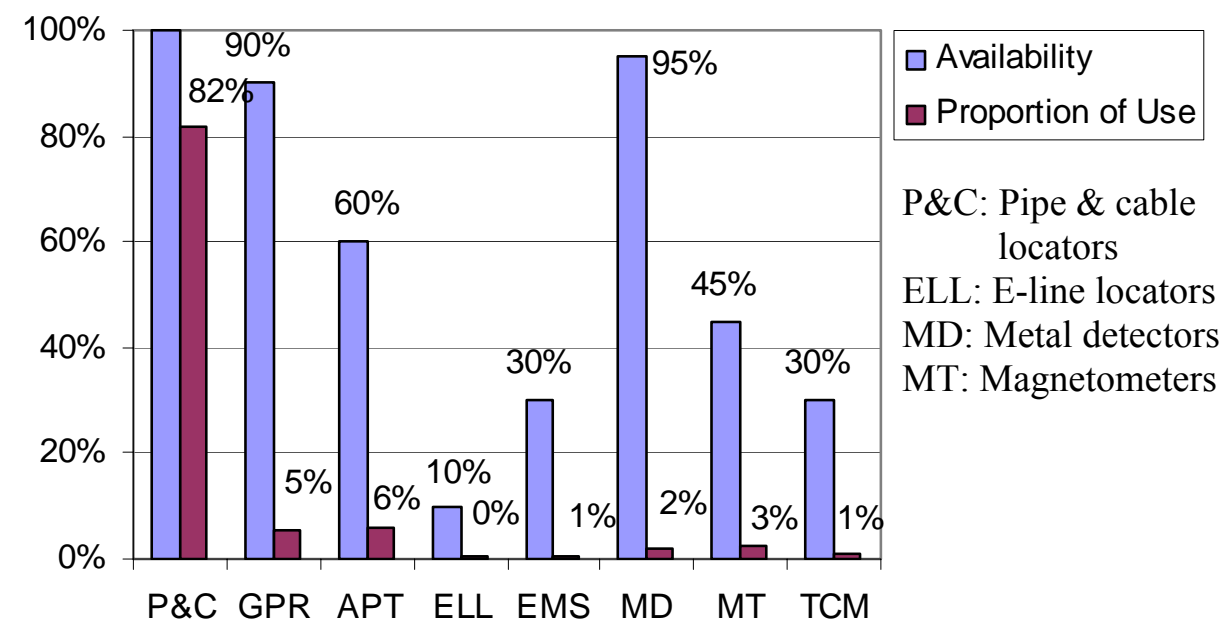

Figure 4.8. Availability and Proportion of Use of Designating Methods

The other designating methods, which are used less than $3 \%$ of the time, include E-line locator, EMS, metal detector, magnetometer and TCM. EMS is only applicable in areas where electronic markers were installed at the time of the utility construction. Metal detector and magnetometers are typically used for searching metallic surface appurtenance such as manhole lids or valve boxes, but they are not useful for tracing utility lines, which explains the low rate of use in designating operation activity. TCM is useful for detecting isolated metallic utilities, underground storage tanks (UST), wells, and vault covers.

The vacuum excavation system is the predominant method for locating underground utilities in order to obtain three-dimensional data and utility properties. Ninety percent of respondents reported that they were equipped with vacuum excavation systems. This process uses vacuum in combination with high-pressure water or air to expose underground utilities. The method guarantees that there will be no damage to existing utilities and that the "hole" in the street pavement is kept to a minimum and is easily repaired.

\section{Surveying \& Data Management Systems}

Ninety-five percent of respondents indicated that they work with traditional surveying tools, such as levels and theodolites, for mapping identified underground utilities, after the designating and 
locating process. For developing a permanent record of utilities locations requested by the project owner, GPS is more likely to be used. Eighty six percent of respondents were equipped with GPS. The rapid development of GPS technology such as RTK method makes it possible to obtain horizontal and vertical accuracy of $\pm 3-5 \mathrm{~cm}$ ("GPS" 2002). The surveying process is sometimes sub-contracted. Small SUE firms find it difficult to maintain a full-time professional survey crew; sub-contracting the surveying process is a better choice for such companies. In such case, these firms typically team up with a local surveyor. Some portion of the surveying is also strategically sub-contracted on DOT work to meet Historically Underutilized Business (HUB), Disadvantaged Business Enterprise (DBE) and Women Business Enterprise (WBE) requirements or to involve a registered surveyor in the state where the work is being performed. Involving outside surveying firms in SUE projects, however, may create a question of responsibility or liability for the data delivered.

The dominant data management tool at present is Computer CADD ( $86 \%$ availability). According to United States General Accounting Office (USGAO 1999), 43 states (84\%) had used CADD for their construction projects while 15 states (29\%) had also used GIS for their construction projects. As the state DOTs are major clients for SUE services, SUE companies are more likely to provide their deliverables in CADD rather than GIS. Of the respondents, 57\% have GIS capability, which is currently used at the request of the client. GIS technology can provide advanced features such as easy data transformation with GPS, data manipulation, and data analysis, which distinguishes it from CADD system. For example, utility attributes such as size, material, condition, installation date, utility owner, and maintenance histories are also recorded with the coordination data and quality levels in GIS. This data inventory can be used to produce a new set of data in tabular forms or visual formats to assist underground infrastructure managers in deciding utility inspection scheduling, areas of rehabilitation, maintenance budgeting, utility routing and permitting, emergency response planning, etc.

\section{Productivity/Unit Cost}

The productivity and unit costs for a designating service typically using pipe and cable locators and for locating services using vacuum excavation system are shown in Table 4.5. As the scope of SUE and the environment in which SUE is used change significantly from project to project, 
the productivity and the unit cost of both activities vary significantly. The large coefficient of variance of productivity of the designating activity implies a significant impact by site conditions on each activity. Traffic congestion, degree of utility congestion, utility material, depth of utility, surface condition, weather, and level of urbanization, all affect the productivity of designating activity. In the locating activity, the depth of the utility and the soil condition were found to be the critical factors. Utilities which are located at depths greater than normal utility depth $(<1.5$ m) under the pavement require a relatively longer time period for location due to pavement breakage, large area of excavation and lack of illumination when locating the utilities. Sticky soils such as clay are also likely to clog the vacuum hose while soil is disposed.

Table 4.5. Productivity and Unit Cost

\begin{tabular}{|c|c|c|c|c|c|c|c|c|}
\hline \multicolumn{2}{|c|}{ SUE activity } & $\mathrm{N}$ & Mean & SD & $\% \mathrm{CV}$ & Minimum & Maximum & $\begin{array}{l}\text { Number of } \\
\text { Technicians }\end{array}$ \\
\hline \multirow[t]{2}{*}{ Designating } & $\begin{array}{c}\text { Productivity } \\
\text { (m/day) }\end{array}$ & 21 & 994 & 794.6 & $79.9 \%$ & 250 & 3,333 & \multirow{2}{*}{2} \\
\hline & $\begin{array}{l}\text { Unit cost } \\
(\$ / \mathrm{m})\end{array}$ & 21 & 3.84 & 2.389 & $62.2 \%$ & 0.75 & 11.25 & \\
\hline \multirow[t]{2}{*}{ Locating } & $\begin{array}{c}\text { Productivity } \\
\text { (holes/day) }\end{array}$ & 21 & 6 & 2.0 & $31.7 \%$ & 4 & 12 & \multirow{2}{*}{$3-4$} \\
\hline & $\begin{array}{l}\text { Unit cost } \\
\text { (\$/hole) }\end{array}$ & 21 & 560 & 442.9 & $83.3 \%$ & 300 & 2,300 & \\
\hline
\end{tabular}

The large coefficients of variance of unit costs for both activities are related to the large standard deviations of productivity, as well as the scope of SUE work. When a simple QL-B/QL-A service is required in relatively favorable site conditions, the low unit cost was derived while the high unit cost is applied to full SUE service that includes engineering services such as utility coordination in relatively unfavorable site environments. The survey participants reported that two technicians are required for a typical designating activity and three or four technicians are necessary for the locating activity. However, in many cases, the designating and locating processes occur at the same time and the technicians are trained for both processes. In general, a SUE team is composed of three or four technicians who work under the direction of a project manager. 


\section{Challenges experienced on SUE Projects}

In the survey, the participating SUE providers were asked to assess the significance of many factors potentially challenging their SUE projects. The factors were scored on five different scales, from 'extremely significant' (5 points) to 'not significant' (1 point). The level of significance of the factors was calculated using the following formula in order to determine the overall ranking of the factors.

$$
\text { Significance Index }=\Sigma \alpha^{*}(\mathrm{f} / \mathrm{N}) * 100 / 5
$$

Where $\alpha=$ constant expressing the weight given to each scale, $\mathrm{f}=$ frequency of the responses, and $\mathrm{N}=$ total number of responses for each factor. The results are provided in Table 4.6.

It can be seen that the most significant factor for a successful SUE project is obtaining appropriate records such as as-built drawings of the project area. The unavailability of adequate information for existing underground utilities causes problems in searching and finding surface appurtenances (starting point of utility tracing) and selecting appropriate equipment for tracing utilities. This also results in low productivity of the designating process and many omissions of underground utilities in the final deliverables. Maintaining a good relationship with local utility companies is a crucial key to obtaining suitable information.

Table 4.6. Factors Challenging SUE Projects

\begin{tabular}{|l|c|c|c|c|c|c|c|}
\hline \multirow{2}{*}{ Factors } & \multicolumn{5}{|c|}{$\begin{array}{c}\text { Degree of Significance } \\
\text { (Frequency of responses) }\end{array}$} & \multirow{2}{*}{$\begin{array}{c}\text { Sig. } \\
\text { Index }\end{array}$} & \multirow{2}{*}{ Rank } \\
\cline { 2 - 6 } & EX & GR & MO & LI & NO & & \\
\hline Getting appropriate record & 12 & 8 & 1 & - & - & 92 & 1 \\
Lack of understanding of SUE & 9 & 6 & 5 & 1 & - & 82 & 2 \\
Traffic safety & 6 & 5 & 7 & 3 & - & 73 & 3 \\
Unfavorable site conditions & 3 & 6 & 9 & 3 & - & 69 & 4 \\
Work scope splitting & 4 & 6 & 6 & 4 & 1 & 68 & 5 \\
Project time frame & 3 & 7 & 5 & 5 & 1 & 66 & 6 \\
Inclement weather & 3 & 1 & 8 & 9 & - & 58 & 7 \\
Deliverable formats & 4 & 4 & 2 & 8 & 3 & 58 & 7 \\
$\begin{array}{l}\text { Sufficient amount of mobilization, } \\
\text { travel, relocation cost }\end{array}$ & 2 & 3 & 4 & 8 & 4 & 51 & 9 \\
\hline EX: Very High, GR: High, MO: Moderate, LI: Little, NO: Not significant. \\
\hline
\end{tabular}


Lack of understanding of SUE by clients was found to be the second biggest challenge in SUE projects. Many potential clients confuse the engineering concept of SUE with "One-Call" system which is a contract service. One-Call's benefits are limited to mere avoidance of utility hits during the construction stage, while SUE is a consulting service provided in the design stage of a project, providing benefits through the whole project. Clear understanding of SUE by clients allows the proper budget by appropriate contract method and consequently, avoids failure to meet the required level of quality of the deliverables.

Traffic control (safety) is of great concern particularly in heavy traffic areas since high concentrations of main lines of underground utilities are found in the right-of-way or under the pavement. Unfavorable site conditions, which include conditions such as non-metallic pipes buried in high conductive soils, deeply buried pipes, and highly congested utility lines, also affect the execution of SUE projects. Currently available designating technologies cannot adequately pinpoint the exact location of underground utilities under these conditions.

\subsection{Comparisons of One-Call Systems and SUE}

A comparison table of the One-Call system and SUE in a construction project is illustrated in Table 4.7. The One-Call system is excavation activity-based while SUE is project-based because One-Call system is mandated by law whenever excavation activity occurs during construction, while SUE is applied by the project owner during the design stage. The use of the One-Call system in the construction stage limits its benefits to avoidance of pipeline hits. The data obtained through the use of SUE can be used not only to prevent pipeline damage but also to minimize the costs of pipeline relocates, design changes, claims and utility related construction delays.

The One-Call system and SUE are not competitive concepts, but rather complementary concepts. The final objective (deliverable) of One-Call process is similar to that of designating activity of SUE. Since these two systems identify the location of underground utilities with different information sources in different time frames, the vulnerability of existing underground pipelines to damages decreases further when both systems are applied to a project. Thus, the synergistic 
use of both systems is recommended. The Federal Highway Administration (FHWA) supports the use of SUE during project development (planning, preliminary engineering and design) and the use of One-Call system during construction (prior to any excavation) (Scott 2001).

Table 4.7. Comparison of One-Call System and SUE in Construction Projects.

\begin{tabular}{|l|l|l|}
\hline \multicolumn{1}{|c|}{ Descriptions } & \multicolumn{1}{c|}{ One-Call System } & \multicolumn{1}{c|}{ SUE } \\
\hline Use & Excavation activity based & Typically project based \\
\hline Applied stage & During construction & During design \\
\hline Obligation & By state law & No obligation \\
\hline Range of Service & 2-D (horizontal location) & 2-D/3-D (including the depth) \\
\hline Deliverables & Marking on the surface & $\begin{array}{l}\text { Transferring the obtained data } \\
\text { into the project plans }\end{array}$ \\
\hline Accuracy/Quality & Relatively low & Relatively high \\
\hline $\begin{array}{l}\text { Work solicitation } \\
\text { practice }\end{array}$ & Bidding - lowest bidder & Typically negotiation \\
\hline $\begin{array}{l}\text { Major contract } \\
\text { method }\end{array}$ & Unit price & Cost-plus-fee and unit price \\
\hline $\begin{array}{l}\text { Major benefits } \\
\text { Avoidance of pipeline hits }\end{array}$ & $\begin{array}{l}\text { Higher accuracy, avoidance of } \\
\text { pipeline hits, construction cost } \\
\text { savings, etc }\end{array}$ \\
\hline $\begin{array}{l}\text { Major } \\
\text { disadvantages }\end{array}$ & $\begin{array}{l}\text { Relatively low accuracy, not } \\
\text { saving tool. }\end{array}$ & Higher cost of use \\
\hline \hline
\end{tabular}




\section{CHAPTER 5}

\section{SUBSURFACE UTILITY IMAGING (DESIGNATING) \\ \& LOCATING TECHNOLOGIES}

\subsection{Introduction}

In typical subsurface utility imaging applications, energy is input to the earth and the reflected energy from underground objects is recorded. Processing of the recorded data yields information about the distribution of the physical properties related to buried bodies. Interpretation of the processed data can indicate the horizontal position of underground utility. Current technologies applying this procedure are based on various different geophysical theories such as electromagnetic theory, elastic wave theory, electrical resistivity theory, energy transfer theory, magnetic theory, gravity theory, etc.

However, limited construction budgets and limited allowances for site instrumentation due to right-of-ways and restriction of noise pollution hinder the use of certain imaging technologies for utility locating purposes. Selection of such imaging technologies may incur additional costs that exceed the project budget (Anspach 1995). Typically, the choice of imaging techniques is limited to those based on electromagnetic methods, acoustic emission methods and magnetic methods.

This chapter first discusses 'widely used methods in practice' which include electromagnetic methods, acoustic emission methods, and magnetic methods. Secondly, this chapter discusses other methods that are rarely used in practice. They include resistivity method, infrared thermography method, micro gravitational method, and seismic refraction/reflection method. Figure 5.1 shows the various designating methods for underground utilities. 


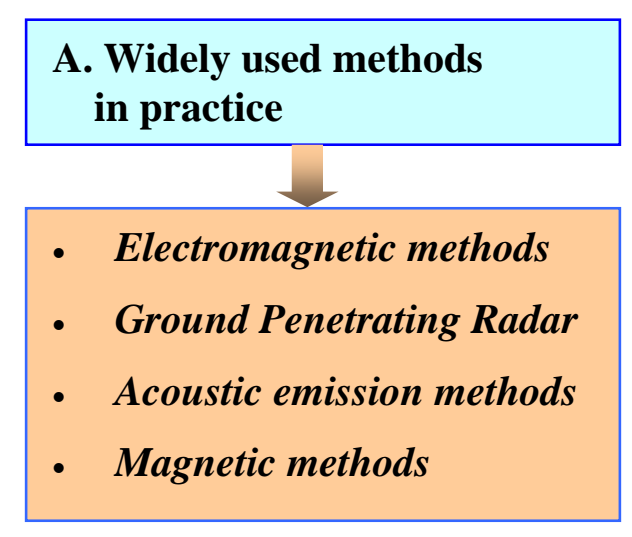

B. Rarely used methods in practice

- Resistivity method

- Infrared thermography method

- Microgravitational method

- Seismic refraction /reflection method.

\section{Electromagnetic methods}

- $\quad$ Pipe and cable locators

- Conductive mode (low frequency)

- $\quad$ Pipe and cable locators

- Conductive mode (high frequency)

- $\quad$ Pipe and cable locators - Inductive mode

- $\quad$ Pipe and cable locators - Passive mode

- Sonde insertion method

- E-line locator method

- Tracing wire/metallic marking tape method

- Terrain conductivity method

- $\quad$ Electronic Marker System (EMS)

- Metal detector

Figure 5.1. Various Designating Methods for Underground Utilities

\subsection{Pipe and Cable Locators - Electromagnetic Method}

\subsubsection{Description}

Pipe and cable locators are based on electromagnetic theory. A transmitter emits an electromagnetic wave (radio frequency) and a receiver is tuned to detect any changes in the wave. If the wave comes in contact with a metallic object, an electromagnetic current is subsequently produced on that object by the emitting wave. This current creates a magnetic field around the conductor. 


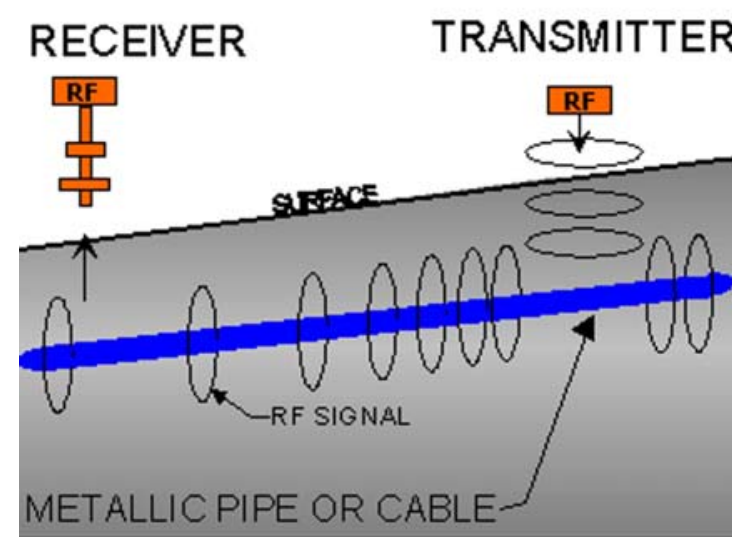

Figure 5.2. Principle of Pipe and Cable Locators (Source: http://www.geo-graf.com)

The receiver will detect and process the magnetic field. Thus, given this signal strength indication, a trained and skilled operator is able to detect the subsurface target. Most cable and pipe locators have separable transmitter and receiver so that an operator can carry the receiver to trace the line of subsurface utility.

\section{Frequency}

A wide range of available frequencies is necessary to trace utilities. In general, frequencies from $50 \mathrm{~Hz}$ to $480 \mathrm{KHz}$ can be successful (ASCE 2002). The frequency selected will have a direct effect on the distance the wave travels, the possible depth of detection and the ability to identify individual utilities.

For example, as the frequency gets higher, then the distance the wave travels decreases (Figure 5.3). This is due to a reduction in the impedance to ground, which causes the electromagnetic current to leak away. The exact distance is not possibly calculated because of other factors. The other factors affecting the distance of the frequency travel are cable and pipe diameter, type of pipe/cable joint, proximity of other conductors, soil conditions, etc. If the diameter of pipe increases, the leakage becomes greater as the surface area of the pipe increases. It causes the signal strength to reduce. Consequently, the distance diminishes. 

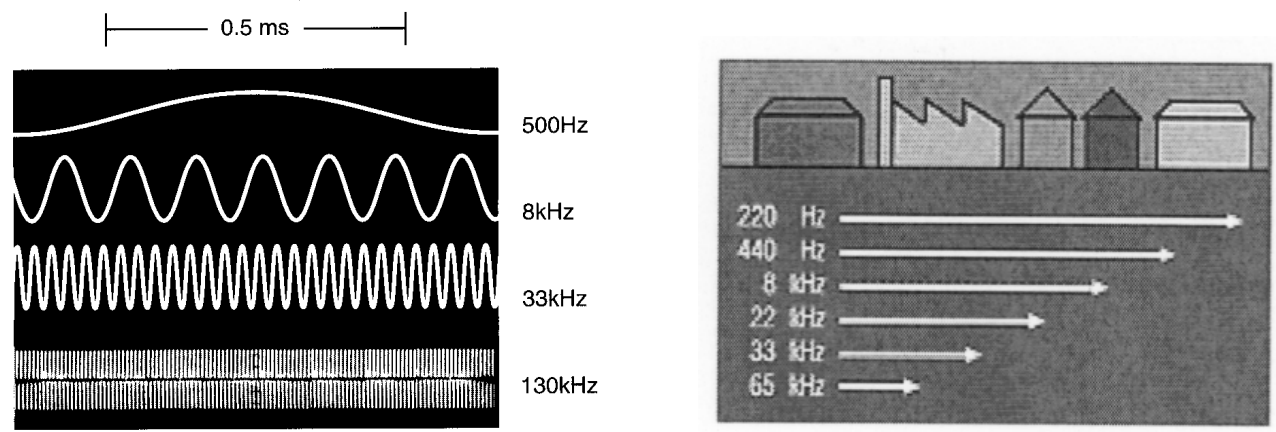

Figure 5.3. Frequency and Length of Radio Frequency Travel (Source: http://www.radiodection.com)

In addition, if the type of pipe joint does not provide electrical continuity, for example, rubber gasket joint for a cast iron pipe, the travel distance of frequency declines sharply as electromagnetic wave cannot go through electrically non-continuous material.

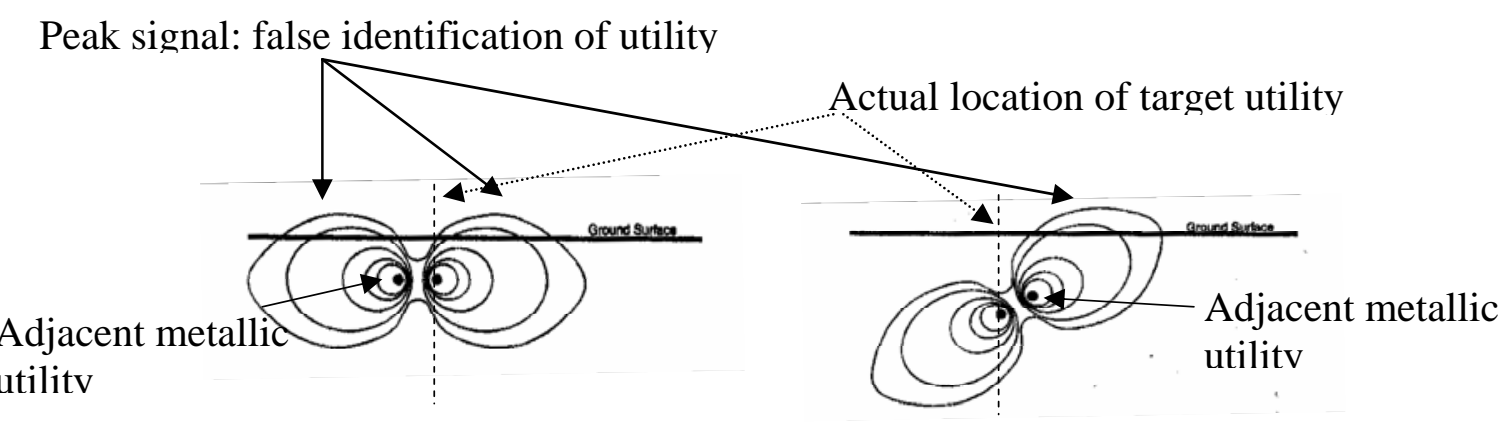

Figure 5.4. Frequencies and Coupling to Adjacent Pipes (Haddon 2001)

Other factor that affects the travel distance of frequency is soil conditions. Since the wet soil or clay dominated soil has a high conductivity, electromagnetic frequency is scattered very easily, thus, frequency cannot go far. On the other hand, in the dry soil condition, electromagnetic frequency travels longer due to the low conductivity of the soil. In identifying individual utilities, as the frequency increases, it becomes easier for the electromagnetic wave to couple to adjacent utilities as shown in Figure 5.4. It is because high frequency of the electromagnetic wave is very easily transferable to near conductive materials. 


\subsubsection{Main Features and Application Ranges}

Pipe and cable locators are the most widely used method in tracing subsurface utilities. In general, pipe and cable locators work well for metallic utilities, utilities that have tracing wire or metallic tape installed above them and utilities that can accept a metallic conductor or transmitter (sonde) inserted into them (e.g. empty conduits, storm/sanitary sewers with access, empty and accessible pipes, etc.). Non-metallic utilities without tracing wire or metallic tape installed or without access for sondes or wires cannot be imaged with this method.

There are various applications of pipe and cable locators depending upon the site conditions. Also, different frequencies and different techniques of using those frequencies are plentiful. They include conductive mode with high and low frequencies, inductive mode, passive mode, sonde insertion method, e-line locator method and tracing wire/metallic tape method.

\section{Conductive Mode}

Conductive mode is one necessary method for tracing because the transmitter makes a direct hook-up with the target utility line (Figure 5.5) to be traced. In order to have the transmitter hooked up with the utility line, there should be a physical access point to the utility such as hydrant, sprinkler head, manhole, valves, service meters, etc.

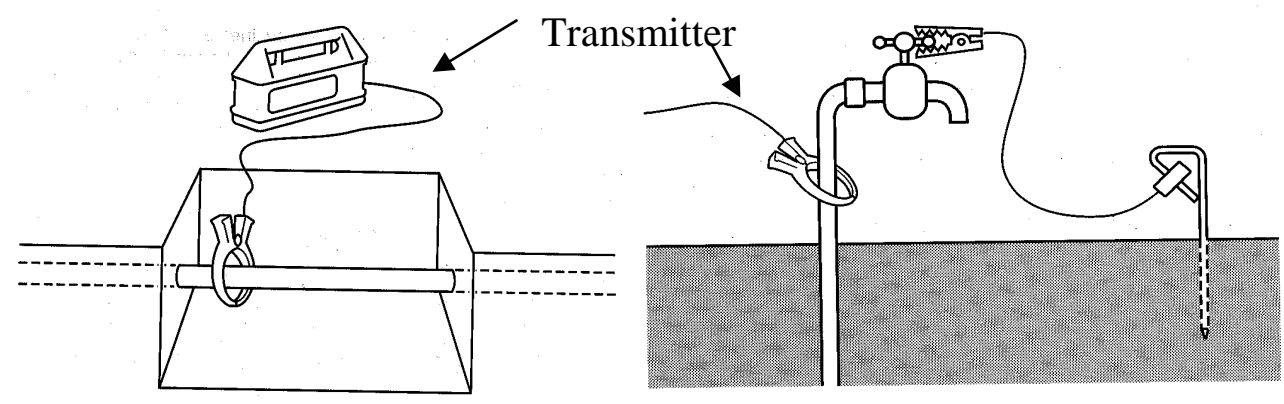

Figure 5.5. Examples of Hook-up to Physical Access Point to Utility (Source: Radiodetection 1994) 
After the transmitter is installed to the physical access point, a radio frequency (electromagnetic wave) is emitted to the utility from the transmitter and a hand-held receiver designates the horizontal location of the subsurface utilities by detecting the magnetic field from the subsurface utilities (Figure 5.6).

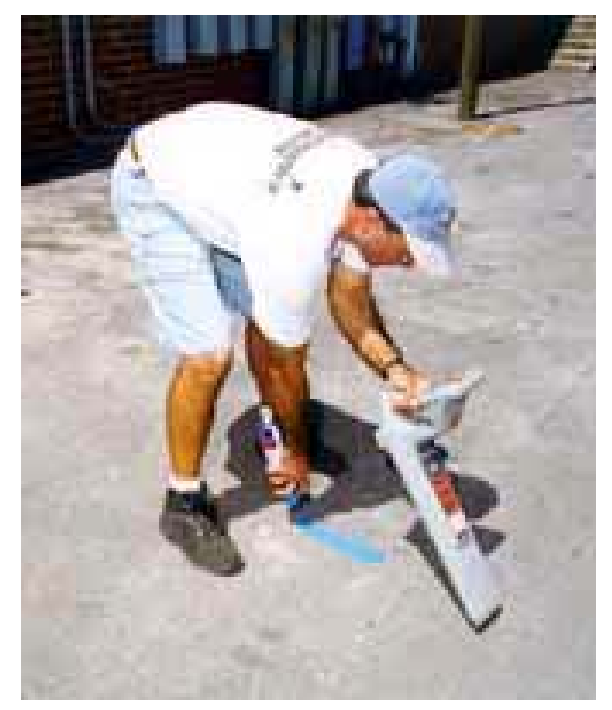

\section{Figure 5.6. Designating Subsurface Utility Using a Receiver (Source: http://www.southeasternsurveying.com/sue.asp)}

\section{- Low frequency}

Low frequencies such as $512 \mathrm{~Hz}$ or $640 \mathrm{~Hz}$ are good for low resistance conductors with good (low conductive) grounds. For example, steel pipe is good for this frequency. These frequencies are applied by direct connection only. The advantage of the low frequency is that an operator can trace utilities over a long distance and it rarely allows the adjacent utilities to be coupled.

\section{- High frequency}

Frequencies such as $8 \mathrm{kHz}$ and $33 \mathrm{kHz}$ are good for general purpose. But it has some probability of coupling to unwanted lines. More high frequencies such as $65 \mathrm{kHz}, 200 \mathrm{kHz}$ and $480 \mathrm{kHz}$ are better for services with higher ground resistance (pipes) or in noisy signal environments and are usually applied to utilities that have low-electrically continuous joints. For example, a cast iron pipe with rubber or other non-metallic jointing material might only be found using the high 480 
$\mathrm{kHz}$ frequency (ASCE 2001). The disadvantage of this mode is that it is easier to couple with other conductors in the vicinity.

\section{Inductive Mode}

Inductive mode can be applied when there is no physical access point to the subsurface utility but approximate location of utility is known. First, transmitter is laid above the approximate location of the target utility (Figure 5.7) and electromagnetic frequency is generated. Standing an appropriate distance (at least 30 feet away from the transmitter to prevent the air coupling is a good rule of thumb), an operator with receiver can detect the location of the utility by catching the high signal or peak sound from the receiver.

Only high and medium-high frequencies are applied to inductive mode. Low frequency and low medium such as $8 \mathrm{kHz}$ are not enough to generate the electromagnetic wave to the target pipe. Since it uses high and medium-high frequencies, the operator can have difficulty in data interpretation because of the coupling to the adjacent utilities. This can be used successfully down to a depth of $6 \mathrm{ft}(2 \mathrm{~m})$ and this method should not be used where the cable is below a metal cover or reinforced concrete pavement (Radiodection 2001).

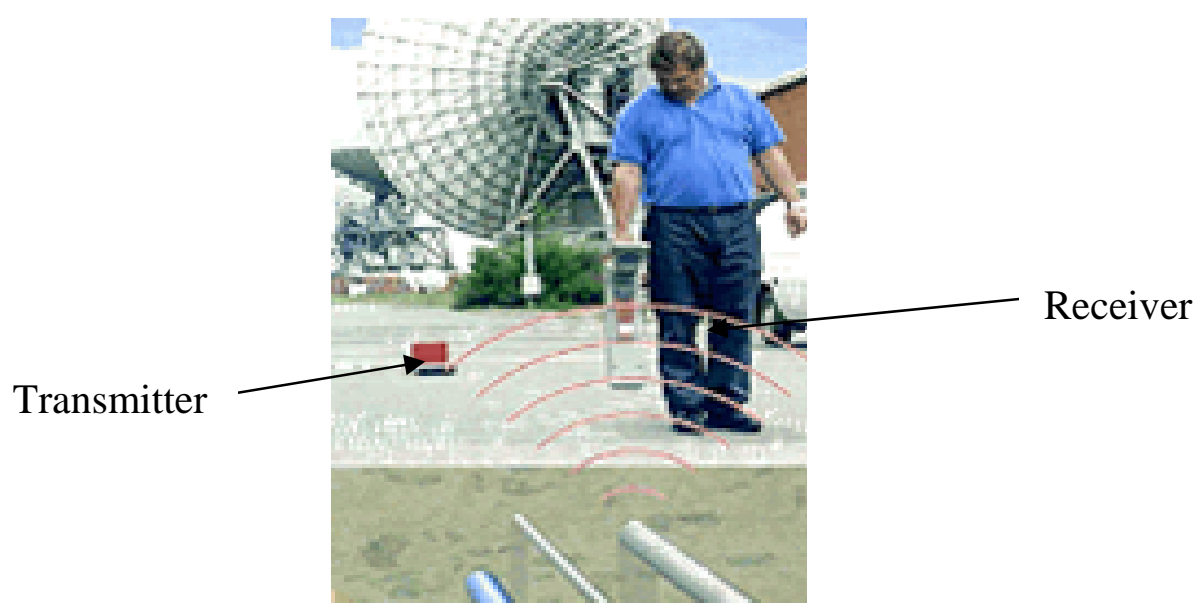

Figure 5.7. Inductive Mode Designating (Source: http://www.radiodection.com) 


\section{Passive Mode}

In passive mode, no transmitter is required. The receiver can detect 50 or $60 \mathrm{~Hz}$ frequency present on buried cables as they radiate very low frequency radio energy. In case of energized and loaded power cables, there is usually enough current at power frequency harmonics that can be detected. Also, most cables that are grounded on both ends carry some circulating and induced frequency currents from power cables (USDOT 1999).

Very low frequency energy from distant transmitter such as electrical lines (Figure 5.8) can generate a radio frequency from subsurface metallic utilities that also can be detectable by passive mode. This method will not necessarily find all lines but offer a lot of information that helps to sort out complex sites, therefore, this method is usually used for searching for unrecorded cables rather than tracing utilities.

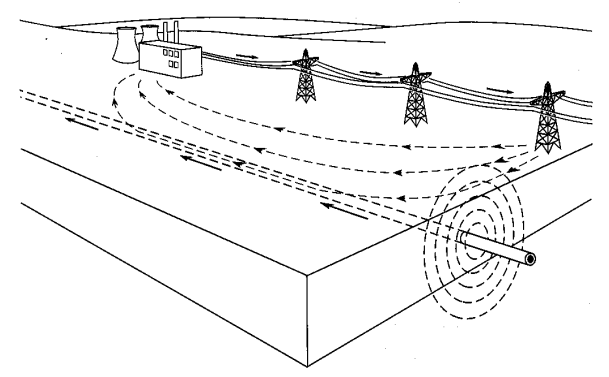

Figure 5.8. Condition of Passive Mode Designating (Source: Radiodection 1990)

\section{Sonde insertion method}

Sonde insertion method is useful for a non-metallic drain, sewer pipe, culvert or duct where there is an access point to the pipe such as manhole. Sonde is a small waterproof transmitter radiating an electromagnetic frequency that is located by the receiver. The sonde is inserted into the pipe and is floated or pulled along the pipe (Figure 5.9). Then, the receiver above the ground can designate the horizontal location of the pipe. A range of sonde is available ranging from a 0.5in 
(13mm) diameter unit with a range of $5 \mathrm{ft}(1.5 \mathrm{~m})$ to a unit detectable down to $60 \mathrm{ft}(18 \mathrm{~m})$ (Radiodection 1994).

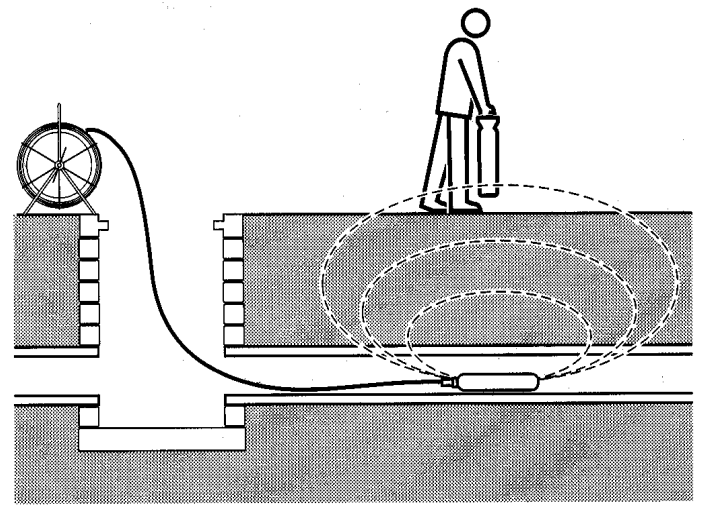

Figure 5.9. Sonde Insertion Method (Source: Radiodetection 1994)

\section{Tracing wire/metallic marking tape method}

Tracing wire or metallic tape has been widely installed above non-metallic pipes or conduits when they are buried underground (Figure 5.10). Special tabs are required to connect sections of tape to ensure electrical continuity. This wire or tape will help to locate the non-metallic utilities easily by cable and pipe locators with conductive or inductive mode. But this wire or tape has also deteriorated over time and some contractors dig into this wire or tape without splicing back together properly. This will make detecting subsurface utility very difficult.
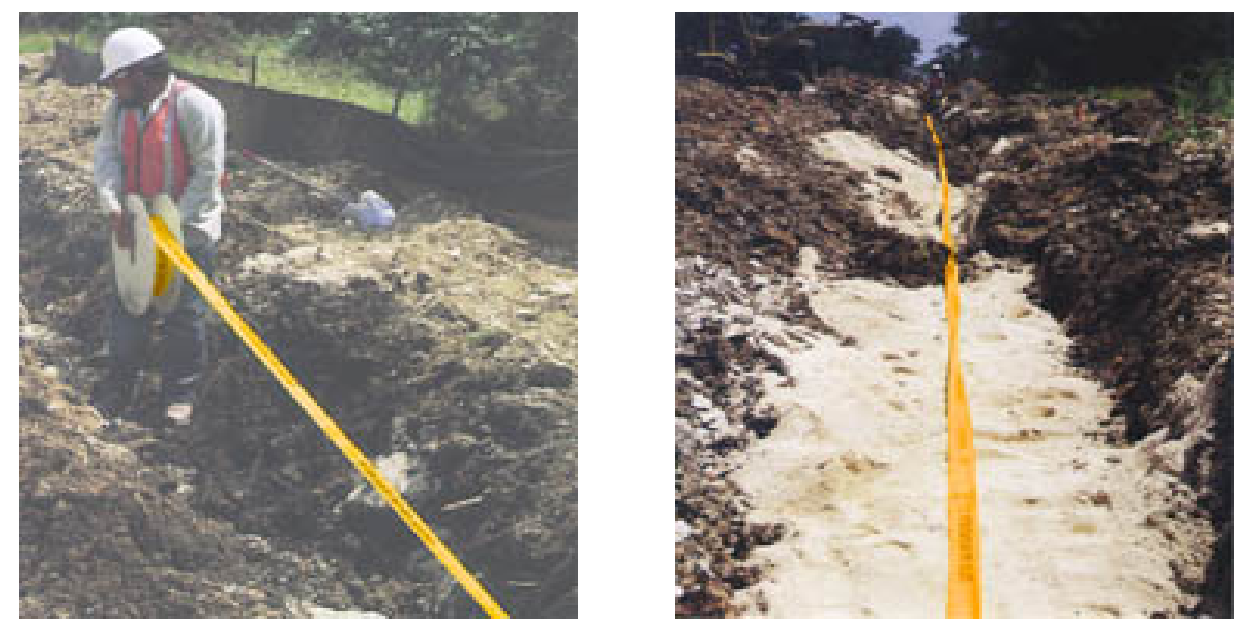

Figure 5.10. Installation of Metallic Tape

(Source: http://telemarksolutions.com/fibertape.html) 


\subsection{E-line locator method - Electromagnetic method}

\subsubsection{Description}

This method is based on electromagnetic theory. But this method requires not only pipe and cable locator equipment but also electro line (E-line) locator (Figure 5.11). This method is mainly used where the other methods failed because digging a hole to make an access point to the target line is necessary.

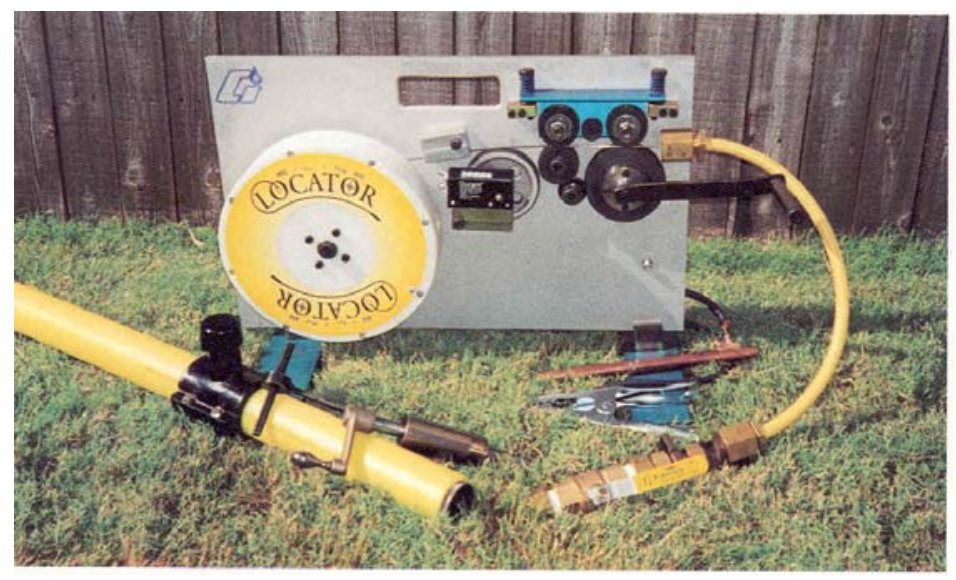

Figure 5.11. E-line Locator (Source: Continental Industries Inc. 1999)

Exactly known location of the pipe is required. When a hole is dug, E-line locator is used to make a mechanical fitting that allows an electro line to be inserted through the pipe. Installation takes about 10 minutes according to the manufacturer and the mechanical fitting made by the Eline equipment does not allow gas to escape. The pipe remains in service so there is no interruption to the customer. Once the electro-line is inserted to the pipe, then cable and pipe locator with conductive mode is applied (P\& GJ 2000). Connecting the transmitter to the electroline in the access point, the receiver follows the signal reflected from the electro-line to designate the pipe. 


\subsubsection{Main Features and Application Ranges}

Up to now, this method has been only applied to plastic gas pipe only since mechanical fitting must be made to the pipes. The E-line locator consists of a 300-foot (100 m) wire. Locates of 600 feet can be done by going each direction from the mechanical fitting. This method has shown its superior applicability where tracing wire or metallic marking tape is deteriorated so that common pipe and cable locators do not work properly.

\subsection{Metal Detectors - Electromagnetic Method}

\subsubsection{Description}

Metal detectors work by transmitting an AC magnetic field into the ground and then analyzing a corresponding magnetic field to see if there have been any changes. When the magnetic field comes across a conductive metal object, the search-coil senses a change in the field. Then, some form of output will occur, which normally is an audio change. As the other electromagnetic method, metallic object reflects the slightly different magnetic field back to the surface from the current reflected from the surrounding soil.

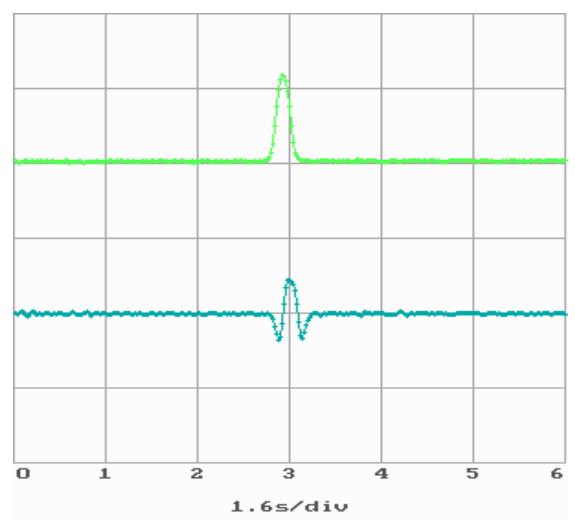

Figure 5.12. Detection of Ferromagnetic Object (Source: http://home.skif.net/ yukol/MetalE.htm) 
The difference is measured in the receiving unit. A reflecting magnetic field is sent to the receiving unit, which drives a loudspeaker, meter or headphones and emits a noise, alerting the operator to the presence of the object (Figure 5.12).

\subsubsection{Main Features and Application Ranges}

Since responses decay exponentially with depth (ASCE 2002), metal detectors are usually only applicable for shallow manhole lids, valve box covers, and so on. In addition to metals, a detector may react to magnetic non-conductive minerals and beach salts due to their high conductivity.
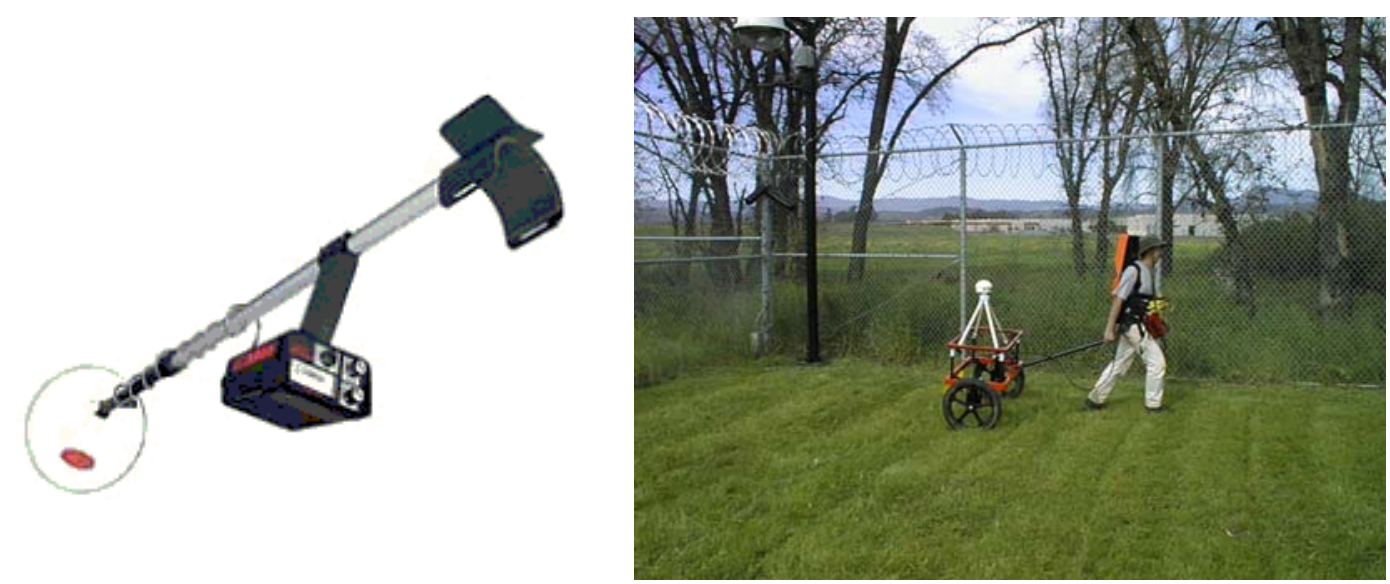

Figure 5.13. Metal Detectors

(Source: http://www.technos-inc.com/surface.html)

This can cause a detector to produce a false signal or ground noise. To eliminate this ground noise, the detector must be ground balanced to compensate for the levels of these substances in the ground being searched. 


\subsection{Electronic Marker System (EMS)}

\subsubsection{Description}

Electronic marker system is also based on electromagnetic theory. The locator transmits a Radio frequency signal to the electronic marker that was buried along with the facility at the time of construction. The marker that consists of passive resonant circuit reflects the signal back to the locator, and the location is indicated with both a visual reading and an audible tone (Figure 5.14).

\subsubsection{Main Features and Application Ranges}

These electronic markers are used for underground marking of special buried features, such as splices, valves, etc., as well as non-metallic utilities. Markers can be detected even in the presence of metal conductors, fences, power lines, etc. because the electronic markers are specially designed to react to a certain level of frequencies.
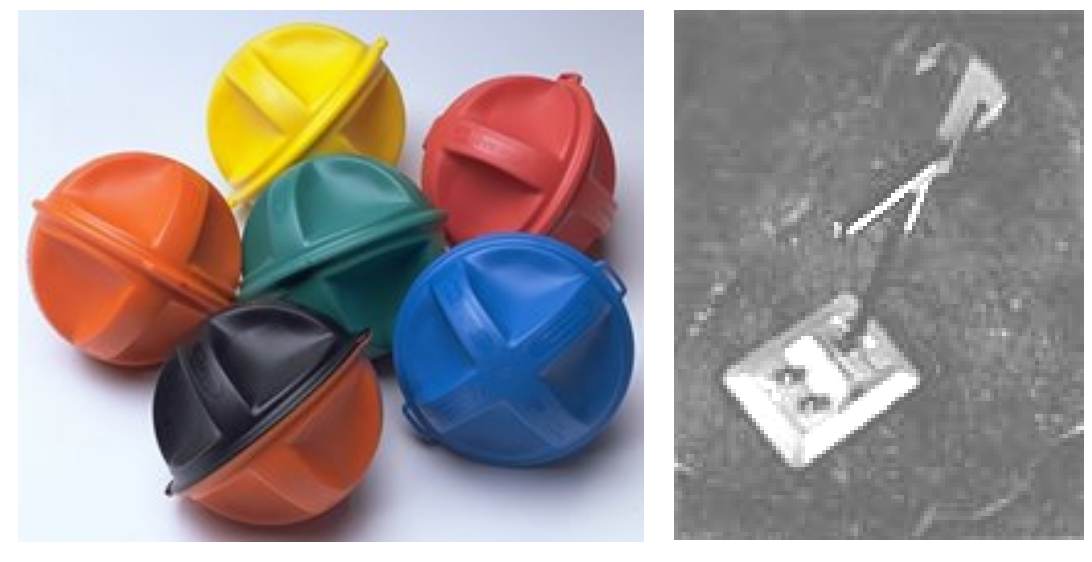

\section{Figure 5.14. Electronic Markers \& Electronic Marker Locator (Source: http://www.indtech.com/OMNI.HTM)}

When electro markers are installed, the operating frequency of the markers is differently adjusted according to the type of utility for the exact detection of the utility (Table 5.1). 
Table 5.1. Operating Frequencies of Electronic Markers (Source: Metrotech 2001)

\begin{tabular}{|l|c|}
\hline \multicolumn{1}{|c|}{ Type of utility } & Frequency \\
\hline Power line & $145.7 \mathrm{kHz}$ \\
\hline Telecommunication line & $121.6 \mathrm{kHz}$ \\
\hline Water pipeline & $169.8 \mathrm{kHz}$ \\
\hline Waste water pipe & $101.4 \mathrm{kHz}$ \\
\hline Gas pipe & $83.0 \mathrm{kHz}$ \\
\hline
\end{tabular}

Marker-to-marker spacing of 20 feet is usually believed to be adequate unless the pipeline makes sharp bends or is installed in the areas where continuous access to the area above the pipe is restricted: in such cases, the markers should be installed at shorter intervals.

\subsection{Terrain Conductivity Method - Electromagnetic Method}

\subsubsection{Description}

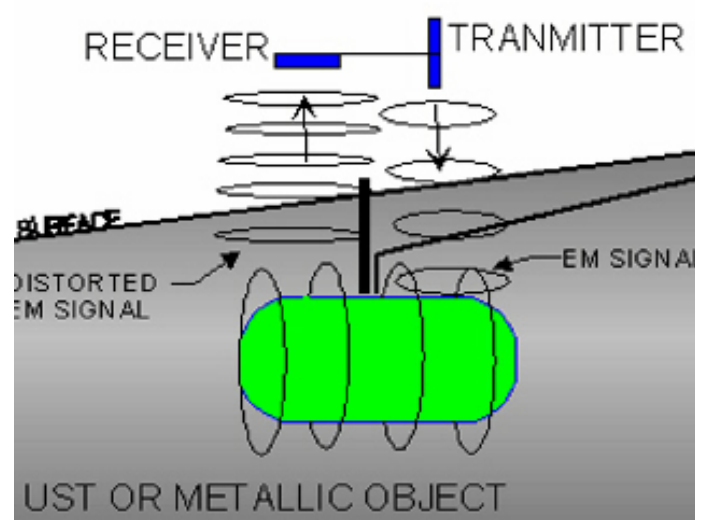

Figure 5.15. Principle of Terrain Conductivity Method (Source: http:// www.geo-graf.com)

The terrain conductivity method is also based on the electromagnetic theory. The terrain conductivity equipment creates and measures eddy currents due to differences in the average conductivity from the ground surface to the effective penetration depth (typically 15 feet (5 
meters) or so) (ASCE 2002). Utilities may exhibit conductivities that are different enough from the average soil conductivities that they can be differentiated by this method. The receiver attached to the end of the equipment analyzes the reflected currents to detect underground utilities (Figure 5.15).

Electromagnetic eddy currents emitted from the transmitter reflects the eddy current back to the ground with a slightly different property when it comes in contact with a metallic object. Since surrounding soil of the metallic object obviously has lower conductivity value than the metallic object, the reflected current can have a distinguishable value from the soil.

Electrical conductivity and in-phase field strength are measured and stored along with line and station numbers in a digital data logger or real time interpretation is possible as an operator can read the number in the equipment and identify the existence of underground utilities. In cases where the terrain conductivity meter is directly over a buried metal target, the apparent conductivity reading may be a negative number. That allows an operator to detect the underground metal objects.

\subsubsection{Main Features and Application Ranges}

The method is moderately inexpensive and useful in non-utility congested areas, or areas of high ambient conductivity (Anspach 1995). Isolated metallic utilities, underground storage tanks, wells, and vault covers are usually detectable via this method, and under some conditions, large non -metallic water pipes in dry soils or large non-metallic empty and dry pipes in wet soils may be imaged (ASCE 2001). Aboveground metal objects, such as fences, vehicles, or buildings influence the resulting value of Terrain Conductivity method. Magnetic fields produced along overhead power lines also interfere with terrain conductivity readings. 


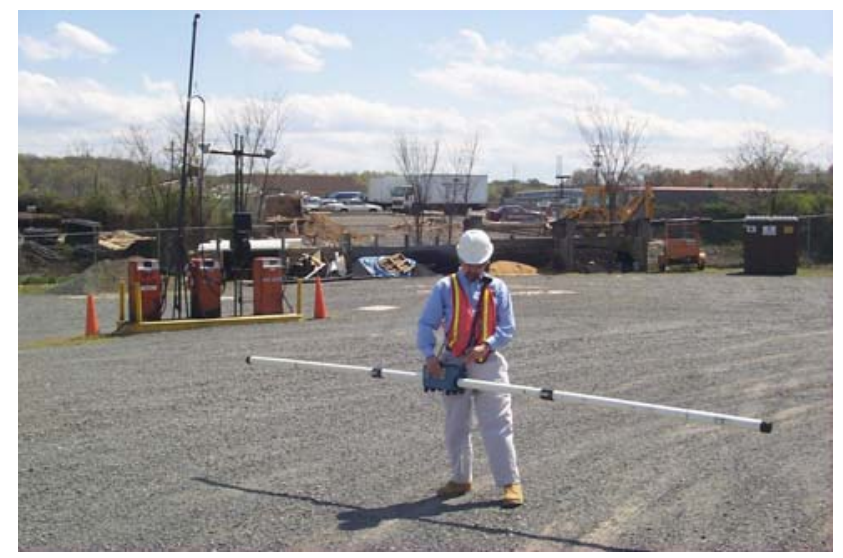

Figure 5.16. Application of Terrain Conductivity Method (Source: So-Deep Inc)

\subsection{Ground Penetration Radar (GPR)}

\subsubsection{Description}

GPR was first developed in the early 1970's for military applications such as locating underground tunnels in the DMZ between North and South Korea; later it was used to locate landmines, unexploded munitions and locating underground utilities (Bower 2001). GPR is a reflection technique, which uses high frequency electromagnetic waves to acquire subsurface information (Figure 5.17). Ground penetrating radar responds to changes in electrical properties (dielectric and conductivity), which are a function of soil and rock material and moisture content (Technos Inc 2001).

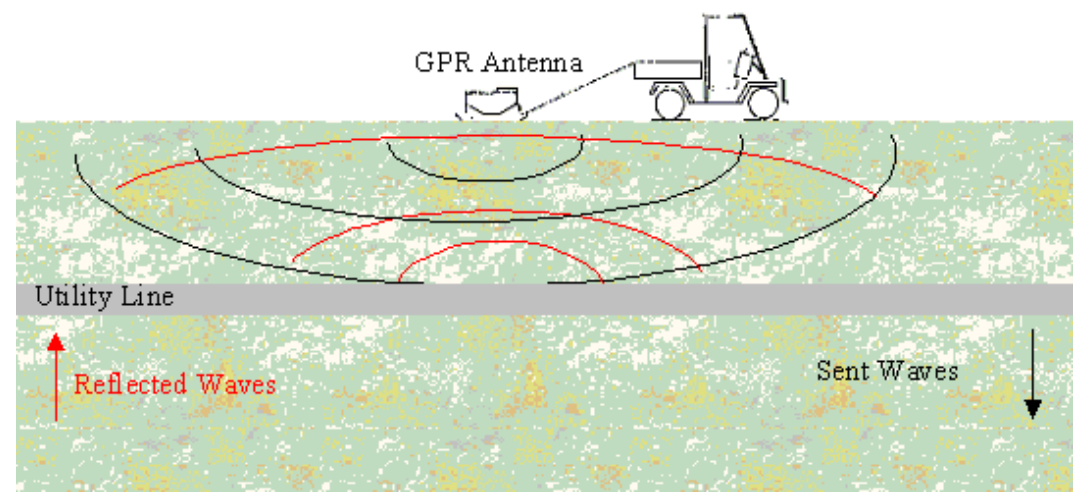

Figure 5.17. Principle of GPR Method 
In order to generate an "image" of a buried object, a GPR profile must be obtained. A GPR profile is generated when the antenna is moved along the surface. This can be done by hand, by vehicle (Figure 5.18), or even by air. The radar unit emits and receives reflected signals millions of times per second. As a result, not only do the relative depths and "strengths" of the targets appear, but also the image or shape of the target is "seen" on the monitor.

GPR waves travel through different materials in the ground, in wide-angle bands. Different types of soil, fill material, debris, and varying amounts of water saturation all have different dielectric and conductive properties that effect the GPR waves, and thus GPR data interpretation. In a "perfect world," all soil would be homogenous, allowing the GPR operator to be able to point to the data and determine that a target is 8 feet below the surface. In the "real world," the soil is a combination of pavement, rebar, and fill material and debris, all at varying degrees of saturation. As a result, the interpretation including the estimation of depth is very difficult.
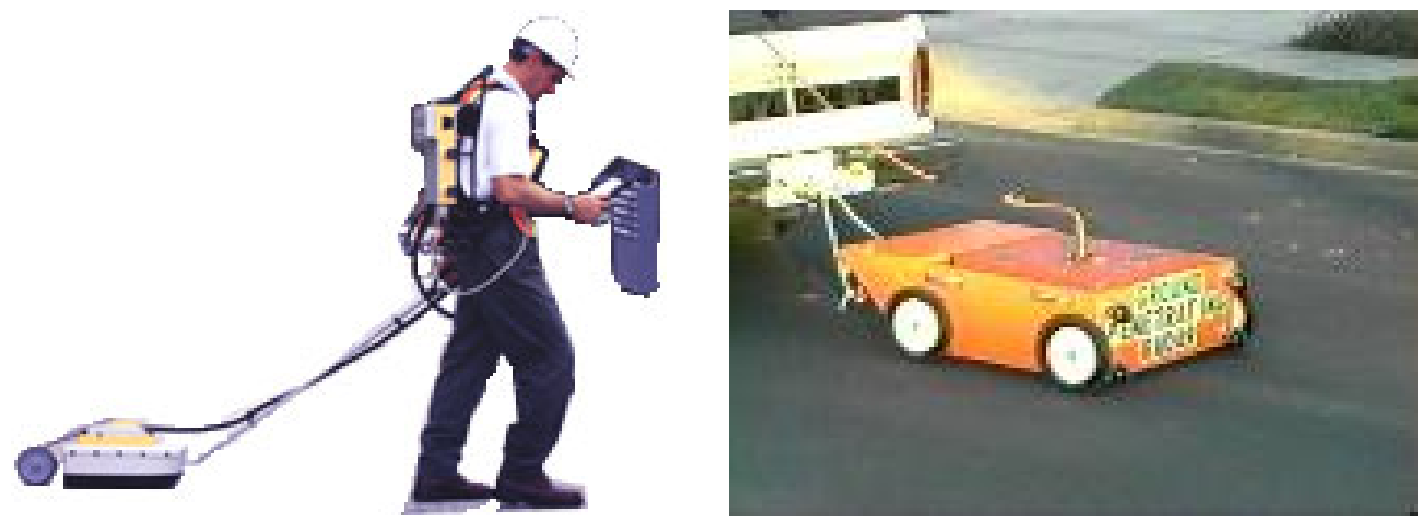

Figure 5.18. GPR Application by Hand and by Truck

(Source: http://www.odelco.com) 


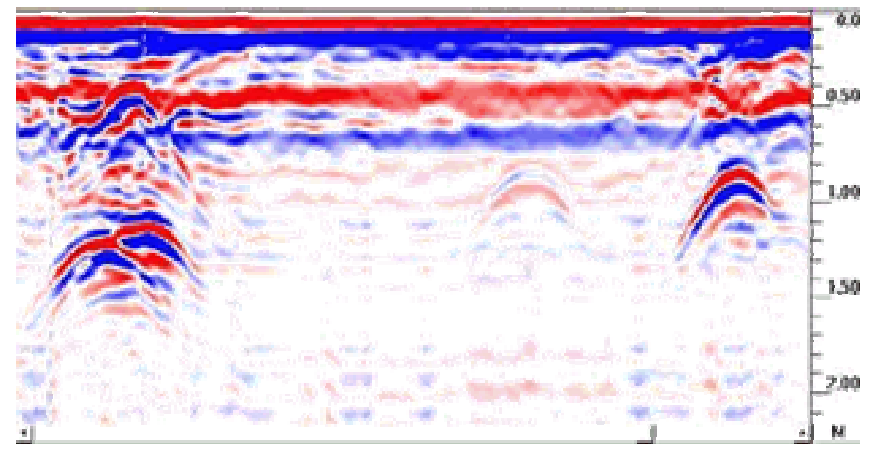

Figure 5.19. Collected Data from GPR

(Source: http://www.geophysical.com/Utility.htm)

Figure 5.19 shows identified underground utilities using GPR. Detected underground utilities that have different properties from the surrounding soil are graphically shown on the screen as cone shapes. From left to right: two steel gas pipes buried in one trench with a telephone cable above them. The two targets on the right are a PVC pipe and a steel pipe buried at approximately the same depth. But, the type of utility cannot be identified based on current technology without previous record or surface identification. The depth of utility is approximately calculated due to the various factors but the correct depth of utility is only verified by potholing.

\subsubsection{Main Features and Application Ranges}

Both metallic and non-metallic utilities may be imaged by GPR. As mentioned above, GPR responds to changes in electrical properties (dielectric and conductivity) of the soil through which the waves are penetrating. Thus, soil condition is the most important parameter for GPR applications. Depth of investigation increases with decreasing frequency but with decreasing resolution. GPR waves can reach $100 \sim 133 \mathrm{ft}(30 \sim 40 \mathrm{~m})$ in low conductivity materials such as dry sand or massive, dry concrete or granite. Considerable depth may be achieved in saturated sands or in lake water if the specific conductance of the water (i.e., the amount of ions or salts in the water) is low. Radar penetration may be reduced to $3 \mathrm{ft}(1 \mathrm{~m})$ or less in clay materials, shale, or other high conductivity materials such as those containing water high in salts. 
A rule of thumb is that, from ground surface to 6 feet of depth and very low conductivity and highly different impedances, a round utility whose diameter in inches does not exceed the depth in feet can be imaged. In other words, under ideal conditions a pipe 5 inches in diameter cannot be detected at 6 feet of depth, but it can be detected at 4 feet of depth. Beyond 6 feet of depth, this relationship is no longer valid and it becomes more difficult to detect pipes of any size (ASCE 2002).

GPR is a highly sophisticated tool that requires a well-trained technician, and in many cases a geophysicist, in order to evaluate the correct instrument settings and to interpret the results. Advances in processor speed and mathematical algorithms promise to make this technique more user-friendly in the future.

\section{Application Properties}

- Accuracy: It has the highest resolution of any geophysical method for imaging the subsurface, with centimeter scale resolution sometimes possible. But there is a trade-off between resolution and penetration depth.

- Speed and Crew Size: The crew size and the speed depend on the size of the investigation area. GPR applications are done by moving the antenna along the investigation area surface by hand or truck, because of that it can be done with a small crew in a short time.

- Equipment: GPR method requires an antenna moved along the surface in order to beam a microwave pulse into the ground and to receive the reflection. Besides the soil properties (conductivity and dielectric) the frequency of the microwave (commonly from $10 \mathrm{MHz}$ to more than $1,000 \mathrm{MHz}$ ) is a prime factor that affects the results. A higher frequency cannot penetrate as deep into the ground as a low frequency, but on the other hand a high frequency resolves smaller scale features than a low frequency. 


\subsection{Magnetic Method}

\subsubsection{Description}

Magnetic methods may be useful for detecting and tracing ferrous (iron or steel) utilities. An instrument called magnetometer is used for the magnetic methods to measure the intensity of the earth's magnetic field. Deviations of magnetic intensity are caused by changes in natural ferrous minerals and ferrous metals. Magnetometer responds to the difference in the magnetic field between two sensors spaced about 20" $(50 \mathrm{~cm})$ apart (Figure 5.20). The response is a change in the frequency of the signal emitted by the piezoelectric speaker.

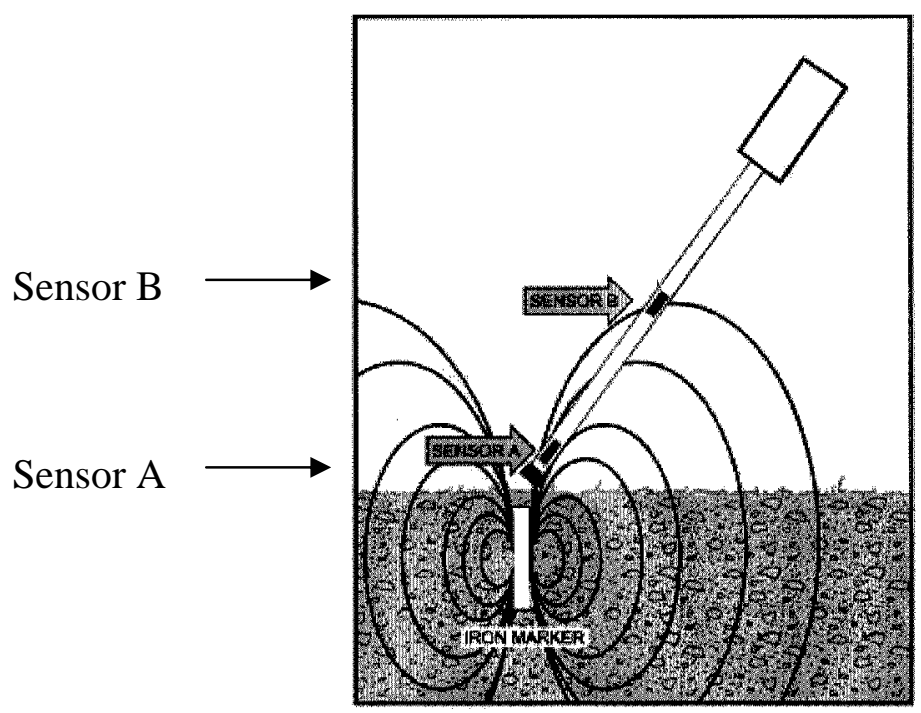

Figure 5.20. Principle of Magnetic Method

(Source: Schonstedt 2000)

As shown in the Figure 5.20, the magnetic field of the iron marker is stronger at sensor A than it is at sensor B. As a result, the frequency from the piezo electric speaker is higher than the idling frequency, $40 \mathrm{~Hz}$, which exists when the field strength is the same at both sensors (Schonstedt 2000). This higher frequency will turn into beeping sound or numeric numbers in a screen so that an operator can detect that metallic objects are under the ground. 


\subsubsection{Main Features and Application Ranges}

There are two basic methods of using magnetism: total field measurements, and gradiometric measurements. Both these methods use the same instrument-magnetometer. The most common total field magnetometer is a proton precession magnetometer and the most common gradiometer is a called a flux-gate magnetometer (ASCE 2002).

Total field measurements may be useful for a utility search over large distances in the absence of power lines, railroads, vehicles, or other sources of interference. Total field measurements are usually performed in a grid pattern. The larger the grid spacing, the less useful this technique for utility tracing (ASCE 2001). Gradiometric measurements are easier to use and useful for detecting shallow metallic buried boxes, manhole lids, property pins and iron and steel utilities. The depth of penetration varies greatly depending upon the ambient field strength and averages approximately 10 to $20 \mathrm{ft}$ (3 to $6 \mathrm{~m}$ ) below grade (Dodge and Anspach 1995).

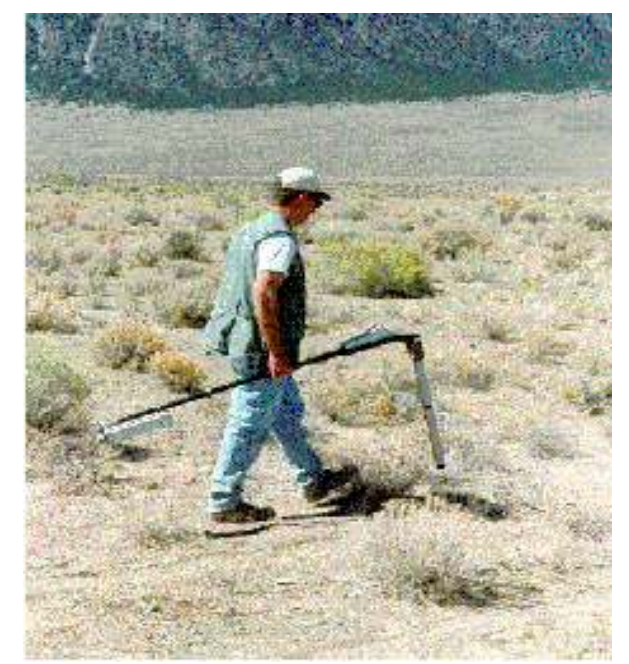

Figure 5.21. Application of magnetic method (Source: http://www.technos-inc.com)

The magnetic locator should be held in the vertical or near vertical position. In this position the instrument audio output is facing the operator and the controls are readily accessible. The Figure 
5.21 shows how to hold the instrument for optimum operation. This technique reduces interference from solar magnetic storms and regional magnetic changes.

This method can detect a magnetized nonmetallic fiber optic cable by the equipment's visual indication that changes from positive to negative every six feet along with the audio signal that also peaks every six feet. Cast iron pipe produce the strongest signals at their joints. By identifying these joints, the pipe can be designated with this method. Typically, 4 in $(10 \mathrm{~cm})$ pipe can be located at depth up to $10 \mathrm{ft}$ (3 m) (Schonstedt 2000). This method is mostly useful in the suburban areas where less susceptibility to vehicles, fences, metallic debris and buildings is guaranteed.

\subsection{Acoustic Emission Method - Elastic Wave Method}

\subsubsection{Description}

An acoustic emission method utilizes an acoustic transducer that, when connected to an opening on a service or main line, applies sound waves (typically from $132 \mathrm{~Hz}$ to $210 \mathrm{~Hz}$ ) into the pipeline. The sound waves travel along the length of the pipe and attenuate through the pipe wall into the surrounding soil. Those sound waves that reach the surface may be detected using special sensors such as geophones or accelerometers (Figure 5.22). The location of the buried facility is indirectly determined by monitoring the highest (peak) vibration amplitude at the surface. Since the sound waves have to travel in the pipe and in the soil, the type of soil and its condition along with the size of the pipe and its content will affect the detection range at the surface from the acoustic transducer. 


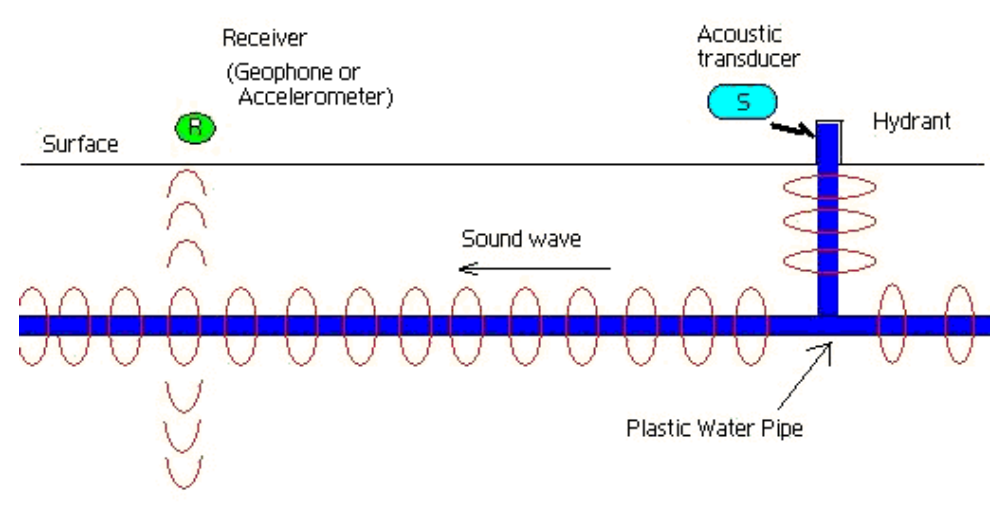

Figure 5.22. Principle of Acoustic Emission Method

This method can be used to determine the location of a buried pipe, usually plastic gas pipe and water pipe. Specifically for gas pipe, a commercialized product that was developed by Columbia Gas Distribution Companies, Southern California Gas Company (SoCal), and Radiodetection Corporation with support from Gas Research Institute (GRI) was introduced to the industry in early 1996.

\subsubsection{Main Features and Application Ranges}

The locator consists of a transonde and a receiver. The transonde is attached to the pipeline either at a fire hydrant, faucet or tap. The transonde sends a sound wave through the pipe. The receiver is used to listen for the sound emitted from the pipe. Once located, the position of the mark can be marked on the ground surface (JR Associates 2001).

There are three ways to generate the sound wave (ASCE 2002). The first one is "active sonic" which generates sound by striking a pipe or by introducing a noise source of some kind into the pipe. The second one is "passive sonic" which generates sound by escaping pipe's product such as water in a water pipe at a hydrant or service peacock. The third one relies upon the pipe's product containing a non-compressible fluid (water in most cases). Interfering the fluid surface 
(at a hydrant for example) and generating a pressure wave in the fluid will in turn create vibrations in the pipe that can be detected.
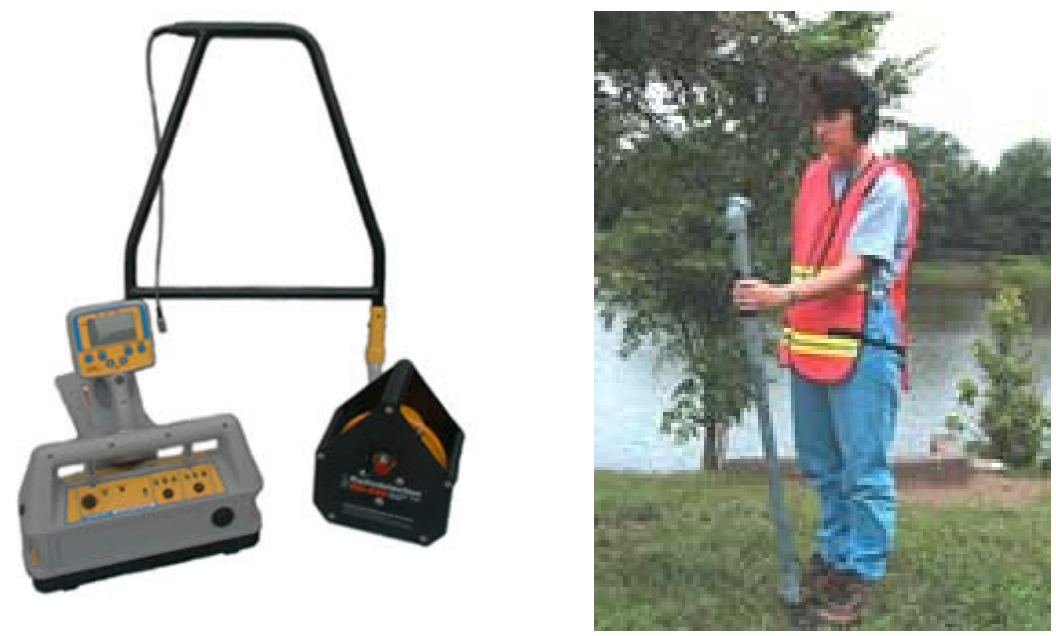

\section{Figure 5.23. Acoustic Pipe Tracers (for Gas pipe (left) and for water pipe (right)) (Source: http://www.radiodetection.com/products)}

Regarding the detectable depth, the more rigid the ground and its surface, the deeper the detection possibility. In physical terms, as the rigidity (inverse of bulk modulus) of the "system" (pipe, ground and ground cover) increases, detection capabilities in depth and distance from source sound increases. For instance, the detection depths will be greater for frozen ground, or concrete cover. Moreover, the capabilities/depth decrease as the distance from the vibrating source increases. It is usually detectable up to eight $\mathrm{ft}(2.5 \mathrm{~m})$ in depth for gas pipe and $6.5 \mathrm{ft}$ (2 m) for water pipe based on expert's opinion. According to the manual of Acoustic Pipe Tracer (APT RD590), this equipment can locate plastic gas pipes up to $1000 \mathrm{ft}$ (300 m) distance and more than $500 \mathrm{ft}$ (150 m) for water pipes.

The Acoustic emission method is a valuable product for the gas industry. It can locate pipes with deteriorated tracer wires, or without tracer wires at all. And it is especially useful for locating older plastic pipe that did not have tracer wire or was inadequately mapped. 


\subsection{Resistivity Method}

\subsubsection{Description}

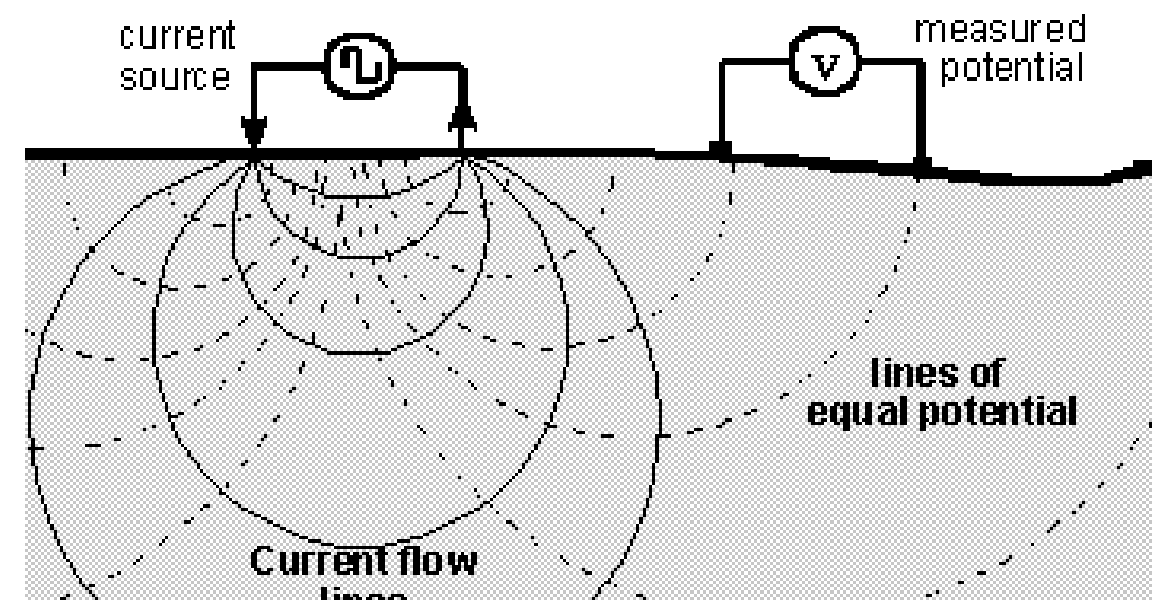

Figure 5.24. Principle of Resistivity Method

(Source: http://www.geop.ubc.ca)

In the resistivity method, an electric current is driven through the ground and the resultant resistivity which is captured by potential (voltage) differences are measured at the receiver in the surface. By moving the current and potential electrodes to different locations, a condition of the subsurface resistivity is drawn in a map. This technique of resistivity surveying was developed by Conrad Schlumberger, who conducted the first experiments (1912) in the fields of Normandy (Sharma 1997). They are many different types of electrode geometrics that produce specific result. According to the array type of electrodes and the spacing of the electrodes, this method can be classified as wenner, schlumbeger, dipole-dipole, pole-dipole, pole-pole, and so on.

Anomalous conditions within the ground, such as electrically better or poorer conducting objects or layers, are inferred from the fact that they deflect the current and distort the normal potentials. The distorted voltage is transmitted to the receiving electrodes to record the anomaly. 


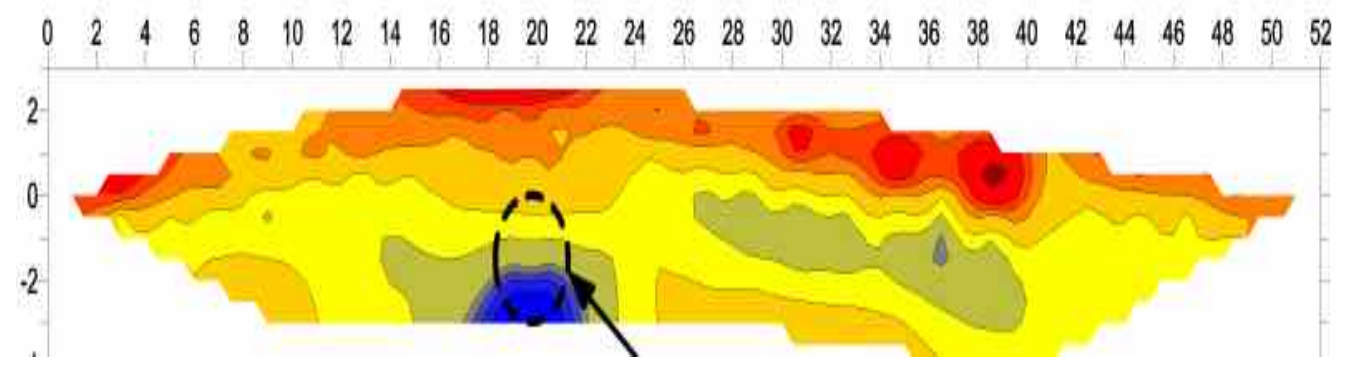

Figure 5.25. 2-D Resistivity Imaging for Detection of a Buried Sewer Pipe (Source: http://www.agiusa.com)

The receiving dipoles record every different measurement of voltage to delineate the underground profile. Recent developments of the resistivity method have improved the resolution and quality of the data interpretation, providing a continuous 2-D model of resistivity along the section lines known as electrical imaging. The data processing procedures for the imaging method are more complicated and the rate of data acquisition is slower, making it most useful for investigating areas of complicated ground conditions.

\subsubsection{Main Features and Application Ranges}

Typically a series of 25 or 50 electrodes are placed in a line at set spacing, and connected to a computer controlled resistivity meter using a multicore cable (Figure 5.26). A special switching unit takes a series of constant separation traverses along the array with increasing electrode spacing.

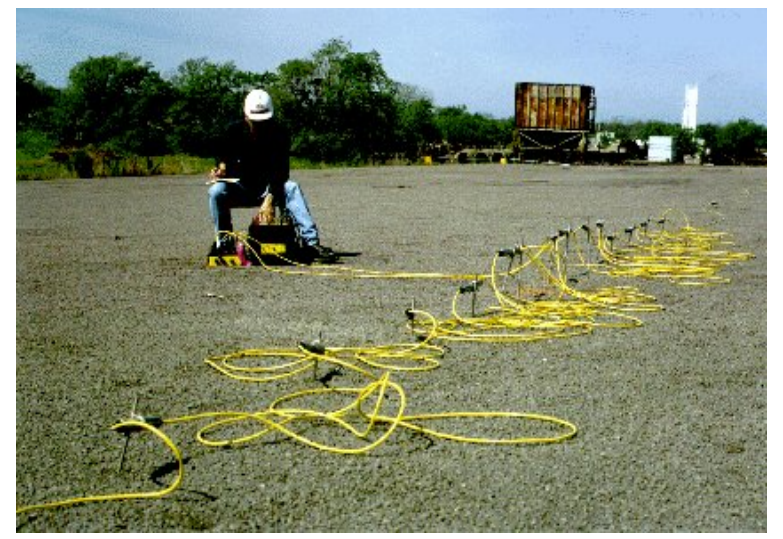

Figure 5.26. Application of resistivity method (Source: http://www.geop.ubc.ca) 
The resistivity method is especially valuable in areas where ground penetrating radar (GPR) and Electromagnetic methods do not work because of conductive overburden. Conductive materials, for example, clay attenuates the electromagnetic radar signal so that no result, or very limited result, can be achieved. In such areas, the resistivity method is an alternative for subsurface mapping of the near surface (AGI 2001). But, in order to implement this method, electrodes should be inserted to the ground; therefore, it is practically not applicable for mapping the paved area. Moreover, this method may be useful for a utility search, not for a utility tracing.

\subsection{Infrared Thermography Method}

\subsubsection{Description}

The principle of the infrared thermography method is based on the energy transfer theory. It uses the characteristic of an infrared light that can measure the radiant energy of an object and converts the data from the infrared region of the electromagnetic spectrum to the visible region of the electromagnetic spectrum. The result is a thermographic image of the object, from which temperature information-heat flux can be gathered. Since thermography measures the temperature of the surface, there are many parameters that can affect the result (Table 5.2). 
Table 5.2. Factors Affecting Result of Infrared Thermography (Weil and Graf 1991)

\begin{tabular}{|l|l|}
\hline \multicolumn{1}{|c|}{ Factors } & \multicolumn{1}{c|}{ Explanation } \\
\hline $\begin{array}{l}\text { Solar } \\
\text { radiation }\end{array}$ & $\begin{array}{l}\text { Testing should be performed during times of the day or night when the } \\
\text { solar radiation or lack of solar radiation would produce the most rapid } \\
\text { heating and/or cooling of the ground cover surface. }\end{array}$ \\
\hline $\begin{array}{l}\text { Cloud } \\
\text { cover }\end{array}$ & $\begin{array}{l}\text { Cloud cover: Clouds will reflect infrared radiation. This has the effect of } \\
\text { slowing the heat transfer process to the sky. Therefore, testing should be } \\
\text { preformed during times of little or no cloud cover in order to allow the } \\
\text { most efficient transfer of energy out of or into the ground. }\end{array}$ \\
\hline $\begin{array}{l}\text { Ambient } \\
\text { temperature }\end{array}$ & $\begin{array}{l}\text { This should have a negligible effect on the accuracy of the testing since the } \\
\text { important consideration is the rapid heating or cooling of the ground } \\
\text { surface. This parameter will affect the length of time (i.e. the window) } \\
\text { during which high contrast temperature measurements can be made. }\end{array}$ \\
\hline Wind speed & $\begin{array}{l}\text { High gusts of wind have a definite cooling effect on surface temperatures. } \\
\text { Measurements should be taken at wind speeds of less than 15 mph. }\end{array}$ \\
\hline $\begin{array}{l}\text { Moisture } \\
\text { on the } \\
\text { ground }\end{array}$ & $\begin{array}{l}\text { Moisture tends to disperse the surface heat and mask the temperature } \\
\text { differences and thus the subsurface anomalies; tests should not be } \\
\text { performed while the ground has standing water or snow. }\end{array}$ \\
\hline
\end{tabular}

\subsubsection{Main Features and Application Ranges}

This method usually can be utilized to pipelines that contain oil, chemicals, water, steam, gas or sewage because the object has different thermal characteristics than the surrounding ground. More specifically, infrared thermographic system has shown its strong cost effectiveness and accuracy in detecting pipe leakage. This method is not widely used for detecting utilities because the other methods may be more definitive and less expensive (ASCE 2002).

In order to get the accurate data, the day preceding the test should be dry with plenty of sunshine. The test of may begin either 2-3 hours after sunrise or 2-3 hours after sunset, both times of rapid heat transfer. The pavement should be cleaned of all debris. Infrared thermography equipment can be hand-carried, vehicle-mounted (normally 1-10 miles per hour) and helicopter mounted depending on the size, depth of pipelines and ground condition. 

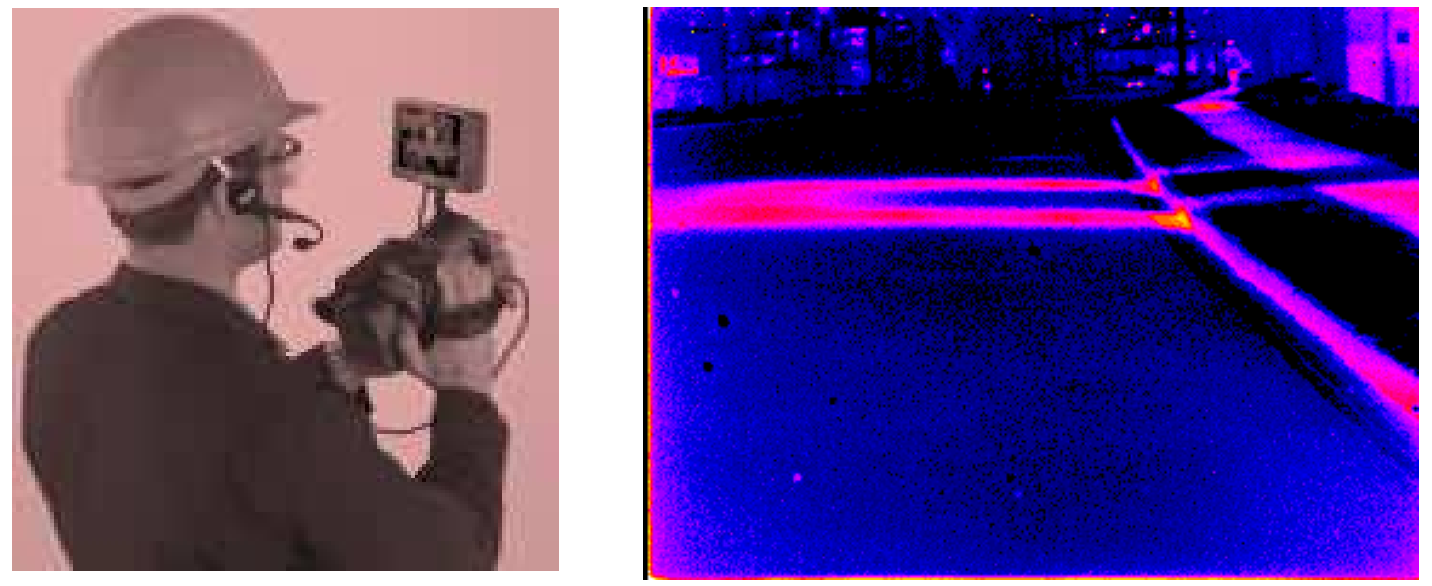

Figure 5.27. Infrared Thermography Equipment and Image Taken (Steam pipe) (Source: http://www.flir.com \& http://www.jerseyir.com)

The advantages of the method are that it does not require any ground contact and can be applied to large areas and also localized area. Measurements are relatively easy to make.

The disadvantages of the method are that thermal measurements are sensitive to daily and seasonal changes and to weather, and this method is only valid for pipelines of chemical, oil, natural gas, water, steam and sewage, and tanks. It cannot measure the characteristics of the pipelines such as diameter and depth of the pipe.

\subsection{Microgravitational Techniques}

\subsubsection{Description}

The Microgravitational techniques may have use on large utilities or tunnels (or cavity) that are

predominantly empty. The principle of the technique is to locate areas of contrasting density in the sub-surface by collecting surface measurements of the variation in the Earth's gravitational field (Figure 5.28). Because a cavity represents a mass deficiency a small reduction in the pull of the Earth's gravity is observed over the cavity. This is called a negative gravity anomaly. 

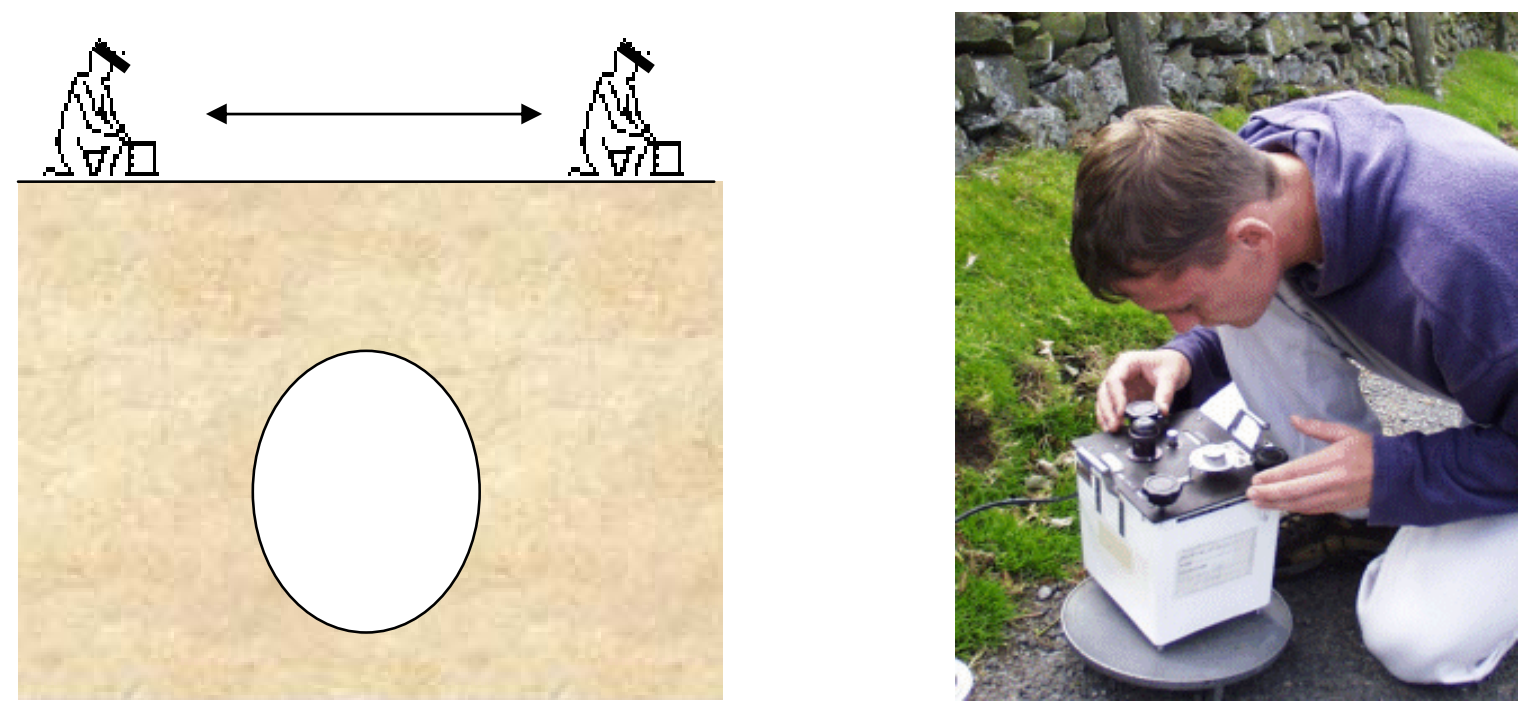

Figure 5.28. Application of Microgravitational Techniques and the Microgravimeter (Source: http://www.microgravity.co.uk/html/what_is_microgravity_.html)

Gravity anomalies are due to differences in density of underlying materials. Gravity anomalies are extremely small relative to the total field and are usually measured in micro-Gals (one microGal is about 1 billionth of the earth's total gravitational field).

A microgravimeter, which is capable of reading to a few microgals, is used to measure the earth's gravitational attraction at various points over the area of interest, usually within the upper few $100 \mathrm{ft}$ (33 m). Microgravity uses closely spaced stations (a few feet to about $50 \mathrm{ft}(16.5 \mathrm{~m})$ ) (Technos Inc 2001).

As mentioned above, the survey must be very precise due to the small values being measured. In the data interpretation, nearby sources of above-grade mass must be addressed as well as regional effects and the movements of celestial bodies. Elevations must be determined to millimeter accuracies. Obviously, data interpretation is time consuming even with the use of sophisticated computer programs and it is expensive (ASCE 2001). 


\subsubsection{Main Features and Application Ranges}

In order to detect a target using Microgravity, there must be a difference in density (mass/volume) between the target and its surroundings. If no density contrast (which called dr) exists, the target will not be detectable using this method and other methods may be more appropriate. However, cavities usually present a significant density contrast with their surroundings. Air- filled cavities offer the largest anomaly condition because of the complete absence of material in the target. Water-filled cavities on the other hand offer an anomaly effect of only $60 \%$ that of the same cavity containing air, and rubble or mud-filled cavities only about $40 \%$ that of air (Microsearch Ltd. 2001) The process of making microgravity measurements is a relatively slow and tedious in the field and requires extensive processing and corrections (Technos Inc 2001).

\subsection{Seismic Reflection/Refraction methods}

\subsubsection{Description}

Seismic investigations utilize the fact that elastic waves (seismic waves) travel with different velocities in different materials (rocks, soils and underground utilities). By generating seismic waves at a point and observing the times of arrival of these waves at a number of other points on the surface of the earth, it is possible to determine the velocity distribution and locate subsurface interfaces where the waves are reflected or refracted. Traditionally, seismic methods are classified into major divisions, depending on the energy source of the seismic waves: (A) Earthquake seismology, and (B) Explosion seismology. The explosion seismology can be divided into two methods: (1) Seismic Reflection, and (2) Seismic Refraction (Figure 5.29). 


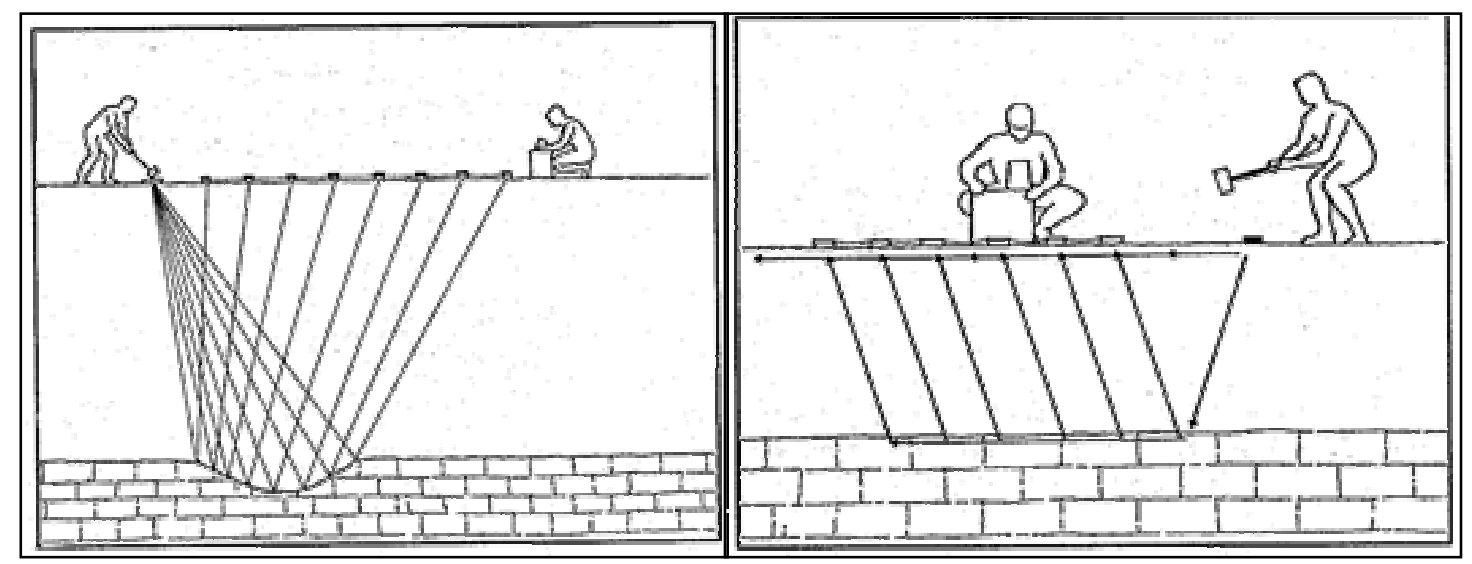

Figure 5.29. Sketch of Seismic Reflection and Seismic Refraction Methods (Source: http://www.technos-inc.com/Surface.html)

\subsubsection{Main Features and Application Ranges}

\section{Seismic Reflection Method}

The seismic reflection technique measures the travel time of seismic waves from the ground surface downward to a geologic contact where part of the seismic energy is reflected back to geophones at the surface while the rest of the energy continues to the next interface. The travel time of the seismic wave is a function of soil and rock density and hardness (Technos Inc 2001).

\section{Seismic Refraction Method}

Seismic refraction measurements are made by measuring the travel time of a refracted seismic wave as it travels from the surface through one layer to another and is refracted back to the surface where it is picked up by geophones. The travel time of a seismic wave is a function of soil and rock density and hardness (Technos Inc 2001). The seismic methods have rarely been used for underground utility designation (Anspach 2001) and only can be used under very specialized conditions. 


\subsection{Vacuum Excavation (Locating Technology)}

\subsubsection{Description}

Usually after the use of geophysical prospecting techniques such as GPR, electro-magnetic field operations and etc., to determine the existence and horizontal position of underground utilities, this vacuum excavation follows to get the exact location (horizontal \& vertical) of utilities, which is not yet possible by any one electronic detection method.

Vacuum excavation belongs to Quality level A, which is the highest of four quality levels of utility information system generally recognized by various organizations.

Vacuum excavation (potholing) is to create $0.3-$ to $0.5-\mathrm{m}$ diameter holes to physically confirm the position and depth of an underground utility. A hole is cut in the road pavement using a rotary core drill, and then the excavation is advanced using compressed air jets and/or highpressure water jets. This excavation process does not normally damage an existing utility, and the hole in the street pavement is kept to a minimum and easily repaired.

Vacuum excavation is a process, which consists of two phases: 1) Reduction, and 2) Removal (Figure 5.30). Reduction can be accomplished in a variety of ways: high-pressure water, air (pneumatic), or mechanical means. The intent of this initial phase of the operation is to reduce or fracture the soil into very small particles that can later be carried from the excavation by a high volume vacuum.

Pneumatic (air) reduction is in most cases a two-man operation. One member of the crew uses a high-pressure air lance to break the soil into small pieces while the second individual vacuums the reduced spoil into the collection tank (Figure 5.31). In most cases air reduction is slower than the use of high-pressure water; but retrieves the soil in a dry condition, and allows the reduced and removed material to be used later as backfill for the pothole. 
A trencher, backhoe, or shovel accomplishes mechanical reduction. This is the slowest and the most unsafe method of the three. The possibility of damaging a utility, injury to an employee using the shovel method, and the amount of restoration to the site, make this method the least desirable.

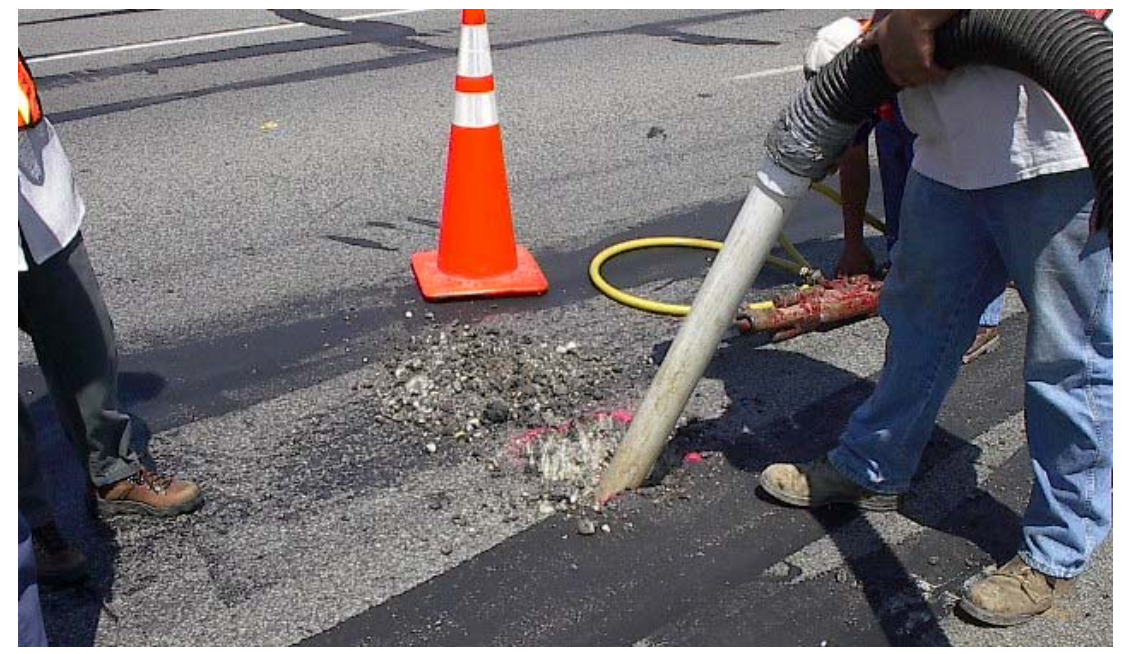

Figure 5.30. Removal Process

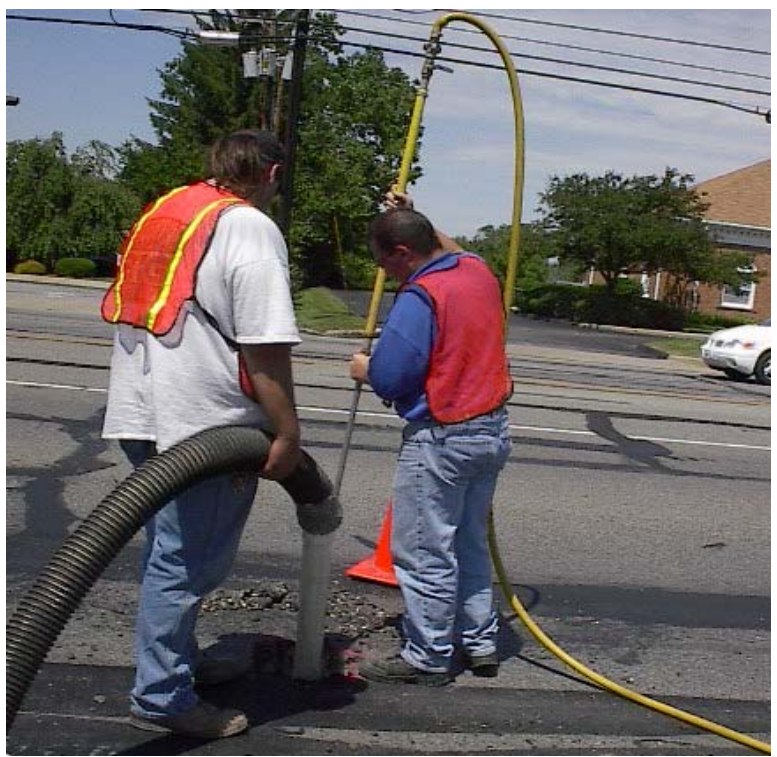

Figure 5.31. Reduction process with High-Pressure Air 
Excavation by the use of high-pressure Air is perhaps the fastest method in most types of soils. In some sandy conditions the use of water may not be required at all, or used only when horizons or layers of clay are encountered.

\subsubsection{Main Features and Application Ranges}

Any soil condition is applicable because lance is used for breaking soil. Even though this method is not adequate for rock or shale, considering that this method is used for detecting utilities, vacuum excavation is applicable to any soil because utilities should not have been installed in the rock or shale.

Speed: Soil conditions will play a major role in the speed at which a pothole can be created. The harder the soil, the longer the time it will take to reduce and remove it from the excavation. In extremely hare soil conditions it could take from 10 to 15 minutes to create a hole 6" to 8" in diameter and 4' and 5' deep. On the average, in reasonable soils, 5 to 7 minutes is the norm, and most utility potholes are less than 6 feet deep.

Crew Size: Usually 2 crew members are needed, one man for excavation and the other man for vacuuming the reduced spoil.

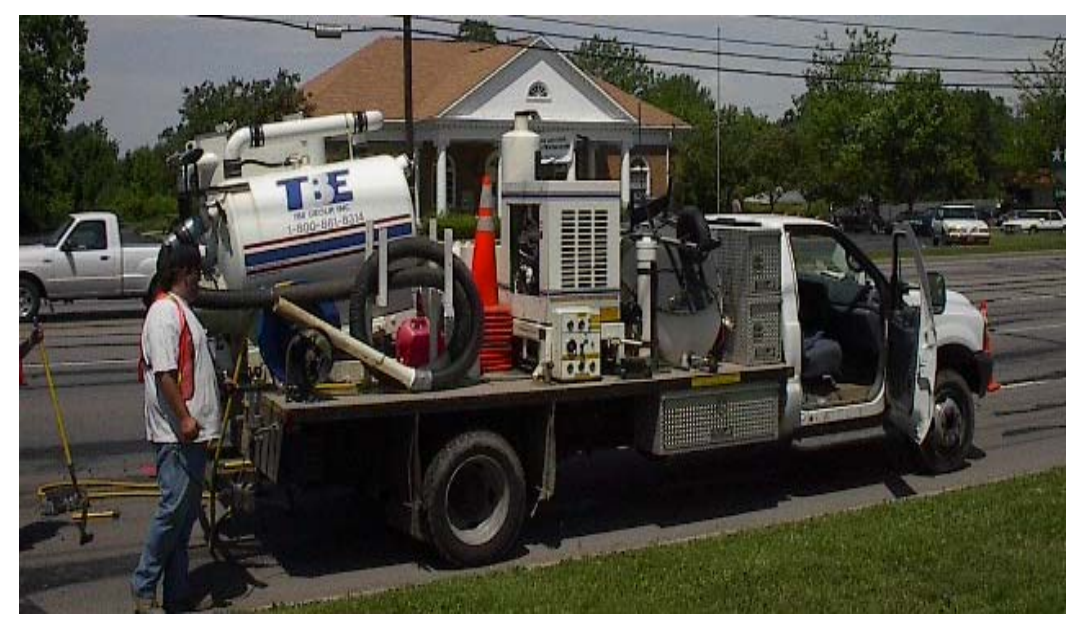

Figure 5.32. Self-contained Vacuum Excavation Truck Systems 
Accuracy: Typically vacuum excavation provides following accuracies: Horizontal location within $0.5 \mathrm{ft}$ and vertical location within $0.05 \mathrm{ft}$ (Subsurface utility engineering [SUE] provider).

Equipment: Vacuum excavation units are composed of two parts; first, vacuum units, they are used routinely to clean out materials. Second, excavators, they can dig small holes to access utility lines. Vacuum excavators range from small trailer models or skid-mounted versions that can fit in the back of a truck to powerful self-contained truck systems (Figure 3.32). Prices range from less than $\$ 7,000$ to more than $\$ 100,000$. 


\subsection{Summary Table of Subsurface Utility Designating Methods}

\begin{tabular}{|c|c|c|c|c|c|}
\hline \multicolumn{6}{|c|}{ A. Widely Used Methods in Practice } \\
\hline \multicolumn{2}{|c|}{ Method } & Principle of the Method & $\begin{array}{c}\text { Energy Propagation over } \\
\text { Utility }\end{array}$ & Interpretation of the Data & Application Information \\
\hline \multirow{5}{*}{$\begin{array}{l}\text { Electromagnetic } \\
\text { methods (EM) }\end{array}$} & $\begin{array}{l}\text { Pipe and } \\
\text { Cable } \\
\text { Locator }\end{array}$ & $\begin{array}{l}\text { A transmitter emits an } \\
\text { electromagnetic wave (radio } \\
\text { frequency, normally ranging } \\
\text { from } 50 \mathrm{~Hz} \text { to } 480 \mathrm{kHz} \text { ) to } \\
\text { the ground or directly to the } \\
\text { pipe and a receiver detects } \\
\text { reflected waves from the } \\
\text { underground utility. }\end{array}$ & \multirow[t]{3}{*}{$\begin{array}{l}\text { Electromagnetic current is } \\
\text { produced on the underground } \\
\text { metallic object by the } \\
\text { emitting wave. This current } \\
\text { generates a radio frequency } \\
\text { through the utility. }\end{array}$} & \multirow[t]{3}{*}{$\begin{array}{l}\text { The receiver detects the } \\
\text { reflected wave and gives an } \\
\text { indication such as beep } \\
\text { sound or visual sign on the } \\
\text { screen for an operator to } \\
\text { detect the existence of } \\
\text { underground utility. }\end{array}$} & $\begin{array}{l}\text { - Only metallic objects can be } \\
\text { detected. } \\
\text { - Various application } \\
\text { techniques (Conductive, } \\
\text { Inductive, Passive, Sonde } \\
\text { insertion, Tracing wire } \\
\text { /metallic marking tape). } \\
\text { - Good for tracing utilities. } \\
\text { - Crew size of 1 2 people. }\end{array}$ \\
\hline & $\begin{array}{l}\text { Terrain } \\
\text { Conductivity }\end{array}$ & $\begin{array}{l}\text { A transmitter emits an } \\
\text { electromagnetic wave to the } \\
\text { ground and a receiver detects } \\
\text { reflected waves from the } \\
\text { underground utility. }\end{array}$ & & & $\begin{array}{l}\text { - Only metallic objects can be } \\
\text { detected. } \\
\text { - Effective depth is typically } \\
15 \text { feet or so. } \\
\text { - Good for searching utilities } \\
\text { - Crew size of } 1 \text { person. }\end{array}$ \\
\hline & $\begin{array}{l}\text { E-line } \\
\text { locator }\end{array}$ & $\begin{array}{l}\text { Same as pipe and cable } \\
\text { locator but digging a hole and } \\
\text { installing an E-line through a } \\
\text { mechanical fitting is needed. }\end{array}$ & & & $\begin{array}{l}\text { - Used for plastic gas pipe. } \\
\text { - Exact location of pipe is } \\
\text { required. } \\
\text { - Relatively expensive. }\end{array}$ \\
\hline & $\begin{array}{l}\text { Metal } \\
\text { Detectors }\end{array}$ & $\begin{array}{l}\text { A transmitter emits an AC } \\
\text { magnetic field into the } \\
\text { ground and a receiver } \\
\text { analyzes a corresponding } \\
\text { magnetic field. }\end{array}$ & $\begin{array}{l}\text { Metallic object reflects a } \\
\text { slightly different magnetic } \\
\text { field from the current } \\
\text { reflected from the } \\
\text { surrounding soil }\end{array}$ & $\begin{array}{l}\text { A receiving unit detects the } \\
\text { different magnetic field and } \\
\text { emits a noise, alerting the } \\
\text { operator to the presence of } \\
\text { the metallic object }\end{array}$ & $\begin{array}{l}\text { - Only metallic objects can be } \\
\text { detected. } \\
\text { - Only applicable for shallow } \\
\text { manhole lids, valve box } \\
\text { covers and so on. } \\
\text { - Crew size of } 1 \text { person. }\end{array}$ \\
\hline & $\begin{array}{l}\text { Electronic } \\
\text { Marker } \\
\text { System } \\
\text { (EMS) }\end{array}$ & $\begin{array}{l}\text { A locator transmits } \\
\text { electromagnetic signal to the } \\
\text { electro marker and a receiver } \\
\text { detects the reflected signal } \\
\text { from the electronic marker }\end{array}$ & $\begin{array}{l}\text { Electronic marker reflects } \\
\text { the electromagnetic signal } \\
\text { back to the locator }\end{array}$ & $\begin{array}{l}\text { The location is indicated } \\
\text { with both visual reading and } \\
\text { audible tone. }\end{array}$ & $\begin{array}{l}\text { - Usually installed for non- } \\
\text { metallic utilities. } \\
\text { - Different frequency of } \\
\text { electro markers for different } \\
\text { type of utility. }\end{array}$ \\
\hline
\end{tabular}




\begin{tabular}{|c|c|c|c|c|}
\hline Method & Principle of the Method & $\begin{array}{c}\text { Energy Propagation over } \\
\text { Utility }\end{array}$ & Interpretation of the Data & Application Information \\
\hline $\begin{array}{l}\text { Ground Penetration Radar } \\
\text { (GPR) }\end{array}$ & $\begin{array}{l}\text { The radar sends } \\
\text { electromagnetic waves } \\
\text { (commonly between } 10 \text { - } \\
1,000 \mathrm{MHz} \text { ) and receives } \\
\text { reflected waves from } \\
\text { subsurface material. } \\
\\
\text { Responds to changes in } \\
\text { electrical properties } \\
\text { (dielectric and conductivity). }\end{array}$ & $\begin{array}{l}\text { GPR profile is generated } \\
\text { when the antenna is moved } \\
\text { along the surface. }\end{array}$ & $\begin{array}{l}\text { The data to interpret is } \\
\text { changes in the materials } \\
\text { electrical properties, through } \\
\text { which GPR waves travel. } \\
\text { The interpretation is to be } \\
\text { made with computer } \\
\text { programs by skilled } \\
\text { geologists. }\end{array}$ & $\begin{array}{l}\text { - Both metallic and non - } \\
\text { metallic utilities may be } \\
\text { imaged. } \\
\text { - Rule of thumb: from } \\
\text { surface to } 6 \text { feet of depth } \\
\text { and very low conductivity } \\
\text { and highly different } \\
\text { impedances, a round utility } \\
\text { whose diameter in inches } \\
\text { does not exceed the depth in } \\
\text { feet can be imaged. }\end{array}$ \\
\hline Magnetic Methods & $\begin{array}{l}\text { It measures the intensity of } \\
\text { the earth’s magnetic field. } \\
\text { Deviation of magnetic } \\
\text { intensity caused by ferrous } \\
\text { objects is detected by the } \\
\text { equipment }\end{array}$ & $\begin{array}{l}\text { Ferrous objects radiates its } \\
\text { own magnetic field }\end{array}$ & $\begin{array}{l}\text { The different intensity of the } \\
\text { magnetic field captured by } \\
\text { two sensors creates a beep } \\
\text { sound or high numeric } \\
\text { number on the screen for an } \\
\text { operator to detect the } \\
\text { existence of metallic object. }\end{array}$ & $\begin{array}{l}\text { - Useful for detecting and } \\
\text { tracing ferrous (steel or } \\
\text { iron) utilities. } \\
\text { - Good for searching utilities. } \\
\text { - Crew size of } 1 \text { person. } \\
\text { - Effective depth is typically } \\
10 \text { to } 20 \text { feet. }\end{array}$ \\
\hline Acoustic Emission Method & $\begin{array}{l}\text { An acoustic transducer } \\
\text { applies a sound wave into the } \\
\text { pipeline. The sound wave } \\
\text { travels along the utility lines } \\
\text { and special sensors on the } \\
\text { ground detect the sound wave } \\
\text { that reach the surface }\end{array}$ & $\begin{array}{l}\text { The utility line emits the } \\
\text { sound wave to the surface }\end{array}$ & $\begin{array}{l}\text { Special sensors such as } \\
\text { geophones or accelerometers } \\
\text { are used to detect the sound } \\
\text { emitted from the pipe. }\end{array}$ & $\begin{array}{l}\text { - The method is useful for } \\
\text { designating plastic pipe } \\
\text { (typically water/gas pipe). } \\
\text { - The method can service up } \\
\text { to } 1000 \mathrm{ft}(300 \mathrm{~m} \text { ) distance } \\
\text { for gas pipe and } 500 \mathrm{ft} \text { for } \\
\text { water pipe. } \\
\text { - Crew size of } 1 \sim 2 \text { people. }\end{array}$ \\
\hline
\end{tabular}




\begin{tabular}{|c|c|c|c|c|}
\hline \multicolumn{5}{|c|}{ B. Rarely Used Methods in Practice } \\
\hline Method & Principle of the Method & $\begin{array}{c}\text { Energy Propagation over } \\
\text { Utility }\end{array}$ & Interpretation of the Data & Application Information \\
\hline Resistivity Method & $\begin{array}{l}\text { An electric current is driven } \\
\text { through the ground by } \\
\text { electrodes and the resultant } \\
\text { resistivity captured by } \\
\text { potential (voltage) differences } \\
\text { is measured at the receiving } \\
\text { electrodes. }\end{array}$ & $\begin{array}{l}\text { Electrically better } \\
\text { conducting objects deflect } \\
\text { the current and distort the } \\
\text { normal potential. }\end{array}$ & $\begin{array}{l}\text { The receiving electrodes } \\
\text { records every different } \\
\text { measurement of potential } \\
\text { and the data are sent to a } \\
\text { computer unit to delineate } \\
\text { the underground profile in } \\
\text { 2-D or 3-D. }\end{array}$ & $\begin{array}{l}\text { - Typically } 25 \text { or } 50 \\
\text { electrodes are placed. } \\
\text { - Valuable in areas where } \\
\text { GPR and EM methods fails } \\
\text { because of high } \\
\text { conductivity of soil. } \\
\text { - Good for searching utilities, } \\
\text { not suitable for tracing } \\
\text { - Crew size of } 2 \text { people. }\end{array}$ \\
\hline Infrared Thermography method & $\begin{array}{l}\text { It uses the characteristic of an } \\
\text { infrared light that can } \\
\text { measure the radiant heat - } \\
\text { flux energy of an object. }\end{array}$ & $\begin{array}{l}\text { The object radiates different } \\
\text { thermal energy than the } \\
\text { surrounding ground. }\end{array}$ & $\begin{array}{l}\text { A digital computer analyzes } \\
\text { the temperature information } \\
\text { and makes thermographic } \\
\text { image of the object to the } \\
\text { computer screen. }\end{array}$ & $\begin{array}{l}\text { - Possibly applicable to } \\
\text { sewer, water, steam pipes } \\
\text { - Very sensitive to daily and } \\
\text { seasonal changes and to } \\
\text { weather. }\end{array}$ \\
\hline Microgravity Methods & $\begin{array}{l}\text { The principle is to locate } \\
\text { areas of contrasting density in } \\
\text { the sub-surface by collecting } \\
\text { surface measurements of the } \\
\text { variation in the Earth's } \\
\text { gravitational field. }\end{array}$ & $\begin{array}{l}\text { A microgravimeter, which is } \\
\text { capable of reading to a few } \\
\text { microgals, is used to measure } \\
\text { the earth's gravitational } \\
\text { attraction at various points } \\
\text { over the area of interest, } \\
\text { usually within the upper few } \\
100 \text { feet. }\end{array}$ & $\begin{array}{l}\text { In the data interpretation } \\
\text { nearby sources of above- } \\
\text { grade mass must be } \\
\text { addressed as well as regional } \\
\text { effects and the movements } \\
\text { of celestial bodies. } \\
\text { Elevations must be } \\
\text { determined to millimeter } \\
\text { accuracies. } \\
\text { Obviously, data } \\
\text { interpretation is time } \\
\text { consuming even with the use } \\
\text { of sophisticated computer } \\
\text { programs and it is expensive }\end{array}$ & $\begin{array}{l}\text { - The method may have use } \\
\text { on large utilities or tunnels } \\
\text { (or cavity) that are } \\
\text { predominantly empty. } \\
\text { - Generally, a three-person } \\
\text { crew (a topographic } \\
\text { surveying crew and the } \\
\text { gravity meter operator) is } \\
\text { required. } \\
\text { - Progress is limited to } 150 \\
\text { meter readings each day or a } \\
\text { profile length of } 750 \mathrm{~m} \text { ( } 5 \mathrm{~m} \\
\text { interval of measurement). }\end{array}$ \\
\hline
\end{tabular}




\begin{tabular}{|c|c|c|c|c|}
\hline Method & Principle of the Method & $\begin{array}{c}\text { Energy Propagation over } \\
\text { Utility }\end{array}$ & Interpretation of the Data & Application Information \\
\hline Seismic Refraction & $\begin{array}{l}\text { Seismic refraction } \\
\text { measurements are made by } \\
\text { measuring the travel time of a } \\
\text { refracted seismic wave as it } \\
\text { travels from the surface } \\
\text { through one layer to another } \\
\text { and is refracted back to the } \\
\text { surface where it is picked up } \\
\text { by geophones. }\end{array}$ & \multirow[t]{2}{*}{$\begin{array}{l}\text { Seismic wave is created by } \\
\text { hitting a sledgehammer on } \\
\text { surface or with an explosive } \\
\text { in a manhole. }\end{array}$} & \multirow[t]{2}{*}{$\begin{array}{l}\text { The travel time of a seismic } \\
\text { wave is a function of the } \\
\text { material, soil and rock } \\
\text { density and hardness. }\end{array}$} & \multirow[t]{2}{*}{$\begin{array}{l}\text { - The method is only useful } \\
\text { under very specialized } \\
\text { conditions and rigorous } \\
\text { technique. }\end{array}$} \\
\hline Seismic Reflection & $\begin{array}{l}\text { The seismic reflection } \\
\text { technique measures the travel } \\
\text { time of seismic waves from } \\
\text { the ground surface downward } \\
\text { to a geologic contact where } \\
\text { part of the seismic energy is } \\
\text { reflected back to geophones } \\
\text { at the surface while the rest of } \\
\text { the energy continues to the } \\
\text { next interface. }\end{array}$ & & & \\
\hline
\end{tabular}




\section{CHAPTER 6}

\section{PERFORMANCE CRITERIA FOR DESIGNATING TECHNOLOGIES}

\subsection{Introduction}

Thirteen different designating techniques that are currently available were identified in Chapter Three. They were based on different geophysical theories and different application conditions. In order to effectively select appropriate designating method, it is crucial to establish a set of criteria based on characteristics of each designating method and information that site engineers can obtain from drawings and site visit.

Ten criteria were identified for selection of appropriate designating methods as follows.

- $\quad$ Type of utility

- Material of utility

- Joint type of metallic pipe

- Special materials for detection

- Access point to utility
- Ground surface condition

- Inner state of pipe

- Soil type

- Depth of utility

- Diameter/Depth ratio

In this chapter, these criteria will be discussed in greater detail and the impact of each entries of criterion on each designating method will be evaluated by assigning one of three linguistic attributes:

- Applicable: a "superior" condition for the use of the designating method.

- Inapplicable: an "unfeasible” condition for the use of the designating method.

- Neutral: the entry is theoretically possible condition for the use of the designating method but is rarely used in practice or the entry has no impact on the use of the designating method.

A summary table showing the relationship between the criteria and the designating methods is provided at the end of this chapter. 


\subsection{Type of Utility}

Based on their main functions, underground utilities can be categorized into water pipe, sewer pipe, steam pipe, gas pipe, oil and chemical pipeline, electric cable/conduit, and telecommunication cable/conduit. Figure 6.1 illustrates the individual shares of underground installation work by responsible agencies in the North America.

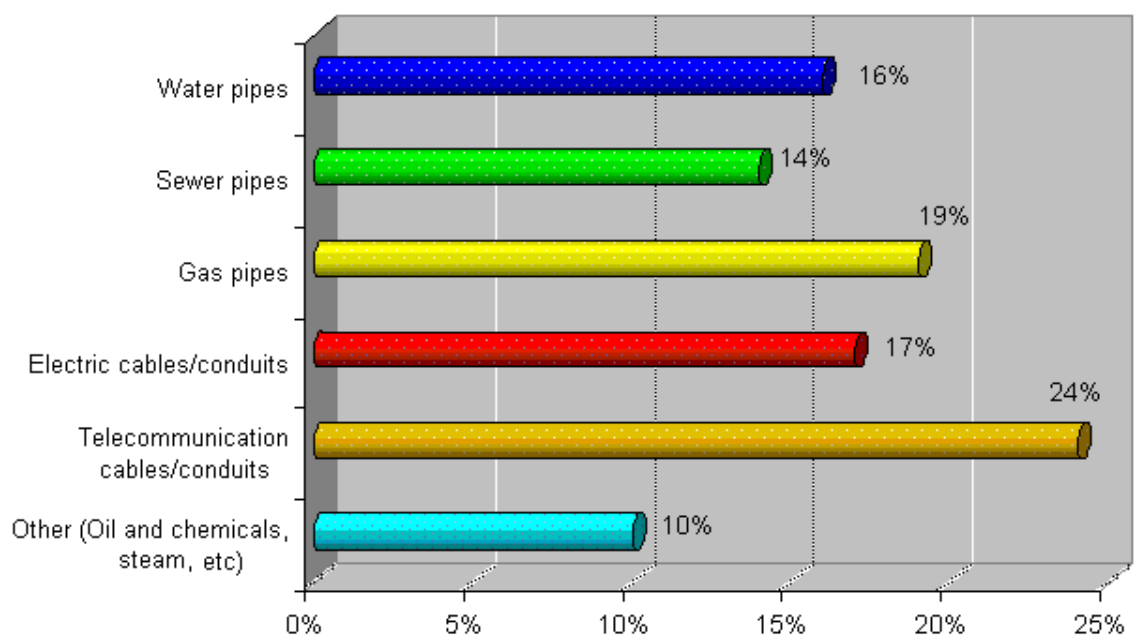

Figure 6.1. Breakdown of Estimated Pipeline Replacement and New Pipeline Installation in the North America by Responsible Agencies (Iseley and Gokhale 1997)

Most of designating methods are not influenced by the type of utility in their operation except for

"Pipe and cable locator-passive mode," "Sonde insertion method," "E-line locator method," and "Acoustic emission method."

\section{Pipe and cable locator-passive mode}

An electric cable carrying alternating current (a.c.) power produces its own signal at 50-60 $\mathrm{Hz}$ frequencies, thus providing a fine source for designation by a passive mode. Very low frequency (long wave) radio energy from distant transmitters is present in the atmosphere world-wide (Radiodetection 1994). The ground provides return paths for this radiation, and buried metallic pipe and cables form preferred paths, therefore, they also may be detected by the passive mode 
theoretically, but in practice, passive mode is usually used to check any unknown utilities in the vicinity of the target utility being designated.

\section{Sonde insertion method}

In order to apply "sonde insertion method" for designation purpose, direct access to the inside of an underground utility such as manhole or any special entry is a prerequisite. Sewer pipe, electrical conduit and telecommunication conduit allow direct access to the inside of the utility through manhole.

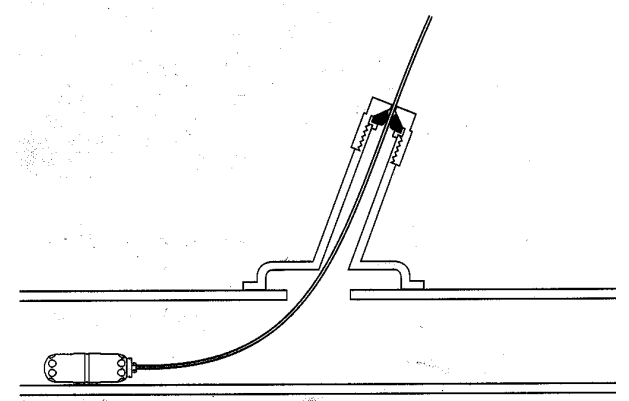

Figure 6.2. Sonde Inserted to a Pipe through a Special Canopy (Source: Radiodetection 1994)

Gas pipe and water pipe also can accept a small size of sonde through a special canopy when it is available (Figure 6.2). In this case, however, the utility service to the customer is disrupted in order to insert a sonde, thus, it is not a preferable method for pipes with flowing material.

\section{E-line locator method}

E-line locator method is typically designed to detect plastic gas pipes when there is no easy access to it (P \& GJ 2000). It requires a pothole and a mechanical fitting on the surface of the pipe in order to insert an e-line. Currently, this method is only applied to gas pipes.

\section{Acoustic emission method}

This method is mainly designed for detecting non-metallic water and gas pipes. It relies on the pressure and the flow of the material in the utility; thus, they can be used for water and gas pipes. The method cannot be applied to oil pipes because thick consistency of the oil product prevents the travel of the sound (Willis 2001). This method is appropriate for designating steam pipe, 
however, since steam pipe is typically made of steel, "pipe and cable locators" are typically used for designating them. Table 6.1 shows the applicability of the type of utility to designating methods.

Table 6.1. Applicability of the Type of Utility to Designating Methods

\begin{tabular}{|c|c|c|c|}
\hline \multirow{2}{*}{ Designating methods } & \multicolumn{3}{|c|}{ Applicability } \\
\hline & Applicable & Inapplicable & Neutral \\
\hline Pipe and cable locator-passive mode & Gas & & All others \\
\hline Sonde Insertion Method & $\begin{array}{l}\text { Sewer, Electric, } \\
\text { Telecom }\end{array}$ & & All others \\
\hline E-line Locator Method & Gas & All others & \\
\hline Acoustic Emission Method & Water, Gas & All others & Steam \\
\hline
\end{tabular}

\subsection{Material of Utility}

Steel, iron, brick, cement, concrete, clay, plastics, composites and fiber optic glass - all have been used for underground utilities, and utilities have been benefited from advances in material technology over the past several decades (Jeyapalan 1990). In the past, utilities were generally metallic, electrically continuous, linear and logically routed so that minimally trained technicians with conventional equipments had a fair chance of finding these metallic utilities (ASCE 2002). However, the advent of plastic, fiber optic glass and composite materials that are not metallic have made the designation of underground utilities significantly complicated.

Table 6.2 classifies all the materials used for underground utilities, based on their metallic property. Also, utility designating methods must be categorized according to their detectable material type in order to evaluate the applicability of the type of material to designating methods. Table 6.3 shows the classification of designating methods for this purpose. 
Table 6.2. Classification of Materials of Underground Utilities

\begin{tabular}{|c|c|c|}
\hline \multirow{2}{*}{ Type of utility } & \multicolumn{2}{|c|}{ Property of material } \\
\hline & Metallic & Non-metallic \\
\hline Water pipe & $\begin{array}{l}\text { Steel, cast iron, ductile } \\
\text { iron, copper }\end{array}$ & $\begin{array}{l}\text { Fiberglass reinforced plastic (FRP), } \\
\text { concrete, asbestos-cement, plastics } \\
\text { (polyethylene (PE), polyvinyl chloride } \\
\text { (PVC), etc) }\end{array}$ \\
\hline Sewer pipe & $\begin{array}{l}\text { Steel, cast iron, ductile } \\
\text { iron }\end{array}$ & $\begin{array}{l}\text { Vitrified clay, concrete, asbestos- } \\
\text { cement, brick, cement, plastics } \\
\text { (polyethylene (PE), polyvinyl chloride } \\
\text { (PVC), acrylonitrile-butadiene- } \\
\text { stryrene (ABS), etc) }\end{array}$ \\
\hline Steam pipe & Steel & - \\
\hline Gas pipe & $\begin{array}{l}\text { Steel, cast iron, ductile } \\
\text { iron, copper, metallic } \\
\text { polyethylene (MPE) }\end{array}$ & Plastics (PE, PVC, etc) \\
\hline Oil and chemical pipe & Steel & $\begin{array}{l}\text { Fiberglass reinforced plastic (FRP), } \\
\text { plastics (High density polyethylene } \\
\text { (HDPE)) }\end{array}$ \\
\hline $\begin{array}{l}\text { Electrical } \\
\text { cables/conduits }\end{array}$ & $\begin{array}{l}\text { Metallic cable (copper, } \\
\text { aluminum, etc), cables in } \\
\text { metallic conduit }\end{array}$ & (a) \\
\hline $\begin{array}{l}\text { Telecommunication } \\
\text { cables/conduits }\end{array}$ & $\begin{array}{l}\text { Metallic cable (copper, } \\
\text { aluminum, etc), cables in } \\
\text { metallic conduit, fiber } \\
\text { optic cable with metallic } \\
\text { shield. }\end{array}$ & $\begin{array}{l}\text { Fiber optic cable with non-metallic } \\
\text { shield, Fiber optic cable with non- } \\
\text { metallic shield in non-metallic } \\
\text { conduit. }\end{array}$ \\
\hline
\end{tabular}

Table 6.3. Classification of Designating Methods by Detectable Material Type

\begin{tabular}{|l|l|}
\hline \multicolumn{1}{|c|}{ Description } & \multicolumn{1}{c|}{ Designating methods } \\
\hline $\begin{array}{l}\text { Used for designating metallic } \\
\text { utility (A) }\end{array}$ & $\begin{array}{l}\text { Pipe and cable locator (conductive with high and low } \\
\text { frequency, inductive mode), metal detector, terrain } \\
\text { conductivity. }\end{array}$ \\
\hline $\begin{array}{l}\text { Used for designating non- } \\
\text { metallic utility (B) }\end{array}$ & $\begin{array}{l}\text { Tracing wire/metallic marking tape method, EMS, } \\
\text { acoustic emission method, sonde insertion method. }\end{array}$ \\
\hline $\begin{array}{l}\text { Not limited by the type of } \\
\text { material }\end{array}$ & GPR \\
\hline Exceptions & Magnetic method, E-line locator method. \\
\hline
\end{tabular}

The methods (A) that are typically used for designating metallic utility depend on the metallic property of the utility when designating. Therefore, they cannot detect non-metallic utilities. The 
methods (B) that are typically applied to designate non-metallic utility, however, are still theoretically applicable for designating metallic utilities because they rely on different properties of the utility such as pressure and flow or metallic object laid above the utility. But, in practice, these methods are rarely used for designating metallic utilities due to the presence of welldeveloped techniques for detecting metallic utilities.

\section{Exceptions}

"Magnetic method" can detect only ferrous metal such as steel and iron; copper or aluminum metals that do not contain ferrous material cannot be detected by this method. "E-line locator method" currently takes only "plastic pipe" for its applicable condition because mechanical fitting (a hole) to the pipe must be made to accept an e-line. The applicability of the type of material to designating methods is summarized in the Table 6.4.

Table 6.4. Applicability of Material of Utility to Designating Methods

\begin{tabular}{|l|l|l|l|}
\hline \multirow{2}{*}{ Designating methods } & \multicolumn{3}{|c|}{ Applicability } \\
\cline { 2 - 4 } & \multicolumn{1}{|c|}{ Applicable } & \multicolumn{1}{|c|}{ Inapplicable } & \multicolumn{1}{c|}{ Neutral } \\
\hline A & Metallic & Non-metallic & - \\
\hline B & Non-metallic & - & Metallic \\
\hline GPR & - & - & All material \\
\hline Magnetic method & Steel, cast/ductile iron & Non-metallic & - \\
\hline E-line locator method & Plastic & All others & \\
\hline
\end{tabular}

A: Designating methods for metallic utility, B: Designating methods for non-metallic utility.

\subsection{Joint Type of Metallic Pipe}

Joint type of metallic pipe determines the electrical continuity of the utility which is one of critical factors in selecting "sonde insertion method," "pipe and cable locators -inductive mode," and the right frequency of the "pipe and cable locators - conductive mode." There are various kinds of joints for metallic pipes. Common types of steel pipes are welded-joints, belland-spigot joints, rubber-gasket joints, sleeve couplings, grooved-and-shouldered couplings, and flanges (Figure 6.4). 


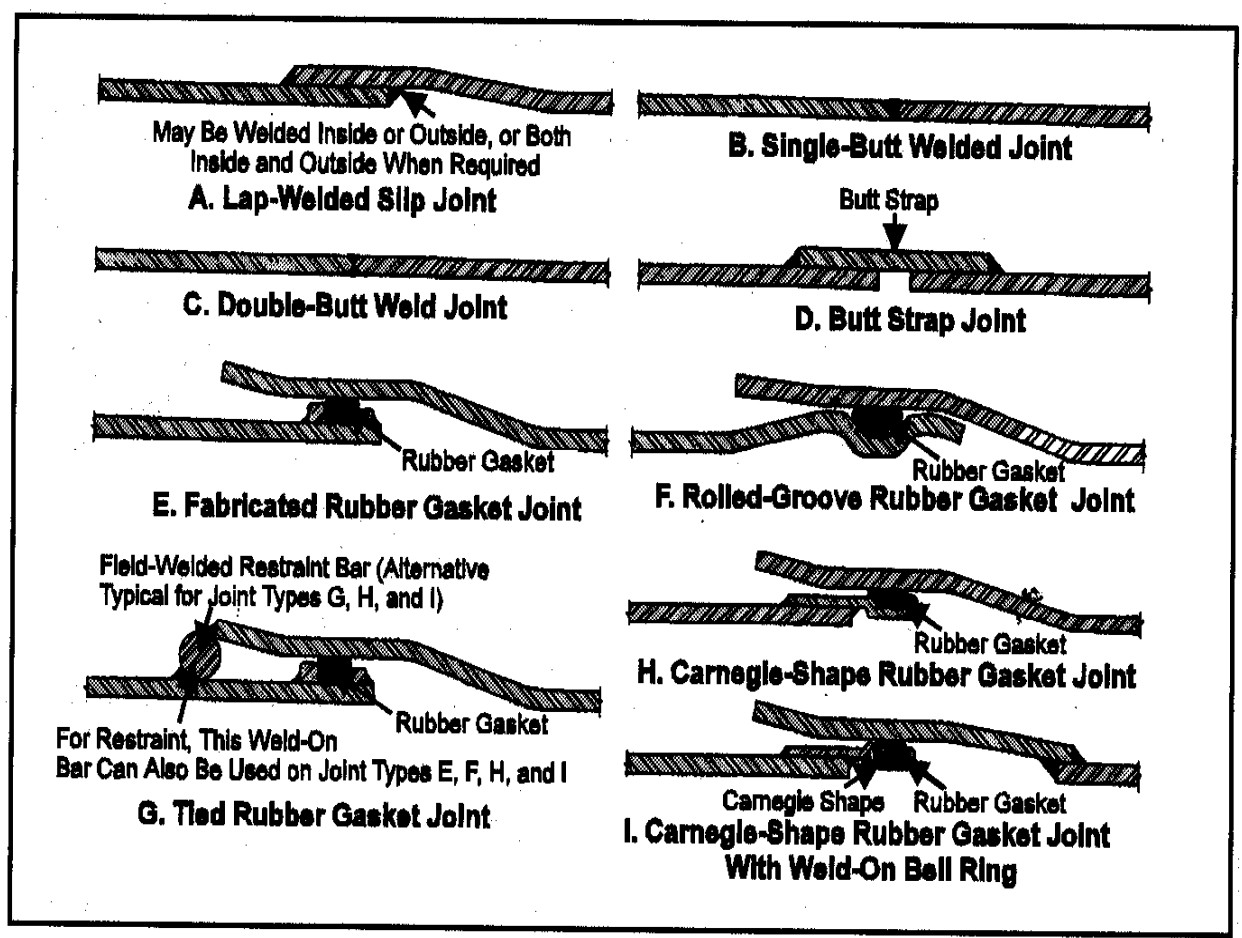

Source: Manual M11, Steel Pipe-A Guide for Design and Installation (1989).

Figure 6.4. Various Joints for Steel Pipes (AWWA 1989)

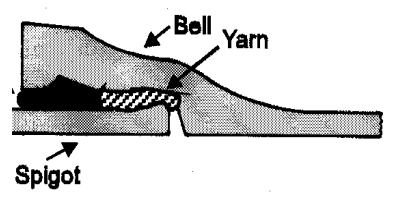

Lead bell-and-spigot
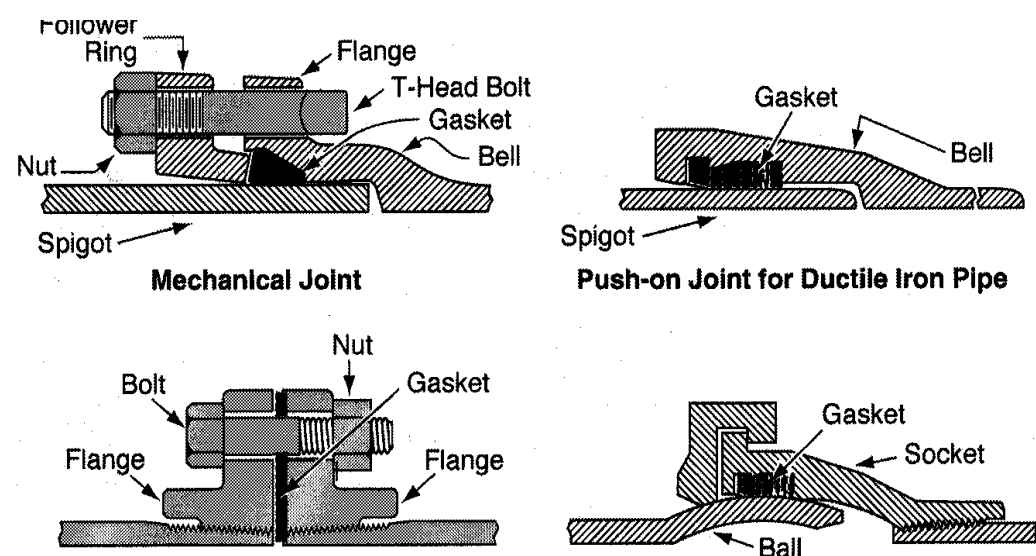

Flanged Joint

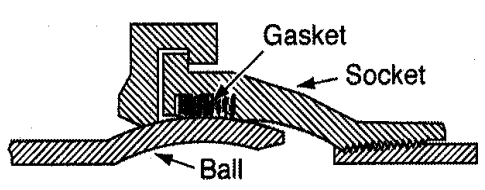

Flex-Lok Boltless Ball Joint

Figure 6.5. Various Joints for Iron Pipes (ANSI/AWWA CIII/A21.11) 
Among these joints, only welded joints of steel pipe guarantee electrical continuity. Some of iron pipes which have metallic joints such as lead or jute have low electrical continuity due to the high electrical resistance of these metals, and often lack the continuity altogether (Irias 1998). Common types of iron pipes are lead joints, jute joints, mechanical joints, push-on joints, flange joints, restrained joints, 'ball and socket joints' and 'grooved and shouldered joints' (Figure 6.5).

\section{Cathodic protection system}

Metal pipes, specifically steel pipes, are very weak at corrosion. Steel or iron produces a current that causes ions to leave their surface especially when it is buried in corrosive soils. In other words, steel/iron works as a corrosive end when two dissimilar metals (the one is the pipe and the other one is a metal naturally existing in the soil) are electrically connected through moisture in the wet soil; therefore, when the electrolytes in the soil move, they always travel from the steel/iron to the other metal, carrying ionized atoms of the pipe. After a long period of time, the pipe is deteriorated. Cathodic protection system reverses the electrochemical force by creating an external circuit between the pipe to be protected and an auxiliary anode (sacrificial metal) immersed in water or buried in the ground (Figure 6.6).

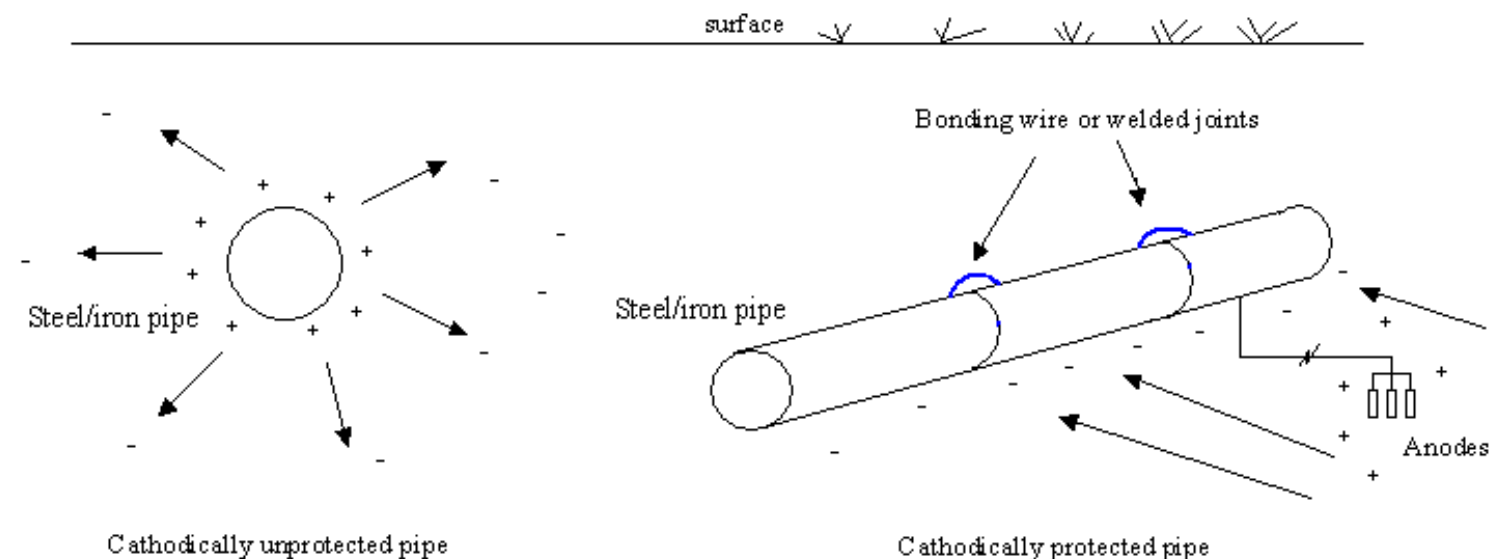

Figure 6.6. Cathodic Protection System

For the cathodic protection, first, the pipe must be electrically continuous at every joint. Thus, it is necessary to electrically bond all joints at the time of installation. Even though cathodic protection system is not always installed to the steel pipe specifically until it is proved to be necessary, it is recommended that all joints in steel pipe be electrically bonded for a possible 
future need because the cost later will be many times greater (AWWA 1989). Consequently, if cathodic protection system is installed in the pipe or bonding jumper (bonding wire) is installed in every joint, electrically continuity of the pipe is ensured.

\section{Insulated metallic pipe}

Some steel pipes in gas service may be fitted with an insulated joint to prevent stray signals traveling along the pipe (Radiodetection 1994). There exists some insulated cast iron pipes buried underground (JR Associates 2001). As this insulating system is too strong for the electrical current to go through the joint, insulated joints provide electrically discontinuous environment for the pipe.

Based on aforementioned factors, joints of metallic pipe can be categorized into three different types based on their electrical continuity as shown in Figure 6.7.

\begin{tabular}{|l|}
\hline \multicolumn{1}{|c|}{ Continuous } \\
\hline \multicolumn{1}{|c|}{$\mid$} \\
\hline Welded joints, \\
Bonding jumper \\
installed joints, \\
Cathodic protection \\
system installed \\
joints \\
\hline
\end{tabular}
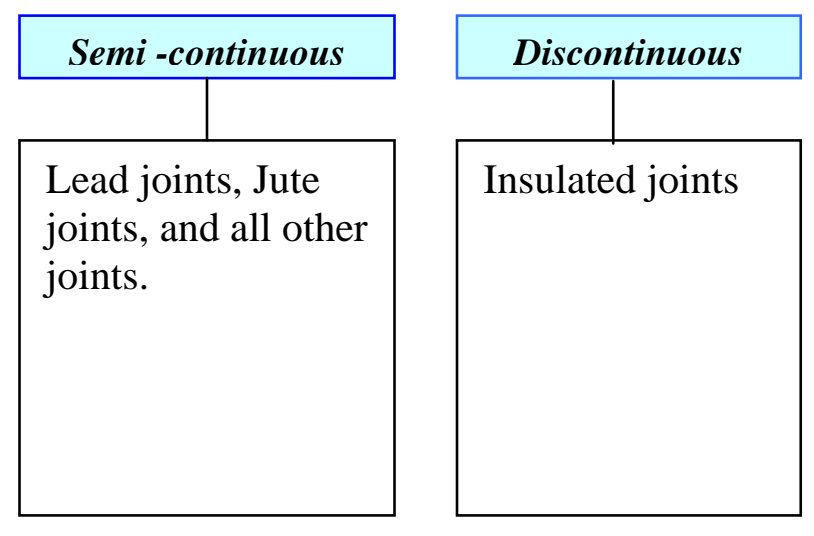

- Continuous: high electrical continuity with low resistance

- Semi-continuous: low electrical continuity with high resistance

- Discontinuous: electrically not-continuous

\section{Figure 6.7. Joint Types of Metallic Pipe}

\section{Frequency and electrical continuity of pipe}

When using "pipe and cable locators-conductive mode" for designating metallic pipes, the choice of the right frequency is a very important factor for the success of the designation. If the pipe is electrically discontinuous, this method cannot be used to trace the utility. If the pipe is 
electrically semi-continuous, only high frequency can designate the utility because low frequency is not able to penetrate through the low conductive joints (Figure 6.8). For electrically continuous pipe, low frequencies are preferable due to their ability of long distance tracing.

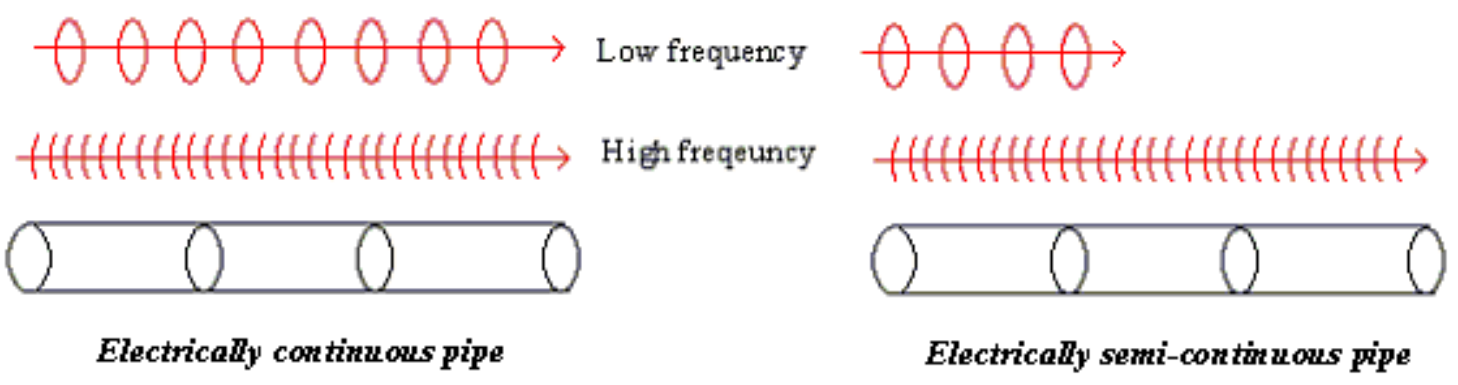

Figure 6.8. Electrical Continuity of Pipe versus Frequency

\section{Shield effect}

"Sonde insertion method" cannot detect electrically continuous pipes due to the shield effect (Figure 6.9). When the electromagnetic field is generated by sonde transmitter through the electrically continuous metallic pipe, the generated wave cannot leak out of the pipe because the electrical continuity of the pipe screens the generated wave from escaping the pipe (Anspach 2001).

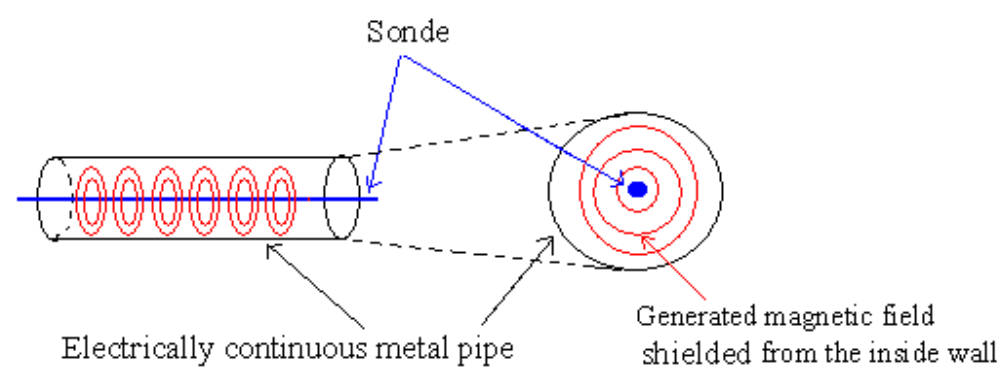

Figure 6.9. Shield Effect

Table 6.5 shows the summary of the applicability of joints to designating methods. 
Table 6.5. Applicable Joints of Metallic Pipe to Designating Methods

\begin{tabular}{|l|l|l|l|}
\hline \multirow{2}{*}{ Designating method } & \multicolumn{3}{|c|}{ Applicability of joint types } \\
\cline { 2 - 4 } & \multicolumn{1}{|c|}{ Applicable } & Inapplicable & \multicolumn{1}{c|}{ Neutral } \\
\hline $\begin{array}{c}\text { Pipe and cable locators } \\
\text { (Conductive mode -High } \\
\text { frequency }\end{array}$ & Electrically semi- continuous & $\begin{array}{l}\text { Electrically } \\
\text { discontinuous }\end{array}$ & $\begin{array}{l}\text { Electrically } \\
\text { continuous }\end{array}$ \\
\hline $\begin{array}{c}\text { Pipe and cable locators } \\
\text { (Conductive mode -Low } \\
\text { frequency) }\end{array}$ & Electrically continuous & $\begin{array}{l}\text { Electrically } \\
\text { discontinuous }\end{array}$ & $\begin{array}{l}\text { Electrically } \\
\text { semi- } \\
\text { continuous }\end{array}$ \\
\hline $\begin{array}{c}\text { Pipe and cable locators } \\
\text { (Inductive mode) }\end{array}$ & $\begin{array}{l}\text { Electrically continuous, } \\
\text { electrically semi-continuous }\end{array}$ & $\begin{array}{l}\text { Electrically } \\
\text { discontinuous }\end{array}$ & \\
\hline Sonde insertion method & $\begin{array}{l}\text { Electrically discontinuous, } \\
\text { Electrically semi- continuous }\end{array}$ & $\begin{array}{l}\text { Electrically } \\
\text { continuous }\end{array}$ & \\
\hline
\end{tabular}

\subsection{Special Materials for Detection of Underground Utility}

The difficulty of designating non-metallic pipes has prompted the installation of special materials on/above non-metallic utilities at the time of construction. There are two different kinds of special materials used for this purpose:

- Tracing wire or metallic marking tape: widely used for non-metallic utilities

- Electronic markers: usually used for special buried features such as valves and splices as well as non-metallic utilities

Table 6.6. Applicability of Special Materials for Detection to Designating Methods

\begin{tabular}{|l|l|l|c|}
\hline \multirow{2}{*}{ Designating methods } & \multicolumn{3}{|c|}{ Applicability } \\
\cline { 2 - 4 } & \multicolumn{1}{|c|}{ Applicable } & \multicolumn{1}{|c|}{ Inapplicable } & Neutral \\
\hline $\begin{array}{l}\text { Tracing wire or } \\
\text { metallic marking tape } \\
\text { method }\end{array}$ & $\begin{array}{l}\text { Tracing wire installed, } \\
\text { metallic marking tape } \\
\text { installed }\end{array}$ & $\begin{array}{l}\text { Electronic markers } \\
\text { installed }\end{array}$ & \\
\hline EMS & $\begin{array}{l}\text { Electronic markers } \\
\text { installed }\end{array}$ & $\begin{array}{l}\text { Tracing wire installed, } \\
\text { metallic marking tape } \\
\text { installed }\end{array}$ & \\
\hline
\end{tabular}


Metallic wire and metallic marking tape deteriorate over time or contractors have dug into this wire or tape without always splicing it back together (P\&GJ, 2000). This creates electrical discontinuity of these lines, resulting in the failure of designation. Table 6.6 summarizes the applicability of the special detection materials.

\subsection{Access Point to Utility}

Access point to utility is the one of the most important factors in selecting appropriate designating method. This criterion includes four entries, which are defined as follows:

- Presence of utility (A): the appurtenance of an underground utility that is physically accessible to the utility is in the vicinity.

- Exactly known location of utility (B): No appurtenance of utility is seen but exact location of utility is known probably from the previous designation record.

- Probable location of utility (C): the location of underground utility is not exactly known but probably known from the drawing or other information.

- None of the above (D): no information is available about the utility.

Table 6.7 lists different kinds of physical access points to underground utilities and Figure 6.10 shows common physical access points to urban utilities.

Table 6.7. Physical Access Points to Underground Utilities

\begin{tabular}{|l|l|}
\hline \multicolumn{1}{|c|}{ Type of utility } & \multicolumn{1}{c|}{ Physical access points to underground utilities } \\
\hline Water Pipe & $\begin{array}{l}\text { Hydrant, valves, meters, stop tap, sprinkler head, garden stand } \\
\text { pipe, post indicator valve, basement/building access, faucet, etc }\end{array}$ \\
\hline Sewer Pipe & Manhole, sewer inlets, catch basin, clean-outs, etc \\
\hline Steam Pipe & Valves, meters, expansion tanks, etc \\
\hline Gas Pipe & Valve box, meters, test stations, regulator stations, drip box, etc \\
\hline Oil and Chemical Pipe & Manhole, test stations, regulator stations, etc \\
\hline $\begin{array}{l}\text { Electrical } \\
\text { cables/conduits }\end{array}$ & $\begin{array}{l}\text { Manhole, meters, street lamp column, electric pole, splice } \\
\text { boxes, pull boxes, terminal box or power socket (house), fuses } \\
\text { box, fink box, etc }\end{array}$ \\
\hline $\begin{array}{l}\text { Telecommunication } \\
\text { cables/conduits }\end{array}$ & $\begin{array}{l}\text { Manhole, splice boxes, pull boxes, manhole, splice boxes, pull } \\
\text { boxes, pedestal, cross box, cabinet, central office, exchange, } \\
\text { domestic socket, protector, etc }\end{array}$ \\
\hline
\end{tabular}




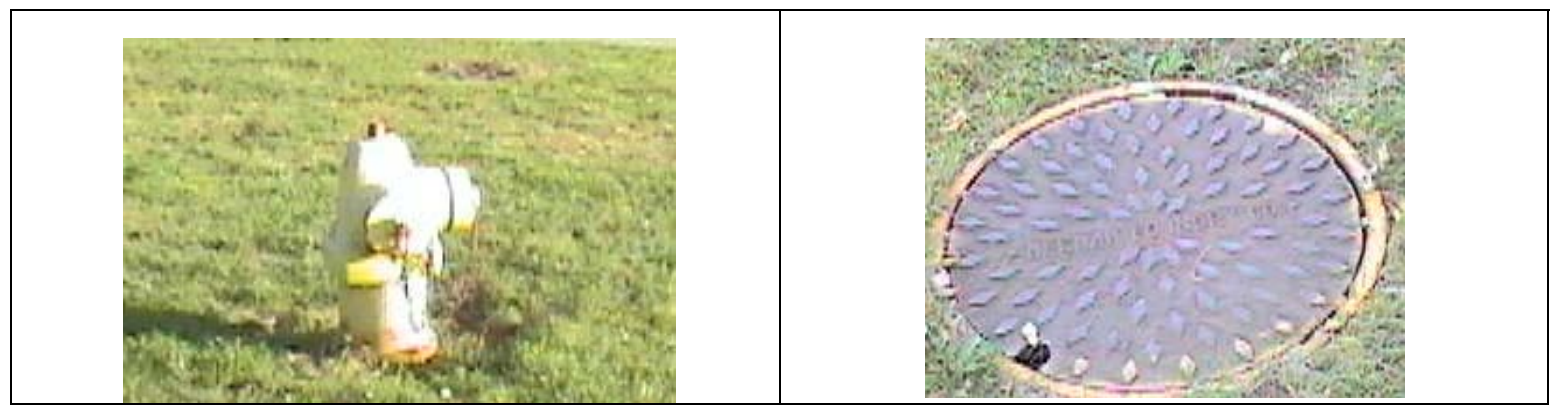

Hydrant (Water pipe)

Manhole (Sewer pipe)

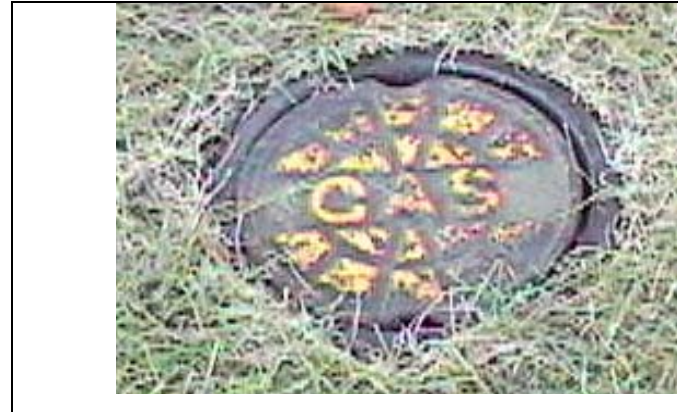

Gas valve (Gas pipe)

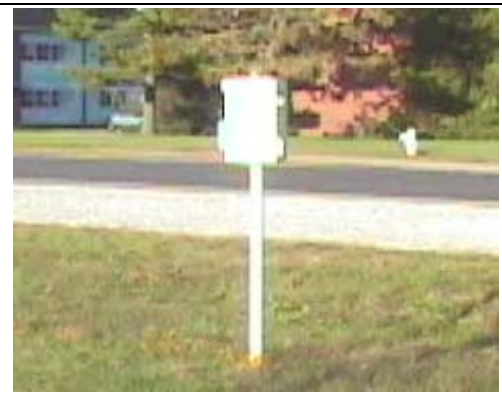

Telephone post (Telecommunication cable)

Figure 6.10. Common Physical Access Points to Urban Utilities

\section{Tracing/searching methods}

Designating methods can be divided into tracing method and searching method."Tracing” is defined as tracking the path of underground utilities from the previously known point. "Searching" is defined as identifying the potential presence of utility (ASCE 2002) when there is no available information about exact location of utility.

Table 6.8. Classification of Subsurface Utility Designating Methods (tracing/searching)

\begin{tabular}{|c|c|c|}
\hline Classification & & Underground utility designating methods \\
\hline \multirow{5}{*}{ Tracing Methods } & $\mathbf{I}$ & $\begin{array}{l}\text { Pipe and cable locator -conductive mode, sonde } \\
\text { insertion method, acoustic emission method. }\end{array}$ \\
\hline & II & Tracing wire or metallic marking tape method \\
\hline & III & Pipe and cable locator-inductive mode \\
\hline & IV & E-line locator method \\
\hline & $\mathbf{V}$ & EMS \\
\hline Searching Methods & VI & Terrain conductivity, metal detector. \\
\hline \multirow{2}{*}{$\begin{array}{l}\text { Both tracing and searching } \\
\text { available methods }\end{array}$} & VII & Pipe and cable locator-passive mode, magnetic method \\
\hline & VIII & GPR \\
\hline
\end{tabular}


Tracing method may be followed after searching methods identify the presence of underground utility. Table 6.8 shows the classification of designating methods based on their ability for tracing or searching utilities.

\section{Methods for tracing only}

Among tracing methods, "pipe and cable locator-conductive mode," "Sonde insertion method," and "Acoustic emission method" only take "presence of utility" as applicable condition because transmitters must be hooked up to the surface appurtenance to generate signal to the utility. "Tracing wire or metallic marking tape method" takes "presence of utility" and "exactly known location of utility" as applicable conditions because either hook-up or surface signal generation is possible if the location of utility is known to the engineer. "E-line locator method" takes only "exactly known location of utility" as the most preferable condition and takes "presence of utility" as neutral condition because this method is typically used when there is no easy access to the pipe and there is exactly known location available.

"Cable and pipe locator-inductive mode" is applied by generating a surface signal right above the underground utility, thus, it is used when "exactly known location of utility" is available, but it still can be used where there is a direct connection to the underground utility. "Conductive mode" is preferable due to its correct and powerful signal emission to the underground pipe. "EMS" is useful for detecting electronic markers installed above the utility, thus, if an approximate location of the utility is known, a site engineer can eventually designate these markers by trial and error.

\section{Methods for searching only}

Searching methods are useful to detect the metallic access points to the utility such as manhole lid and valve box cover when there is no available information about utility location.

\section{Both tracing and searching available methods}

The "Pipe and cable locator-passive mode," which is widely used for tracing electrical lines and for searching unknown metallic utilities, takes "probable location of utility" and "none of the above" for its good applicable conditions, and "presence of utility" and "exactly known location 
of utility" for its neutral conditions due to a better performance of "pipe and cable locators" in the same condition. "Magnetic method" is good for searching ferrous metallic objects and sometimes can be used for tracing cast iron pipes by detecting their joints (Schonstedt 2000). The final summary of the applicability of "access point to utility" to designating methods is illustrated on Table 6.9.

Table 6.9. Applicability of Access Point of Utility to Designating Methods

\begin{tabular}{|c|c|c|c|}
\hline \multirow{2}{*}{$\begin{array}{c}\text { Designating } \\
\text { methods }\end{array}$} & Applicable & Inapplicable & Neutral \\
\cline { 2 - 4 } & A & B, C, D & \\
\hline II & A, B & C, D & A, C \\
\hline III & B & D & A \\
\hline IV & B & C, D & \\
\hline V & A, B, C & D & A, B \\
\hline VI & C, D & A, B & A, B, C, D \\
\hline VII & C, D & & \\
\hline VIII & & & \\
\hline
\end{tabular}

- Designating methods (I, II, III, IV, V, VI, VII, VIII) => refer to Table 6.9.

- A: presence of utility, B: exactly known location of utility, C: probable location of utility, D: none of the above.

\subsection{Ground Surface Condition}

The area where subsurface utilities are buried is typically covered with the one of the following different types of ground surfaces.

- Paved: paved without reinforcement (asphalt paved, concrete paved, etc)

- Reinforced concrete paved: concrete paved with reinforcement (or wire mesh)

- Natural surface: not paved and natural ground surface 
This criteria affects the operating capability of "terrain conductivity," "metal detector," "magnetic method," and "pipe and cable locator-inductive mode."

\section{Terrain conductivity, metal detectors, and magnetic method}

The "Terrain conductivity" and the "metal detectors" detect underground metallic objects by emitting an electromagnetic wave from the equipment and interpret the reflected signal from the ground. Magnetic method detects ferrous material by sensing magnetic field from the underground. Presence of reinforcements in the paved area reflects signals of the reinforcements back to the interpreting system of these methods; consequently, making it impossible to detect the underground utility that is below the reinforcements.

\section{Pipe and cable locator-inductive mode}

The "Pipe and cable locator-inductive mode" is also affected by the reinforcement embedded in the paved area because an induced signal also travels through the reinforcements. However, reinforcements are generally not electrically-continuous at each joining segment due to the mortar intrusion during the concrete placing. In addition, pipe and cable locator is usually recommended to start to locate underground utility at least $30 \mathrm{ft}(10 \mathrm{~m})$ apart from the transmitter to prevent aerial induction (Radiodetection 1994). Therefore, this method still can be used in this condition, having a possibility of detecting false signal from the reinforcements. The applicability of ground surface condition to designating methods is shown in Table 6.10.

Table 6.10. Applicability of Ground Surface Condition to Designating Methods

\begin{tabular}{|l|l|l|l|}
\hline \multirow{2}{*}{ Designating methods } & \multicolumn{3}{|c|}{ Applicability } \\
\cline { 2 - 4 } & \multicolumn{1}{|c|}{ Applicable } & \multicolumn{1}{c|}{ Inapplicable } & Neutral \\
\hline $\begin{array}{l}\text { Terrain conductivity, Metal } \\
\text { detector, Magnetic method }\end{array}$ & $\begin{array}{l}\text { Paved, natural } \\
\text { surface }\end{array}$ & $\begin{array}{l}\text { Reinforced } \\
\text { concrete paved }\end{array}$ & \\
\hline $\begin{array}{l}\text { Pipe and cable locator- } \\
\text { inductive mode }\end{array}$ & $\begin{array}{l}\text { Paved, natural } \\
\text { surface }\end{array}$ & & $\begin{array}{l}\text { Reinforced } \\
\text { concrete paved }\end{array}$ \\
\hline
\end{tabular}




\subsection{Inner State of Pipe/Conduit}

"Sonde insertion method" and "acoustic emission method" detect the location of utility by inserting a transmitter and generating a signal through the flowing material. Therefore, inner state of pipe/conduit plays an important role in selecting these methods. Inner state of pipe/conduit can be categorized into five different states as follows.

- Full with flowing material (a): pipe with full of flowing material such as water, gas and oil.

- Partially full with flowing material (b): pipe with partially full of flowing material such as sewer in gravity flow.

- Conduits full of cables (c): no space in conduit

- Full and empty conduit (d): Usually found in a duct bank system which contains many conduits - some of them empty and some of them occupied.

- $\quad$ Empty pipe or conduit (e): hollow or abandoned pipe or conduit.

\section{Sonde insertion method}

In order to apply "sonde insertion method," there must be a room for a sonde to move in the pipe or conduit. Therefore, "Partially full with flowing material or product”, "Full and empty pipe or conduit" and "Empty pipe or conduit" are superior condition for this method. "Full with flowing material or product" is also a possible condition for the method because sonde can be flowed down through the pipe but this should not be the first alternative because service of the pipe is disrupted. “Conduits full of cables” are inapplicable conditions for the method.

\section{Acoustic emission method}

The acoustic emission method is based on the pressure or flowing material to transport the sound wave along the pipe; thus, it cannot be used for conduit systems which contain electric or telecommunication cables and partially full pipes. Only "Full with flowing material" is applicable for this method. The applicability of inner state of pipe and conduit to designating methods is shown in Table 6.11. 
Table 6.11. Applicability of Inner State of Pipe and Conduit to designating methods

\begin{tabular}{|l|c|c|c|}
\hline \multirow{2}{*}{\multicolumn{1}{|c|}{ Designating methods }} & \multicolumn{3}{|c|}{ Applicability } \\
\cline { 2 - 4 } & Applicable & Inapplicable & Neutral \\
\hline Sonde insertion method & b, d, e & c & a \\
\hline Acoustic emission method & $\mathrm{a}$ & b, c, d, e & \\
\hline
\end{tabular}

\subsection{Soil Type}

As discussed in Chapter Three, soil type is directly related to the electrical conductivity, which greatly affects the propagation capacity of electromagnetic wave from the transmitter through the ground. High degree of soil conductivity impedes electromagnetic wave from traveling to the target object by scattering waves so that the results obtained are limited. This criterion includes five different entries based on their electrical conductivity.

- Highly conductive soil (1): Water saturated (wet) soil or soil where water table is above the utility, highly salty soil which is usually found in northern roadways in the United States where salt is used for ice melting, marine clays, tidal areas, etc (ASCE 2002)

- Clay dominated soil (2): usually includes quite amount of moisture, making it relatively high conductive.

- Silt dominated soil (3): usually found in topsoil, containing some amount of moisture, making it moderately conductive.

- Sand dominated soil (4): containing little amount of moisture, and hence is low conductive.

- Granular and compacted soil (5): usually found under the paved area, and having very low conductivity.

Figure 6.11 illustrates the range of soil conductivity of different soils. The soil of high degree of moisture content and high degree of electrolytes such as salt and ions maintains high electrical conductivity. "Terrain conductivity" and "GPR" are directly affected by this criterion (Anspach 2001). 


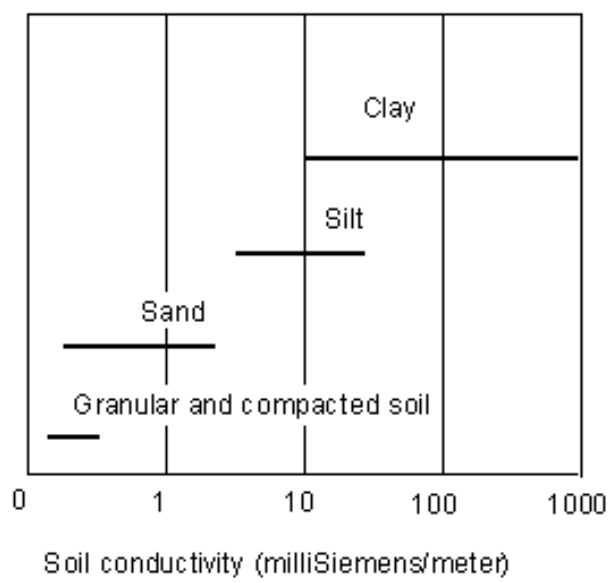

Figure 6.11. Soil Conductivity (Source: http://www.pdsinc.org)

\section{Terrain conductivity and GPR}

High conductivity of soil hinders the travel of the probing wave through the ground and disturbs the interpretation, but they are still used in practice with a high chance of no result or limited result. These methods operate more precisely when the soil provides low conductivity and high resistivity. The relationship between soil type and designating methods are shown in Table 6.12.

Table 6.12. Relationship between Soil Type and Designating Methods

\begin{tabular}{|l|c|l|c|}
\hline \multirow{2}{*}{ Designating methods } & \multicolumn{3}{|c|}{ Applicability } \\
\cline { 2 - 4 } & Applicable & Inapplicable & Neutral \\
\hline Terrain conductivity and GPR & $(3),(4),(5)$ & & $(1),(2)$ \\
\hline
\end{tabular}

\subsection{Depth of Utility}

Propagation depth of designating methods depends on various factors such as the subsurface soil condition, material property of target utility, dimension of utility and the capability of currently commercialized equipment. Since all of these factors are hardly to quantify, it is reasonable to determine the detectable range of depth of each designating method based on experts' opinion and manufacturer's technical reports. 
The detectable depth of electromagnetic methods is a function of the transmitter-to-receiver coil separation and the coil orientation (horizontal and vertical). Small coil separations, as in metal detectors and pipe and cable locators, may propagate 2 to 6 feet into the ground. Larger coil separations that tend to be very expensive and heavy can be used to detect conductive materials up to several hundreds feet deep (NGS, 2001). In practice, "Pipe and cable locator" equipment can typically designate underground utilities buried within 15 feet $(5 \mathrm{~m})$ from the surface for "Conductive mode" and within 6 feet $(2 \mathrm{~m})$ from the ground for "Inductive mode" because the electromagnetic energy is generated indirectly from the surface and for the "Passive mode," the detectable range is within 4.5 feet (1.5 m) (Willis 2001). "Metal detector" typically with small coil separation can detect metallic materials buried within 2 feet $(0.67 \mathrm{~m})$ from the surface.

"Sonde insertion method" is typical limited to within 15 feet $(5 \mathrm{~m})$ from the surface but if a special sonde with high power is applied, a utility buried in 60 feet $(18 \mathrm{~m})$ from the ground can also be designated. "E-line locator method" and "Tracing wire/metallic marking tape method" has the same range as "Pipe and cable locator-conductive mode" because that equipment is utilized for designating process. Currently developed terrain conductivity equipment can be used to detect utilities buried within 15 feet $(5 \mathrm{~m})$ below the surface in an ideal condition (ASCE 2002).

The detectable range of GPR depends on the frequency range used in the GPR instrument, the type and the moisture content of soil (USDOT 1999). In practice, the GPR is difficult to detect pipes of any size buried beyond six feet from the surface (ASCE 2001). The detectable depth of the magnetic method depends on the amount of magnetic material present and its distance from the sensor. In practice, locating depth ranges up to $10 \mathrm{ft}$ (Schonstedt 2001).

The "Acoustic emission method" can be divided into two different range of detectable depth according the type of utility. For gas pipe, utilities buried within $8 \mathrm{ft}(2.5 \mathrm{~m})$ from the surface are ideal for this method and for water pipe; utilities buried within $6.5 \mathrm{ft}(2 \mathrm{~m})$ can be designated by this method (Radiodetection 2001). Table 6.13 lists the ideal depth range for the use of each designating method. 
Table 6.13. Detectable Range of Depth of Designating Methods

\begin{tabular}{|l|l|l|}
\hline \multicolumn{1}{|c|}{ Designating methods } & \multicolumn{1}{|c|}{$\begin{array}{c}\text { Range of } \\
\text { detectable depth }\end{array}$} & \multicolumn{1}{|c|}{ Remarks } \\
\hline $\begin{array}{l}\text { Pipe and cable locator- conductive mode } \\
\text { (Low frequency) }\end{array}$ & $<15 \mathrm{ft}(5 \mathrm{~m})$ & \\
\hline $\begin{array}{l}\text { Pipe and cable locator- conductive mode } \\
\text { (High frequency) }\end{array}$ & $<15 \mathrm{ft}(5 \mathrm{~m})$ & \\
\hline Pipe and cable locator - inductive mode & $<6 \mathrm{ft}(2 \mathrm{~m})$ & \\
\hline Pipe and cable locator - passive mode & $<4.5 \mathrm{ft}(1.5 \mathrm{~m})$ & \\
\hline Sonde insertion method & $<15 \mathrm{ft}(5 \mathrm{~m})$ & $\begin{array}{l}\text { Practically applicable } \\
\text { Special sonde is required }\end{array}$ \\
\hline Tracing wire/metallic marking tape method & $<15 \mathrm{ft}(5 \mathrm{~m})$ & Buried in detectable depth \\
\hline E-line locator method & $<15 \mathrm{ft}(5 \mathrm{~m})$ & $\begin{array}{l}\text { Same as pipe and cable } \\
\text { locator }- \text { conductive mode }\end{array}$ \\
\hline Terrain conductivity & $<15 \mathrm{ft}(5 \mathrm{~m})$ & \\
\hline EMS & $<6.5 \mathrm{ft}(2 \mathrm{~m})$ & $\begin{array}{l}\text { Water pipe } \\
\text { Gas pipe }\end{array}$ \\
\hline Metal detector & $<2 \mathrm{ft}(0.67 \mathrm{~m})$ & Buried in detectable depth \\
\hline GPR & $<6 \mathrm{ft}(2 \mathrm{~m})$ & \\
\hline Magnetic method & $<10 \mathrm{ft}(3 \mathrm{~m})$ & \\
\hline Acoustic emission method & $<.5 \mathrm{~m})$ & \\
\hline
\end{tabular}

\subsection{Utility Diameter/Depth Ratio}

This criterion is practically used to evaluate the potential use of "GPR." It is a rule of thumb that from the ground surface to six feet of depth and very low conductivity and highly different impedance, a round utility can be imaged whose diameter in inches does exceed the depth in feet (ASCE 2002).

- $\quad$ Diameter (in) / Depth (ft) $>1$----- applicable to GPR

- Diameter (in) / Depth (ft) $<1$----- inapplicable to GPR 


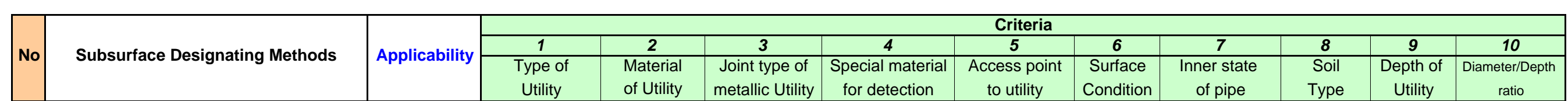

A. Electromagnetic methods

a. Cable and Pipe locators

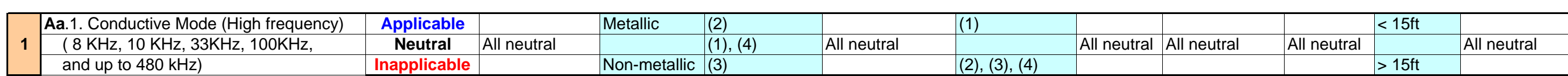

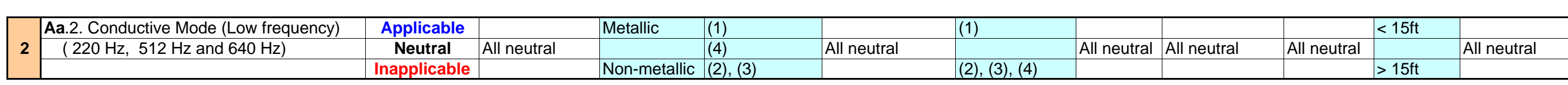

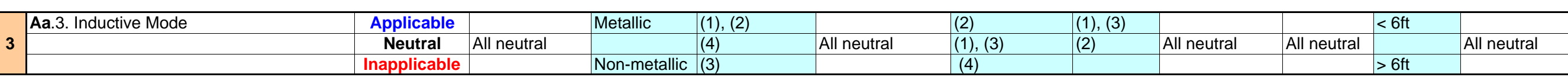

\begin{tabular}{|c|c|c|c|c|c|c|c|c|c|c|c|c|}
\hline Aa.4. Passive Method & Applicable & $\mathrm{E}$ & Metallic & & & $(3),(2$ & & & & & $<1$ & \\
\hline (Identifying 50/60 Hz frequency) & Neutral & Neutra & & All neutral & All neutral & (1), (2 & All neu & & II neutral & All neu & & All neutral \\
\hline
\end{tabular}

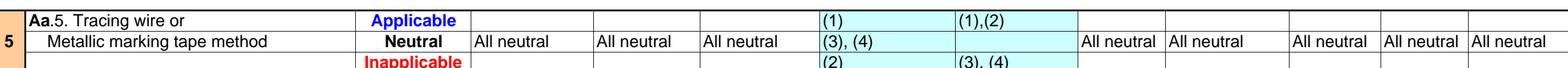

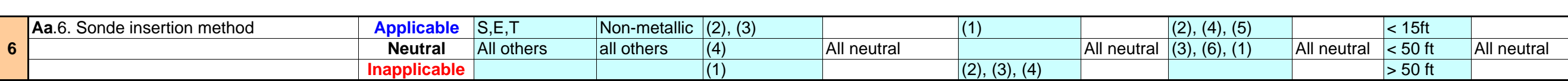

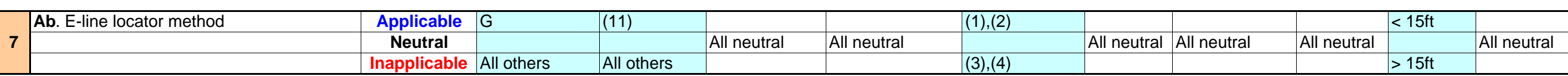

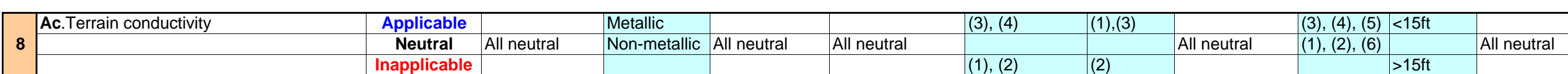

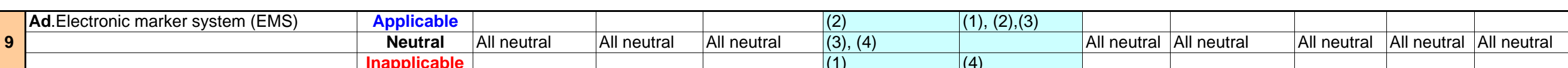

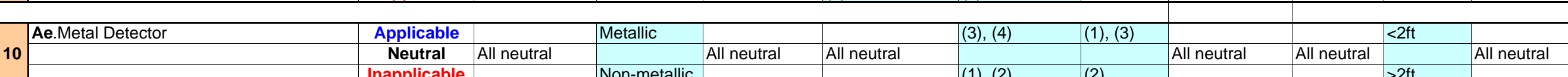

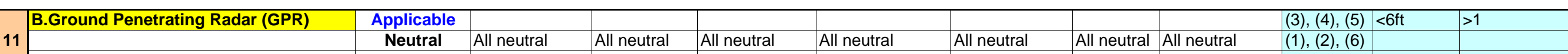

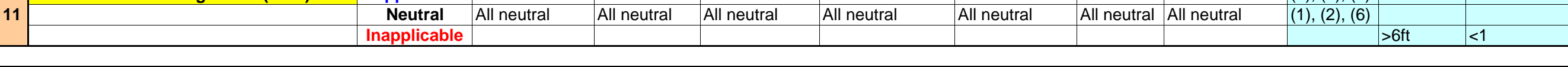

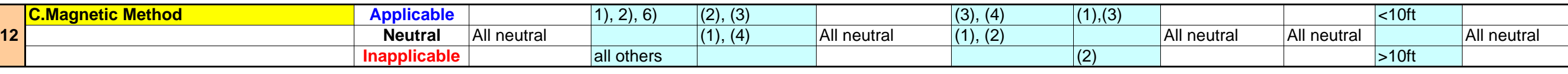

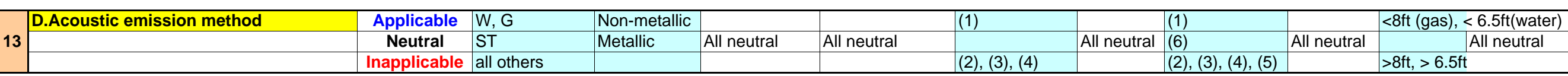

\section{Entries of each criterion}

$1>$ Type of Utility

er(W), Sewer(S), Steam(ST), Gas(G) Oil(O). Electrical(E) Telecomm

\section{2> Material of utility}

Metallic:

1) Steel, 2) Cast iron/ductile iron,

5) Metallic cable (Copper, aluminum, etc) cables in metallic conduit, 7) Fiber optic cable with metallic shie

8) Fiberglass reinforced plastic(FRP)

11) Plastics(PE, PVC, ABS, etc)

2) Fiber optic cable with metallic shield 13) Fiber optic cable with non-metallic shield

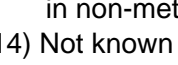

3> Joint type of metallic pipe 1) Electrically continuous

3) Electrically discontinuous, 4) Not known

$4>$ Special material for detection

1) Tracing wire or metallic marking tape

2) Electronic markers installed
3) Not installed, 4) Not known

5> Access point to utility

1) Presence of utility

2) Exactly known location of utility

4) None of the above

$6>$ Ground surface condition

1) Paved, 2) Reinforced concrete paved

7> Inner state of pipe/conduit

1) Full with flowing material

3) Conduits with full of cablesterial

3) Conduits with full of cables

) Empty pipe or conduit, 6) Not known

8> Soil Type

2) Clay doninative sol

3) Silt dominated soil

4) Sand dominated soil

5) Granular and compacted soil

$9>$ Depth of Utility (ft)

$10>$ Diameter(in) / Depth(ft) ratio 


\section{CHAPTER 7 \\ IMAGTECH - A DECISION TOOL FOR THE SELECTION OF APPROPRIATE DESIGNATING METHODS}

In this chapter, the IMAGTECH, a decision support system for the selection of appropriate designating methods are described. First, commonly used decision frameworks are examined and their underlying principles, applications and limitations are discussed. Next, specific features required of the decision tool in selecting appropriate designating methods are described. Next, the concept and application of Deterministic Parallel Selection Technique (DPST), which is used as a decision framework for the IMAGTECH, are explained. Finally, IMAGTECH is described in detail and validated with two case studies.

\subsection{Common Decision Tools}

Commonly used decision tools include decision trees, analytical hierarchy process (AHP), fuzzy logic, artificial neural network (ANN) and genetic algorithms (GA). Their underlying principles, applications and limitations are briefly discussed in this section.

\subsubsection{Decision Tree}

A decision tree is applicable to simple, straightforward and deterministic decisions. It consists of three types of nodes and arrows (Figure 7.1). Decision nodes (square) represent points at which a decision maker has to make a choice of one alternative from a number of possible alternatives. Chance nodes (big circle) represent points at which chance, or probability, plays a dominant role and reflect alternatives over which the decision maker has (effectively) no control. Terminal nodes (diamond) represent the ends of paths from left to right through the decision tree (Beasley 2001).

Arrows connect these nodes and assist the flow of decision. Once a decision tree is drawn based on the written or linguistic description of the problem, the solution procedure is quite 
straightforward (Beasley 2001). Because it is easy to use, the decision tree is utilized in a range of applications, such as drug testing, choosing a health plan, disease diagnostics, test marketing of new products, land acquisition, competitive bidding and so on (Lasdon 2001).

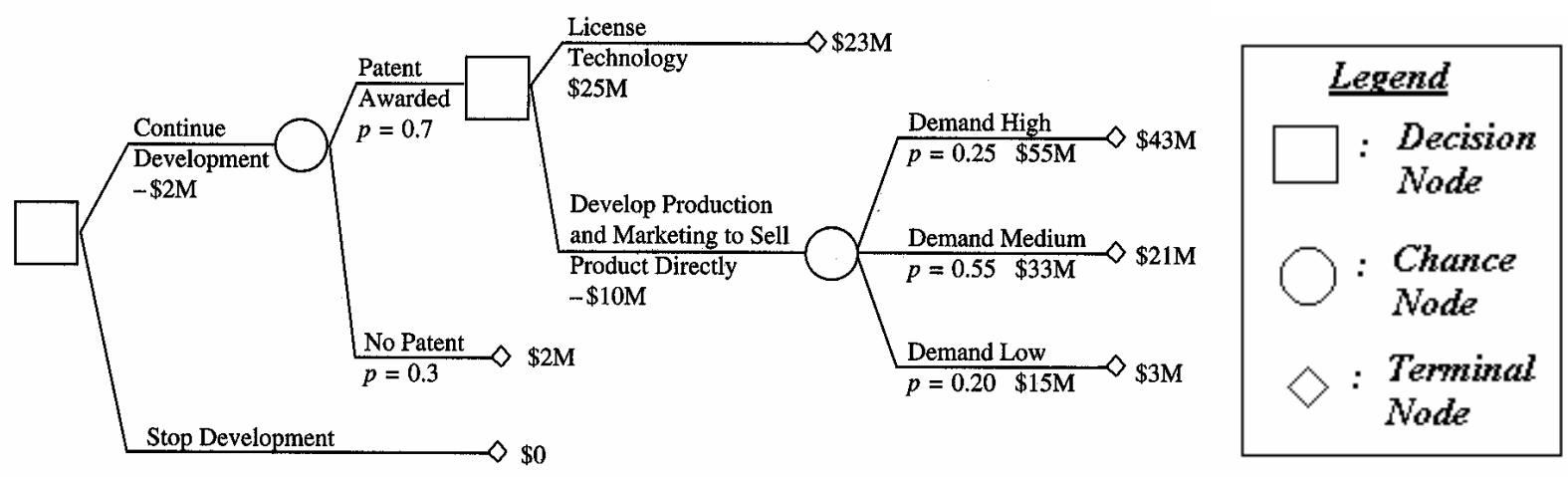

Figure 7.1. Research and Development Decision Tree (Clemens 1996)

However, one of the biggest shortcomings of the decision tree is that when the number of decision nodes becomes large, and each decision node has many alternatives, the decision tree gets "messy" (Clemens 1996) and becomes difficult to create and read. The decision tree is also difficult to use in intangible, subjective decisions due to its deterministic nature.

\subsubsection{Analytical Hierarchy Process (AHP)}

The Analytical Hierarchy Process was designed by Thomas L. Saaty as a decision making aid. The AHP is especially suitable for complex decisions that involve the comparison of decision factors that are difficult to quantify. It is based on the assumption that when people are faced with a complex decision, they try to solve the problem by clustering the decision elements according to their common characteristics.

It starts with the establishment of the overall hierarchy of the decision and then the making of pair-wise comparisons between each possible pair in each cluster as a matrix. This gives a weighting for each element within a cluster or level of the hierarchy and also a consistency ratio 
that is useful for checking the consistency of the data (Saaty 1980). The finalized hierarchy system decides the most appropriate alternative, which has the highest numeric value.

The AHP is widely used in many areas, such as economics, strategic management decisions, sociology, politics and engineering (Lee 2000). However, since the AHP is mainly designed for subjective decisions, and all factors (clusters) must be ranked in hierarchy, this method cannot be used in deterministic decisions or decisions where all factors are equally important. Moreover, AHP requires pair-wise comparisons of clusters as well as comparisons of possible pairs in each cluster; thus, the large number of clusters and pairs makes such comparisons unmanageable (Kelly 1996).

\subsubsection{Fuzzy Logic}

The fuzzy logic provides a simple way to draw definite conclusions from vague, ambiguous or imprecise information. In a sense, fuzzy logic resembles human decision making with its ability to work from approximate data and find precise solutions.

The simplified procedures of fuzzy logic are as follows. A set of input variables, which are usually imprecisely defined, such as "very tall," "strong," and so on, is fed into the fuzzy control system. The values of input variables undergo a process termed "fuzzification," which converts the input values into a range of numeric values from zero to one. Fuzzified inputs are evaluated against a set of production rules. Whichever production rules are selected will generate a set of outputs. Output data are "defuzzified" as distinctive output values (Yen 1995). Fuzzy logic has proven to be an excellent choice for many control system applications and for other areas such as fault and failure diagnosis, image processing, pattern classifying, traffic problems, collision avoidance, decision support, project planning, fraud detection and so on.

However, several drawbacks are innate in fuzzy logic. There is no inherent learning algorithm available. Thus, a trial and error or extended involvement of experts is required to identify "IfThen" rules and create membership functions of input and output variables to arrive at a desired output with requisite precision. 


\subsubsection{Artificial Neural Network (ANN)}

An artificial neural network is a computing system made up of a number of simple, highly interconnected processing elements, which processes information by its dynamic state response to external inputs. It is good at solving problems that are too complex for conventional technologies (e.g., problems that do not have an algorithmic solution or for which an algorithmic solution is too complex to be found) (PNNL 2001).

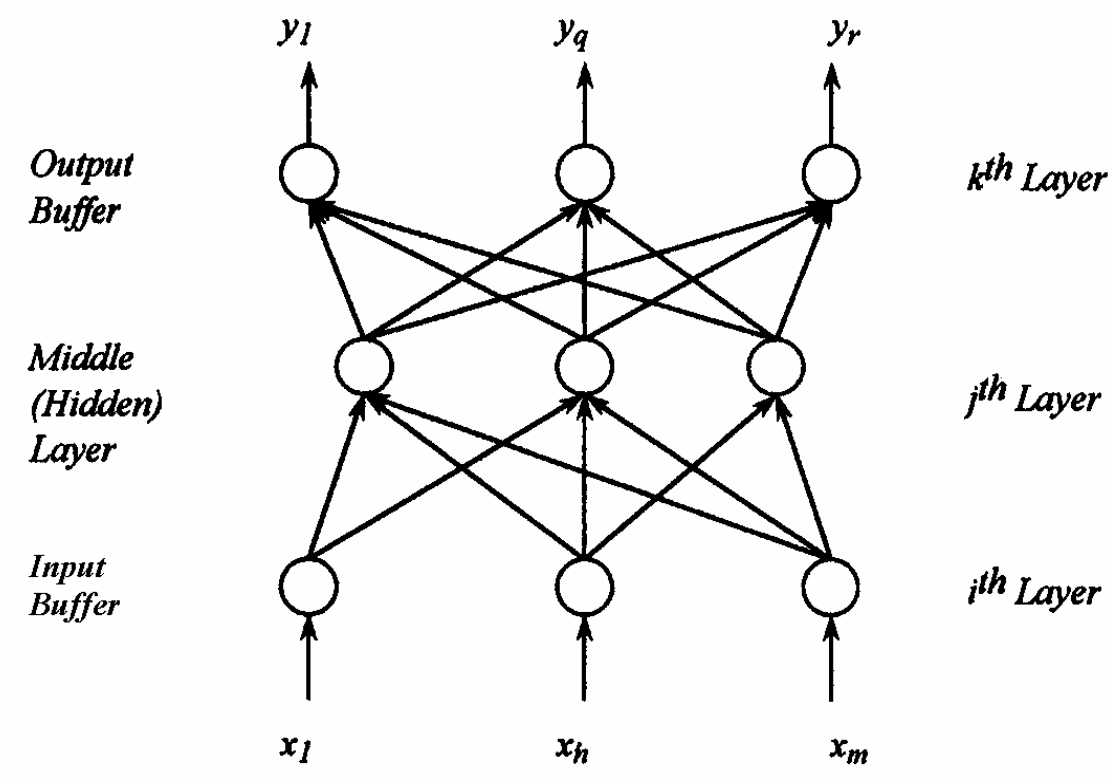

Figure 7.2. Architecture of Artificial Neural Network (Tsoukalas and Uhrig 1997)

The ANN consists of at least three layers. They include the input, hidden, and output layers designated by $i^{\text {th }}, j^{\text {th }}$ and $k^{\text {th }}$ layers in Figure 7.2. The input layer presents data to the network. The top layer is the output layer, which presents the output response to a given input. The other layer or layers are called hidden layers, which receive weighted input data from the input layer and send weighted decisions to the output layer. The weights become reliable as the user trains the system by providing sufficient data. 
The ANN is a good pattern recognition engine and robust classifier with the ability to generalize in making decisions about imprecise input data. It also offers ideal solutions to a variety of classification problems, such as speech, character and signal recognition, as well as functional prediction and system modeling where the physical processes are not understood or are highly complex (PNNL 2001).

The ANN, in spite of its extraordinary usefulness, has relatively limited capabilities. The ANN must be trained using available data, tested, and put into use. All it can do is recall an output when presented with an input consistent with the training data (Tsoukalas and Uhrig 1997). Therefore, the ANN may not be successfully used without a sufficient quantity of training data.

\subsubsection{Genetic Algorithm (GA)}

Genetic algorithm is a kind of evolutionary computing, inspired by Darwin's theory about evolution (Obitko 1998). The primary purpose of using GA is optimization (Tsoukalas and Uhrig 1997). The GA starts with a set of solutions (represented by chromosomes) called a population. Solutions from one population are taken and used to form a new population. This is motivated by the hope that the new population will be better than the old one. Solutions that are selected to form new solutions (offspring) are selected according to their fitness-the more suitable they are, the more chances they have to reproduce. This is repeated until an optimal condition (for example, number of populations or improvement of the best solution) is satisfied (Obitko 1998). The GA is being used in a wide variety of optimization tasks and other areas, such as evolutionary aspects of social systems, the development of bidding strategies, strategy planning, scheduling, the emergence of economic markets, and machine learning.

Although the GA is a powerful decision tool due to its automated problem solving ability, it is not suitable as knowledge based decision tool. This tool solves a problem by generating a new population from the previous population, not by retrieving data from a database or analyzing the input data based on the accumulated knowledge. 


\subsection{Features Required for a Decision Tool in the Study}

In a process of selecting the most appropriate designating method, four major features were identified to be vital. They are: (1) knowledge-based decision, (2) crisp and tangible input values, (3) parallelism among criteria, and (4) possibility of alternatives.

(1) Knowledge-based decision: Since the required tool has to choose a technically applicable designating method based on given site conditions, technical information and experts' opinion about each designating method are basic requirements for the decision tool. The data must be well organized and classified in order to establish key criteria.

(2) Crisp and tangible input values: Input values for the decision tool must be very clear and crisp in their definition. For instance, entries of criterion "Material of utility" in Chapter Five include "steel," "cast iron," "concrete," etc. They are tangible values, not ambiguous, such as "strong," "big," and so on. Consequently, there is no need for a decision tool dealing with intangible input values.

(3) Parallelism among criteria: Established criteria in Chapter Five do not include any subjective criteria that might be hierarchically ranked. For instance, both the "Material of utility" criterion and "Depth of utility" criterion have equal effect on the selection of appropriate designating method. Moreover, since each criterion has many entities, the common algorithm "If-Then" rules are not easily applicable to the decision process. Therefore, hierarchical decision tools and "If-Then" rule-based decision tools may not be appropriate in this case.

(4) Possibility of alternatives: It is very common that when the first attempted designating method fails, the second or the third alternative is tried to designate subsurface utilities. Therefore, the decision tool must be able to provide not only the most appropriate method, but also second or third alternatives. 


\subsection{Analysis of Decision Tools}

Comparison of five decision tools with respect to the four features was performed. Table 51 displays decision tools versus features of the required decision tool for the study.

Table 7.1. Analysis of Five Decision Tools

\begin{tabular}{|c|c|c|c|c|}
\hline Decision tools & $\begin{array}{c}\text { Knowledge } \\
\text { base }\end{array}$ & $\begin{array}{c}\text { Crisp \& } \\
\text { tangible input } \\
\text { value }\end{array}$ & $\begin{array}{c}\text { Parallelism among } \\
\text { criteria }\end{array}$ & $\begin{array}{c}\text { Possibility of } \\
\text { alternatives }\end{array}$ \\
\hline Decision tree & - & - & No & - \\
\hline AHP & - & No & No & - \\
\hline Fuzzy Logic & $=$ & No & No & - \\
\hline ANN & - & - & - & - \\
\hline GA & No & - & - & - \\
\hline
\end{tabular}

For instance, AHP is clearly not applicable to parallel criteria because all criteria must be ranked hierarchically. It is also not applicable to crisp and tangible input values, because it is designed to be used in subjective, not quantifiable, input values. Based on Table 7.1, it appears that ANN may be suitable. However, ANN requires sufficient data to train the system, which is not available for this study.

\subsection{Deterministic Parallel Selection Technique (DPST)}

Since the five decision tools analyzed are in some way inappropriate as a decision tool for the study, a new tool, namely Deterministic Parallel Selection Technique (DPST), was developed to meet the basic requirements. In this section, the concept behind the DPST and its application are discussed. 


\subsubsection{Concept of DPST}

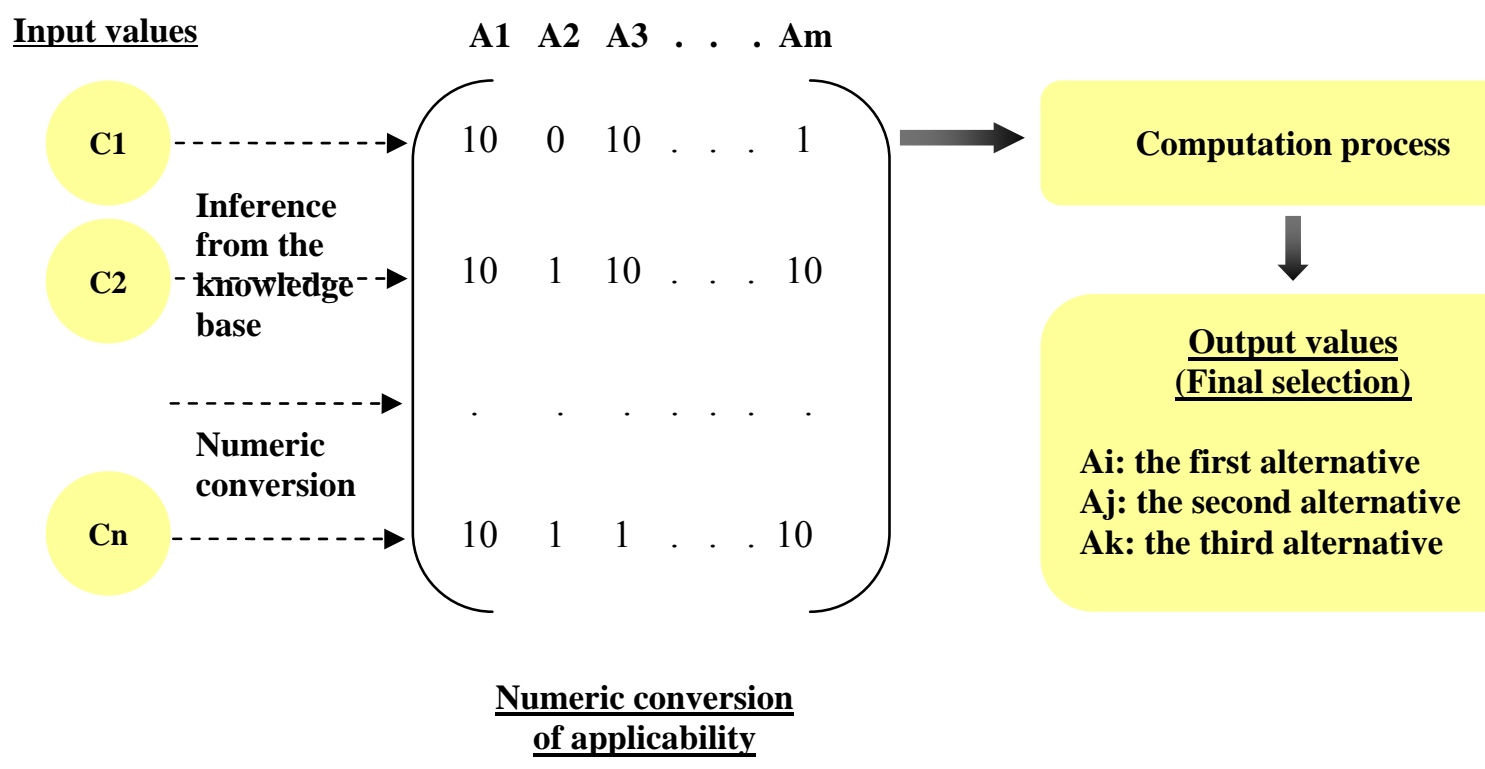

$\mathrm{Cn}$ : Selected entry in the criterion number $\mathrm{n}$

Am: Candidate imaging technology number $\mathrm{m}$

Figure 7.3. Schematic Diagram of DPST

A technique, named Deterministic Parallel Selection Technique (DPST), was developed as a decision framework. This framework satisfies the four major features required of decision tool for imaging buried utilities. The DPST works as an inference engine. When input values are provided, the DPST evaluates the input data to determine the applicability to each imaging technology based on the established knowledge base. The next process involves the conversion of values of linguistic applicability to numeric values. A computational process using the obtained numeric values discard inappropriate methods, and rank the selected appropriate imaging technologies. A schematic diagram of the DPST is illustrated in Figure 7.3.

\subsubsection{Application of DPST}

A simplified example is employed to discuss the different steps in this technique. Suppose three different imaging technologies A1, A2, A3 are available, and there are four criteria $(\mathrm{C} 1, \mathrm{C} 2, \mathrm{C} 3$ and C4) affecting the selection of appropriate imaging technologies. The three imaging 
technologies are A1: Pipe and cable locator - conductive mode with high frequency, A2: Sonde insertion method, and A3: Acoustic emission method. The four criteria include C1: type of utility, C2: material of utility, C3: type of joint in the metallic utility, and C4: access point to utility. Suppose each criterion consists of only three or four entries, as shown in Figure 7.4.

\begin{tabular}{|c|c|c|c|c|}
\hline \multicolumn{2}{|c|}{ Imaging Technologies } & \multirow{2}{*}{ 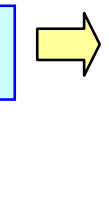 } & \multirow{2}{*}{\multicolumn{2}{|c|}{$\begin{array}{l}\text { A1. Pipe and cable locator - conductive } \\
\text { mode (high frequency) } \\
\text { A2. Sonde insertion method } \\
\text { A3. Acoustic emission method }\end{array}$}} \\
\hline \multicolumn{2}{|l|}{ Criteria } & & & \\
\hline $\begin{array}{l}\text { C1. Type of } \\
\text { utility }\end{array}$ & C2. & rial of & $\begin{array}{l}\text { C3. Type of joint } \\
\text { in the metallic }\end{array}$ & $\begin{array}{l}\text { C4. Access point } \\
\text { to utility }\end{array}$ \\
\hline $\begin{array}{l}\text { - Water pipe, } \\
\text { - Sewer pipe, } \\
\text { - Gas pipe, } \\
\text { - Not known }\end{array}$ & $\begin{array}{l}- \text { Stee } \\
- \text { Cas } \\
\text { - PE } \\
\text { (Poly } \\
\text { - Not }\end{array}$ & ene), & $\begin{array}{l}\text { - Electrically } \\
\text { continuous, } \\
\text { - Electrically } \\
\text { semi-continuous } \\
\text { - Not Known }\end{array}$ & $\begin{array}{l}\text { - Presence of } \\
\text { utility, } \\
\text { - Exact location of } \\
\text { the utility is known, } \\
\text { - None of the above }\end{array}$ \\
\hline
\end{tabular}

Figure 7.4. Simplified Example for Application of DPST

First, the entries of criteria that are applicable to each imaging technology must be identified as shown in Table 7.2. According to Table 7.2., A3: the acoustic emission method operates effectively in a condition when the type of a utility is water pipe or gas pipe, when the material of utility is polyethylene (PE), and a physical access point to the utility is provided in the vicinity. Hence these conditions are deemed "appropriate" for acoustic emission method. However, acoustic emission method is not applied to the sewer pipe or if there is no utility present in the vicinity. "Neutral" signifies that the entry in the criterion exerts no influence on the selection of the relevant imaging technology. Once the identification of applicability (knowledge base) is completed, the collected information about the site conditions is provided to the DPST as input values.

Suppose the area where utility locating is to be performed has the following characteristics. The utility is a water pipe made of cast iron which has a bonding jumper installed (electrically continuous joints), and there is a fire hydrant in the vicinity (presence of utility). 
Table 7.2. Identification of Applicability of Entries to Each Imaging Technology

\begin{tabular}{|c|c|c|c|c|c|}
\hline $\begin{array}{l}\text { Criteria } \\
\text { Imaging technologies }\end{array}$ & Applicability & $\begin{array}{l}\text { C1. Type } \\
\text { of Utility }\end{array}$ & $\begin{array}{c}\mathrm{C} 2 . \\
\text { Material of } \\
\text { Utility }\end{array}$ & $\begin{array}{l}\text { C3. Joint of } \\
\text { Metallic } \\
\text { pipe }\end{array}$ & $\begin{array}{l}\text { C4. Access } \\
\text { point to } \\
\text { utility }\end{array}$ \\
\hline \multirow{3}{*}{$\begin{array}{l}\text { A1. Pipe and cable } \\
\text { locator - conductive } \\
\text { mode with high } \\
\text { frequency }\end{array}$} & Applicable & & ST, CI & $\mathrm{EC}, \mathrm{ESC}$ & $\mathrm{P}$ \\
\hline & Neutral & $\begin{array}{c}\mathrm{W}, \mathrm{S}, \mathrm{G}, \\
\mathrm{NK}\end{array}$ & NK & NK & \\
\hline & Inapplicable & & $\mathrm{PE}$ & & $\mathrm{E}, \mathrm{N}$ \\
\hline \multirow{3}{*}{$\begin{array}{l}\text { A2. Sonde insertion } \\
\text { method }\end{array}$} & Applicable & $\mathrm{S}$ & $\mathrm{PE}$ & ESC & $\mathrm{P}$ \\
\hline & Neutral & $\mathrm{W}, \mathrm{G}, \mathrm{NK}$ & $\begin{array}{c}\text { ST, CI, } \\
\text { NK }\end{array}$ & NK & \\
\hline & Inapplicable & & & $\mathrm{EC}$ & $\mathrm{E}, \mathrm{N}$ \\
\hline \multirow{3}{*}{$\begin{array}{l}\text { A3. Acoustic emission } \\
\text { method }\end{array}$} & Applicable & $\mathrm{W}, \mathrm{G}$ & $\mathrm{PE}$ & & $\mathrm{P}$ \\
\hline & Neutral & NK & $\begin{array}{l}\mathrm{ST}, \mathrm{CI}, \\
\mathrm{NK}\end{array}$ & $\begin{array}{l}\text { EC, ESC, } \\
\text { NK }\end{array}$ & \\
\hline & Inapplicable & $\mathrm{S}$ & & & $\mathrm{E}, \mathrm{N}$ \\
\hline
\end{tabular}

(W: water pipe, S: Sewer pipe, G: Gas pipe, ST: Steel, CI: Cast iron, PE: Polyethylene, NK: Not Known, EC: Electrically continuous, ESC: Electrically semi-continuous, P: Probable Presence of utility in the vicinity, E: Exact Location of utility is known)

From Table 7.2 (knowledge base), the linguistic applicability of input values to each imaging technology can be established in a matrix as shown in Figure 7.5. These linguistic values are converted to numeric values based on the following rules.

Applicable: 10

Neutral: 1

Inapplicable: 0

$\underline{\text { Input values }}$

A1 A2 A3

A1 A2 A3

C1: water
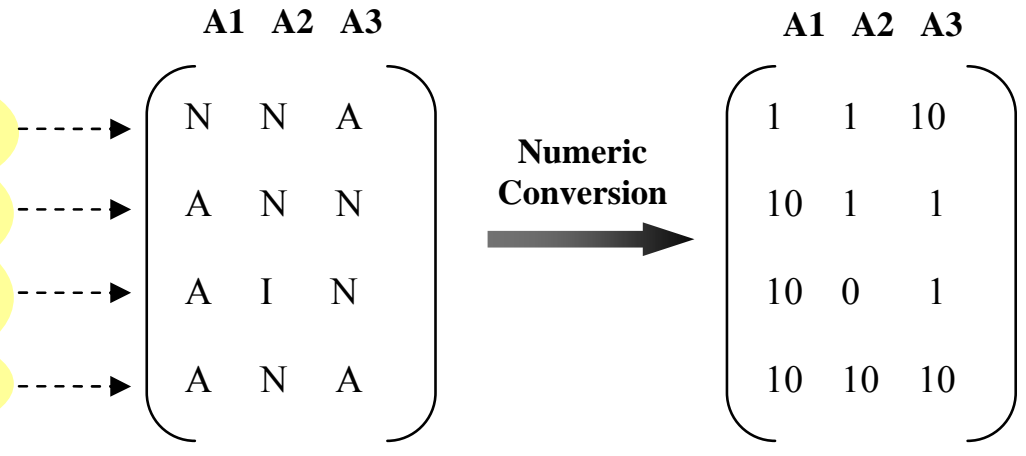

Linguistic matrix

$\underline{\text { Numeric Matrix }}$

A: Applicable, N: Neutral and I: Inapplicable

Figure 7.5. Numeric Conversion of Linguistic Applicability 
The converted numeric matrix is also shown in Figure 7.5. The numeric matrix is used to calculate the appropriateness and the reliability of imaging technologies through the following steps.

\section{Step 1: Multiplication of values in columns}

The numeric values in each column in the numeric matrix are multiplied with each other to create a step 1 matrix of one row. The resulting value of multiplication is always a value of 0 or $10^{\mathrm{x}}$ since the multiplication is a combination of 0,1 and 10 .

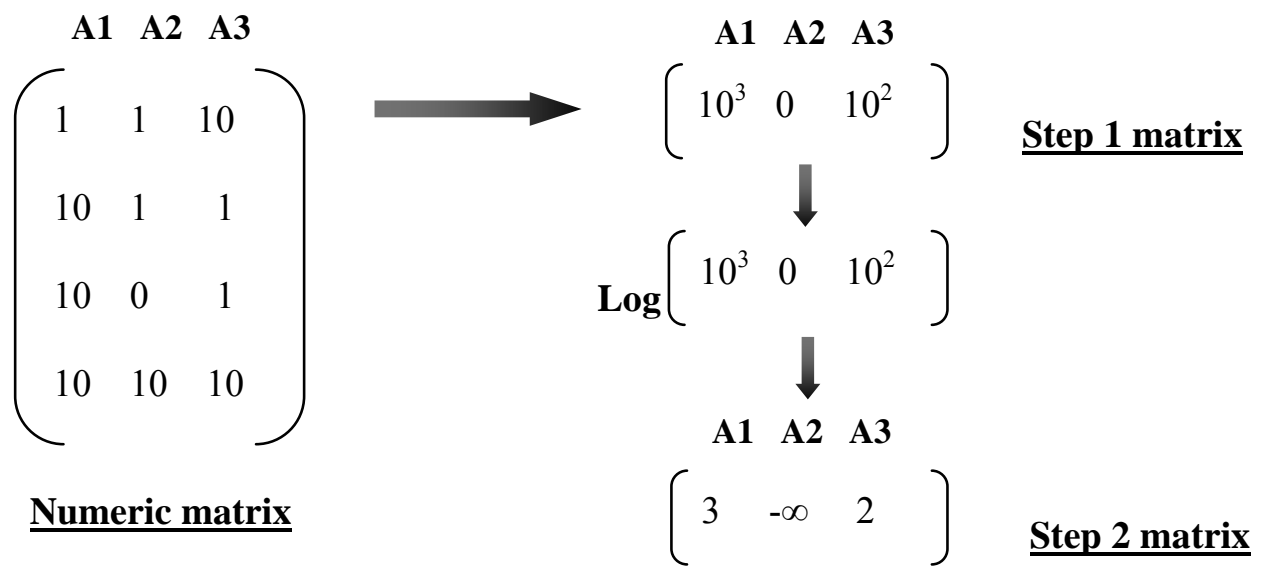

\section{Figure 7.6. Step 1 and Step 2 Matrices}

\section{Step 2: Step 2 matrix}

The logarithm of the step 1 matrix with respect to a base 10 produces a step 2 matrix in which matrix elements take the exponent numbers in the step 1 matrix. The number in the resultant matrix reveals the number of applicable conditions for each imaging technology. Infinity implies that at least one inapplicable condition is selected.

\section{Step 3: Maximum number of applicable conditions for the imaging technology}

Table 5, which works as a knowledge base, classifies imaging technologies based on the applicability of the entry of criterion. The total number of criteria which include "applicable" conditions for the imaging technology indicates the number of criteria for its optimal operating circumstances. As shown in Figure 7.7, Table 7.2 can be used to create a new matrix (step 3 matrix) in which each element corresponds to the number of criteria for optimal operating conditions. 


\section{Step 4: Selection of appropriate imaging technologies}

The numbers in the step 2 matrix represent the number of applicable conditions selected for the imaging technology. The outcome of dividing the step 2 matrix by the step 3 matrix determines the appropriateness of the imaging technology. The closer this outcome is to 1 , the greater the appropriateness of the imaging technology for the specified site conditions.
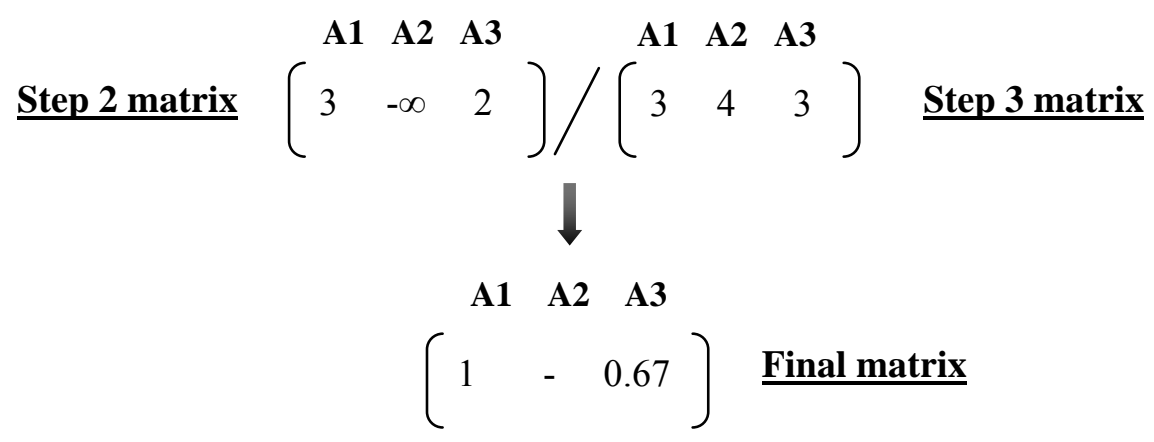

\section{Reliability A1: $100 \%$ Index (RI): A2: - \\ Final decision: A1: the first alternative \\ A3: $67 \%$ \\ A3: the second alternative}

\section{Figure 7.7. Step 4: Selection of Appropriate Imaging Technologies}

In this study, reliability index (RI) indicates the level at which input information supports the use of the imaging technology. This index is a percentage value of each imaging technology in the final matrix.

$$
\text { RI }(\%)=\text { the value of each technology in the final matrix } \times 100
$$

The most appropriate method and the other alternatives can be determined by ranking the reliability of each imaging technology. In this example with four criteria and three technologies, the first alternative is A1: pipe and cable locator - conductive mode with high frequency with $100 \%$ RI which implies that all selected entries in criteria are appropriate conditions for the use of this method. The second alternative is A3: Acoustic emission method with 67\% RI.

\subsection{Main Algorithm of the IMAGTECH}

The established criteria and the determined applicability of each entry to each designating method in Chapter Four are used as a knowledge database, which is stored in the memory area in the application. When the user selects or inputs data at input screens, which consist of one pre- 
step screen, five sequential selection/input screens and a final summary screen of input data, the application stores input data as numeric numbers converted based on the knowledge database for each designating method in a temporary memory area of the computer.

Once the user completes and confirms the input data, the prototype DPST evaluates the applicability of each designating method by multiplication of earned values from each criterion. Next, the DPST discards inapplicable methods, and calculates and ranks the level of reliability of applicable methods to suggest the best appropriate method, band the first and the second alternatives. This procedure is shown in Figure 7.8 


\section{STEP}

INPUT ON THE

SCREEN

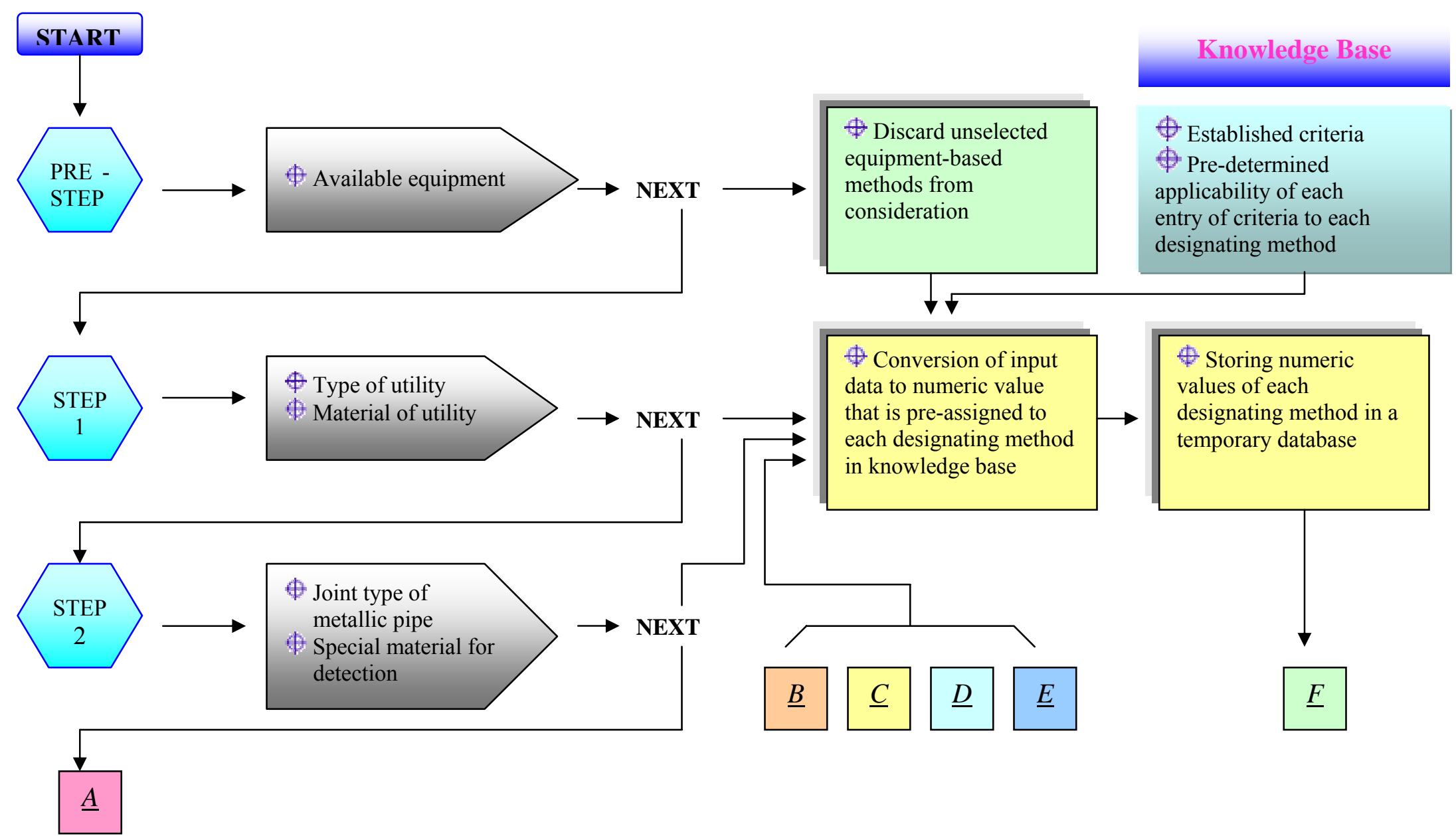

\section{INTERNAL PROCESS}

designating method in a

temporary database 


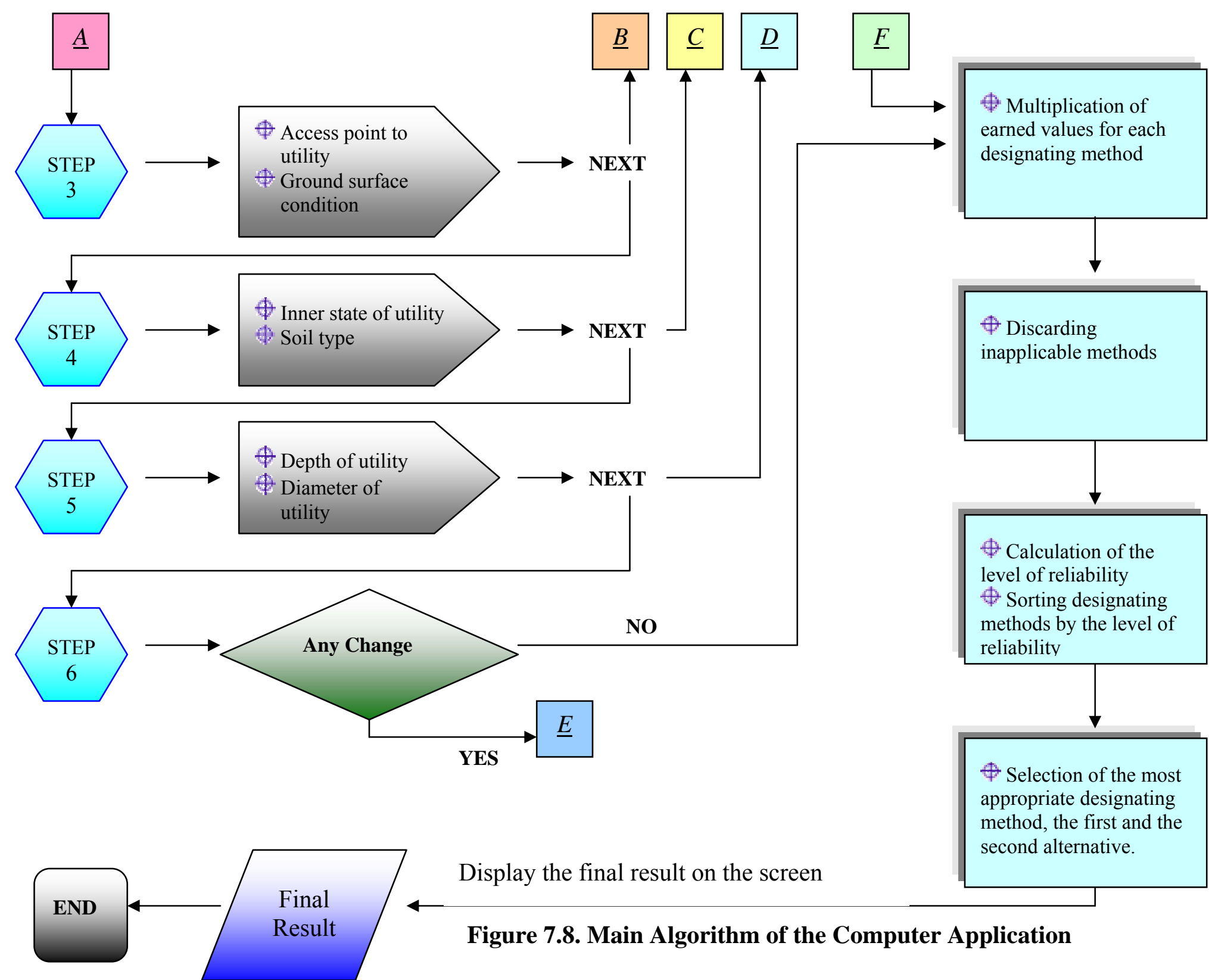




\subsection{IMAGTECH}

\subsubsection{Initial Screen and Pre-Stage}

When a user runs the program named "IMAGTECH.EXE," the initial screen is displayed as shown in Figure 7.9. By clicking on the "START" button, the user embarks on the decision making process for selecting the most appropriate designating method and alternative designating methods for a proposed project. The description of IMAGTECH and the program are accessible through the website of "Emerging Construction Technologies" (http://rebar.ecn. purdue.edu/utilities/index.htm).

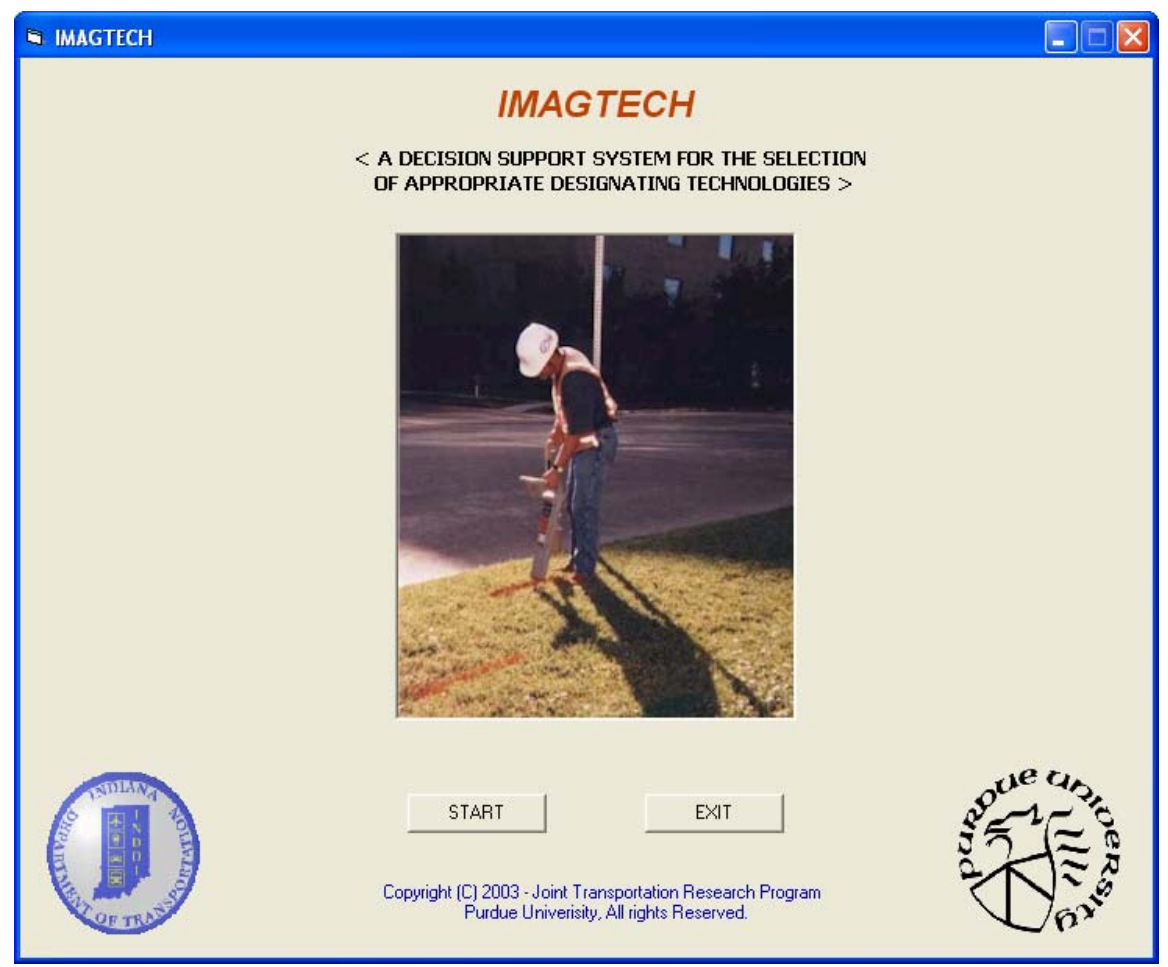

Figure 7.9. Initial Screen

The first phase is a pre-stage screen (Figure 7.10). In this screen, the user is requested to select currently available equipment among ten different types of equipment that are practically used for utility designation purpose in industry. The user can click checkboxes that are on the left side of the equipment or he/she can click the "CHECK $A L L$ " checkbox to select all the equipment. By 
selecting specific equipment, the user interacts the program to consider only those methods in the decision making process.

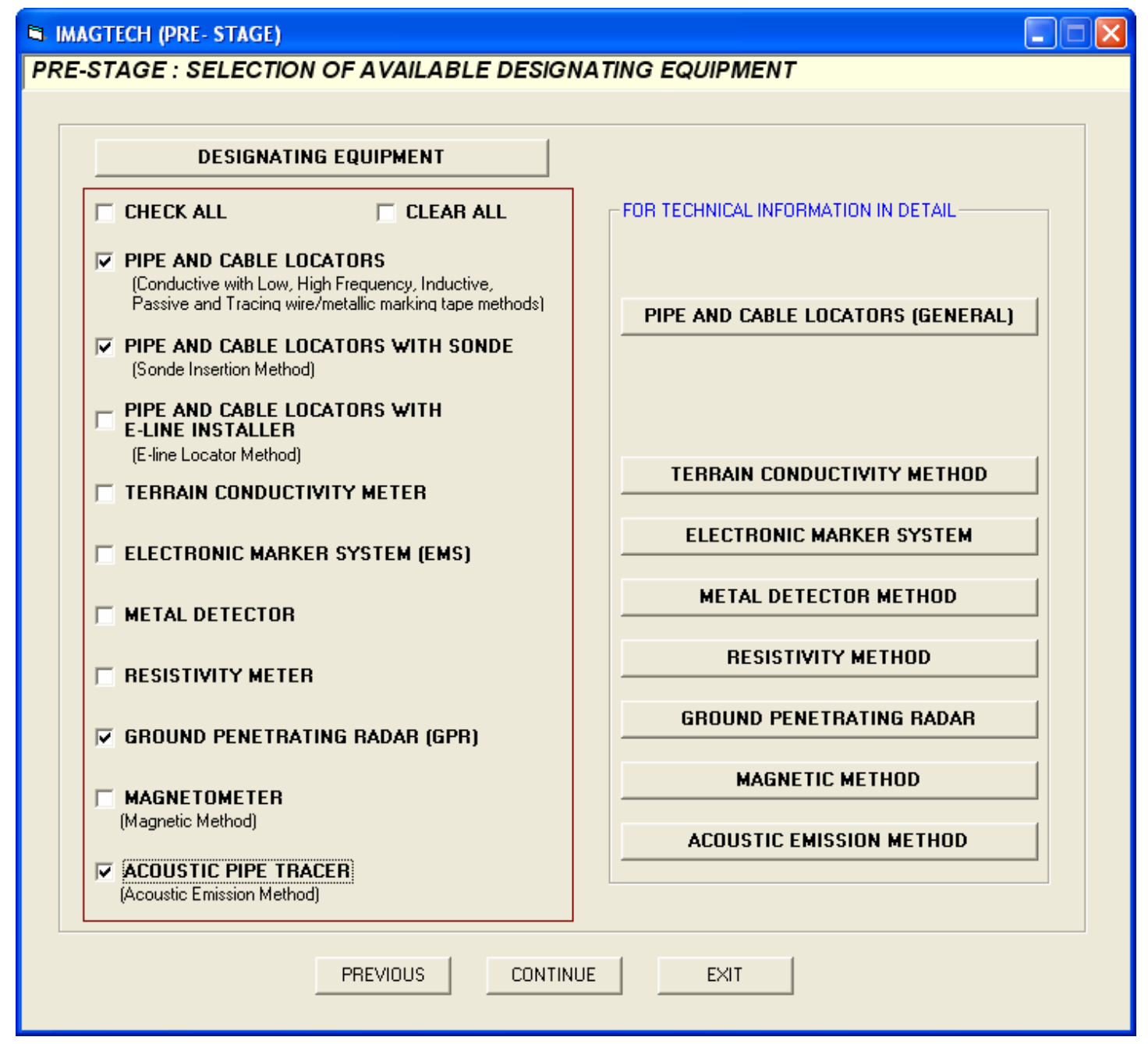

Figure 7.10. Pre-Stage Screen

A list of the different methods is displayed on the right side with a title, "FOR TECHNICAL INFORMATION IN DETAIL." A click on the button of each method leads to a website that contains the theory and application of the method. For instance, when the user clicks on "Acoustic Emission Method," the application opens the "Internet Explorer" program and accesses the specified website (Figure 7.11). 
In order to use this function, the user of the application must have an Internet Service Provider (ISP) and he/she must have Internet Explorer (IE) 4.0, or later, installed on his/her Personal Computer (PC), because the control uses IE to interact with the Internet.

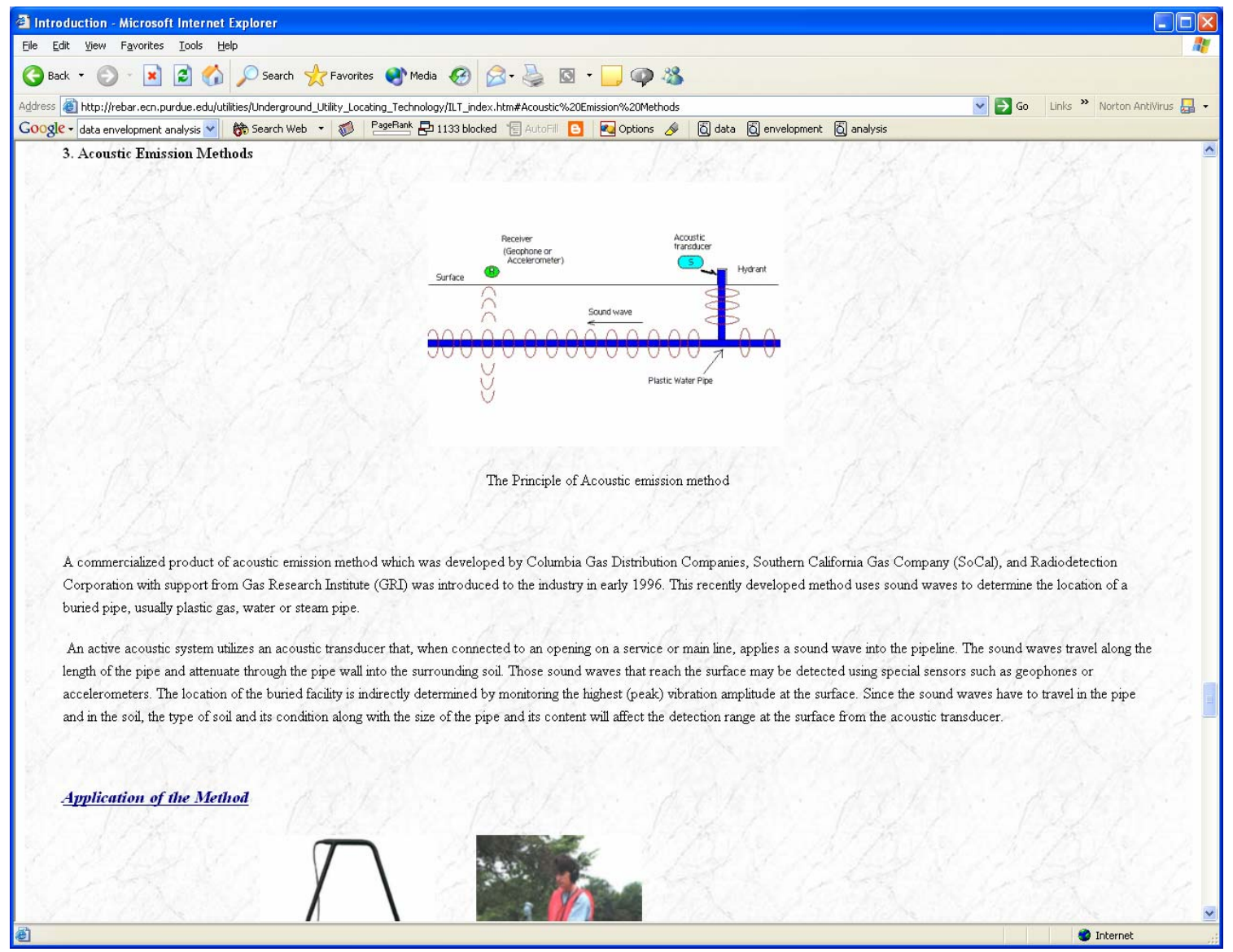

Figure 7.11. Connected Internet Page (Terrain Conductivity Method)

However, this is not a major encumbrance due to the wide acceptance of the Internet and World Wide Web (WWW) by almost every company and individual. The user can proceed to the next stage by clicking the "Continue" button. If no equipment was chosen in this stage, the application warns the user to select at least one type of equipment in order to proceed to the next step (Figure 7.12). The "Previous" button and the "Exit" button will take the user to the previous screen and allows the user terminate the program. 


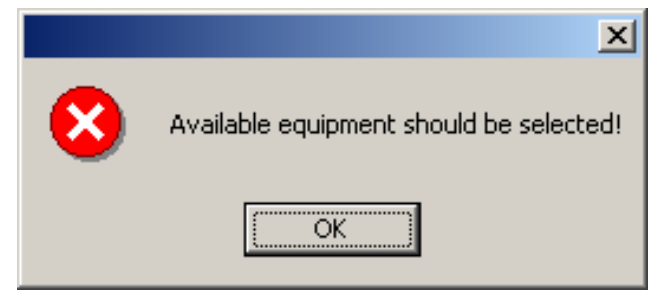

Figure 7.12. Warning Message

\subsubsection{Step 1: Type of Utility \& Material of Utility}

The Step 1 screen is used for the selection of the type of utility and the material of the utility to be designated. If the user clicks one type of utility, the range of the material typically used for the construction of the utility is specified.

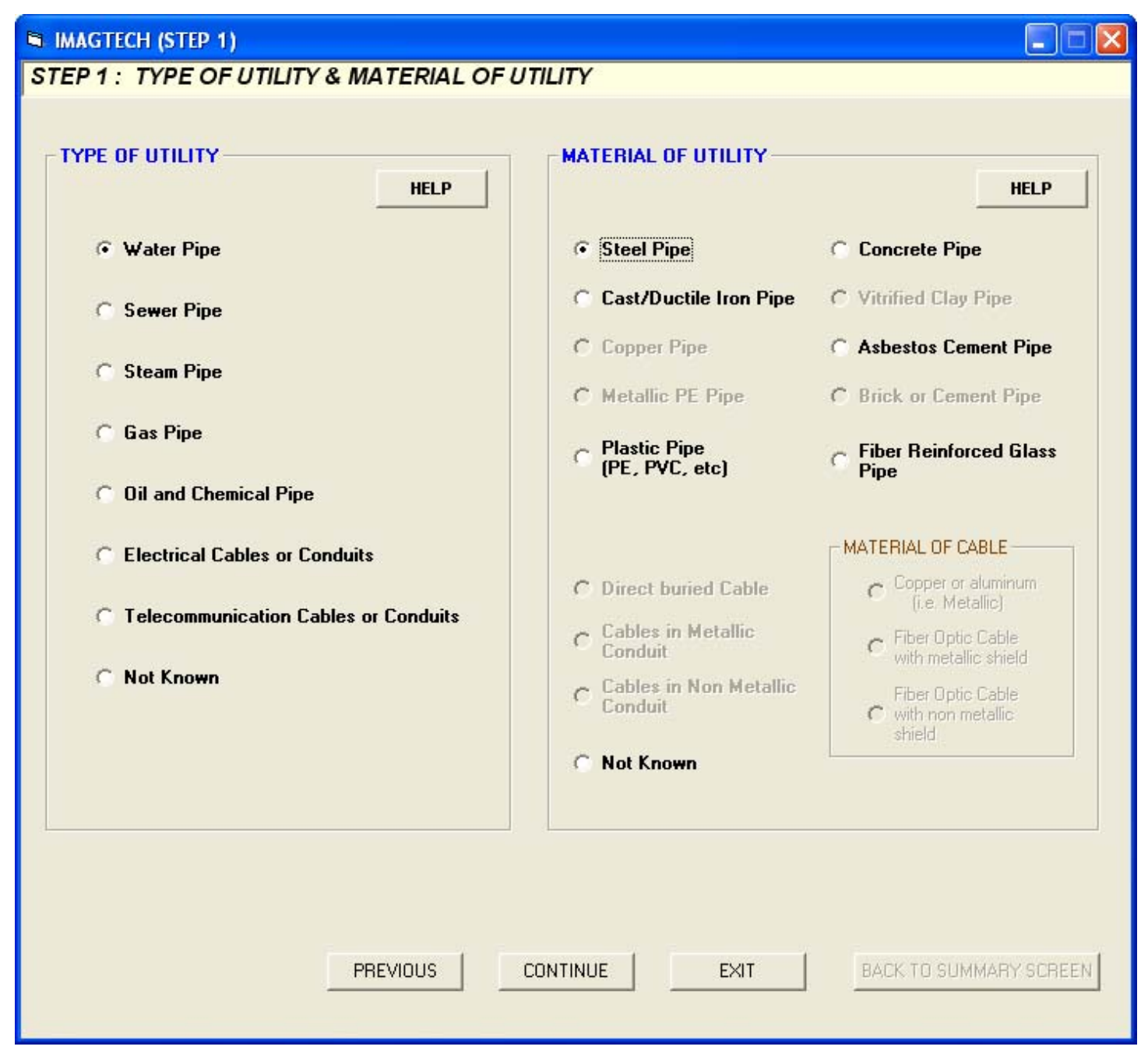

Figure 7.13. Step -1 Screen: Type of Utility \& Material of Utility 
For instance, if a "Water Pipe" is selected, then the computer application activates option buttons for materials used for water pipe, such as "Steel pipe," "Cast/Ductile Iron pipe," "Concrete pipe," "Plastic pipe," "Fiber Reinforced Glass pipe," and "Not Known" and disables option buttons for all other types of material (Figure 7.13). The click on the "Continue" button takes the user to the next step and instructs the program to save the input data in temporary memory for future use. If the user clicks the "Continue" button without selecting any entry in each category, the application warns the user with a message box similar to that shown in Figure 7.12.

The "HELP" button that is located on the right upper side at each category frame is designed for the user who is not familiar with each entry of the criterion. A click on this button will open a "help" screen (Figure 7.14), which contains detail information about the each entry.

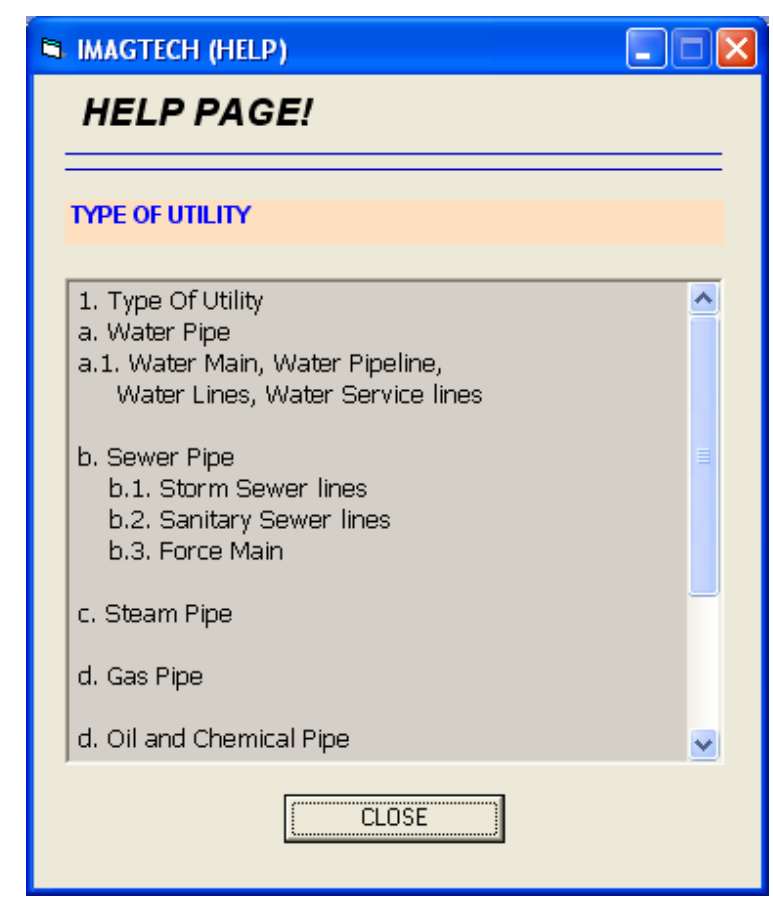

Figure 7.14. Help Screen for Material of Utility

The "Previous" button and the "Exit" button return the user to the previous page and allow the user to terminate the program. The "Back to Summary Screen " button is not activated at this stage. This is to prevent the user from clicking the button by accident. This button is only enabled when the user comes back to this page again after he/she clicks the "Change" button in 
the step six screen ("Summary of Input Data") in order to modify the previously saved input data. Once the change is performed, the user can go back to the summary page directly by clicking this button.

\subsubsection{Step 2: Joint Type of Metallic Pipe \& Special Material for Detection}

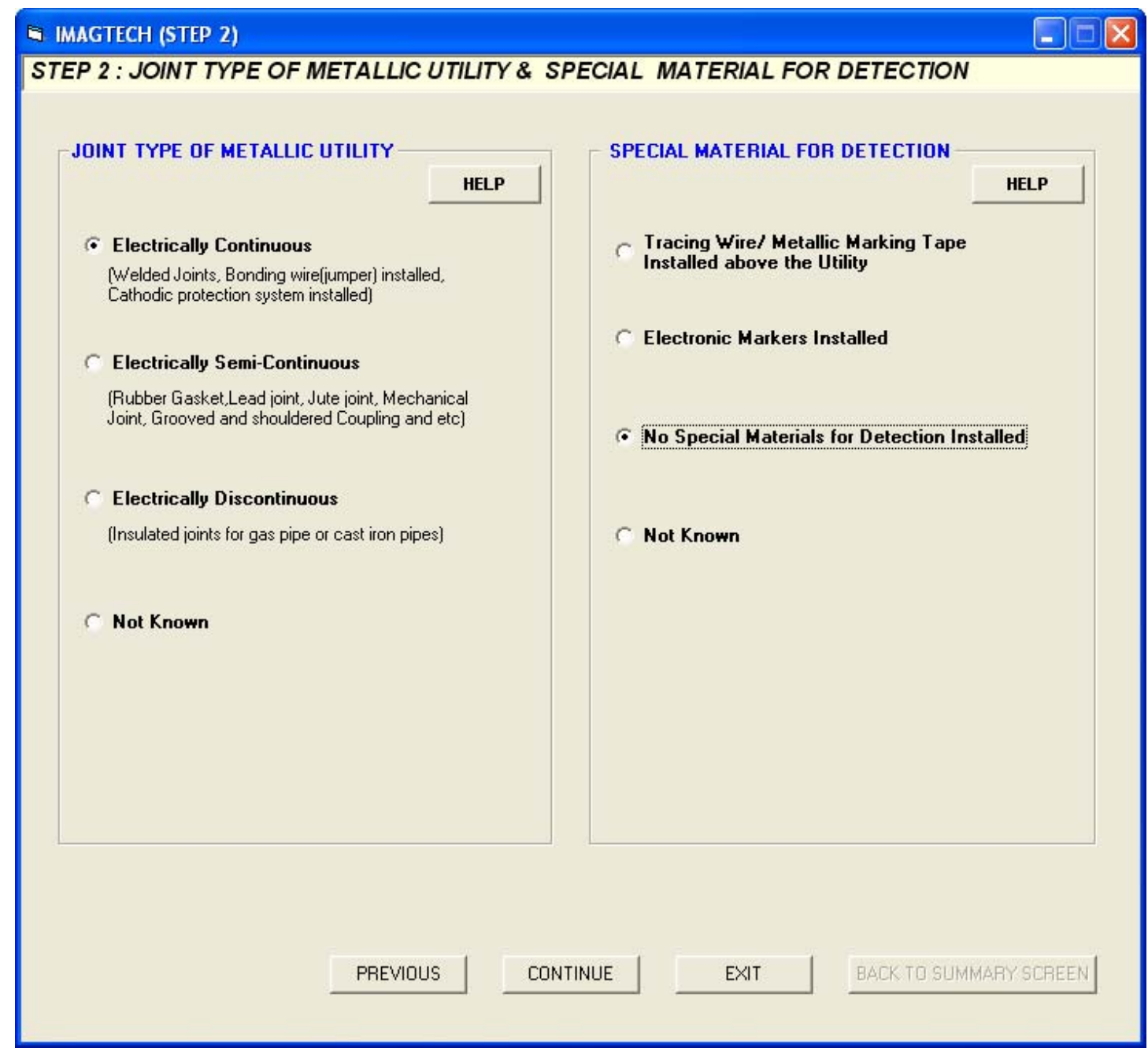

Figure 7.15. Step 2 Screen: Joint Type of Metallic Pipe \& Special Material for Detection

The Step 2 screen is for the selection of the joint type of metallic pipe \& special material for detection (Figure 7.15). The first category is primarily governed by the selection of "Material of the Utility" on the first step. The selection of non-metallic material such as "Concrete," 
"Plastics," "Vitrified clay," "Fiber Reinforced Glass," and so on inactivates all the option buttons in this category so that the user can skip this criterion.

The second category requests the user if there are any special materials such as "tracing wire," "metallic marking tape," and "electronic markers" installed above the utility at the time of construction. Once the selections from these two categories have been made, the user can click the "Continue" button to save the input data and proceed to the next step.

\subsubsection{Step 3: Access Point to Utility \& Ground Surface Condition}

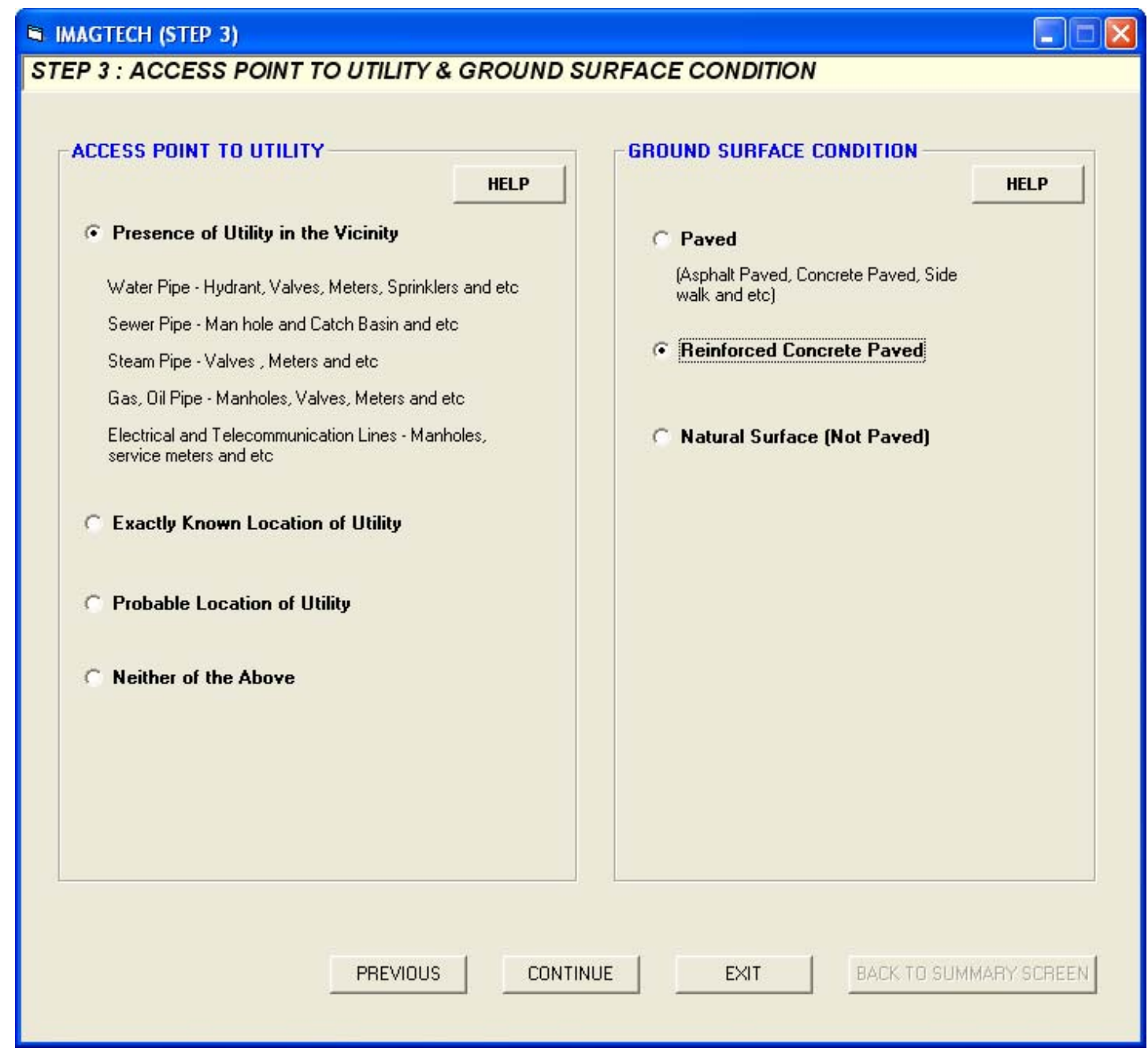

Figure 7.16. Step 3 Screen: Access Point to Utility \& Ground Surface Condition 
The Step 3 screen is used for the selection of access point to the utility \& ground surface condition (Figure 7.16). The selection from the category of "Access Point to Utility" can be made by the site examination for the entry of "Presence of Utility in the Vicinity" and by previous designation record or drawings for the entries of "Exactly Known Location of Utility" and "Probable Location of Utility." In the category of "Ground Surface Condition," the "Not known" entry is not included, which is different from the other categories. It is because the information about this criterion can be obtained from the site examination. The user can click the "Continue" button to go for the next step.

\subsubsection{Step 4: Inner State of the Pipe and Soil Type}

The step 4 screen is used for the selection of the inner state of the pipe and soil type (Figure 7.17). The inner state of the pipe is highly related to the selection of "the type of utility" in the first step. The selection of "Water pipe," "Steam pipe," "Gas pipe," and "Oil and chemical pipe" on the first step activates option buttons of "Full with flowing material," "Empty pipe or Conduit," and "Not known," inactivating the others. The selection of "Sewer pipe" activates option buttons of "Full with flowing material," "Partially full with flowing material," "Empty pipe or Conduit," and "Not known" because the sewer pipe has two different kinds of pipes: force main and gravity flow pipe. The selection of "Electrical cables/conduits" and "Telecommunication cables/conduits" only activates "Conduits full of cables," "Full and Empty Conduits," "Empty Pipe or Conduits," and "Not Known." However, if the selected material of these two types of utility is "Directed buried cables," then it is clear that no choice is required for this category. Hence all option buttons are inactivated. In the second category, approximate soil type of the proposed site can be selected. 


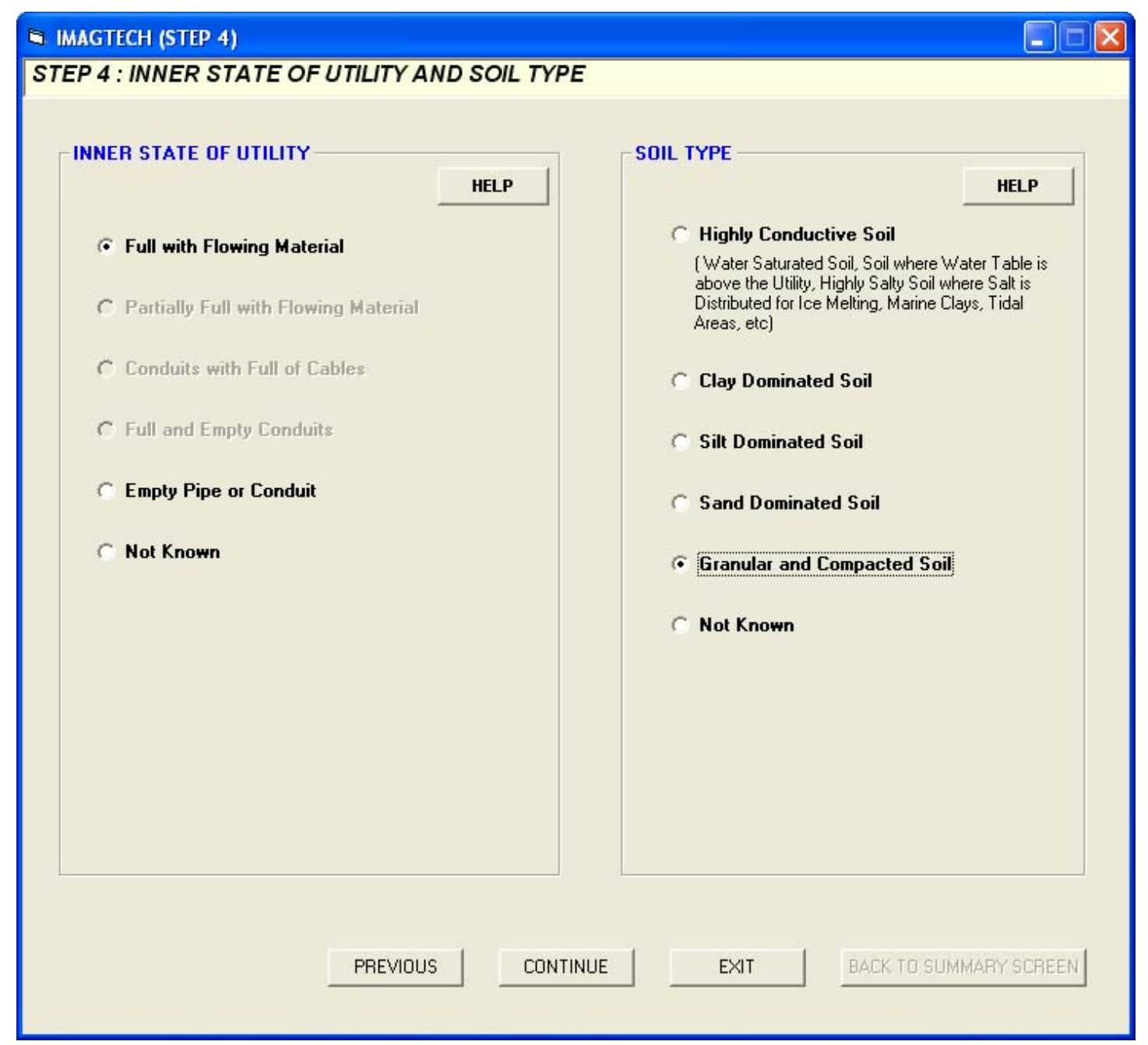

Figure 7.17. Step 4 Screen: Inner State of the Pipe and Soil Type

\subsubsection{Step 5: The Depth of Utility \& Diameter of Utility}

The Step 5 screen is used for the selection of the depth and diameter of the utility (Figure 7.18). A small slot for the input of the depth and the diameter is only activated when the "Known" option button is clicked. The data type for this slot must be a numeric type; therefore, if the wrong data type, such as word or symbol mark is given, the application warns the user by displaying a similar message box as shown in Figure 7.12. 


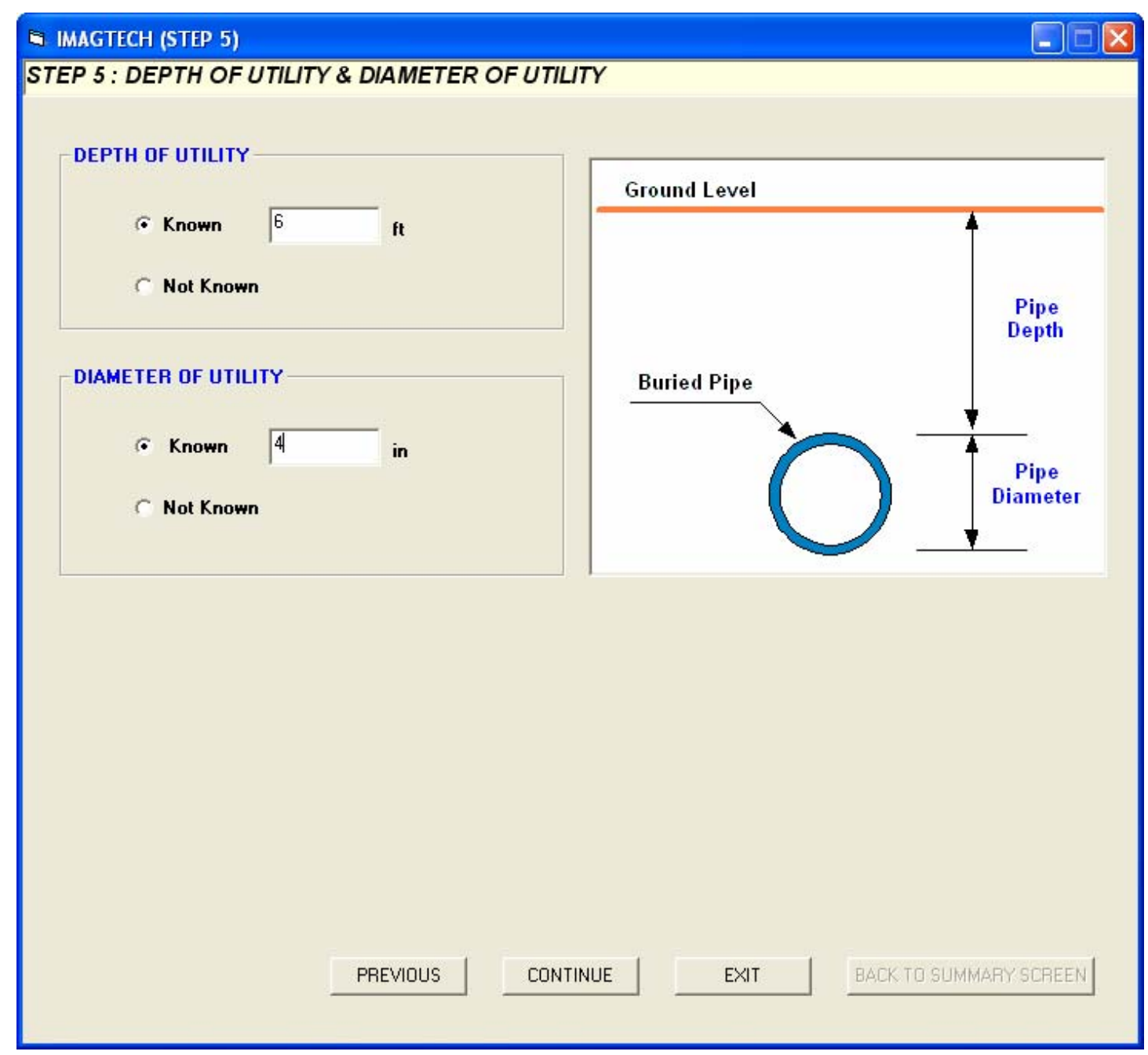

Figure 7.18. Step 5 Screen: The Depth of Utility \& Diameter of Utility

\subsubsection{Step 6: Summary of the Input Data}

The Step 6 screen displays a summary of the input data from the previous five steps (Figure 7.19). The user can review his/her input data on the screen and change the input data by clicking the "CHANGE" button located on the right side of each criterion. This button opens the relevant screen and inactivates the "Previous" and "Continue" buttons of the opened page while activating "Exit" and "Back To Summary Screen" buttons. Therefore, once the user makes changes, he/she can return to the summary screen directly by clicking the "Back To Summary Screen" button. 


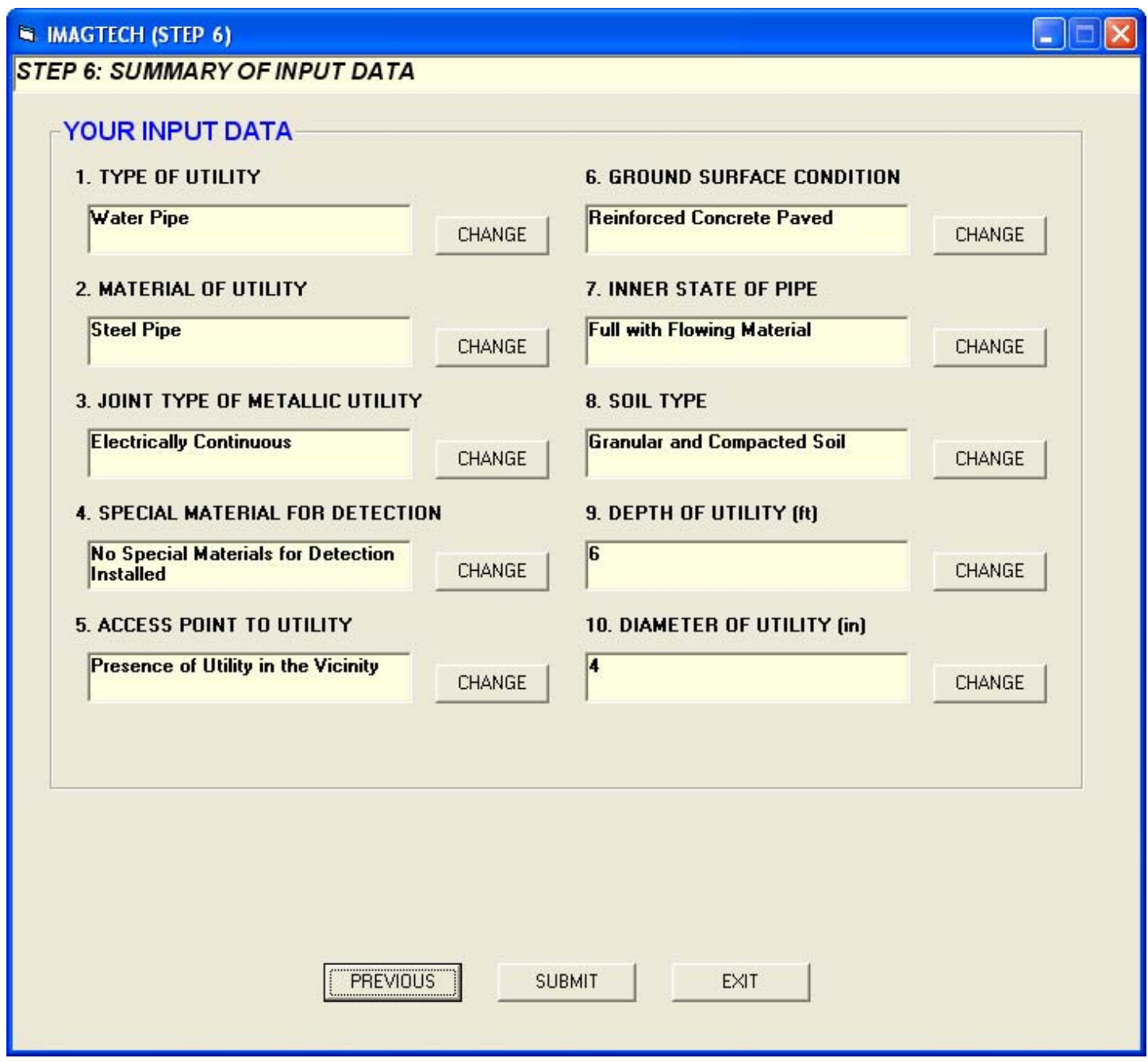

Figure 7.19. Step 6 Screen: Summary of the Input Data

The click on the "Submit" button finalizes the input data. The computer application checks the input data - whether any change has been made or not. If any change is made, the application replaces the modified input data with the previously saved data. The DPST evaluates the applicability of each designating method by multiplying earned numeric values from each criterion and then discards inapplicable designating methods, which has a zero value from the result of multiplication. Next, it calculates the level of reliability of applicable designating methods and ranks them to suggest the most appropriate method, the second and the third. Finally, it sends the results to the final screen to display them. 


\subsubsection{Final Result: Recommended Designating Methods}

The final result screen is shown in Figure 7.20. In this screen, three alternatives are listed according to their level of reliability (illustrated on the right side of the screen under the heading "Reliability"). In each comment box under the recommended alternative, the user can acquire technically critical information by scrolling down the scroll bar. If the user needs to know more about the technical knowledge other than that provided in the comment box, he/she could click on the button that is located on the right side of the recommended method. This opens an Internet page where detail information is posted on the web as shown in Figure 7.11.

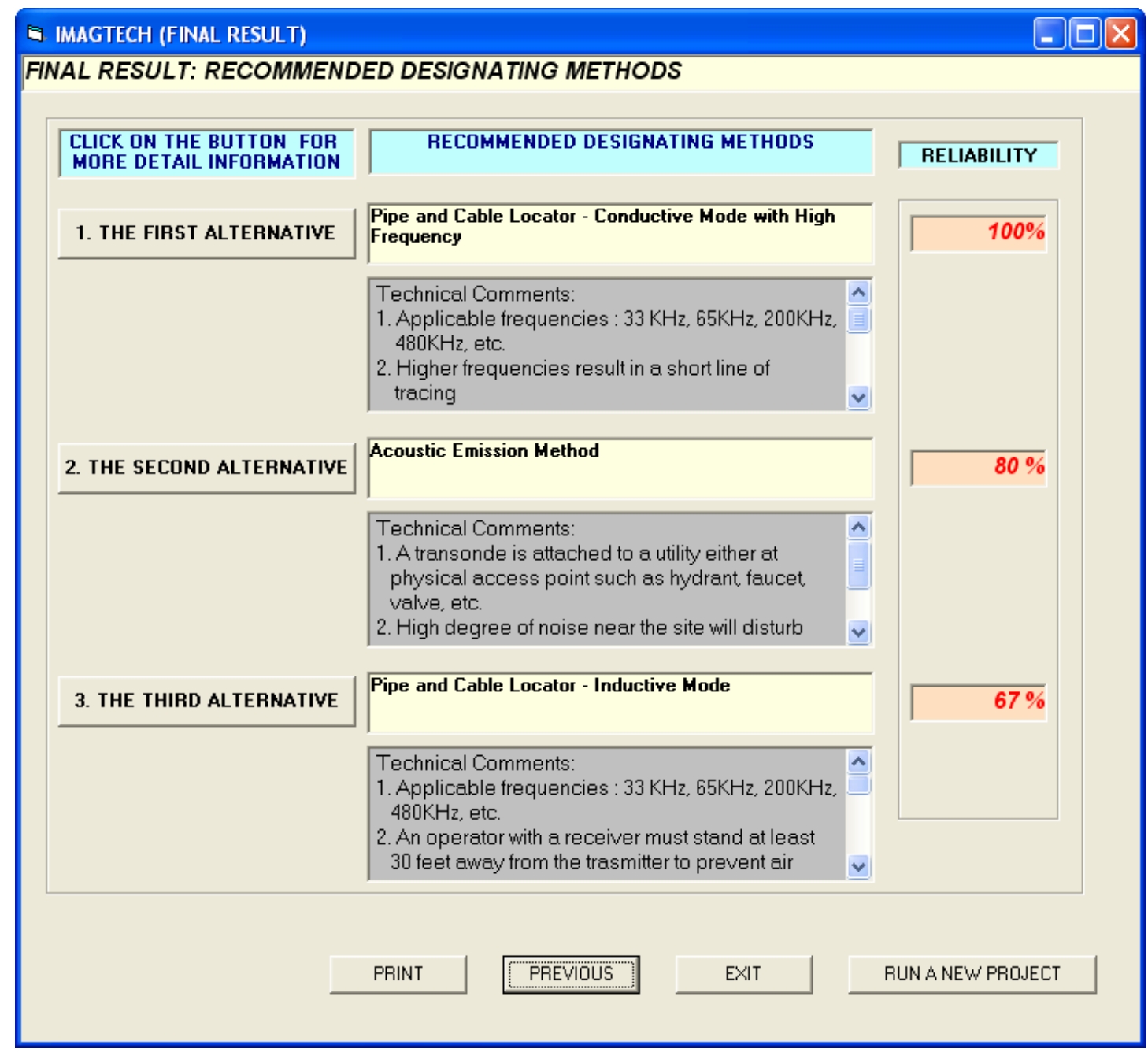

Figure 7.20. Final Screen: Recommended Designating Methods 
The "Print" button enables the user to produce a hardcopy of the final report, including the summary of the input data and the three recommended methods. If the user wants to run a new project, he/she can simply click on the "Run a New Project" button, which opens a pre-stage screen for the user. Finally, the "EXIT" terminates the program.

\subsection{Validation of IMAGTECH}

The prototype of the decision tool must be validated to assess its utility in practical settings. Two completed projects were chosen for this purpose: "Mira Vista St./Vista Del Sol Dr. Bridges project" and "INDOT-SUE on SR27 in Richmond. In this chapter, the two projects will be briefly described. The actual designating methods used on the projects will be compared to the recommended designating methods obtained using the computer application.

\subsubsection{Mira Vista St./Vista Del Sol Dr. Bridges Project, Las Vegas, NV}

\section{Project description}

The owner of the project was the R2H Engineering Company, which was going to design and build the "Mira Vista St./Vista Del Sol Dr. Bridges" in Las Vegas, Nevada. The project location is shown in Figure 7.21. The company requested the Tampa Bay Engineering (TBE) group to dig four potholes at two different water mains (two on each main) buried under the proposed bridge construction site. The purpose of the project was to acquire the exact location of water mains in order to adjust and finalize the location of the bridges.

The TBE group contracted this project for two days' work at $\$ 2,300$. They started the project on June 5, 2001 and completed it on June 6, 2001. At the Mira Vista street area, they found that a $16 "(40.5 \mathrm{~cm})$ transite (asbestos-cement) water main was buried at an approximate depth of $8 \mathrm{ft}$ $(2.64 \mathrm{~m})$ based on the record search.

In order to designate the water main prior to potholing, they used the "Acoustic Pipe Tracer, $R D$ 500 (Acoustic Emission Method).” First, an engineer connected a transonde (sound transmitter) 
to a fire hydrant that was approximately $200 \mathrm{ft}(66 \mathrm{~m})$ away from the pothole location and generated sound waves. Next, the other engineer with a sound receiver designated the main within $3 \mathrm{ft}(1 \mathrm{~m})$ of the actual location by hearing a peak of the reflected sound waves right above the water main. This location was in natural soil.

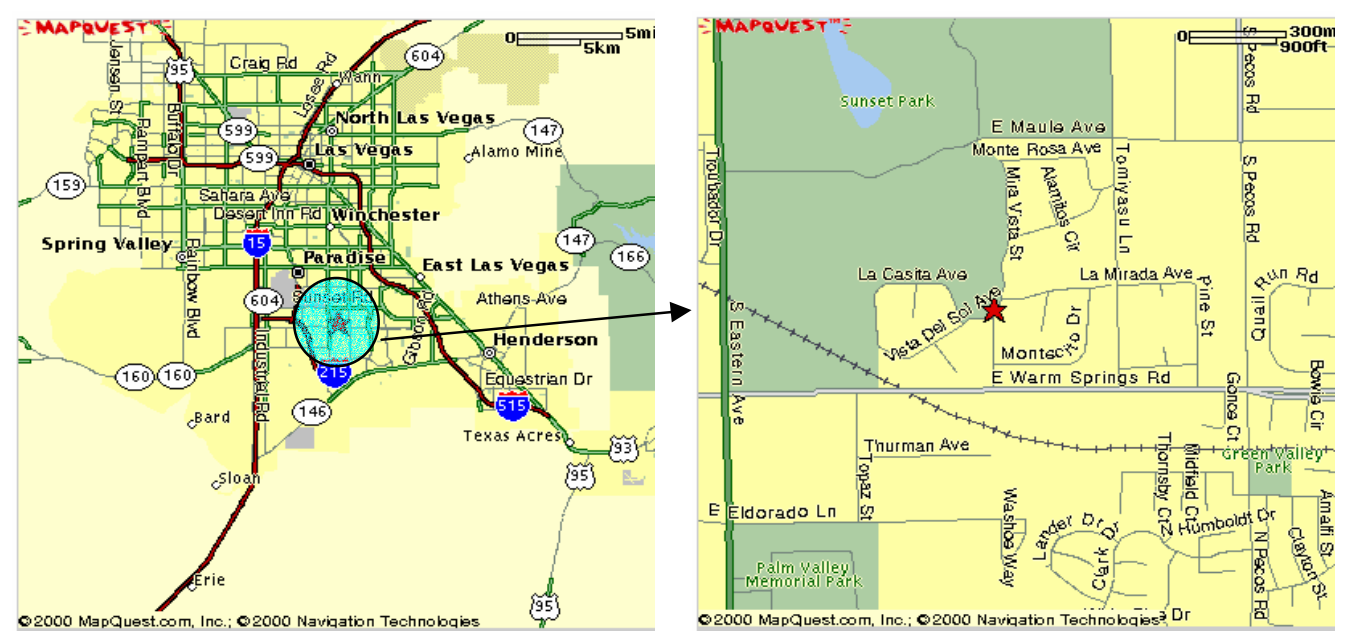

Figure 7.21. Project Location: Mira Vista St./Vista Del Sol Dr. Bridges

At the Vista Del Sol Drive Area, 8" $(20 \mathrm{~cm})$ transite pipe was buried at a depth of $3.5 \mathrm{ft}(1.16 \mathrm{~m})$. The TBE group team also used the "Acoustic Pipe Tracer, RD 500 (Acoustic Emission Method)" to designate this main. A fire hydrant that was approximately $100 \mathrm{ft}(30 \mathrm{~m})$ away from the proposed pothole location was a connection point to the transonde. The main was designated within $4 \mathrm{ft}(1.31 \mathrm{~m})$ of the actual location; this was verified by potholing. The water line was under asphalt pavement. The project data is summarized in Table 7.3 and data record sheet is provided in Appendices.

\section{Recommended methods by the prototype}

The data on Table 7.3 was used as input data for the prototype. The result in the computer screen for the Mira Vista street case is shown in Figure 7.23. Table 7.4 shows the comparison between the actual applied methods and the methods recommended by the prototype for both cases. 


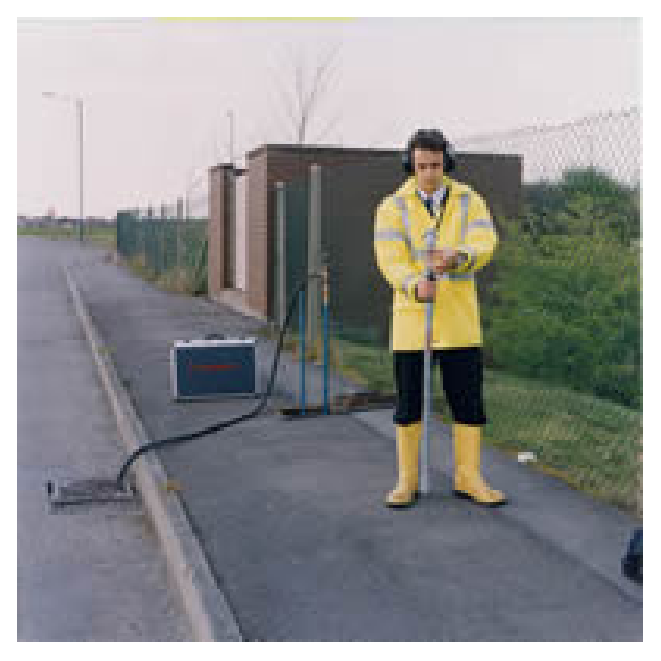

Figure 7.22. Application of Acoustic Pipe Tracer (RD 500)

(Source: www.radiodetection.com)

Table 7.3. Summary of Project Data (Mira Vista St./Vista Del Sol Dr. Bridges)

\begin{tabular}{|l|l|l|}
\hline \multicolumn{1}{|c|}{ Description } & \multicolumn{1}{|c|}{ Mira Vista St } & \multicolumn{1}{c|}{ Vista Del Sol Drive } \\
\hline 1. Type of Utility & Water pipe & Water pipe \\
\hline 2. Material of Utility & Transite (asbestos-cement) & Transite (asbestos-cement) \\
\hline 3. Joint type of Metallic Utility & N/A & N/A \\
\hline $\begin{array}{l}\text { 4. Special Material for } \\
\text { Designation }\end{array}$ & Not Known & Not Known \\
\hline 5. Access point to Utility & Fire hydrant & Fire hydrant \\
\hline 6. Ground Surface Condition & Natural surface & Asphalt paved \\
\hline 7. Inner State of Utility & Filled with flowing material & Filled with flowing material \\
\hline 8. Soil Type & Not Known & Not Known \\
\hline 9. Depth of Utility & $8 \mathrm{ft}(2.67 \mathrm{~m})$ & 4 ft (1.31 m) \\
\hline 10. Diameter of Utility & 16 in $(43 \mathrm{~cm})$ & 8 in $(20 \mathrm{~cm})$ \\
\hline Applied Designating method & Acoustic Emission Method (Acoustic pipe tracer, RD 500) \\
\hline
\end{tabular}

The method recommended for both of the cases is the "Acoustic emission method," which was used for the actual project. The GPR is recommended with $67 \%$ reliability for the Vista Del Sol drive case. This is because the depth of utility is within the propagation depth of the GPR, and the diameter (in) to depth (ft) ratio is greater than 1, which is also applicable condition for the 
GPR, but the soil condition which is one of the critical criteria for applying the GPR is not known, therefore "Neutral" value is given to the system, it lowers down the reliability.

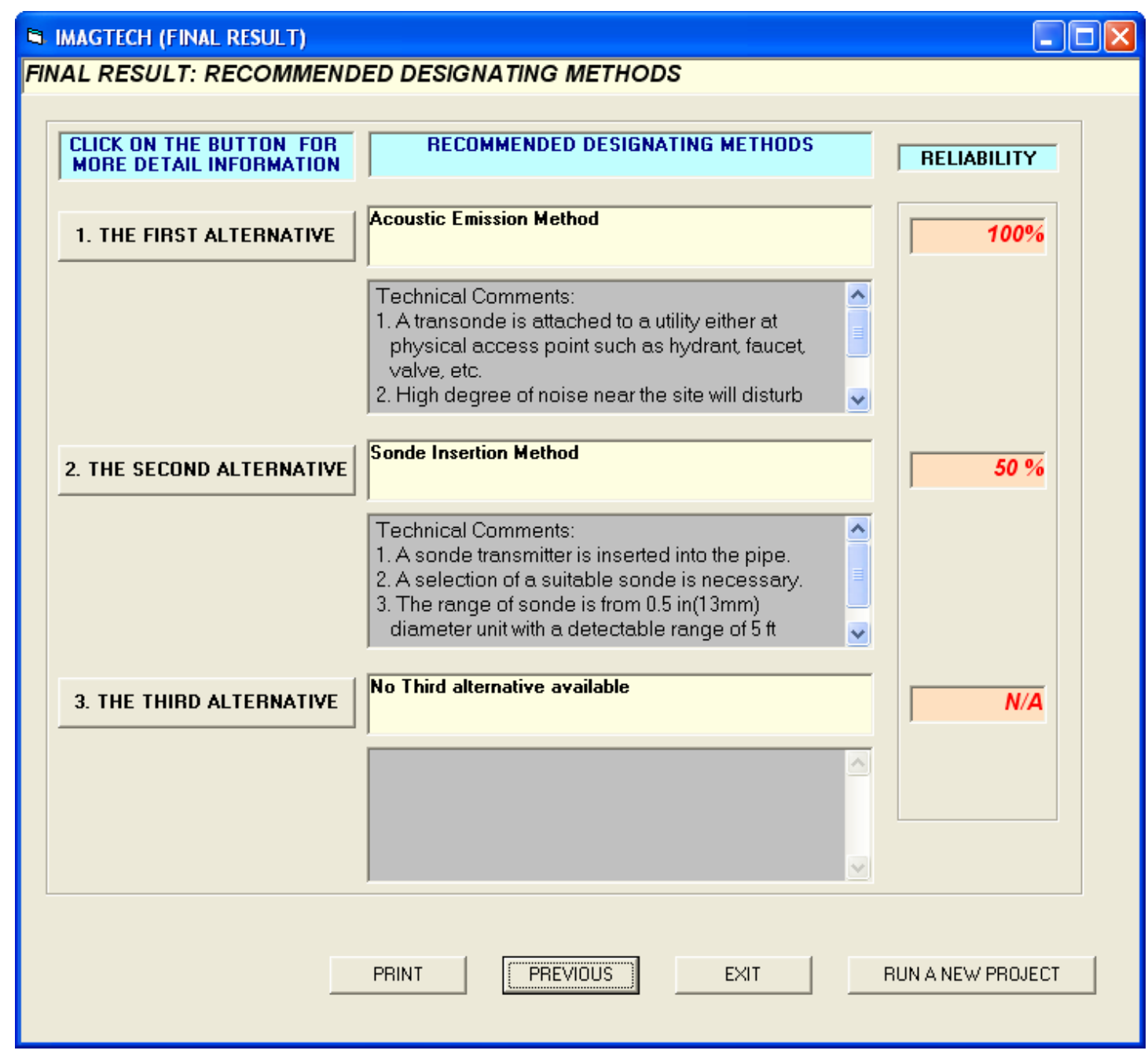

Figure 7. 23. Results of the Computerized Decision Tool for the Mira Vista Street Area

Table 7.4. Comparison of Actually Applied Method and Recommended Methods

\begin{tabular}{|c|l|l|}
\hline Project Area & \multicolumn{1}{|c|}{ Applied method } & \multicolumn{1}{c|}{ Recommended methods } \\
\hline \multirow{4}{*}{ Mira Vista Street } & $\begin{array}{l}\text { Acoustic emission } \\
\text { method }\end{array}$ & Acoustic emission method (100\%) \\
\cline { 3 - 3 } & & Sonde Insertion Method (50\%) \\
\cline { 2 - 3 } Vista Del Sol Drive & $\begin{array}{l}\text { Acoustic emission } \\
\text { method }\end{array}$ & Acoustic emission method (100\%) \\
\cline { 3 - 3 } & & GPR (67\%) \\
\cline { 2 - 3 } & & Sonde Insertion Method (50\%) \\
\hline
\end{tabular}




\subsubsection{INDOT- SUE on SR27 in Richmond, IN}

\section{Project description}

The Indiana Department of Transportation (INDOT) hired the Tampa Bay Engineering (TBE) group for developing QL-A and QL-B information of underground utilities buried along SR27 in Richmond, IN (Figure 7.22). The project started near the intersection of SR227 and SR27 and ended at the north of Locust Drive on SR 27. The purpose of the project was to collect the exact information about the location of the utilities for a final design adjustment of a future road construction. The contract was signed between the two parties at a consulting fee of $\$ 101,653$. The project duration was from March 22, 2001 to July 12, 2001 using approximately three crews a day.

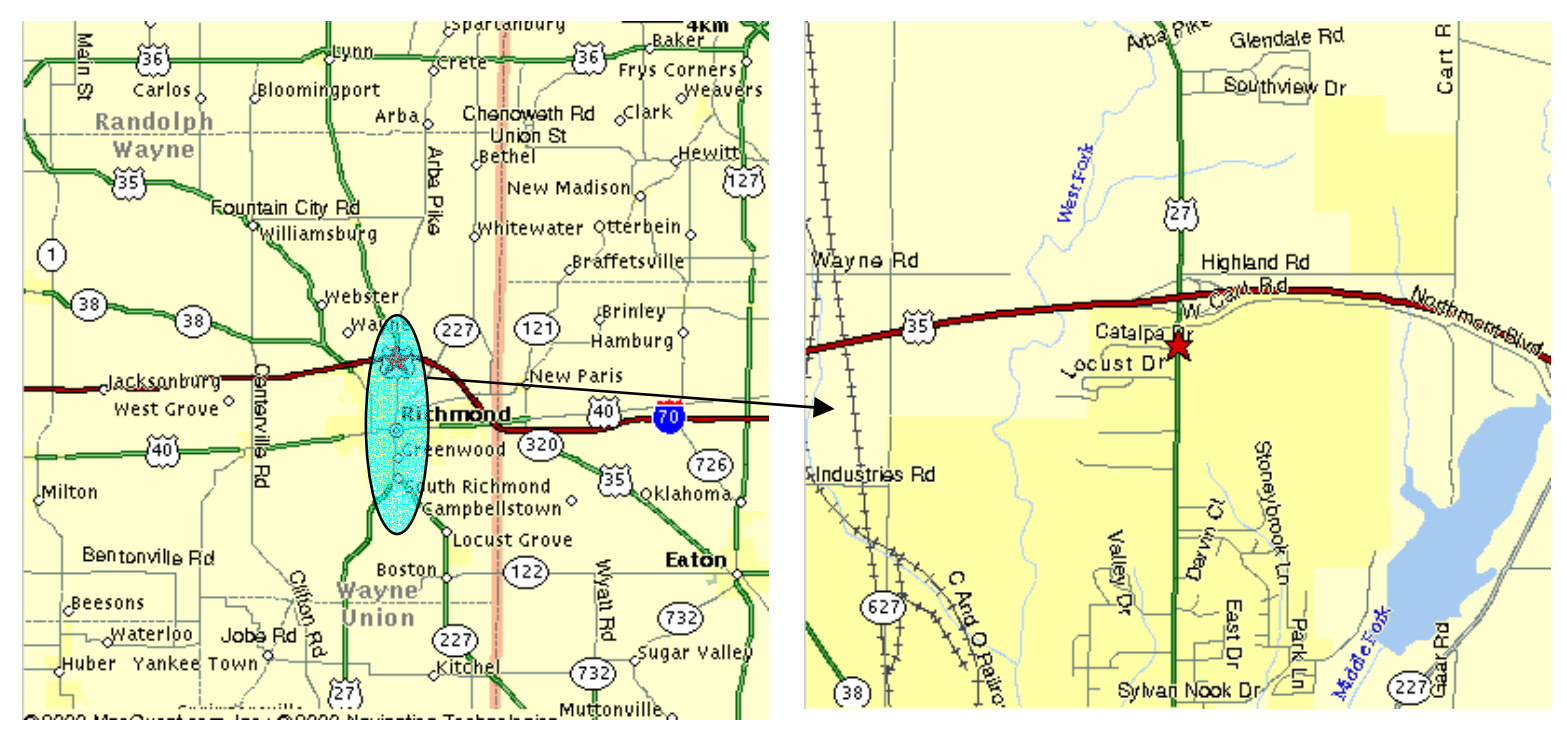

Figure 7. 24. Project Location: INDOT- SUE on SR27 in Richmond, IN

In order to create three-dimensional data for the underground utilities, three major steps were required. In the first step, the project team designated the utilities using "Pipe and Cable locators" and secondly, located them using the "Vacuum excavation technique." In this step, site engineers identified each utility in the aspect of material, diameter, depth and horizontal location of the utility. Surveying equipment such as levels and leveling staffs were utilized to measure the depth of the utility and the horizontal distance of the utility from the curb or the edge of the 
pavement. The data acquired from this step was filled out in a field data sheet (the data sheets are provided in Appendix). In the final step, the data was transferred into the drawing using Computer Aided Design and Drafting (CADD) system in the office.

Since the project has gas pipes and water pipes made of steel or cast iron, two different techniques of "Pipe and cable locators" were applied for designation purpose: "Pipe and cable locator - Conductive mode" and "Pipe and cable locator - Inductive mode." The team hooked up a transmitter to the access point such as a valve box or manhole, generated an electromagnetic wave through the pipe, and designated the pipe using "Pipe and cable locator - Conductive mode with low/high frequency."

When there was no physical access point to the utility, the team used the exactly known location of the pipe from previous designation results in order to apply "Pipe and Cable locator Inductive mode" for the successful designation. The crew placed the transmitter on the surface, exactly above the pipe, and generated electromagnetic waves of high frequency. An engineer with a receiver then designated the pipe at least $30 \mathrm{ft}(10 \mathrm{~m})$ away from the transmitter (Figure 7.25).

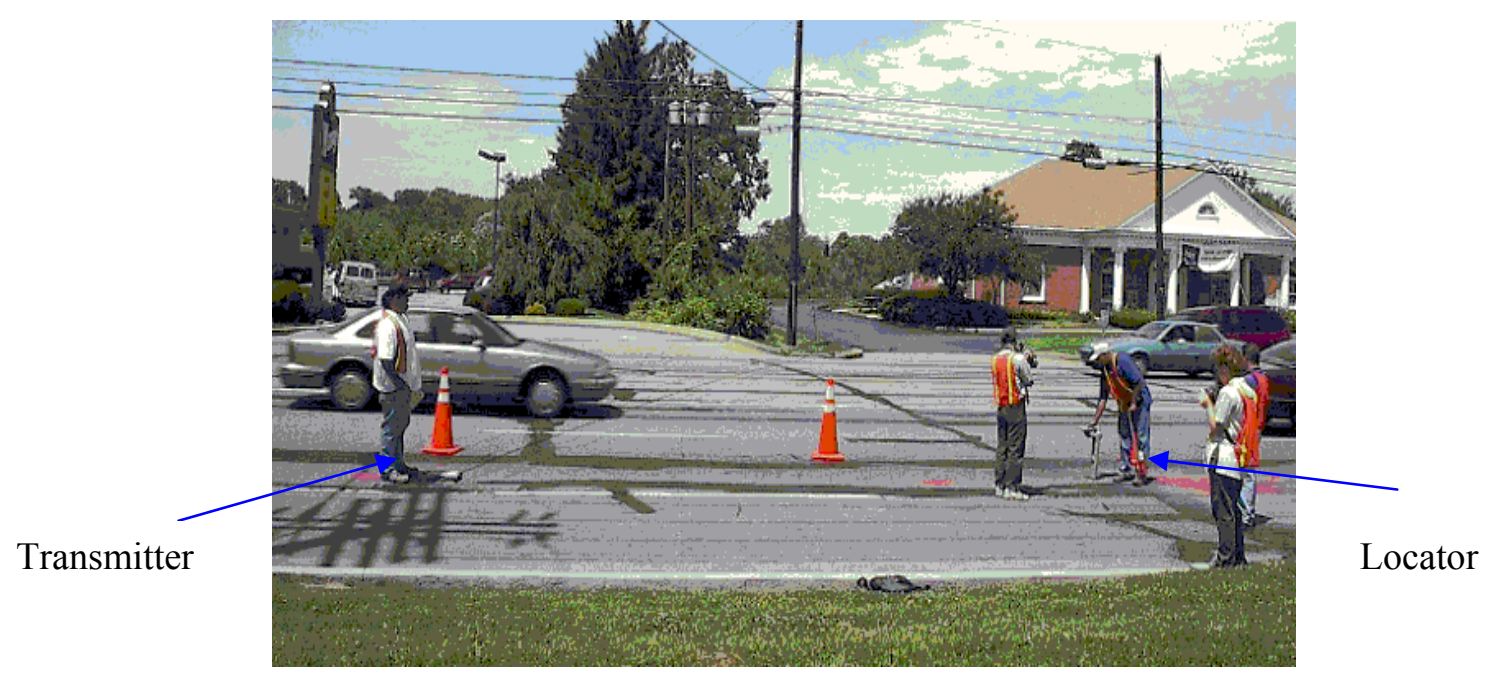

Figure 7.25. Applications of Pipe and Cable Locator -Inductive Mode 
On June 15, 2001, the team attempted to designate the gas pipe along the SR27 road near the Meijer supermarket (2507 Chester Blvd). This area did not provide any physical access point to the gas pipe but the team knew the exact location of the pipe based on results of previous work. The team applied "Pipe and Cable locator - inductive mode" and effectively designated the buried gas pipe. The site conditions in that area are summarized in Table 7.5.

Table 7.5. Summary of the Site Condition (INDOT- SUE on SR27 in Richmond, IN)

\begin{tabular}{|l|l|}
\hline \multicolumn{1}{|c|}{ Description } & \multicolumn{1}{c|}{ Data } \\
\hline 1. Type of Utility & Gas Pipe \\
\hline 2. Material of Utility & Steel \\
\hline 3. Joint type of Metallic Utility & Not Known \\
\hline 4. Special Material for Designation & Not Known \\
\hline 5. Access point to Utility & Exactly known location of the utility \\
\hline 6. Ground Surface Condition & Paved \\
\hline 7. Inner State of Utility & Filled with flowing material \\
\hline 8. Soil Type & Granular and compacted soil \\
\hline 9. Depth of Utility & 1.2 $\mathrm{ft}(0.4 \mathrm{~m})$ \\
\hline 10. Diameter of Utility & 6 in (150 mm) \\
\hline Applied Designating method & Pipe and Cable locator - Inductive mode \\
\hline
\end{tabular}

\section{Recommended methods by the prototype}

The data in Table 7.5 was used as input to the decision tool. The "results" screen is shown in Figure 7.26. Table 7.6 shows the comparison between the actually used method and the methods recommended by the prototype.

Based on the results obtained from the decision tool, GPR is the first alternative that can be applied for the given site conditions. "Pipe and Cable Locator - Inductive mode" is the second alternative, with $83 \%$ reliability, and the magnetic method is the third alternative with $75 \%$ reliability. 


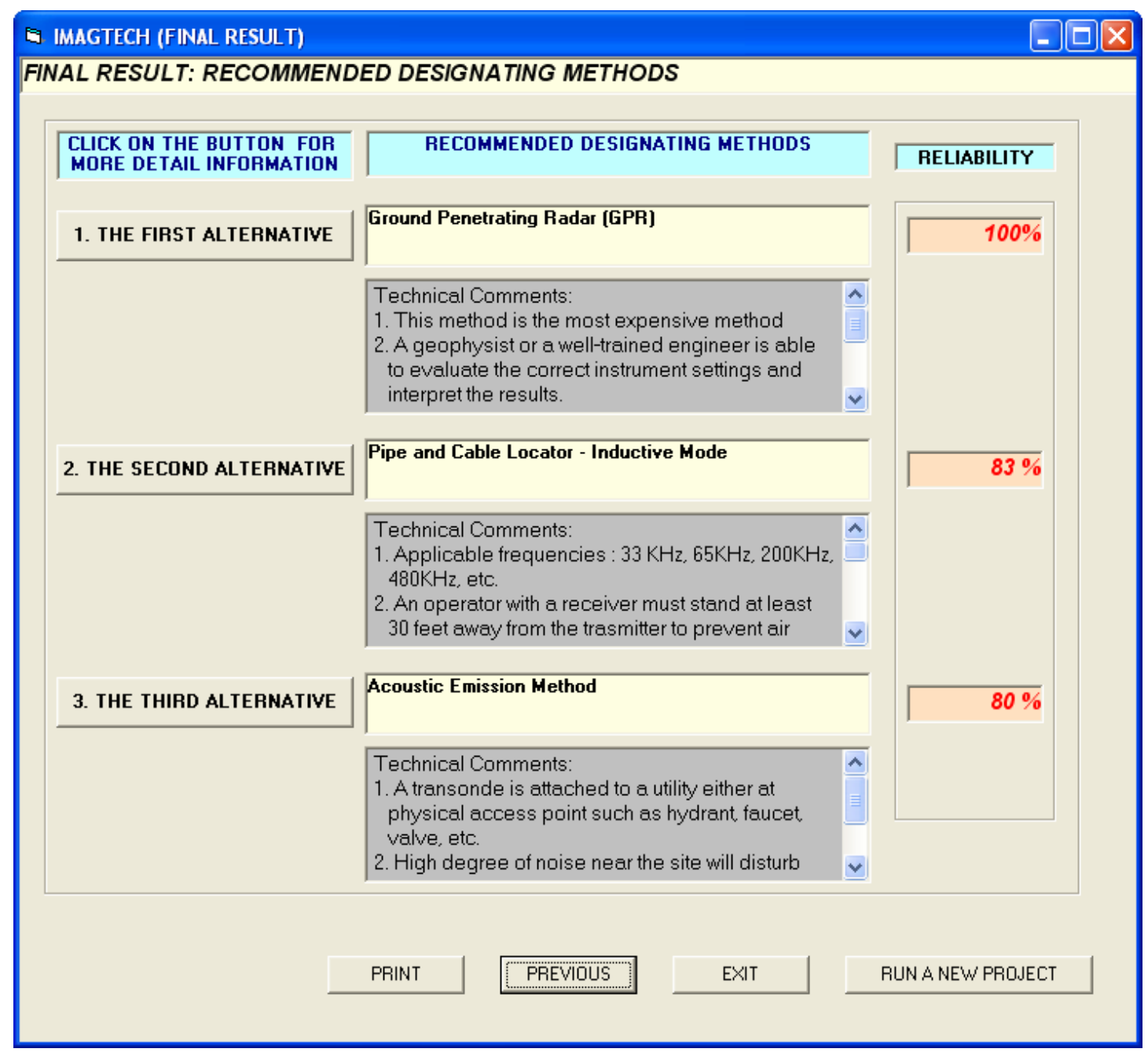

\section{Figure 7.26. Result Screen for INDOT- SUE on SR27 in Richmond, IN Project}

"Pipe and Cable Locator - Inductive mode" and "Acoustic Emission Method" have 83\% and $80 \%$ reliability because some of the input data that are critical factors to these methods were "Not Known." For instance, "Joint type of metallic utility" impacts the appropriate operation of "Pipe and Cable Locator - Inductive mode" significantly, which was "Not Known" to the project team before the designation task. In practice, steel pipe is usually welded, and if this is the case for the gas pipe, the joint type must be "electrically continuous," which would lead to a $100 \%$ reliability for the "Pipe and Cable Locator - Inductive mode." 
In the actual project, the TBE crew had no trouble using "Pipe and cable locator - Inductive mode," which implies that the joint type was at least "Electrically semi-continuous" or "continuous." When there is lack of information, the alternatives suggested by the decision tool can have a low value for "reliability." On closer examination of the recommended methods, GPR is the most expensive method; thus, engineers might prefer to use "Pipe and cable locator Inductive mode" or "Magnetic method" for designation.

Table 7.6. Comparison of Actually Applied Method and Recommended Methods

\begin{tabular}{|c|c|c|}
\hline Project & Applied method & Recommended methods \\
\hline \multirow{3}{*}{$\begin{array}{l}\text { INDOT-SUE on } \\
\text { SR27 in Richmond, } \\
\text { IN }\end{array}$} & \multirow{3}{*}{$\begin{array}{l}\text { Pipe and Cable Locator } \\
\text { - Inductive mode }\end{array}$} & GPR $(100 \%)$ \\
\hline & & $\begin{array}{l}\text { Pipe and Cable Locator - Inductive } \\
\text { mode }(83 \%)\end{array}$ \\
\hline & & Acoustic Emission Method (80\%) \\
\hline
\end{tabular}




\section{CHAPTER 8}

\section{MULTIMEDIA EDUCATION TOOL}

\subsection{Introduction}

The multimedia education tool was developed to facilitate a better understanding of the underground utility locating systems by the many in the construction domain, entry-level engineers in SUE industry area who are relatively unfamiliar with it. These web pages can be accessed at http://rebar.ecn.purdue.edu/utilities/index.htm. The main page of these web pages is also linked to a website (http://www.new-technologies.org/ECT/Other/imagtech.htm) of "Emerging Construction Technologies (ECT)," which is managed by the Construction Engineering and Management division at Purdue University. The structure of this multimedia educational tool has a structure as shown in Figure 8.1. The following sections describe each webpage.

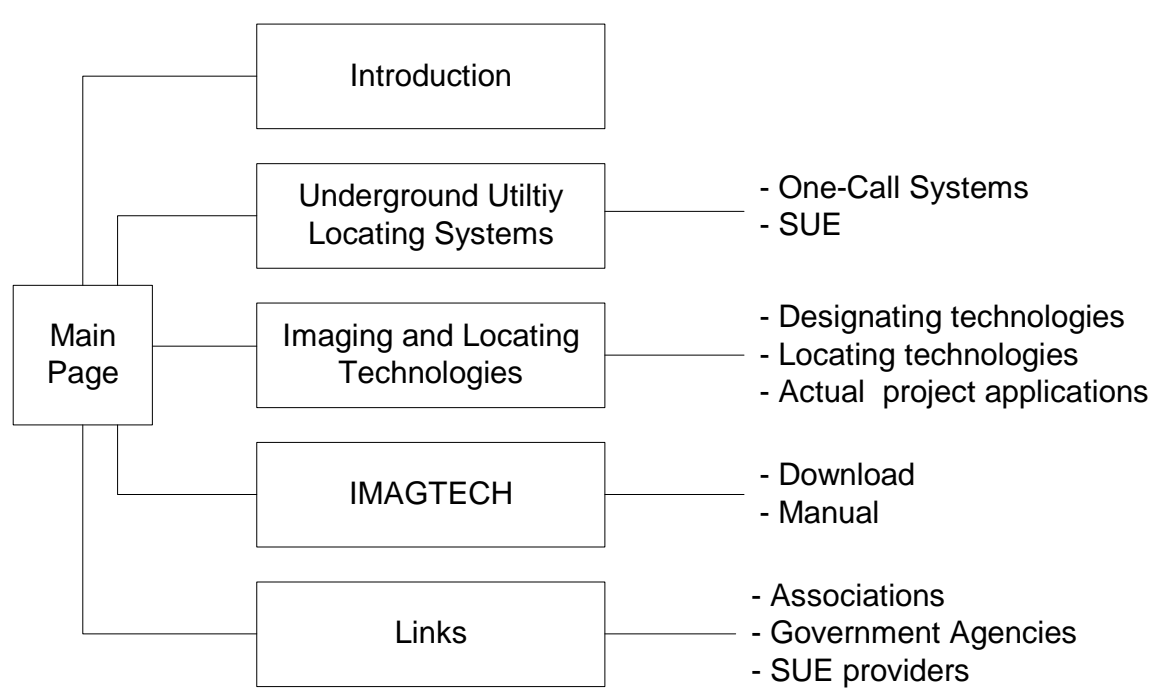

Figure 8.1. Structure of Multimedia Web Pages 


\subsection{Main Page}

The main page (Figure 8.2) contains of five different categories: Introduction, Underground utility locating systems, Imaging and locating technologies, IMAGTECH, and Links. These hyperlinked texts lead the users to the web page which includes detailed description of each category. This web page includes INDOT and Purdue University logos on top of the page to indicate that the study was completed with the collaboration effort of these two.

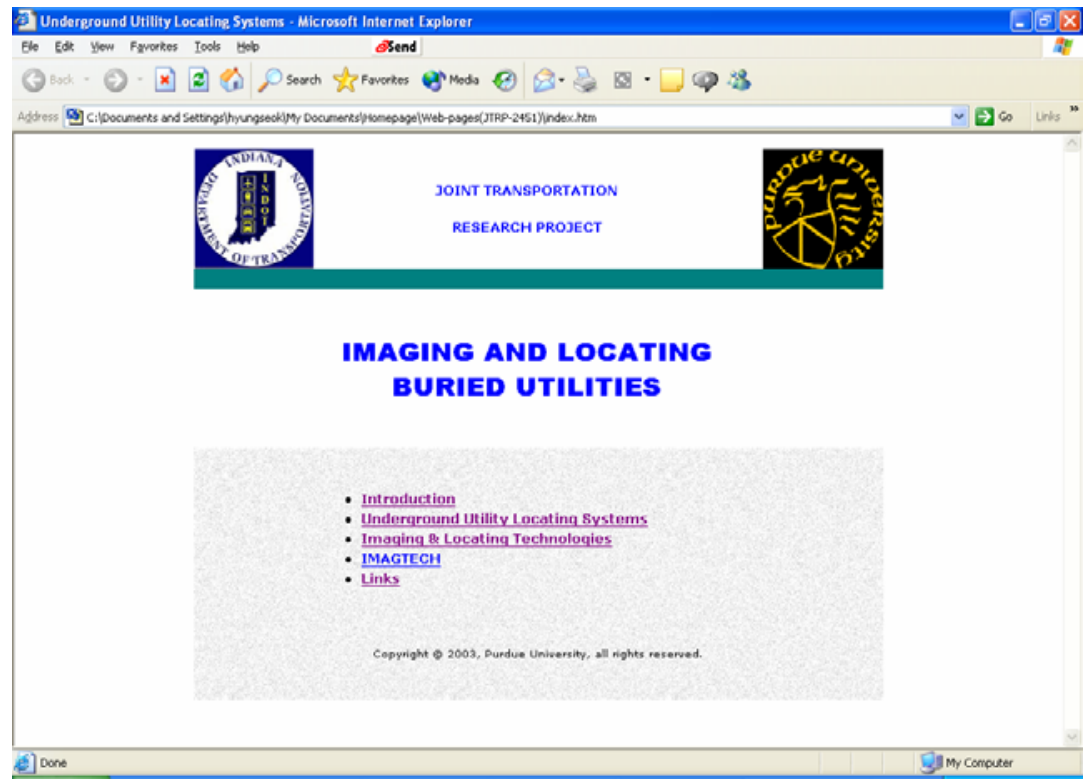

Figure 8.2. Layout of Main Web Page

\subsection{Web Page for Introduction}

The introduction web page briefly discusses the importance of underground utility locating work and describes what contents are included in each section. Web pages describing each category have similar format. As shown in Figure 8.3, there is a bar on the top side, which consists of 6 different hyperlinks texts. Click on these texts will open the specific web pages for that category. Table of contents first appear in each web page. The texts are also hyperlinked for easy access. 


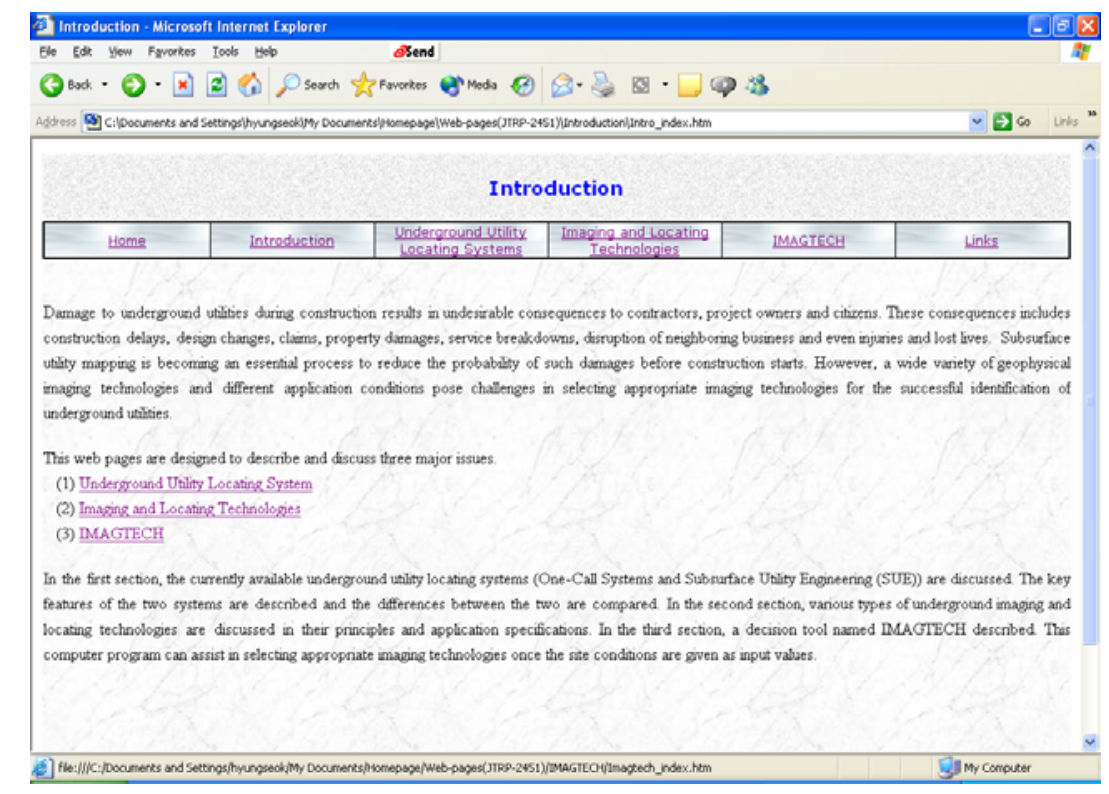

Figure 8.3. Layout of Introduction Page

\subsection{Web Pages for Underground Utility Locating Systems}

This web page describes the One-Call system and Subsurface Utility Engineering as organized and currently available underground utility locating systems in industry. It provides the comparison results of these two systems. Since these two systems identify the location of underground utilities with different information sources in different time frames, the vulnerability of existing underground pipelines to damages decreases further when both systems are applied to a project. Thus, the synergistic use of both systems is recommended. The Federal Highway Administration (FHWA) supports the use of SUE during project development (planning, preliminary engineering and design) and the use of One-Call system during construction (prior to any excavation) (Scott 2001). 


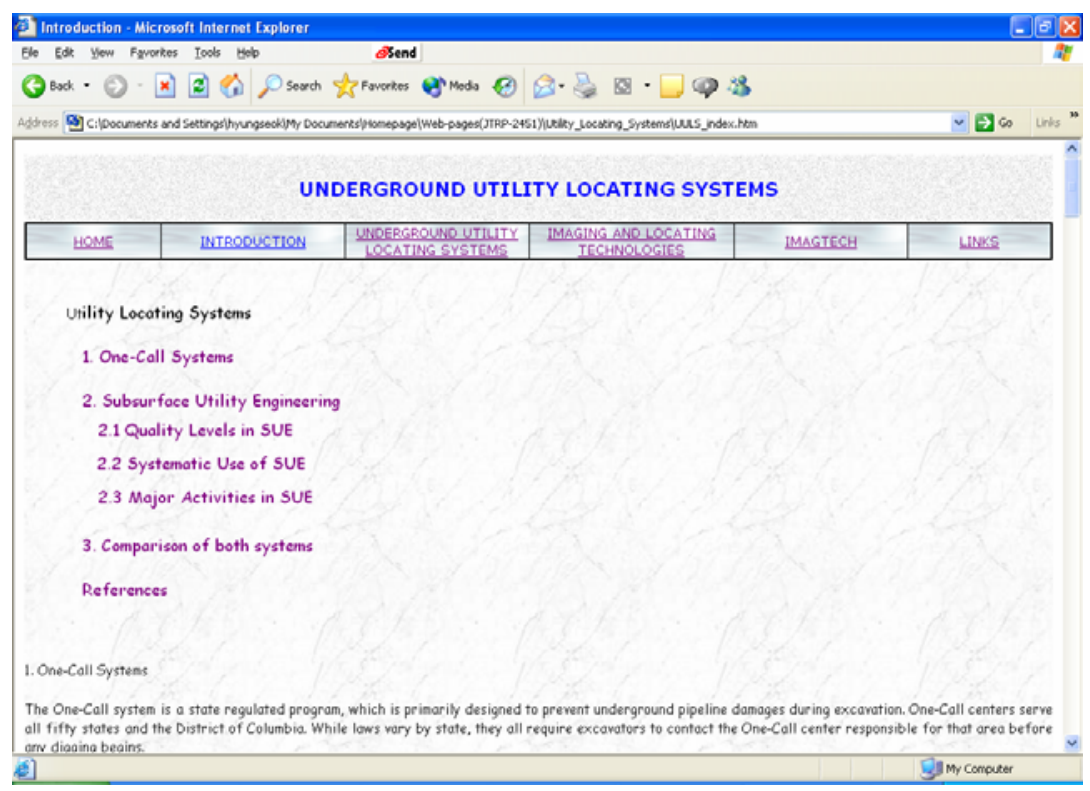

Figure 8.4. Layout of Underground Utility Locating Systems Web Page

\subsection{Web Pages for Imaging and Locating Technologies}

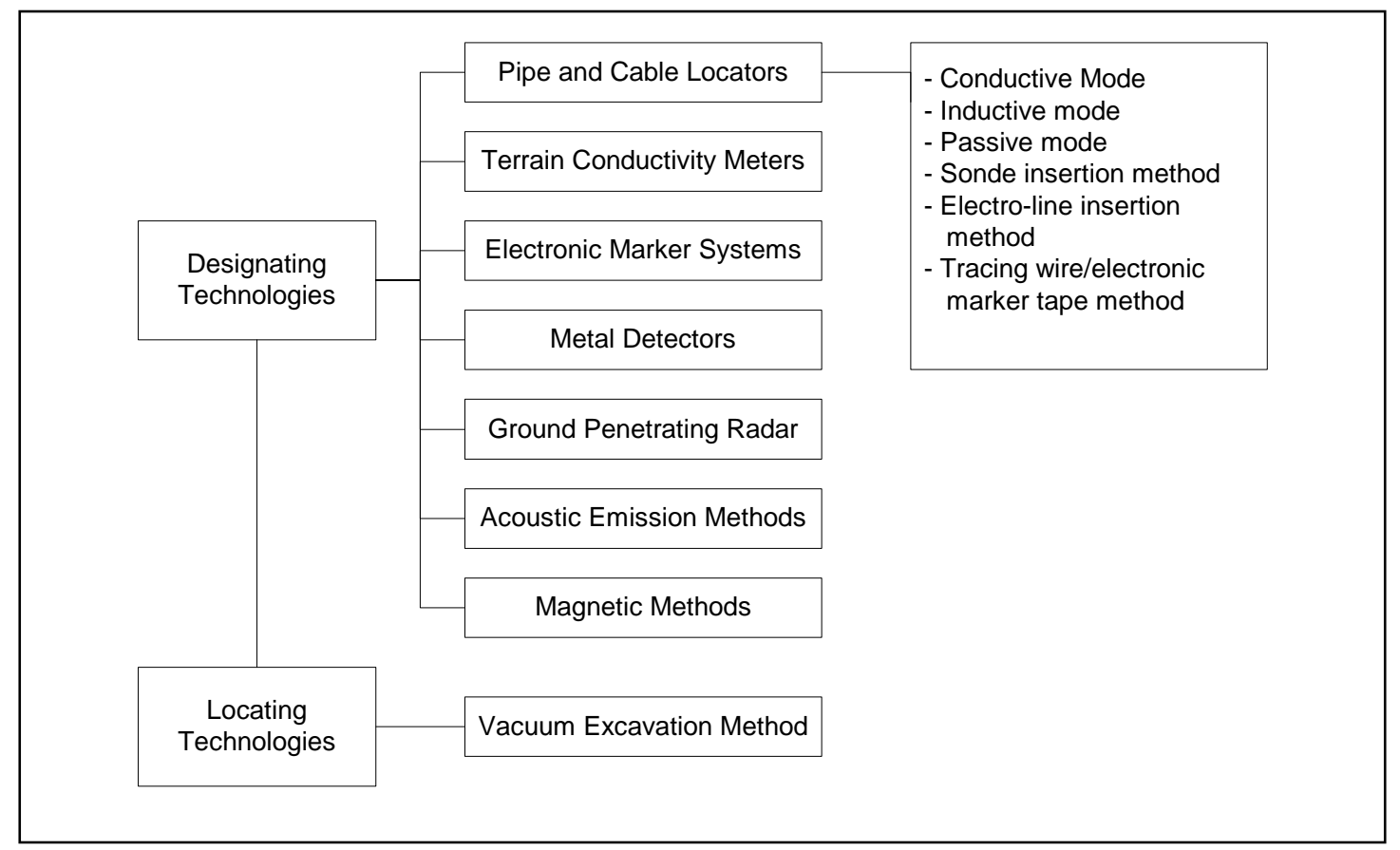

Figure 8.5. Designating and Locating Technologies Described in Web Pages 
This section describes imaging (designating) and locating technologies in detail. Their background theory and application features and ranges are discussed with photographs. The designating technologies include the following technologies in Figure 8.5. The contents of this web page are summary of chapter 5 in this report. The rarely used methods are not included. Vacuum excavation method is described as locating methods.

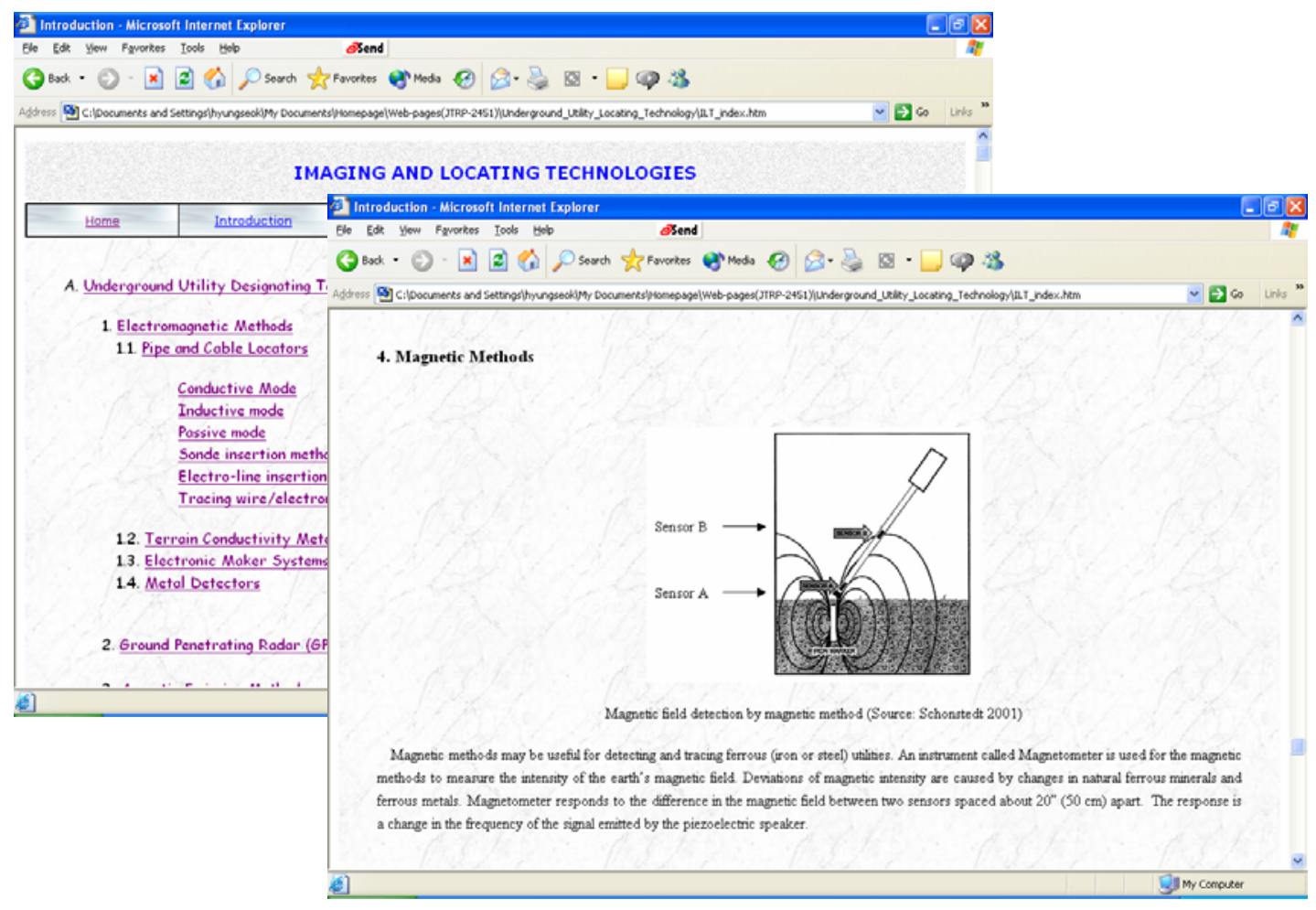

Figure 8.6. Layout of Imaging and Locating Technologies Web Pages

The actual project application sections contain video streaming files for different imaging technologies to detect underground utilities recorded from the site visits by the research team. The three most widely used imaging technologies such as pipe and cable locators, ground penetrating radar, and acoustic pipe tracers are described in detail. Different steps in each method can be observed by opening a video file associated with the brief description of the step. The video clips (Figure 8.7) enable users to see the procedures of each method and assist the users in understanding the technologies. 


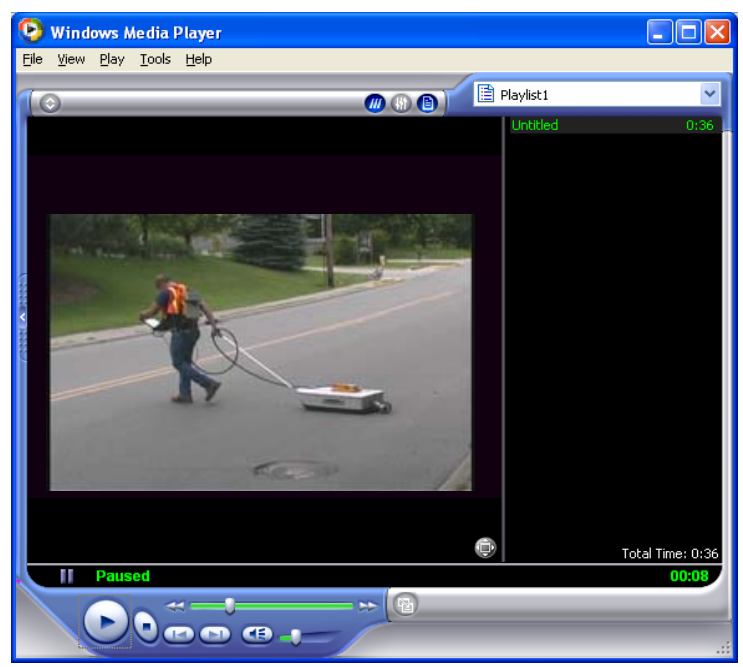

Figure 8.7. Captured Image of Video Clips

\subsection{Web Pages for IMAGTECH}

This web page describes the IMAGTECH. Its basic system architecture is shown and described. In this web page, the IMAGTECH program can be downloaded for use. The manual for the IMAGTECH is included in the following section. The content is the same as in Chapter 7.6 in this report.

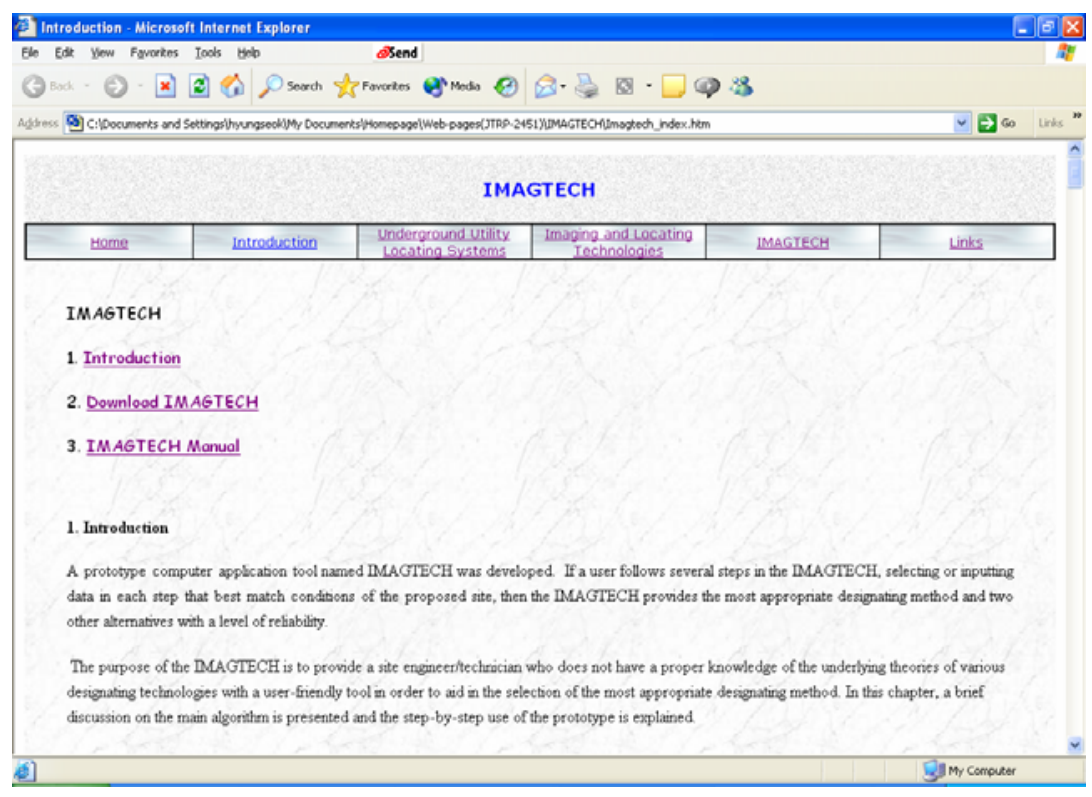

Figure 8.8. Layouts of IMAGTECH Web Page 


\subsection{Web Pages for Related Links}

The web page contains links to other web sites related to underground utility locating activities. They are categorized into three different sections: Associations, Government Agencies and Department of Transportations, and SUE providers. The layout is shown in Figure 8.9.

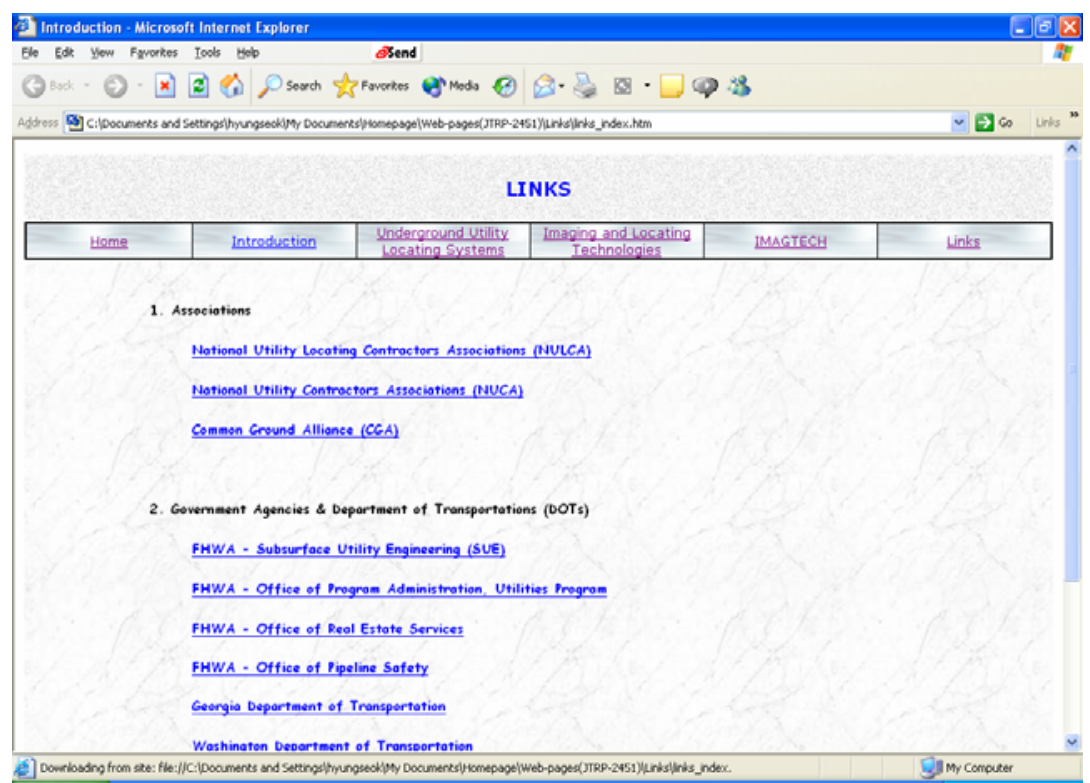

Figure 8.9. Layout of Links Web page 


\section{CHAPTER 9}

\section{SUMMARY}

\subsection{Conclusions}

Damage to underground infrastructures results in injury and death, as well as severe property damage and loss of vital services and products. Obtaining accurate information of underground infrastructure is becoming more critical during the planning and design phases of construction projects. However, detecting the presence of underground infrastructure is challenging due to the lack of complete as-built drawings, the different capabilities of imaging technologies operating under different conditions, and the high level of skill required in interpreting the images/data collected by the technologies.

This report evaluated and compared currently available systems for locating underground utility. The synergistic use of One-Call system and SUE is recommended to improve the safety of the underground pipelines in construction projects. The report presents a comprehensive insight into the various aspects of a new and rapidly growing market in SUE. The cost-benefit analysis, based on seventy one actual construction projects where SUE was employed, revealed that more than four times the funds invested in the SUE service were returned to project owners. The highest cost savings factor was the reduced number of utility relocations. This strongly indicates that SUE is a promising tool for cost savings in highway construction projects particularly where utilities are congested. Questionnaire surveys of State DOTs revealed an average increase of $17 \%$ in the annual SUE program budget during the 1999-2001 period, high satisfaction with the use of SUE (>90\%), and an increasing number of states that have initiated the use of SUE for their highway construction projects.

The questionnaire survey of the SUE industry revealed various aspects of SUE practices in the private sector. The majority of SUE firms have less than 10 years of experience. The rapid growth rate of SUE business (173\%) in the past five years is a good indicator for the bright 
future of this area. State DOTs and federal agencies are major clients (>50\%), but other clients such as municipalities, utility companies and engineering firms are also increasing their use of SUE. SUE firms are highly dependent on pipe and cable locators for the designating process and vacuum excavation system for the locating process. Currently, traditional survey methods and CADD are the prevailing data management system, but GPS and GIS appear to be the next generation for data management systems due to their apparent advantages over traditional surveying methods and CADD. Several factors challenging SUE projects were identified. They are highly related to the productivity and quality of SUE projects. Identification of these factors in the early stage of the project and an effective management strategy were pointed out to be essential for the successful completion of a SUE project.

In order to obtain two-dimensional mapping information (quality level B), various surface geophysical techniques are available: pipe and cable locators (conductive, inductive and passive mode), the sonde insertion method, an E-line locator, terrain conductivity, metal detectors, GPR, resistivity method, an electronic marker system, the magnetic method, the acoustic emission method, an infrared thermography method, a micro gravitational technique, etc. Selecting the most appropriate method for detecting utilities is not a simple task. As a result, the success rate of locating utilities during ONE-CALL operation is not very high (Anspach 2001).

The study examined a variety of underground utility designating methods, interpretation of the results obtained from each designating method and application of the methods. The theory behind each designating method was studied, and the characteristics of these designating methods were identified and organized into ten criteria: type of utility, material of utility, joint type of metallic pipe, special material for detection, access point to utility, surface condition, inner state of utility, soil type, the depth of utility and the diameter of utility. The study can be a useful resource for people who have just begun to explore subsurface utility engineering or who do not have a strong understanding of different designating methods.

Deterministic Parallel Selection Technique (DPST) was developed to meet the four basic requirements in the process of selecting the most appropriate designating method: (a) a knowledge-based decision, (b) crisp and tangible input values, (d) parallelism among criteria and 
(d) the possibility of alternatives. The DPST starts with an established knowledge database. When the input values are provided, the inference engine evaluates the input data to determine the most appropriate designating method. In this process, the input values are converted to numeric values, which are pre-assigned in the knowledge database. These numeric values then undergo a simple computation to discard inappropriate methods, and to rank and select the appropriate designating methods with a level of reliability.

Based on the criteria and the established applicability of each entry to designating methods as well as the DPST, a decision support system named, IMAGTECH was developed using Visual Basic. When a user selects or inputs data in each step that best match the conditions at the proposed site, the application provides the most appropriate designating method and two other alternatives with a level of reliability assigned to each designating method. IMAGTECH can be a user-friendly and easy access tool in assisting in the selection of the most appropriate designating method for site engineers or technicians. Furthermore, it can be used as a training tool to simulate designating operations. A multimedia education tool was also developed to facilitate a better understanding of the underground utility locating systems by the many in the construction domain, entry-level engineers in SUE industry area that are relatively unfamiliar with it.

\subsection{Recommendations}

\section{A need for new locating technologies}

Imaging technologies are not magic wands. The complexity existing in the selection of the most appropriate imaging technology stems from the shortcomings of each imaging technology. There is a strong need in industry for a new and robust imaging technology which can overcome these drawbacks. Sterling (2000) studied innovative technologies for locating utilities which can be transferable to industry. Most of them were based on the GPR technique but did not overcome the innate problems of GPR such as low operating capability in highly conductive soils. Efforts at the Construction Automation Research Laboratory (CARL) in North Carolina State University have focused on integrating both GPR and electromagnetic equipment onto an excavator for safely locating 2 or 3 three meters ahead of the excavation. Such systems would be helpful to detect all types of utility while performing excavations (i.e., during the construction phase of the 
project), but cannot be used in the planning stage of the project. Research is underway at the Trenchless Technology Center (TTC) in Louisiana Tech University to account for uncertainty of the position of underground utilities utilizing approximate reasoning techniques and simple sensor fusion method. By combining data from site visits, as-built drawings and GPR systematically, the system attempts to delineate the location of underground utility in a probabilistic manner.

\section{Data interpretation system}

GPR is the most single area of technology development since it can identify non-conducting pipes and cables. Only highly trained technicians or geophysicists can interpret effectively the reflected signal data from the underground utilities using the GPR. Artificial Neural Networks and fuzzy logic as well as other pattern matching methods may be used to interpret raw or processed field measurements. Expert systems may also be used to reduce the need for a trained expert for the interpretation of results (Sterling 2000).

\section{Decision aid system for selecting underground utility material}

Newly developed materials such as plastics, composites, fiber optic cables, etc., that are not metallic are finding increasing use in the underground utility market. These materials are very difficult to locate with currently developed technologies. Since the adverse effect of mis-locates or utility hit is becoming more and more apparent, utility owners now must consider the ease of locating utilities prior to construction. For instance, providing permanent and correct record of the newly constructed utilities at the time of construction can be one of the most effective solutions. If a relationship among various materials used for underground utilities, current designating methods, utility construction methods, bedding materials as well as the depth and diameter of utilities is clearly identified, then such a relationship can assist in making more appropriate decisions regarding material to be used for newly constructed utilities.

\subsection{Implementation}

The potential users of the IMAGTECH are two-fold. First, new engineers in the Indiana Department of Transportation (INDOT) could benefit from the developed program as a training 
tool to enhance their knowledge of imaging technologies. Second, from the perspective of SUE consultants, IMAGTECH can be an excellent tool to select the most appropriate technology for novice engineers in field who are not familiar with the technical specifications of different imaging technologies or to ensure that the utility imaging technology chosen is comprehensive and accurate.

The multimedia educational tool is hosted on a Purdue server (http://rebar.ecn.purdue.edu /utilities/index.htm). In addition, IMAGTECH is loaded on the "Emerging Construction Technologies" website (http://www.new-technologies.org/ECT/Other/imagtech.htm) which is managed by Construction Engineering and Management division at Purdue University. The source code of the IMAGTECH program will be transferred to the Information Technology group at INDOT for further development and implementation of the program. 


\section{REFERENCES}

AGI (American Geosciences Inc.) (2001). "SuperSting R8/IP Multi-channel Resistivity Imaging System." <http://www.agiusa.com> (Jun. 23, 2001).

American Society of Civil Engineers (2002) "Standard Guidelines for the Collection and Depiction of Existing Subsurface Utility Data” ASCE Codes and Standards Activity Committee (CSAC), New York, N.Y.

American Water Works Association (1989) "Manual M11 - Steel Pipe- A Guide for Design and Installation.” $3^{\text {rd }}$ Ed, American Water Works Association, Denver, CO., 1989.

Anspach, J. H. and Wilson, S. E. (1994). “Case study of an underground $138 \mathrm{KV}$ transmission line design utilizing subsurface utility engineering." Proceedings of the American Power Conference. Publ by Illinois Inst of Technology, Chicago, IL, USA. v 56 pt 1 1994. p 137141

Anspach, J. H. (1995) Subsurface utility engineering: upgrading the quality of utility information International Conference on Advances in Underground Pipeline Engineering - Proceedings 1995. ASCE, New York, NY, USA. 813-824.

Arnold, J. E. (2001). <http://www.ghcc.msfc.nasa.gov/sparcle/sparcle_tutorial.html> (June 10, 2001)

Beasley, J. E. (2001) “Decision Tree.” Sep 29 2001, available: http://www.ms.ic.ac.uk /jeb/or/detree.html.

Bower, P. (2000). “Introduction to environmental science." < http://www.columbia.edu /itc/barnard/envsci/bc1001/bfaref/groundpenetrationradarintro.thml> (August 12, 2000). 
Bridges, B. (2001). "Laser Tracker Maps Three-Dimensional Features.” The Industrial Physicist. American Institute of Physics. Aug/Sep, 28-32

Common Ground Alliance (1999). "Study of One-Call Systems and Damage Prevention Best Practices” Sponsored by the United States Department of Transportation; Research and Special Programs Administration; Office of Pipeline Safety, as authorized by the Transportation Equity Act of the $21^{\text {st }}$ Century (TEA 21). $<$ http://www.commongroundalliance.com /docs/s8/p0002/090499_Composite.pdf> (April $1,2001)$

Clemens, R.T. (1996) “Making hard decisions: and introduction to decision analysis.” Elmont, Calif.: Duxbury Press, 1996.

CSIRO (Commonwealth Scientific \& Industrial Research Organisation) (2001).

$<$ http://www.em.csiro.au/mine_environment_imaging/research/projects/applications3d/> (Sep. 23, 2000).

Doctor, R.H., N.A. Dunker and N.M. Santee, 1995. Third-party Damage Prevention Systems, Final Report for Gas Research Institute Contract No. 5094-810-2870, Oct. 1995, by Nicor Technologies, Naperville IL.

Dodge, L. J., Anspach, J. H. (1995) "Case Study of an Environmental Assessment Combining Historical Practices and Subsurface Utility Engineering.” Proc., the American Power Conference. v 57-2 1995. Illinois Inst of Technology, Chicago, IL, USA. 870-873.

Federal Highway Administration (FHWA). (2002). "Subsurface Utility Engineering." $<$ http://www.fhwa.dot.gov/programadmin/basicinf.htm> (March 8, 2002)

GeoSpec LLC (2002). "Subsurface Utility Engineering (SUE)" < http://www.geospecllc.com/downloads/SUE_white_paper.PDF> (May 11,2002) 
“GPS Data Collection and Utility Infrastructure Inventory.” <http://www.woolpert.com /surveying/gpsdata.html> (August 12, 2002)

Iseley, T., Gokhale, S. (1997). "Trenchless Installation of Conduits Beneath Roadways.” NCHPR Synthesis 242. Transportation Research Board/National Research Council, Washington, D.C., 36.

Haddon, M.K (2001). “Better Training Needed for Locate Technicians” Underground Focus, May/June 2001, 24-25.

Hassan, A., Karimi, Aemal, J., Khattak, and Hummer, J.E. (2000). Evaluation of Mobile Mapping system for roadway data collection. ASCE. Journal of Computing in Civil Engineering, 14(3). 168-173.

Heinrich, J. (1996), Assessment of the Cost of Underground Utility Damages, North Carolina State University Tech. Report (August 1996).

Herman, H. (1997). "Robotic Subsurface Mapping Using Ground Penetrating Radar” doctoral dissertation, tech. report CMU-RI-TR-97-19, Robotics Institute, Carnegie Mellon University.

Irias, N. J., and Miller, M. L. (1998). “Cathodic Protection of Cast Iron Pipe.” Proc., the 1998 Pipeline Division Conference, ASCE, San Diego, CA.

Jeyapalan, J. K. (1990). “Advances in pipeline materials and design in Europe and North America.” Pipeline Design Installation Proceedings of International Conference. ASCE, New York, NY. 1-16.

JR Associates (2001). "Utility Locating." <http://www.greategeophysics.com/pipe.htm> (Oct. 7, 2001). 
Jeong, H. S. (2001) “A Decision Tool for Subsurface Utility Engineering” Independent Research Study, School of Civil Engineering, Purdue University, December 2001.

Jeong, H.S., Abraham, D. M., Anspach, J. H., Zembillas, N. M., Lew, J. J. and Halpin, D. W. (2002), “Identification of Buried Utilities Using Subsurface Utility Engineering” NO-DIG 2002, $11^{\text {th }}$ Conference of North American Society of Trenchless Technology (NASTT), April 2002, Montreal, Canada.

Kavanagh B. F., 2001. Surveying with Construction Applications, Prentice Hall, Englewood Cliff, NJ.

Lee, S. W. (2000) “Analytical Methods for Bid-markup Decisions in Microtunneling Projects.” Independent Research Study, School of Civil Engineering, Purdue University, December 2000.

Leica (2003), “Leica Geosystems” <http://www.leica-geosystems.com/> ( September 20, 2003)

Lew, J. J., Lew, J. C. (2001) "Evaluation of the performance of subsurface utility engineering as a design cost reduction tool.” CIB world Building congress, April 2001, Wellington, New Zealand.(CD-ROM formatted).

Lew, J. J. (2000) Cost Savings on Highway Projects Utilizing Subsurface Utility Engineering. Research Report - FHWA-IF-00-014, Purdue University/ Federal Highway Administration. Washington DC.

Lew, J. J., \& Anspach, J. H. (2000). "Elimination of utility line cuts on a highway project using subsurface utility engineer.” Proceedings of the CIB W99 International Conference on Designing for Safety and Health, London, England. June 2000. 235-242.

Lew, J. J., Lew, J. C., \& Harter, J. E. (2000). “ Procedures for the Incorporation of Subsurface Utility Engineering (SUE) in the Design Process.” Proceedings of the CIB W89 
International Conference on Building Education and Research, May 2000, Atlanta, GA. Georgia Tech \& Clemson University, 165-172.

Lew, J. J. (1996). "Subsurface Utility Engineering - An initial step in Project Development." The Proceedings of the Associated Schools of Construction, Texas A\&M University, Texas, April 1996, 217-222.

Lorenc, Steven J., and Bernold, Leonhard E.(1998) `Smart' Attachment for Utility Damage Prevention. Proceedings of the ASCE Specialty Conference on Robotics for Challenging Environments. ASCE, Reston, VA, USA. 140-146.

Los Alamos National Laboratory (2003), “Cyrax" ${ }^{\mathrm{TM}}$ : A Portable 3D Laser Mapping and Imaging System” <http://www.lanl.gov/orgs/p/rh/cyrax.html> ( September 20 03)

Mala GeoScience (2002). “RAMAC GPR” Company technical brochure, Sweden.

Microsearch Ltd. (2001) “What is Microgravity?” < http://www. microgravity. co.uk/html/what_is_microgravity_.html> (June 12, 2001).

NGS (North Geophysical Service) (2001). “Methods \& Applications Reference Manual.” $<$ http://www.negeophysical.com> (Apr. 27 2001).

Noone, J. F. Moyer, P. D. Gracie, M. (1999) “Use of Subsurface Utility Engineering Techniques to Assess Existing Buried Pipeline Condition.” 1999 International Public Works Congress and Exposition 1999. Reston, VA, USA.. p 205-218.

Obitko, M. (2001) “Introduction to Genetic Algorithms.”, <http://cs.felk.cvut.cz / xobitko/ga> ( Sep 30 2001). 
P \&GJ (Pipeline \& Gas Journal) (2000). “Location Tool Providence Gas Finds Answer to Help Find Plastic Pipe.” <http://www.undergroundinfo.com/pgj\%20archive /archive78.htm> (July 13, 2000).

Pacific Northwest National Laboratory (PNNL) “Artificial Neural Networks.” Sep 30 2001, Available:http://www.emsl.pnl.gov:2080/proj/neuron/neural/what.html

Radiodetection Corp, (1994) “ABC and XYZ of Locating Buried Pipes and Cables.” Radiodetection Ltd., Technical Report, Bristol, UK.

Radiodetection Corp, (1990) “The Theory of Buried Pipe and Cable Location.” Radiodetection Ltd., Technical Report, Bristol, UK.

Radiodetection Corp, (2001) “Acoustic Pipe Tracer.” Radiodetection Ltd., Technical report, Bristol, UK.

Reid, J. (1999) “Are Contractors, Engineers and Architects Ready for a Crisis?” American Institute of Constructors (AIC), July/August, 28, 1-7.

Schonstedt Instrument Co. (2000) “Instruction Manual Model MAC-51Bx (Magnetic and DualFrequency Pipe and Cable Locator).” Schonstedt Instrument Company, Technical Report, 4 Edmond Road, Kearneysville, WV 25430.

Sharma, P. V. (1997) “Environmental and Engineering Geophysics.” Cambridge University Press, Cambridge, U.K.

“Side-Scan Sonar Image” <http://www.punaridge.org/doc/factoids/DigitalData/Default.htm> (May 11, 2002). 
Sterling, R. L. (2000). "Utility Locating Technologies: A Summary of Responses to a Statement of Need Distribution by the Federal Laboratory Consortium for Technology Transfer.” Federal Laboratory Consortium Special Reports Series No.9 ISSN 1075-9492C, Feb 2000.

Stevens, R. E. (1993). “Adding value through the innovations of Subsurface Utility Engineering (SUE)." Proceedings of the society of American Value Engineers, Washington, D.C.

Stevens, R. E., and Anspach, J. H. (1993). "New technology overcomes the problems of underground system interferences on power projects.” Proceedings of the American Power Conference. Publ by Illinois Inst of Technology, Chicago, IL, USA. v 55 pt 1 1993. 323326

Stinson, W., 1998. "Preventing damage to unlocatable infrastructure," Session handout, Session A5, Damage Prevention Convention, Sponsored by Underground Focus Magazine, Atlanta GA, Dec 2-4, 1998.

Survey Solutions (2003), “A New Approach to Robotic and Survey Equipment.” (http://www.surveyrobotics.com/trimble5600drsystem.htm) <October 9, 2003).

Technos, Inc. (2001). "Surface Geophysics.” <http://www.technos-inc.com/surface.html> (Sep. 10, 2001).

Tommelein, I.D. and Zouein, P.P. (1993). "Interactive Dynamic Layout Planning." ASCE, J. of Constr. Engrg. and Mgmt., 119 (2) 266-287

Tommelein, I.D. (1994). "MoveCapPlan: An Integrated System for Planning and Controlling Construction Material Laydown and Handling." ASCE, Proc. 1st Computing Congress, ASCE, New York, NY, 1172-1179.

Tommelein, I.D. (1995). "New Tools for Site Materials Handling and Layout Control." Proc. Construction Congress '95, Ibbs, C.W. (editor), ASCE, New York, NY, 479-486. 
Tsoukalas, L.H., Uhrig, R.E., (1997) “Fuzzy and Neural Approaches in Engineering.” John Wiley and Sons, Inc., New York, NY.

U.S. Department of Transportation, Office of Pipeline Safety, Research and Special Programs Administration (1999) "Common Ground: Study of One-Call Systems and Damage Prevention Best Practices.” as authorized by the Transportation Equity Act for the $21^{\text {st }}$ Century (TEA 21), Aug. 1999.

United States General Accounting Office (USGAO). (1999). “Transportation Infrastructure: Impacts of Utility Relocations on Highway and Bridge Projects.” Publication No. GAO/RCED-99-131. Washington, DC: U.S. Government Printing Service.

Weil, G. J., and Graf, R. J. (1991). "Infrared Thermography based Pipeline Leak Detection System.” Proc., International Conference on Thermal Sensing and Imaging Diagnostic Applications, 3-5 April 1991, Orlando, Florida.

Wilson, K., Smith, C., Neagley, D., Kacyra, B., Dimsdale, J., and Zayhowski, J.J. (1998). “CYRAX ${ }^{\mathrm{TM}}$ : A Portable Three-Dimensional Laser-Mapping and Imaging System.” Los Alamos National Laboratory, Progress Report, Physics Division, 76-79

Wirahadikusumah, R., Abraham, D. M., Iseley T., and Prasanth, R. K. (1998). “Assessment Technologies for Sewer System Rehabilitation.” J. Automation in Constr., 7(4), 259-270, ELSEVIER Science, New York, New York.

Yvan, J., Beliveau, J., Williams, M., King, M.G. and Niles, A.R.(1995). Real-Time Position Measurement Integrated with CAD: Technologies and Their Protocols. ASCE, J. of Constr. Engrg. and Mgmt., 121(4), 346-354.

Yen, M. (1995) “Fuzzy Logic.” <http://cati.csufresno.edu/upda/95/winter/story1.html> (Sep. 30, 2001). 
Zembillas, N. (2002). "Subsurface utility engineering - A technology-driven process that results in increased safety, fewer claims and lower costs.” Conference of the International Society of Trenchless Technologies (ISTT), Copenhagen, Denmark, May 28-31, 2002. (in CDROM).

\section{Personal Contacts}

Anspach, J. H., Principal of So-Deep, Inc., Personal Communication, August October, 2001.

Willis, S., Technical support engineer of Radiodetection Corp., Personal communication, September October 2001. 


\section{Appendix A:}

\section{Site Visit Reports}

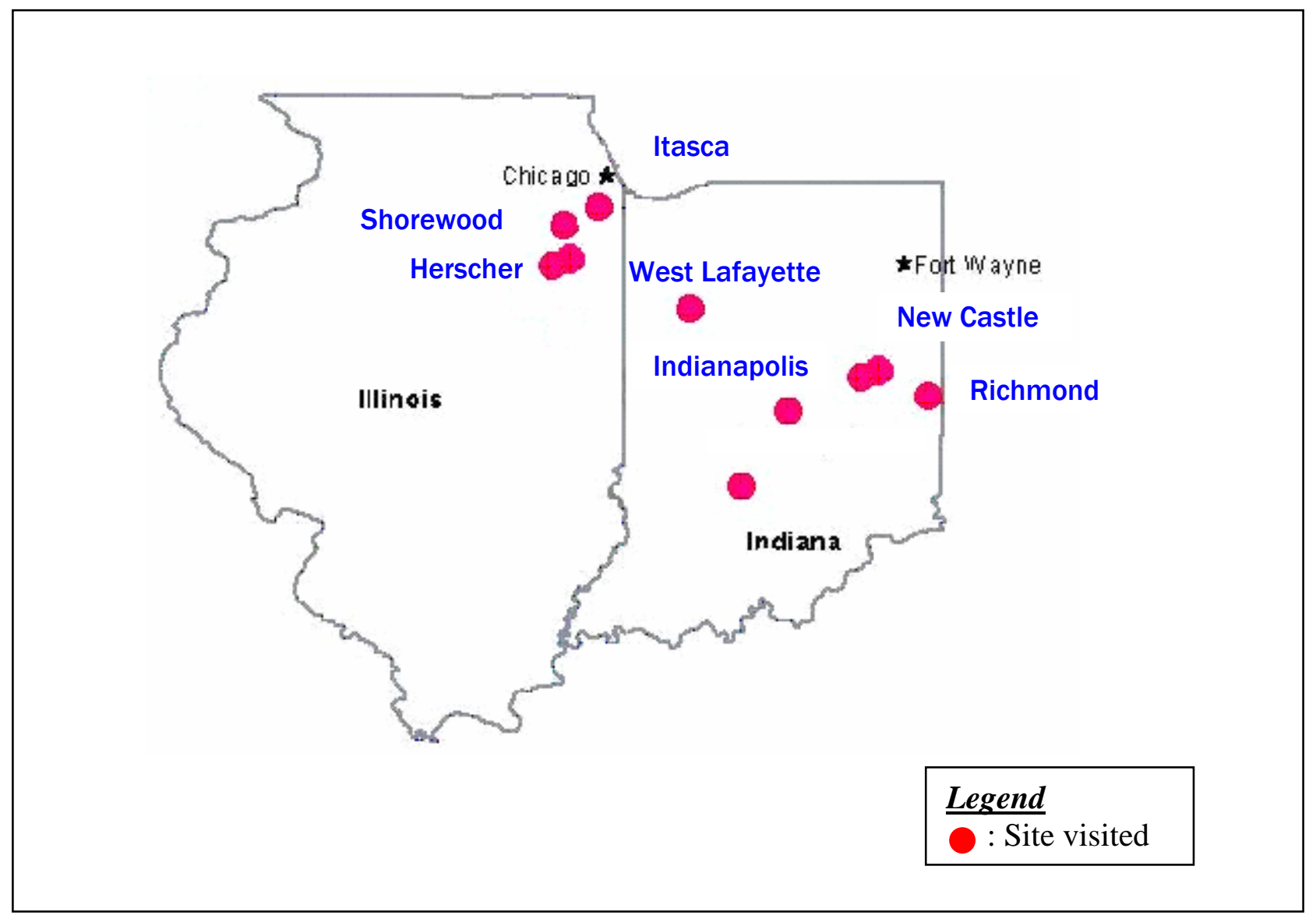

\begin{tabular}{|c|c|}
\hline Visited States & Name of City (number of visit) \\
\hline Indiana & $\begin{array}{r}\text { Richmond (1), New Castle (2), Martinsville (1), } \\
\text { Indianapolis (1), West Lafayette (1) }\end{array}$ \\
\hline Illinois & Shorewood (1), Herscher (2), Itasca (1) \\
\hline
\end{tabular}




\section{SITE VISIT REPORT (1)}

\begin{tabular}{|l|l|}
\hline 1. Date & June 15, 2001 \\
\hline 2. Location & SR27 in Richmond, IN \\
\hline 3. Owner/Client & INDOT \\
\hline 4. Contractor/Contact & $\begin{array}{l}\text { TBE group Inc. } \\
\text { (Bob Clemens, Tel: 317-585-3540) }\end{array}$ \\
\hline
\end{tabular}

\section{Project Description}

- $\quad$ The project started near the intersection of SR227 and SR27 and ended at the north of Locust Drive on SR 27

- $\quad$ The project duration was from March 22, 2001 to July 12, 2001 using approximately three crews a day

- $\quad$ In 2004, INDOT intends to add two travel lanes to I-70 from the interchange at I70 and

I-27 to approximately 2 miles (3.2 kilometers) to the east.

(Site work on June 15, 2001)

- Designating \& locating a gas pipeline (made of steel)

- $\quad$ Process for designating the gas pipeline

o Equipment: Pipe and cable locator - inductive mode

0 A) put a transmitter on the surface exactly above the gas pipe (the location is identified through pre-designation process)

o B) Designating with a receiver (applied frequency: $33 \mathrm{KHz}$ ).

o C) Mark on the surface

- $\quad$ Process for locating the gas pipeline

o Equipment: Vacuum excavation system

o A) Break the concrete pavement

o B) Vacuum excavation (Vacuum + soil breaker)

0 C) Find the gas pipe

o D) Record utility features such as depth, diameter, material, condition, etc.

o E) Surveying (record three dimensional location of the utility)

o F) Recover the hole and the pavement 


\begin{tabular}{|l|l|l|l|}
\hline 6. Site Conditions & Gas pipe & $\begin{array}{l}\text { f) Ground surface } \\
\text { condition }\end{array}$ & Paved \\
\hline a) Type of utility & $\begin{array}{l}\text { g) Inner state of } \\
\text { pipe }\end{array}$ & $\begin{array}{l}\text { Filled with flowing } \\
\text { material }\end{array}$ \\
\hline b) Material of utility & Steel & h) Soil type & $\begin{array}{l}\text { Granular and } \\
\text { compacted soil }\end{array}$ \\
\hline $\begin{array}{l}\text { c) Joint type of } \\
\text { metallic pipe }\end{array}$ & Not known & i) Depth of Utility & $1.2 \mathrm{ft}(0.4 \mathrm{~m})^{*}$ \\
\hline $\begin{array}{l}\text { d) Special material } \\
\text { for detection }\end{array}$ & None & 6 in $(150 \mathrm{~mm})^{*}$ \\
\hline $\begin{array}{l}\text { e) Access point to } \\
\text { utility }\end{array}$ & $\begin{array}{l}\text { Known from } \\
\text { previous designation }\end{array}$ & $\begin{array}{l}\text { j) Diameter of } \\
\text { Utility }\end{array}$ \\
\hline $\begin{array}{l}\text { Traffic control required / utility not congested } \\
\text { *: Known after locating the utility }\end{array}$ \\
\hline \begin{tabular}{l} 
7. Map of the Project Location \\
\hline
\end{tabular}
\end{tabular}

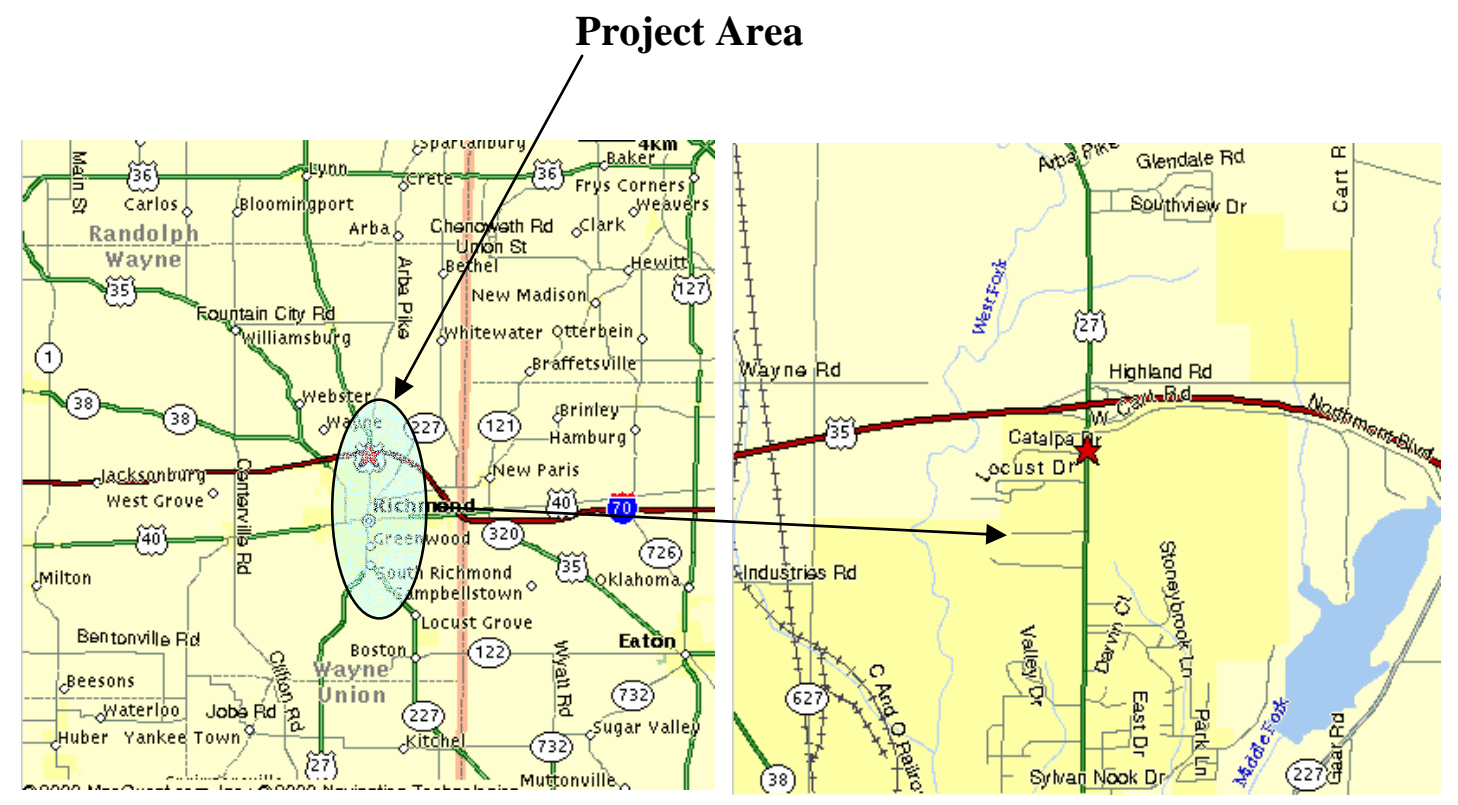

Richmond, IN 


\section{SITE VISIT REPORT (2)}

\begin{tabular}{|l|l|}
\hline 1. Date & May 30, 2002 \\
\hline 2. Location & SR 103, New castle, IN \\
\hline 3. Owner/Client & INDOT \\
\hline 4. Contractor/Contact & $\begin{array}{l}\text { TBE group Inc. } \\
\text { (Allen Pearson, supervisor, Tel: 317-691-2938) }\end{array}$ \\
\hline 5. Project Description & \multicolumn{2}{|l}{$\mid$}
\end{tabular}

- $\quad$ Designating/Locating underground utility lines along SR 103 (South $18^{\text {th }}$ street)

- $\quad$ Buried utilities: gas, sewer and water pipes.

(Site work on may 30, 2002)

- $\quad$ Process for designating gas pipelines

o Equipment: Pipe and cable locator - conductive mode

o A) hook up a transmitter to tracing wire on the gas meter

o B) Designating with a receiver(Applied frequency: $33 \mathrm{KHz}$ )

o C) Mark on the surface

- $\quad$ Process for locating gas pipelines

o Equipment: Vacuum excavation system.

o A) Vacuum excavation (vacuum + soil removal).

$0 \quad$ B) Find the gas pipe.

o C) Record the utility features such as depth, diameter, material, etc.

o D) Recover the hole. 


\begin{tabular}{|l|l|l|l|}
\hline 6. Site Conditions & Gas pipe & $\begin{array}{l}\text { f) Ground surface } \\
\text { condition }\end{array}$ & Natural surface \\
\hline a) Type of utility & $\begin{array}{l}\text { g) Inner state of } \\
\text { pipe }\end{array}$ & $\begin{array}{l}\text { Filled with flowing } \\
\text { material }\end{array}$ \\
\hline b) Material of utility & Plastic pipe & h) Soil type & Silt and clay \\
\hline $\begin{array}{l}\text { c) Joint type of } \\
\text { metallic pipe }\end{array}$ & Not Applicable & i) Depth of Utility & $* 2.3 \mathrm{ft}(0.75 \mathrm{~m})$ \\
\hline $\begin{array}{l}\text { d) Special material } \\
\text { for detection }\end{array}$ & Tracing wire & $\begin{array}{l}\text { j) Diameter of } \\
\text { Utility }\end{array}$ & $* 2$ in \\
\hline $\begin{array}{l}\text { e) Access point to } \\
\text { utility }\end{array}$ & Gas meter \\
\hline $\begin{array}{l}\text { Traffic control required/ Utility not congested } \\
*: \text { Known after locating the utility }\end{array}$ & \\
\hline 7. Map of the Project Location & \\
\hline
\end{tabular}

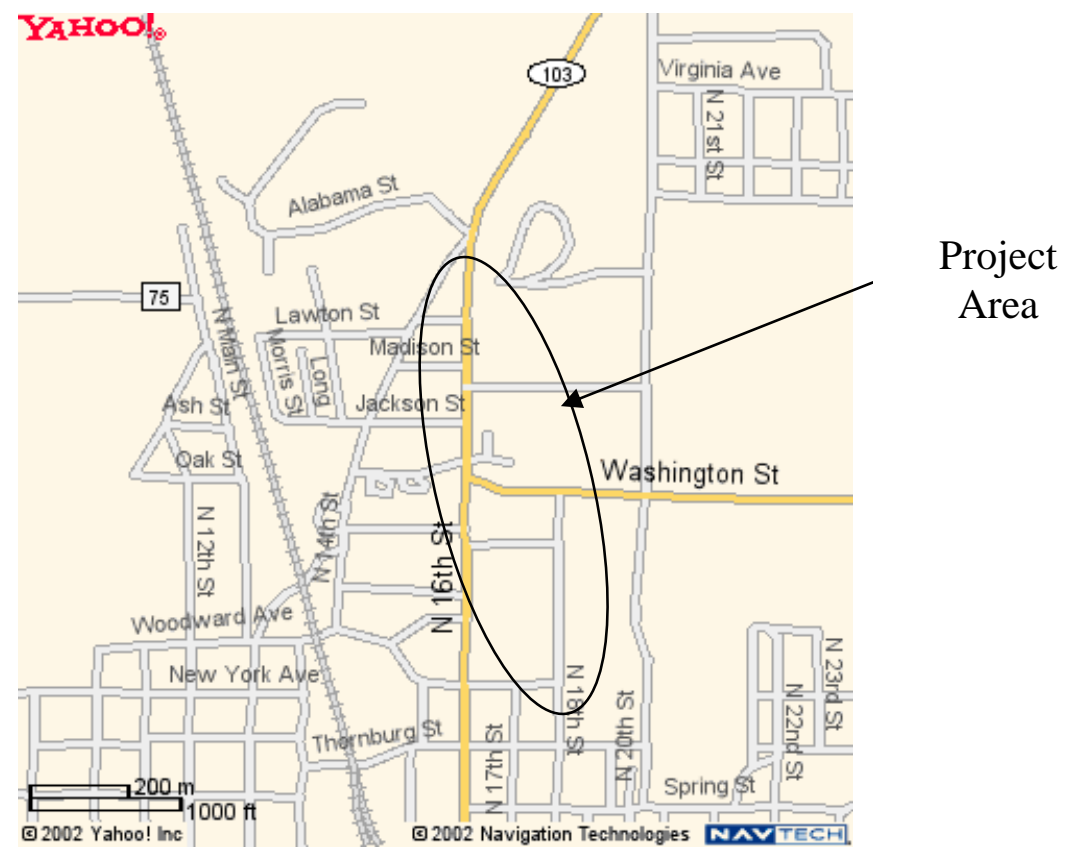

$\underline{\text { New Castle, IN }}$ 


\section{SITE VISIT REPORT (3)}

\begin{tabular}{|l|l|}
\hline 1. Date & June 13, 2002 \\
\hline 2. Location & SR 103, New castle, IN \\
\hline 3. Owner/Client & INDOT \\
\hline 4. Contractor/Contact & $\begin{array}{l}\text { TBE group Inc. } \\
\text { (Thomas Randles, GPR specialist, Tel: 317-691-2938) }\end{array}$ \\
\hline 5. Project Description &
\end{tabular}

- Designating underground utility lines along SR 103 (South $18^{\text {th }}$ street)

- Buried utilities: gas, sewer and water pipes.

(Site work on June 13, 2002)

- $\quad$ Process for designating gas, water, sewer lines.

- Utilities of some areas were not designated by pipe and cable locator system. Thus, GPR was tried in these areas to find them.

o Equipment: GPR

o A) Drag the GPR on the surface where utilities were supposed to exist.

o B) Mark on the surface where utilities were found.

o C) Mark on the surface 


\begin{tabular}{|l|l|l|l|}
\hline 6. Site Conditions & $\begin{array}{l}\text { Water, Gas, Sewer } \\
\text { and Telephone lines }\end{array}$ & $\begin{array}{l}\text { f) Ground surface } \\
\text { condition }\end{array}$ & Paved \\
\hline b) Material of utility & Not known & $\begin{array}{l}\text { g) Inner state of } \\
\text { pipe }\end{array}$ & $\begin{array}{l}\text { Filled with flowing } \\
\text { material }\end{array}$ \\
\hline $\begin{array}{l}\text { c) Joint type of } \\
\text { metallic pipe }\end{array}$ & Not known & h) Soil type & $\begin{array}{l}\text { Granular and } \\
\text { compacted soil }\end{array}$ \\
\hline $\begin{array}{l}\text { d) Special material } \\
\text { for detection }\end{array}$ & Not known & $\begin{array}{l}\text { i) Depth of Utility } \\
\text { (typical) }\end{array}$ & - \\
\hline $\begin{array}{l}\text { e) Access point to } \\
\text { utility }\end{array}$ & Hydrants & $\begin{array}{l}\text { j) Diameter of } \\
\text { Utility (typical) }\end{array}$ & - \\
\hline $\begin{array}{l}\text { Traffic control required/ Utility not congested } \\
\text { *: Known after locating the utility }\end{array}$ \\
\hline \begin{tabular}{l} 
7. Map of the Project Location \\
\hline
\end{tabular}
\end{tabular}

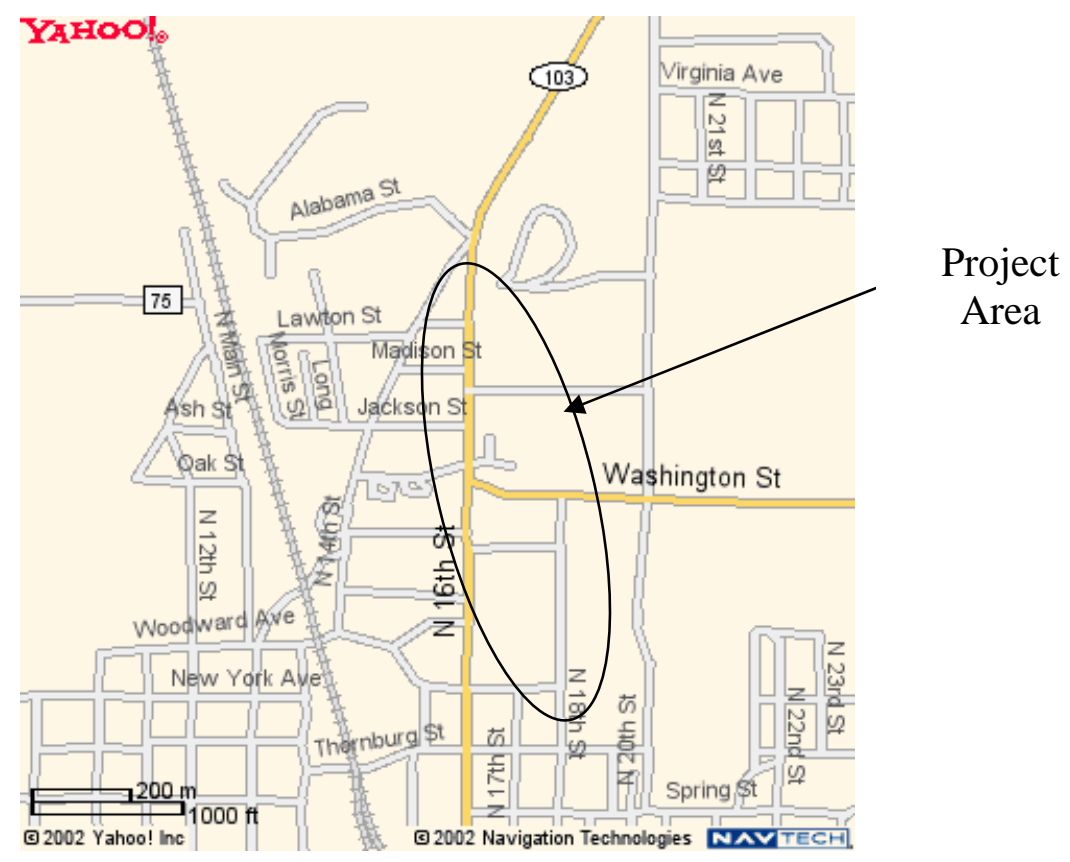

New Castle, IN 


\section{SITE VISIT REPORT (4)}

\begin{tabular}{|l|l|}
\hline 1. Date & July 3, 2002 \\
\hline 2. Location & SR 39, Martinsville, IN \\
\hline 3. Owner/Client & INDOT \\
\hline 4. Contractor/Contact & $\begin{array}{l}\text { TBE group Inc. } \\
\text { (Allen Pearson, Tel: 317-691-2938) }\end{array}$ \\
\hline 5. Project Description &
\end{tabular}

- $\quad$ Locating underground utility lines along SR 39.

(New drainage system will be constructed along SR 39)

- Buried utilities: Force main, water pipelines and telephone lines.

- Process for locating the utility lines

o Equipment: Vacuum Excavation System.

o Utility designation process completed.

0 A) Find the location where utility conflict may occur (typically marked by designers of the project on the as-built drawing)

o B) Vacuum excavation

o C) Measure the pipe depth, diameter, material, etc.

o D) Mark on the surface

\subsection{Site Conditions for Force Main}

\begin{tabular}{|l|l|l|l|}
\hline a) Type of utility & Force main (sewer) & $\begin{array}{l}\text { f) Ground surface } \\
\text { condition }\end{array}$ & Natural \\
\hline b) Material of utility & Ductile iron* & $\begin{array}{l}\text { g) Inner state of } \\
\text { pipe }\end{array}$ & $\begin{array}{l}\text { Filled with flowing } \\
\text { material }\end{array}$ \\
\hline $\begin{array}{l}\text { c) Joint type of } \\
\text { metallic pipe }\end{array}$ & Not known & h) Soil type & Clay + Silt \\
\hline $\begin{array}{l}\text { d) Special material } \\
\text { for detection }\end{array}$ & None & i) Depth of Utility & $4.2 \mathrm{ft} \mathrm{(1.4m)*}$ \\
\hline $\begin{array}{l}\text { e) Access point to } \\
\text { utility }\end{array}$ & Man Hole & $\begin{array}{l}\text { j) Diameter of } \\
\text { Utility }\end{array}$ & 16 in (400 mm)* \\
\hline *: Known after locating the utility & \multicolumn{3}{|l|}{} \\
\hline 6.2 Site Conditions for Water Pipe & $\begin{array}{l}\text { f) Ground surface } \\
\text { condition }\end{array}$ & Natural surface \\
\hline a) Type of utility & Water & $\begin{array}{l}\text { g) Inner state of } \\
\text { pipe }\end{array}$ & $\begin{array}{l}\text { Filled with flowing } \\
\text { material }\end{array}$ \\
\hline b) Material of utility & PVC (plastic pipe) & Silt and clay \\
\hline $\begin{array}{l}\text { c) Joint type of } \\
\text { metallic pipe }\end{array}$ & Not known & h) Soil type & $3.4 \mathrm{ft} \mathrm{(1.13m)}$ \\
\hline $\begin{array}{l}\text { d) Special material } \\
\text { for detection }\end{array}$ & None & i) Depth of Utility \\
\hline $\begin{array}{l}\text { e) Access point to } \\
\text { utility }\end{array}$ & Hydrant & $\begin{array}{l}\text { j) Diameter of } \\
\text { Utility }\end{array}$ & 6 in (150 mm) \\
\hline
\end{tabular}




\begin{tabular}{|c|c|c|c|}
\hline \multicolumn{4}{|c|}{ *: Known after locating the utility } \\
\hline \multicolumn{4}{|c|}{ 6.3 Site Conditions for Telephone Lines } \\
\hline a) Type of utility & Telephone & $\begin{array}{l}\text { f) Ground surface } \\
\text { condition }\end{array}$ & Paved \\
\hline b) Material of utility & $\begin{array}{l}\text { Cables in metallic } \\
\text { conduit* }\end{array}$ & $\begin{array}{l}\text { g) Inner state of } \\
\text { pipe }\end{array}$ & Conduit of cables \\
\hline $\begin{array}{l}\text { c) Joint type of } \\
\text { metallic pipe }\end{array}$ & Not known & h) Soil type & Silt and clay \\
\hline $\begin{array}{l}\text { d) Special material } \\
\text { for detection }\end{array}$ & None & i) Depth of Utility & $3.6 \mathrm{ft}(1.2 \mathrm{~m})^{*}$ \\
\hline $\begin{array}{l}\text { e) Access point to } \\
\text { utility }\end{array}$ & Pull boxes & $\begin{array}{l}\text { j) Diameter of } \\
\text { Utility }\end{array}$ & 2 in $(150 \mathrm{~mm}) *$ \\
\hline \multicolumn{4}{|c|}{ *: Known after locating the utility } \\
\hline
\end{tabular}

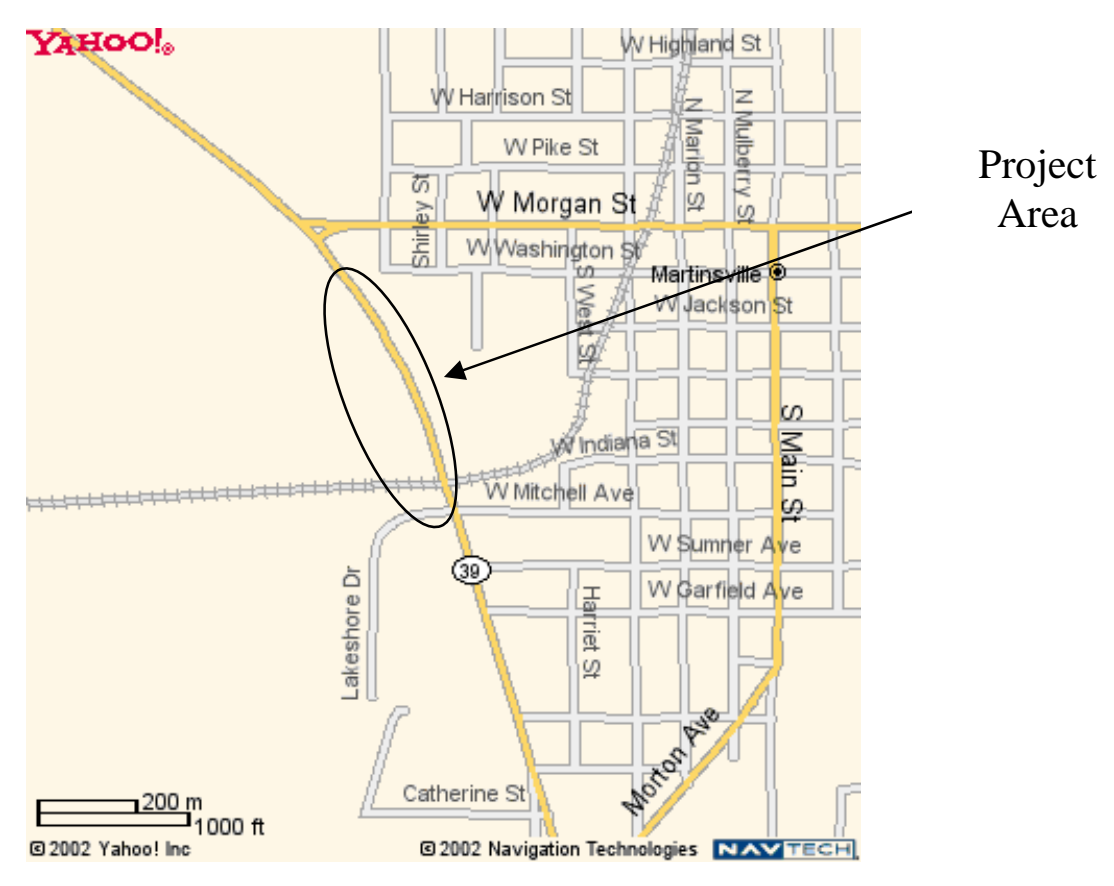

\section{Martinsville, IN}




\section{SITE VISIT REPORT (5)}

\begin{tabular}{|l|l|}
\hline 1. Date & September 4, 2002 \\
\hline 2. Location & Cottage Street, Shorewood, IL. \\
\hline 3. Owner/Client & ILDOT \\
\hline 4. Contractor/Contact & $\begin{array}{l}\text { TBE group Inc. } \\
\text { (Allen Pearson, Tel: 317-691-2938) }\end{array}$ \\
\hline
\end{tabular}

\section{Project Description}

- Designating underground utility lines along Cottage Street.

( Cottage Street will be expanded for additional travel lanes by ILDOT)

- Buried utilities: telephone lines in duct, water pipe and gas pipe.

- Station distance: 50ft (specified by the client(ILDOT))

(Site works on September 4, 2002)

- Process for designating telephone lines

o Equipment: Pipe and cable locator - conductive mode

o A) hook up a transmitter to telephone in duct through manhole

0 B) Designating with a receiver

o C) Applied frequency: $33 \mathrm{Khz}$

- $\quad$ Process for designating water mains

o Equipment: Pipe and cable locator - conductive and inductive mode

o A) Hook up a transmitter to a nearby hydrant

0 B) Designating with a receiver (conductive mode)

$0 \quad$ C) Move the transmitter to the designated point of water main

0 D) Designate the water pipe on the next station with a receiver (inductive)

\subsection{Site Conditions (for water pipe)}

\begin{tabular}{|l|l|l|l|}
\hline a) Type of utility & Water pipe & $\begin{array}{l}\text { f) Ground surface } \\
\text { condition }\end{array}$ & Paved \\
\hline $\begin{array}{l}\text { b) Material of utility } \\
\text { g) Inner state of } \\
\text { pipe }\end{array}$ & $\begin{array}{l}\text { Filled with flowing } \\
\text { material }\end{array}$ \\
\hline $\begin{array}{l}\text { c) Joint type of } \\
\text { metallic pipe }\end{array}$ & Not known & $\begin{array}{l}\text { hranular and } \\
\text { compacted soil }\end{array}$ \\
\hline $\begin{array}{l}\text { d) Special material } \\
\text { for detection }\end{array}$ & None & i) Depth of Utility & Not known* \\
\hline $\begin{array}{l}\text { e) Access point to } \\
\text { utility }\end{array}$ & Hydrant & $\begin{array}{l}\text { j) Diameter of } \\
\text { Utility }\end{array}$ & Not known* \\
\hline \multirow{2}{*}{ : will be known after locating the utility } & \\
\hline
\end{tabular}




\begin{tabular}{|l|l|l|l|}
\hline \multicolumn{4}{|l|}{ 6.2 Site Conditions for gas pipe } \\
\hline a) Type of utility & Gas pipe & $\begin{array}{l}\text { f) Ground surface } \\
\text { condition }\end{array}$ & Paved \\
\hline b) Material of utility & Steel & $\begin{array}{l}\text { g) Inner state of } \\
\text { pipe }\end{array}$ & $\begin{array}{l}\text { Filled with flowing } \\
\text { material }\end{array}$ \\
\hline $\begin{array}{l}\text { c) Joint type of } \\
\text { metallic pipe }\end{array}$ & Not known & h) Soil type & $\begin{array}{l}\text { Granular and } \\
\text { compacted soil }\end{array}$ \\
\hline $\begin{array}{l}\text { d) Special material } \\
\text { for detection }\end{array}$ & None & i) Depth of Utility & Not known* \\
\hline $\begin{array}{l}\text { e) Access point to } \\
\text { utility }\end{array}$ & Gas meter & $\begin{array}{l}\text { j) Diameter of } \\
\text { Utility }\end{array}$ & Not known* \\
\hline *: will be known after locating the utility & \multicolumn{3}{|l}{} \\
\hline 7. Map of the Project Location
\end{tabular}

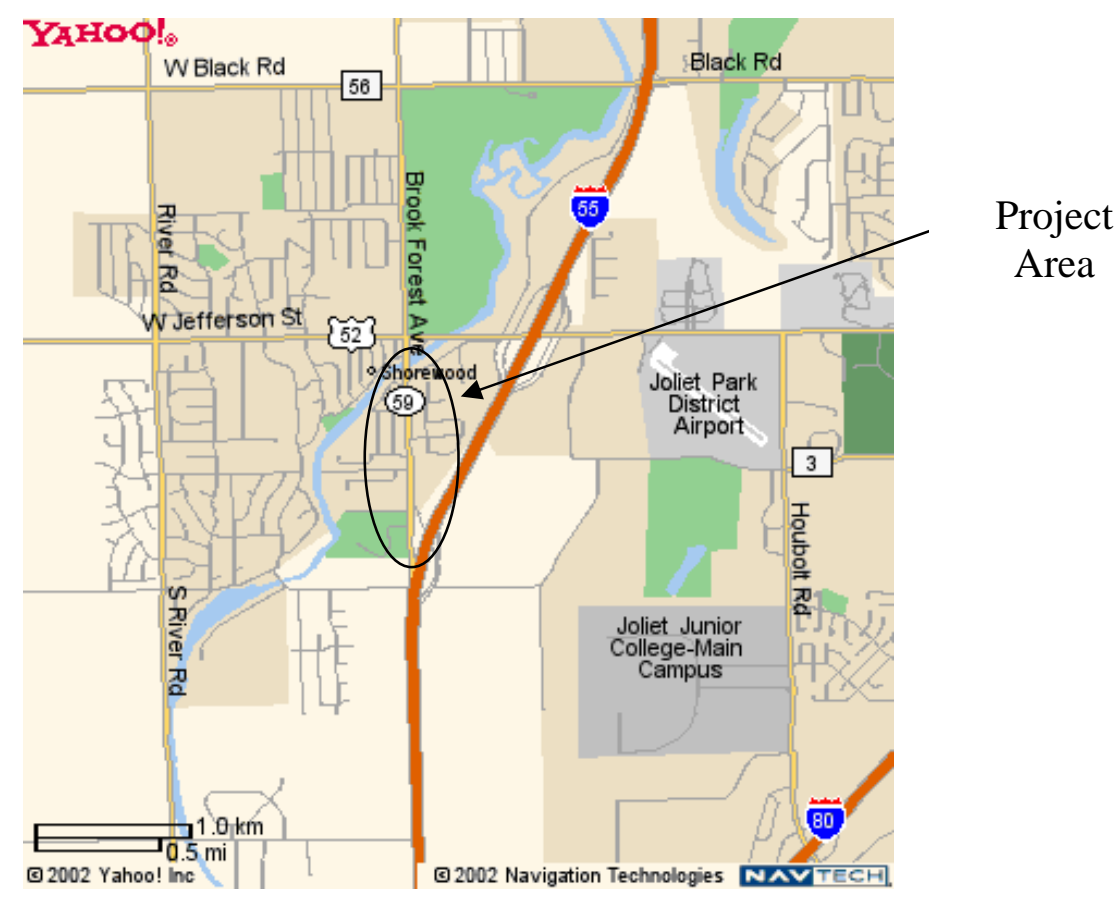

Shorewood, IL 


\section{SITE VISIT REPORT (6)}

\begin{tabular}{|l|l|}
\hline 1. Date & March 10, 2003 \\
\hline 2. Location & Highway 53 in Itasca, IL. \\
\hline 3. Owner/Client & IDOT \\
\hline 4. Contractor/Contact & $\begin{array}{l}\text { TBE group Inc. } \\
\text { (Stephen Brothers, supervisor, Tel: 630-773-6850) }\end{array}$ \\
\hline 5. Project Description & \multicolumn{2}{|l}{} \\
\hline
\end{tabular}

- $\quad 182,000 \mathrm{ft}$ long project divided into three sections $(36,000 / 76,000 / 74,000 \mathrm{ft})$ due to budget allocation.

- Contracted at \$400,000 on Lump Sum method.

- Designating/Locating underground utility lines along Highway 53

- $\quad$ Work performed prior for future drainage improvement and addition of travel lanes. (It's in the preliminary design stage of the project.)

- Buried utilities: water, sewer, telephones, electricity, gas, communication lines.

(Site work on March 10, 2003)

- Process for designating gas pipelines

o Equipment: Pipe and cable locator - conductive mode

o A) hook up a transmitter to tracing wire on the gas meter

o B) Designating with a receiver(Applied frequency: $33 \mathrm{KHz}$ )

o C) Mark on the surface 


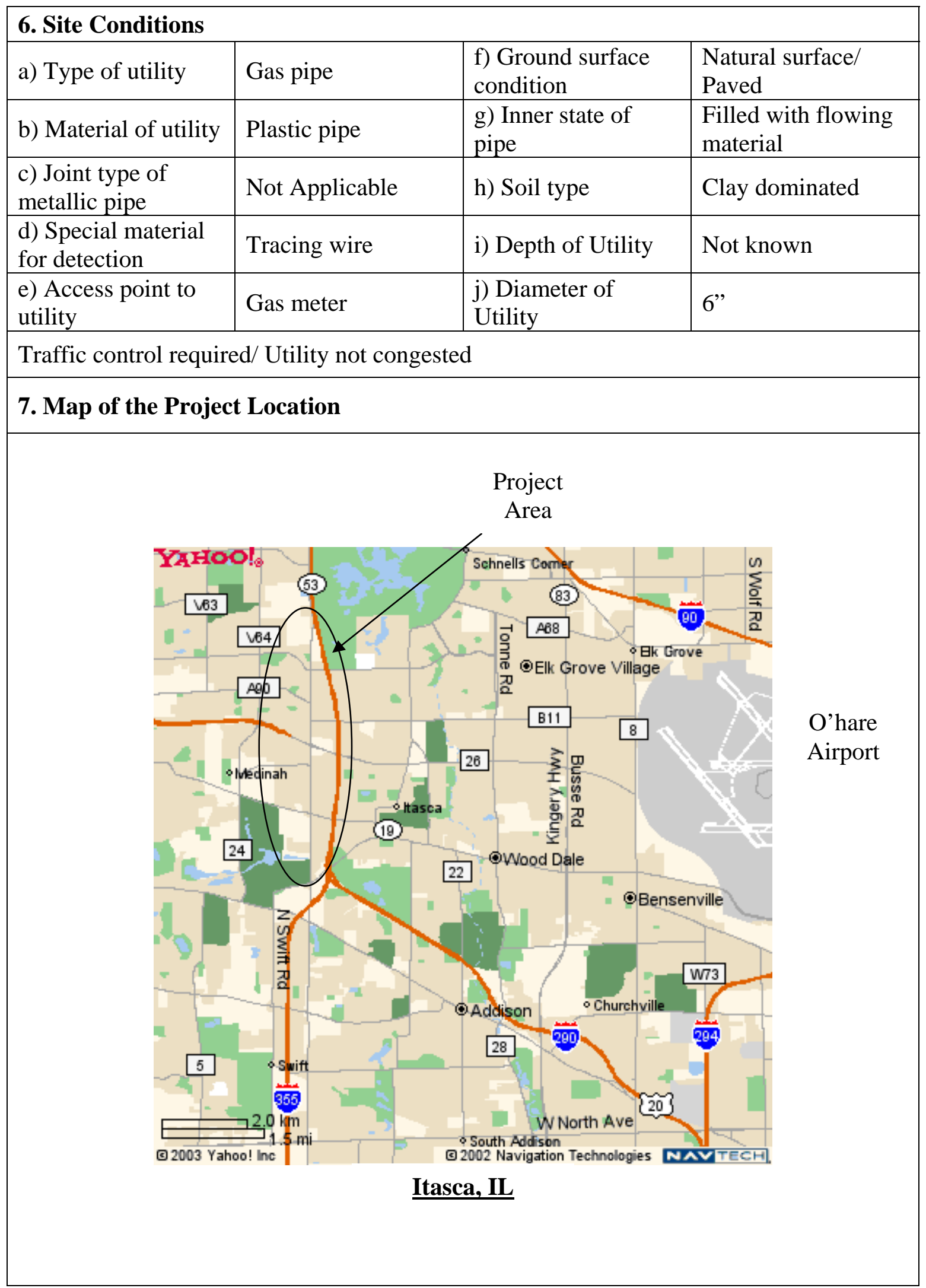




\section{SITE VISIT REPORT (7)}

\begin{tabular}{|l|l|}
\hline 1. Date & March 17, 2003 \\
\hline 2. Location & Lindbergh Rd in West Lafayette \\
\hline 3. Owner/Client & Unknown - Holly Molly \\
\hline 4. Contractor/Contact & $\begin{array}{l}\text { SM \& P } \\
\text { Dan Baker (574)206-8993 }\end{array}$ \\
\hline 5. Project Description
\end{tabular}

\section{Project Description}

- $\quad$ This site visit consisted of the demonstration of designating process by using typical pipe and cable locator and metal detector

- The project was located in West Lafayette on Lindbergh Rd.

- The demonstration was conducted on March 17, 2003.

(Work on March 17, 2003)

- $\quad$ Designating \& locating phone cable and TV lines

- $\quad$ Process for designating the phone, cable and TV lines:

o Equipment: Pipe and cable locator - inductive mode

o A) put a transmitter on the surface exactly above the electric line (the location is identified through pre-designation process)

o B) Designating with a receiver (applied frequency: $33 \mathrm{KHz}$ ).

o C) Mark on the surface

- Process for designating water valve/manhole cover:

o Equipment: Metal Detector

o A) Scan proposed area

o B) Adjust control knob for intensity

o C) Interpret magnetic readings (noise) to determine location

o D) Find the water valve

o E) Record location 


\begin{tabular}{|l|l|l|l|}
\hline \multicolumn{4}{|l}{ 6. Site Conditions } \\
\hline a) Type of utility & $\begin{array}{l}\text { Phone, Cable and } \\
\text { TV / Water Valve }\end{array}$ & $\begin{array}{l}\text { f) Ground surface } \\
\text { condition }\end{array}$ & Unpaved \\
\hline b) Material of utility & Not known & $\begin{array}{l}\text { g) Inner state of } \\
\text { pipe }\end{array}$ & Not known \\
\hline $\begin{array}{l}\text { c) Joint type of } \\
\text { metallic pipe }\end{array}$ & Not known & h) Soil type & $\begin{array}{l}\text { Granular and } \\
\text { compacted soil }\end{array}$ \\
\hline $\begin{array}{l}\text { d) Special material } \\
\text { for detection }\end{array}$ & $\begin{array}{l}\text { Trace Wire - Valve } \\
\text { Box }\end{array}$ & i) Depth of Utility & $1.2 \mathrm{ft}$ \\
\hline $\begin{array}{l}\text { e) Access point to } \\
\text { utility }\end{array}$ & Pedestal & $\begin{array}{l}\text { j) Diameter of } \\
\text { Utility }\end{array}$ & Not known \\
\hline Traffic control not required & & \\
\hline
\end{tabular}

\section{Map of the Project Location}

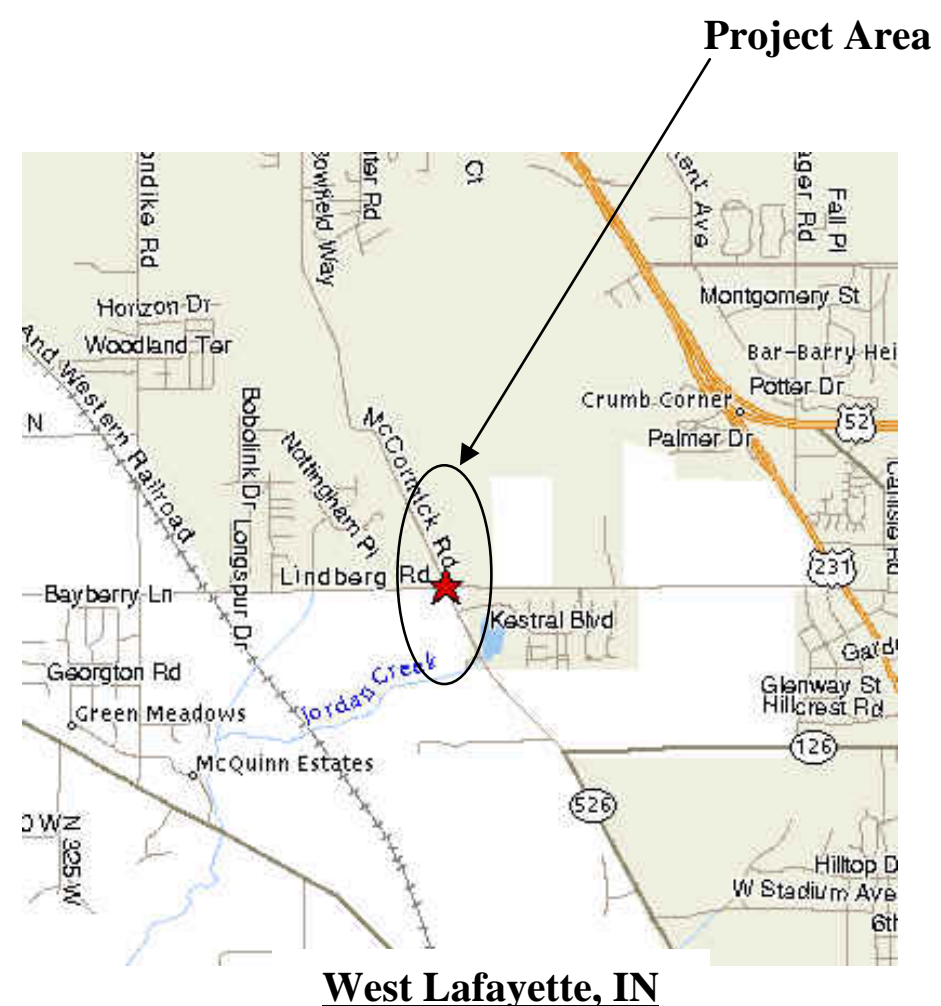




\section{SITE VISIT REPORT (8)}

\begin{tabular}{|l|l|}
\hline 1. Date & March 21,2003 \\
\hline 2. Location & W. $86^{\text {th }}$ Street and I-465 \\
\hline 3. Owner/Client & INDOT \\
\hline 4. Contractor/Contact & $\begin{array}{l}\text { Woolpert LLP } \\
\text { (Thomas Mahen, Group Manager, Tel: 317-299-7500) }\end{array}$ \\
\hline 5. Project Description &
\end{tabular}

- Designating underground utility lines along $86^{\text {th }}$ street in Indianapolis

- Buried utilities: gas, electric, telephone, water, and sewer lines.

(Site work on March 21, 2003)

- $\quad$ Process for designating gas, electric, telephone, water, and sewer lines.

- $\quad$ Utilities were designated by pipe and cable locator system.

- Process for designating electric lines

o Equipment: Pipe and cable locator -

o A) The transmitter was hooked up to a electricity line on the electric meter

o B) Designating with a receiver (applied frequency: $33 \mathrm{KHz}$ ).

o C) Mark on the surface

- Process for designating gas pipelines

o Equipment: Pipe and cable locator - conductive mode

o A) hook up a transmitter to tracing wire on the gas meter

o B) Designating with a receiver (Applied frequency: 33KHz)

o C) Mark on the surface

- $\quad$ Process for designating water valve/manhole cover:

o Equipment: Magnetometer

o A) Scan proposed area

o B) Adjust control knob for intensity

o C) Interpret magnetic readings (noise) to determine location

$0 \quad$ D) Find the water valve

o E) Record location 


\begin{tabular}{|c|c|c|c|}
\hline \multicolumn{4}{|l|}{ 6. Site Conditions } \\
\hline a) Type of utility & Electric lines & $\begin{array}{l}\text { f) Ground surface } \\
\text { condition }\end{array}$ & Paved/Unpaved \\
\hline b) Material of utility & Copper & $\begin{array}{l}\text { g) Inner state of } \\
\text { pipe }\end{array}$ & Not Applicable \\
\hline $\begin{array}{l}\text { c) Joint type of } \\
\text { metallic pipe }\end{array}$ & Not Applicable & h) Soil type & Clay dominated \\
\hline $\begin{array}{l}\text { d) Special material } \\
\text { for detection }\end{array}$ & None & $\begin{array}{l}\text { i) Depth of Utility } \\
\text { (typical) }\end{array}$ & - \\
\hline $\begin{array}{l}\text { e) Access point to } \\
\text { utility }\end{array}$ & Electric pole & $\begin{array}{l}\text { j) Diameter of } \\
\text { Utility (typical) }\end{array}$ & - \\
\hline
\end{tabular}

\section{Map of the Project Location}

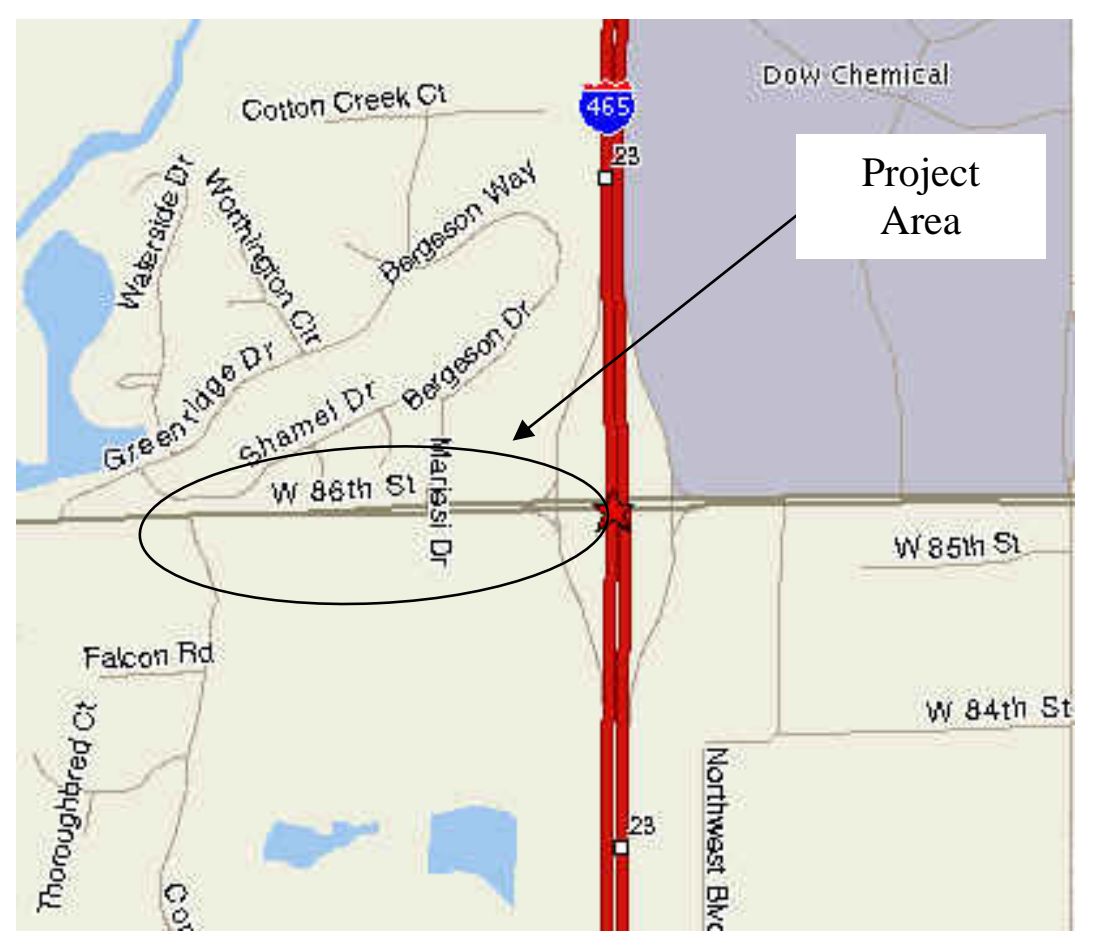

Indianapolis, IN 


\section{SITE VISIT REPORT (9)}

\begin{tabular}{|l|l|}
\hline 1. Date & March 25, 2003 \\
\hline 2. Location & IL Route 115, Herscher, IL \\
\hline 3. Owner/Client & IDOT \\
\hline 4. Contractor/Contact & $\begin{array}{l}\text { Geotrack } \\
\text { (George Lamplota, Tel: 630-530-7609) }\end{array}$ \\
\hline 5. Project Description &
\end{tabular}

- Locating of utility lines on IL Route 115.

- New Drainage System construction / Additional travel lanes will be added

- High priority job with fast turnaround. Coordination with surveyors

- Buried utilities: Telephones, Gas, Water, Fiber Optic Cables, Sewer pipes, Electricity, and Cable TV lines.

(Work on March 25, 2003)

- $\quad$ Process for locating the utility lines

o Equipment: Vacuum Excavation System.

o Utility designation process completed.

0 A) Find the location where the test hole is desired

o B) Vacuum excavate

o C) Find utility

o C) Measure the pipe depth, diameter, material, etc.

0 D) Mark the surface and move to next hole 


\section{Site Conditions}

\begin{tabular}{|l|l|l|l|}
\hline a) Type of utility & Telephones lines & $\begin{array}{l}\text { f) Ground surface } \\
\text { condition }\end{array}$ & Natural Surface \\
\hline b) Material of utility & Plastics & g) Inner state of pipe & $\begin{array}{l}\text { Conduit - full of } \\
\text { cable }\end{array}$ \\
\hline $\begin{array}{l}\text { c) Joint type of } \\
\text { metallic pipe }\end{array}$ & Not Applicable & h) Soil type & Clay dominated \\
\hline $\begin{array}{l}\text { d) Special material } \\
\text { for detection }\end{array}$ & Tracing wire & $\begin{array}{l}\text { i) Depth of Utility } \\
\text { (typical) }\end{array}$ & $2 \mathrm{ft} *(0.66 \mathrm{~m})$ \\
\hline $\begin{array}{l}\text { e) Access point to } \\
\text { utility }\end{array}$ & Pedestal & $\begin{array}{l}\text { j) Diameter of Utility } \\
\text { (typical) }\end{array}$ & $2 \mathrm{in} *(5 \mathrm{~cm})$ \\
\hline
\end{tabular}

Traffic control required/ Utility congested

*: known after locating them

\section{Map of the Project Location}

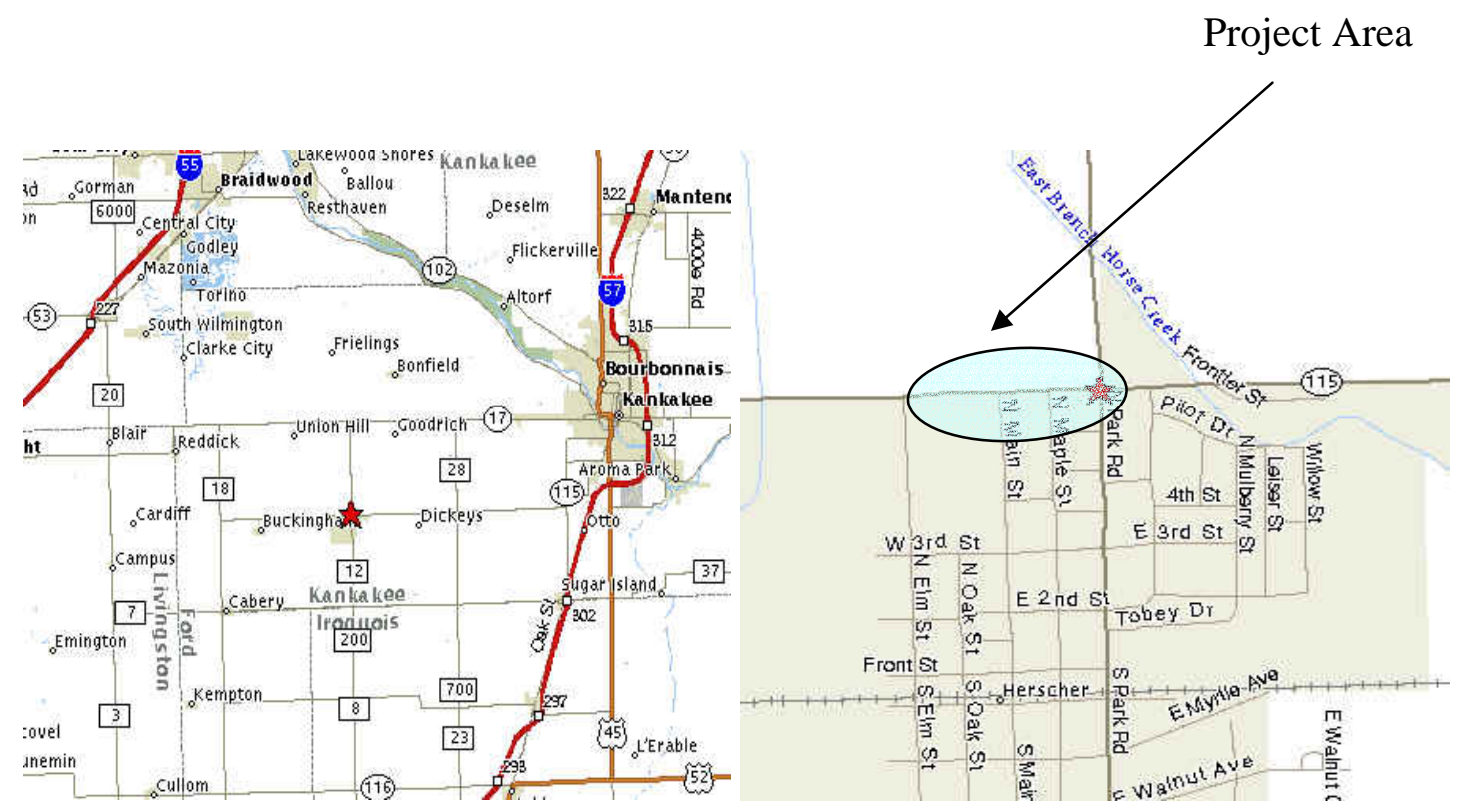




\section{SITE VISIT REPORT (10)}

\begin{tabular}{|l|l|}
\hline 1. Date & March 28, 2003 \\
\hline 2. Location & IL Route 115, Herscher, IL \\
\hline 3. Owner/Client & IDOT \\
\hline 4. Contractor/Contact & $\begin{array}{l}\text { Geotrack } \\
\text { (George Lamplota, Tel: 630-530-7609) }\end{array}$ \\
\hline
\end{tabular}

\section{Project Description}

- $\quad$ Locating of utility lines on IL 115.

- New drainage system construction / Additional travel lanes will be added

- High priority job with fast turnaround. Coordination with surveyors

- Buried utilities: Telephones, Gas, Water, Fiber Optic Cables, Sewer pipes, Electricity, and Cable TV lines.

- Process for designating water valve/manhole cover:

o Equipment: Magnetometer

o A) Scan proposed area

o B) Adjust control knob for intensity

o C) Interpret magnetic readings (noise) to determine location

$0 \quad$ D) Find the water valve

o E) Record location

- Process for designating water line:

o Equipment: Acoustic Pipe Tracer (RD 500)

o A) Hook up a transducer (thumper) to a nearby hydrant

0 B) Install water hose to hydrant in order to regulate water flow

o C) Using highly sensitive acoustic receivers, listen to water flowing. Location can be verified by using display board

o D) Move the receiver by $1-\mathrm{ft}$ intervals to the designated point of water main

o E) Designate the water pipe and mark the location of water pipe

0 In practice, effective length of designation using acoustic pipe trace is about $100 \mathrm{ft}(33 \mathrm{~m})$. 


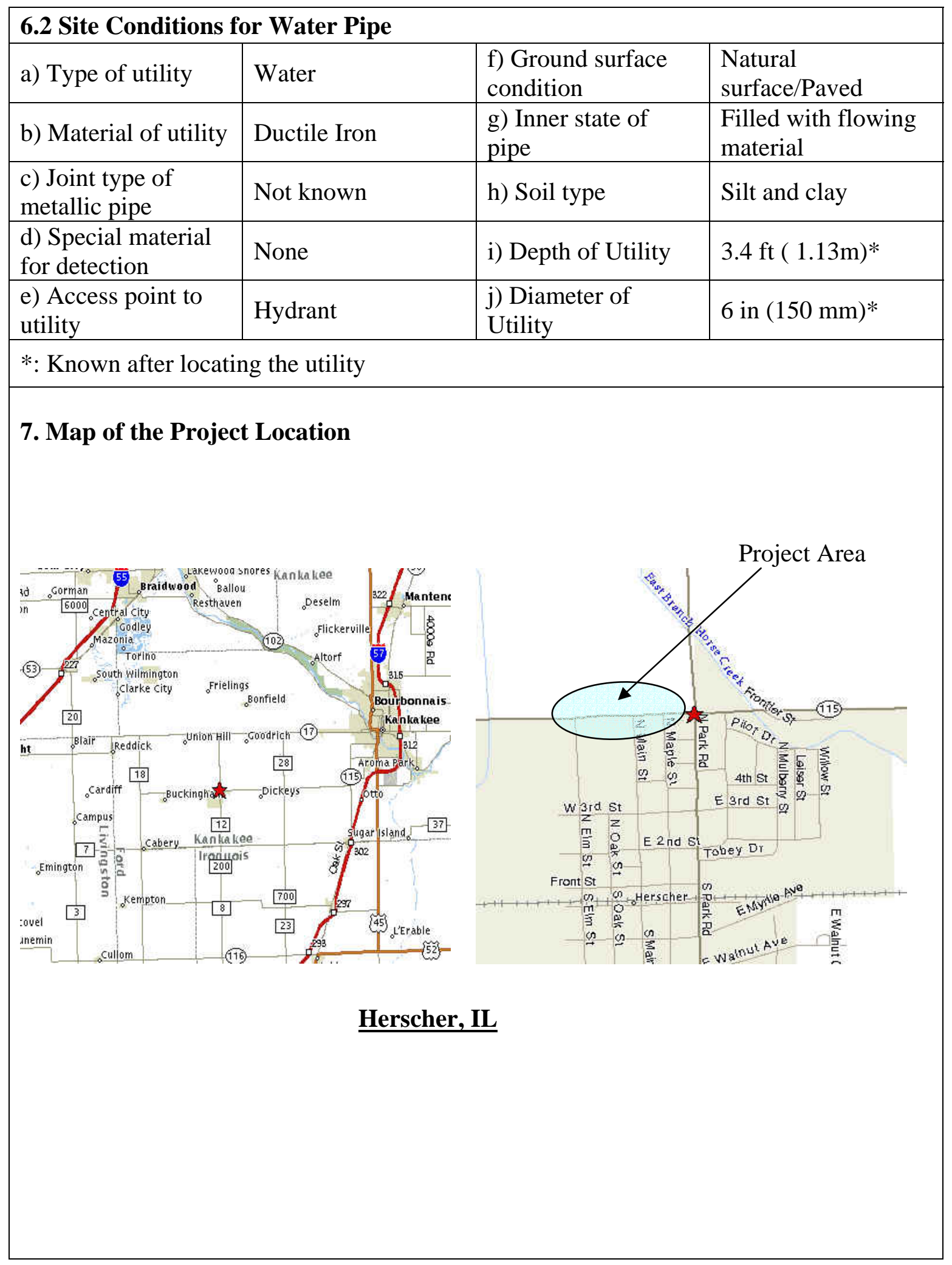




\section{Appendix B: Questionnaire used for Field Data Collection}

\section{PURDUE UNIVERSITYIINDIANA DEPARTMENT OF TRANSPORTATION JOINT TRANSPORTATION RESEARCH PROGRAM}

"Imaging and Locating Buried Utilities"

SUE Project Data Collection Sheet

Date:

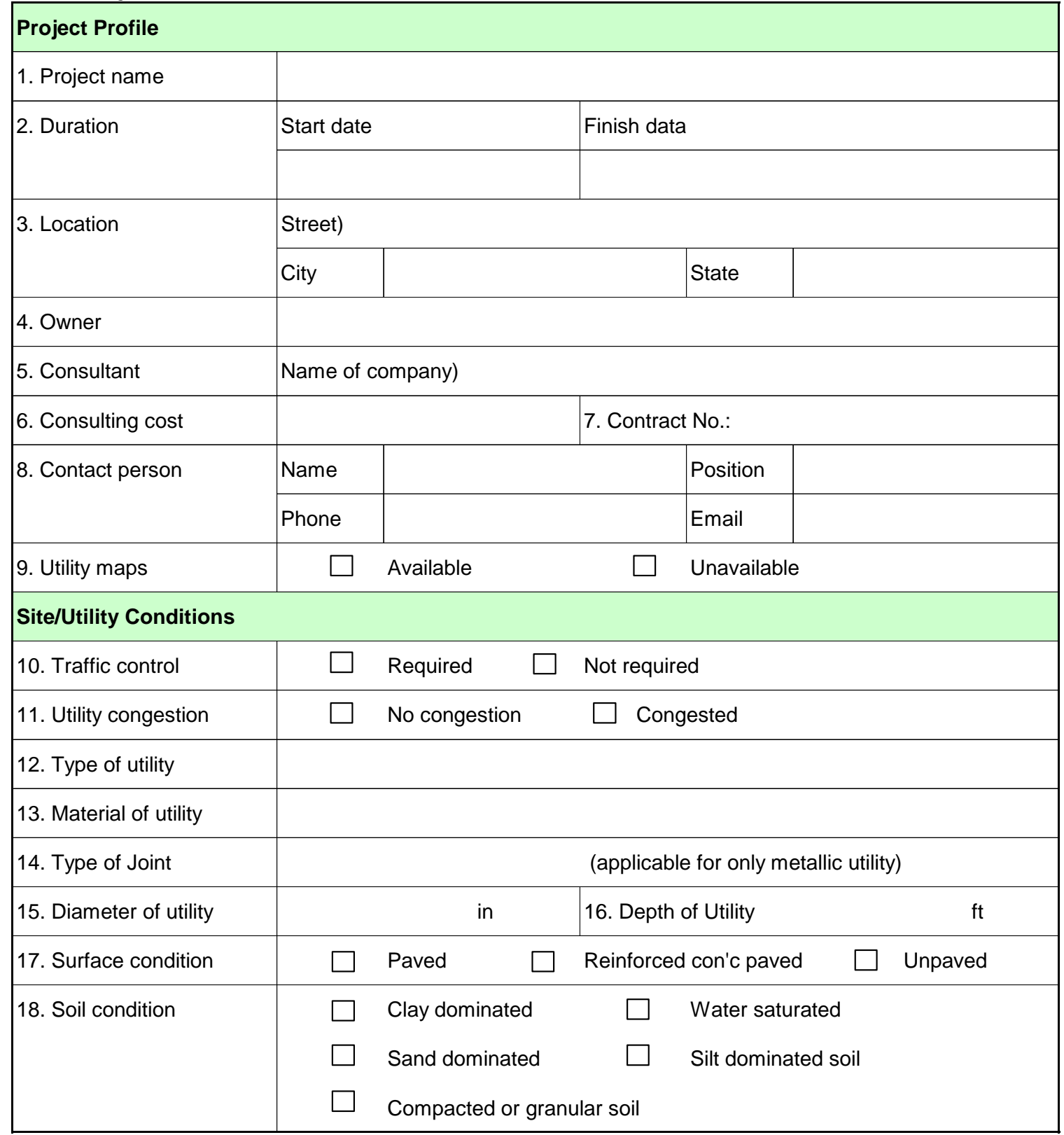




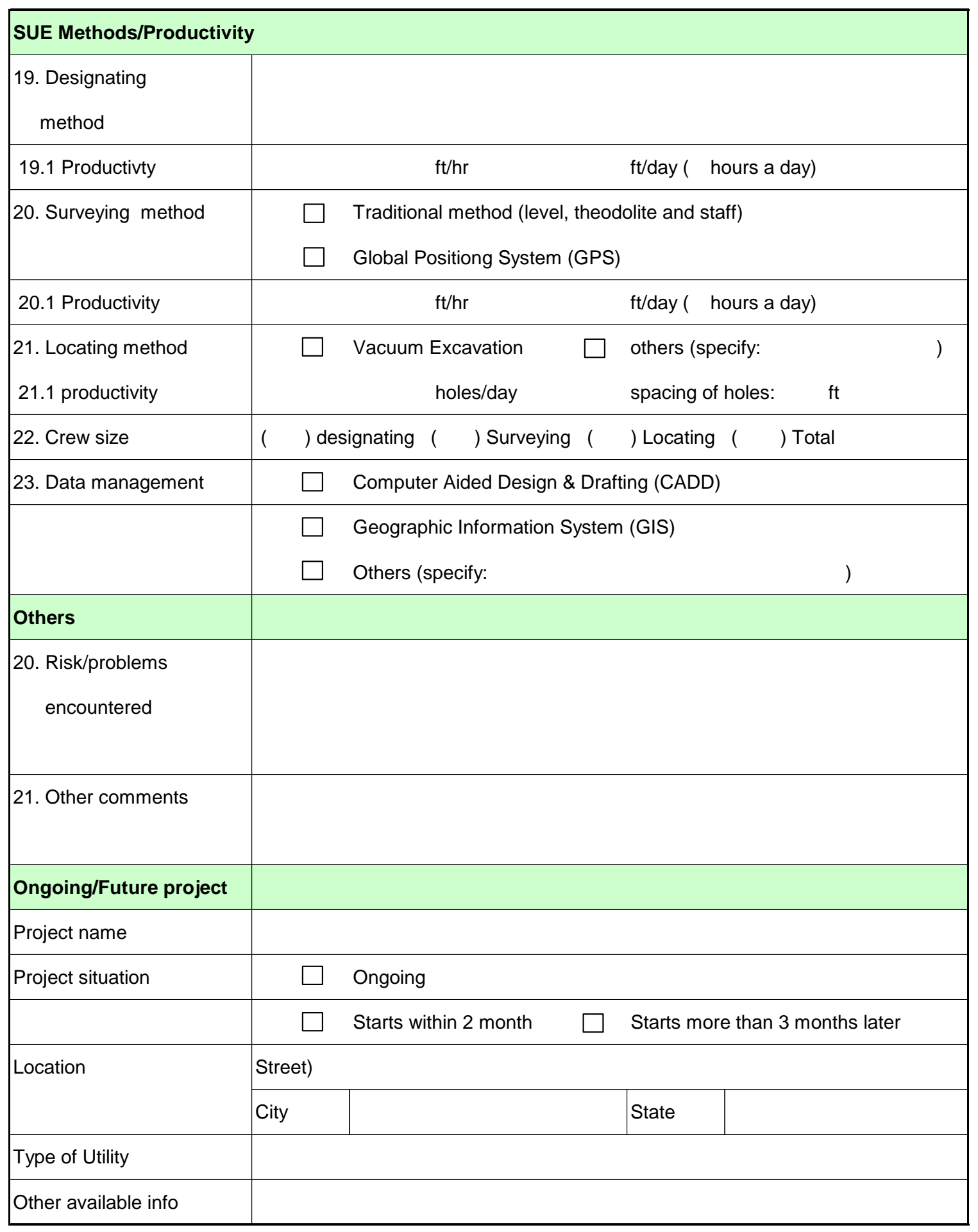




\section{Appendix C: Questionnaire (State DOTs)}

\section{Questionnaire for the Evaluation and Use of SUE by DOTs, $3^{\text {rd }}$ Survey}

(Please complete this form even if you completed a similar one last year)

1. Name:

Address:

Phone:

Email: State:

2. Does your state utilize Subsurface Utility Engineering (SUE) on construction projects?

Yes No

If "Yes," Please answer all the following questions, If "No," answer for the question No.8 \& No. 13

3. What is the annual amount of \$ spent on the SUE program in your state?

4. How is a project selected for the use of SUE and which department is responsible for that decision?

5. What are the criteria for the selection of a SUE provider for the SUE service?

6. Do you agree with that SUE is a consulting service rather than a contract? If yes, why?

7. What type of contract methods does your State use for SUE service and why?

Cost plus (fixed) fee ___ Per Diem / Hourly ___ Unit price ___ Lump Sum

8. What kinds of data management system do you use to incorporate SUE data to construction plans? Checkmark all the applicable systems.

CADD _ _ ( \% of use $)$ GIS ___ ( \% of use $)$ Others 
9. Were there any utility line cuts or damage reported on construction projects where SUE was used during the design stage?

Yes No

10. Has the use of SUE in your state met the expectations of your DOT? Yes No

11. How do you evaluate the quality of SUE service provided to your DOT?

12. Has your state increased, decreased, or maintained the use and funding of SUE during the past year?

13. What are your state's future plans for SUE?

Purdue University thanks you for your cooperation in this important effort.

$\underline{\text { By mail) }}$

Please return this survey to:

Professor Jeffrey J. Lew, Department of Building Construction Management, Room 443

Purdue University, Knoy Hall, West Lafayette, IN 47907

By Fax) 765-496-2246, By Email) jilew@tech.purdue.edu

If you have any questions, call Jeffrey J. Lew at (765) 494-2464. 


\section{Appendix D: Questionnaire (SUE Industry)}

QUESTIONNAIRE

Imaging and Locating Buried Utilities

\section{All the information is strictly confidential and is not for public use.}

This is a questionnaire being used to collect data for the research project entitled "Imaging and Locating Buried Utilities,” funded by the Indiana Department of Transportation (INDOT) and conducted at Purdue University, School of Civil Engineering. Professors Dulcy Abraham and Daniel Halpin are the principal investigators for this project.

Subsurface Utility Engineering (SUE) has emerged in the past two decades as a means to better characterize the quality of subsurface utility information and to manage the risks associated with construction activities that may affect existing subsurface utilities. SUE is gaining credibility as a proven solution for the reduction of damage to underground facilities, and in some cases, the prevention of this problem. As the SUE is becoming an important step in any construction project requiring excavation works and the SUE business is expanding rapidly, there is a need to evaluate the overall SUE practice in the aspects of owners and contractors.

The questionnaire was designed to obtain a good understanding of SUE practice in the private sectors. The collected information and data will be solely used for the research purpose. The name of your company will not be identified on the analysis process and the final report.

There are some technical terms that we assume that you are familiar with. However, for the consistency of the questionnaire, the definition of different stages of SUE application is given below:

Designating: the use of surface geophysical techniques to determine the existence and horizontal position of underground utilities

Locating: the process of exposing and recording the precise vertical and horizontal location of a utility using minimally intrusive excavation methods

Surveying: the use of traditional surveying equipment or Global Positioning System (GPS) to record 2-dimensional (horizontal) or 3-dimensional (horizontal \& vertical) location of the identified subsurface utility in field. 
Data Management: the process of transferring obtained subsurface utility information onto the project design and construction documents using Computer Aided Design and Drafting (CADD) system or Geographical Information System (GIS).

If you have any questions regarding this questionnaire, please contact me at jeong1@purdue.edue or 765-496-0696 (office).

\section{Return Information:}

Please return the completed questionnaire to David H. Jeong at the following address:

By Mail) David H. Jeong (Ph.D. student), CEM, School of Civil Engineering, 1284 Civil

Engineering Building, West Lafayette, Indiana 47907-1284

By Fax) (765) 494-0644

By E-mail: jeong1@purdue.edu 


\section{Company Information}

\section{1}

Name:

Company Name:

Address:

Phone:

Fax:

Email:

1.2. How many years has your company been involved in the SUE business?

years since

1.3. Annual sales

What was your company's annual sale (mainly from SUE business) during the last five years?

\begin{tabular}{l|l|l}
\hline \hline Year & Annual Sales (US \$) & Remarks \\
\hline 1997 & & \\
\hline 1998 & & \\
\hline 1999 & & \\
\hline 2000 & & \\
\hline 2001 & & \\
\hline \hline
\end{tabular}

1.4. Please estimate the percentage of annual billings of your company for the following SUE tasks (year 2001).

Utility Mapping QLD \% Utility Coordination

Utility Mapping QLC $\%$ Utility Relocation Design $\%$

Utility Mapping QLB \% Utility Condition Assessment

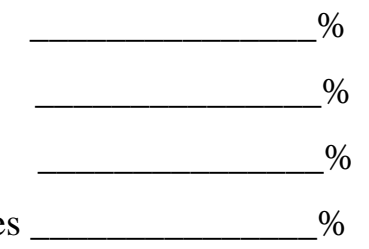

Utility Mapping QLA \% Utility Relocation Cost Estimates $\%$

(All utility mapping includes applicable survey and CADD)

1.5. What is the geographical domain of your SUE business?

(List down name of states)

Total number of offices: 


\subsection{Number of employees}

How many employees (geophysicists, project engineers (including managers), technicians and others) are hired for the SUE business in your company?

\begin{tabular}{c|c}
\hline \hline Title & Number of employees \\
\hline Geophysicists & \\
\hline Project Engineers & \\
\hline Technicians & \\
\hline Others (Please specify) & \\
\hline Total & \\
\hline \hline
\end{tabular}

\section{Project Information}

2.1. Availability of equipment/system

\begin{tabular}{|c|c|c|}
\hline \multicolumn{2}{|r|}{ Name of Equipment/System } & $\begin{array}{c}\text { Availability } \\
(\mathbf{Y}=\text { Yes, } N=\text { No) }\end{array}$ \\
\hline \multirow{10}{*}{$\begin{array}{l}\text { Designating } \\
\text { Equipment }\end{array}$} & Pipe and Cable Locators & \\
\hline & Ground Penetrating Radar (GPR) & \\
\hline & $\begin{array}{l}\text { Acoustic Pipe Tracer } \\
\text { (For example, APT RD590, RD 500- } \\
\text { Radiodetection Co.) }\end{array}$ & \\
\hline & $\begin{array}{l}\text { E-line Locator } \\
\text { (Continental Industries Co.) }\end{array}$ & \\
\hline & Electronic Marker Locating System (EMS) & \\
\hline & Metal detectors & \\
\hline & Magnetometers & \\
\hline & $\begin{array}{l}\text { Terrain conductivity meters } \\
\text { (For example, Geonics EM31, EM34) }\end{array}$ & \\
\hline & Infrared Thermography camera & \\
\hline & Others (Specify) & \\
\hline \multirow{2}{*}{$\begin{array}{l}\text { Locating } \\
\text { Equipment }\end{array}$} & Vacuum Excavator & \\
\hline & Others (Specify) & \\
\hline \multirow{3}{*}{$\begin{array}{l}\text { Surveying } \\
\text { Equipment }\end{array}$} & Levels, Theodolites & \\
\hline & Global Positioning System (GPS) & \\
\hline & Others (Specify) & \\
\hline \multirow{3}{*}{$\begin{array}{l}\text { Data } \\
\text { Management } \\
\text { System }\end{array}$} & Computer Aided Design and Drafting (CADD) & \\
\hline & Geographic Information System (GIS) & \\
\hline & Others (Specify) & \\
\hline
\end{tabular}


2.2. Proportion of your clients

What percentage (estimate) of your SUE billings comes from the following clients?

\begin{tabular}{|c|c|c|c|}
\hline Federal Government & Percentage (\%) & \multirow{7}{*}{$\begin{array}{l}\text { State Governments } \\
\text { Highway } \\
\text { Transit } \\
\text { Airport } \\
\text { Port } \\
\text { Other(describe) }\end{array}$} & Percentage (\%) \\
\hline $\begin{array}{l}\text { FHWA } \\
\text { FAA }\end{array}$ & & & \\
\hline DOE & & & \\
\hline DOD & & & \\
\hline FTA & & & \\
\hline GSA & & & \\
\hline Other(describe) & & & \\
\hline Municipalities/Counties & Percentage (\%) & \multirow{5}{*}{$\begin{array}{l}\text { Other Agencies } \\
\text { Engineering firms } \\
\text { Industrial facilities } \\
\text { Utility owners } \\
\text { Contractors } \\
\text { Other (describe) }\end{array}$} & Percentage (\%) \\
\hline Streets \& Roads & & & \\
\hline Water/Wastewater treatment & & & \\
\hline Sewers and water systems & & & \\
\hline Other(describe) & & & \\
\hline
\end{tabular}

2.3. Type of contracts

What is the major type of SUE contract with your client?

\begin{tabular}{|c|c|c|}
\hline Type of Contract & Percentage (\%) & Clients who prefer this method \\
\hline \multicolumn{3}{|l|}{ Unit Price } \\
\hline \multicolumn{3}{|l|}{ Lump Sum } \\
\hline \multicolumn{3}{|l|}{ Per Diem (daily rate) } \\
\hline \multicolumn{3}{|l|}{ Cost plus } \\
\hline \multicolumn{3}{|l|}{ Others (Specify) } \\
\hline Total & $100 \%$ & \\
\hline
\end{tabular}

2.4 Project Duration/Budget

What is the typical duration of SUE projects and their approximate project budget?

\begin{tabular}{c|c||c|c}
\hline \hline $\begin{array}{c}\text { Duration of } \\
\text { Project }\end{array}$ & Percentage (\%) & Project dollar value & Percentage (\%) \\
\hline$<1$ week & & Up to $\$ 10,000$ & \\
\hline$<2$ weeks & & $<\$ 20,000$ & \\
\hline$<3$ weeks & & $<\$ 50,000$ & \\
\hline$>3$ weeks & & $>\$ 50,000$ & \\
\hline Total & $\mathbf{1 0 0} \%$ & Total & $\mathbf{1 0 0} \%$ \\
\hline \hline
\end{tabular}


2.5. In applying designating methods, what is the proportion of use of each designating method (approximate popularity) to find utilities within a reasonable budget based upon a typical highway project?

\begin{tabular}{l|l}
\hline \hline \multicolumn{1}{c|}{ Designating Methods } & Percentage \\
\hline 1.Pipe and cable locator & \\
\hline 2.GPR & \\
\hline 3.Terrain conductivity meter & \\
\hline 4.Acoustic pipe tracer & \\
\hline 5.Magnetometer & \\
\hline 6.Metal detector & \\
\hline 7.EMS $\quad$ Total & \\
\hline 8.Others (Specify) & $\mathbf{1 0 0 \%}$ \\
\hline
\end{tabular}

2.6. What is the general profit margin of your SUE business?

$\%$

\section{Cost Estimating, Project Planning and Control of Operations}

3.1 What is the approximate average productivity in each phase of the SUE operation?

\begin{tabular}{l|l|c|l|c}
\hline \hline \multicolumn{2}{c|}{ Phase of SUE project } & Unit & Productivity & Remarks \\
\hline \multirow{4}{*}{$\begin{array}{l}\text { Designating } \\
\text { Phase }\end{array}$} & Pipe and Cable Locators & $\mathrm{ft} /$ day & & Day $=8 \mathrm{hrs}$ \\
\cline { 2 - 5 } & GPR & $\mathrm{ft} /$ day & & \\
\cline { 2 - 5 } & Acoustic Pipe Tracers & $\mathrm{ft} /$ day & & \\
\cline { 2 - 5 } & Others (Specify) & $\mathrm{ft} /$ day & & \\
\cline { 2 - 5 } & & & & \\
\hline \multirow{2}{*}{$\begin{array}{l}\text { Locating } \\
\text { Phase }\end{array}$} & Vacuum excavation & Holes/day & & \\
\cline { 2 - 5 } & Others (Specify) & & & \\
\hline \hline
\end{tabular}


3.2 What is the approximate unit price of each phase of SUE operation?

\begin{tabular}{l|l|l}
\hline \multicolumn{1}{c|}{ Phase of SUE project } & Unit & Unit price \\
\hline $\begin{array}{l}\text { Designating service } \\
\text { (including applicable survey and CADD) }\end{array}$ & & \\
\hline $\begin{array}{l}\text { Locating service } \\
\text { (including applicable survey and CADD) }\end{array}$ & & \\
\hline \hline
\end{tabular}

(The unit price of designating service, for instance, can be $\$ X X / f t$ or $\$ X X / h r$, the unit price of locating service can be $\$ \mathrm{XX} /$ hole.)

3.3. Please list down the most important factors for productivity

3.4. How many people are typically required in each phase of the SUE operation?

\begin{tabular}{|c|c|c|}
\hline \multicolumn{2}{|r|}{ Phase of SUE project } & Number of people \\
\hline \multirow{4}{*}{$\begin{array}{l}\text { Designating } \\
\text { phase }\end{array}$} & GPR & \\
\hline & Pipe and cable Locators & \\
\hline & Acoustic Pipe Tracers & \\
\hline & Others (Specify) & \\
\hline \multirow{2}{*}{$\begin{array}{l}\text { Locating } \\
\text { Phase }\end{array}$} & Vacuum Excavation & \\
\hline & Others (Specify) & \\
\hline \multirow{3}{*}{$\begin{array}{l}\text { Surveying } \\
\text { Phase }\end{array}$} & Traditional Surveying & \\
\hline & Global Positioning System (GPS) & \\
\hline & Others (Specify) & \\
\hline \multirow{3}{*}{$\begin{array}{l}\text { Data } \\
\text { Management }\end{array}$} & Computer Aided Design and Drafting (CADD) & \\
\hline & Geographic Information System (GIS) & \\
\hline & Others (Specify) & \\
\hline
\end{tabular}

3.5 Do you use your company’s own crew or subcontract for surveying purpose?

Always use our crews: ( )

Sometimes subcontract: $(\quad)$

Always subcontract: $(\quad)$ 
3.6 If your company subcontracts for surveying sometimes or always, why is that?

3.7. Does your company have the following plans?

Hire new personnel? Yes No Purchase new equipment for SUE operation purpose? Yes No Increase your region of business? Yes No

3.8. Do you think that SUE industry will continuously grow in the near future?

Yes No Why:

3.9. What are the most urgent things to develop and expand SUE industry?

1) Education: 2) State Regulation:

3) New versatile equipment 4) others:

3.10. Would you please evaluate the degree of significance of the factors (major obstacles when entering a new SUE project, based on the following scale?

EX: extremely significant (5)

GR: Greatly significant (4)

MO: Moderately significant (3)

LI: Little significant (2)

NI: Not significant (1)

Factors:

A: Getting appropriate record (as-built drawings):

B: Heavy traffic (traffic safety/control):

C: (Unfavorable) site conditions:

D: Understanding of SUE by clients:

E: Inclement weather:

F: Final deliverable formats:

G: Amount of mobilization, travel, relocation cost:

$\mathrm{H}$ : Project time frame:

I: Scope splitting:

Thank you for your assistance in completing this questionnaire.

Your opinion will be a valuable resource for the research. 


\section{Appendix E: Accident and Damage Prevention Model}

This chapter describes the work underway on a GPR-integrated excavator for safely locating 2 or 3 three meters ahead of the excavation. The work was performed at the Construction Automation Research Laboratory (CARL) at North Carolina State University, and was completed by Dr. Leonhard Bernold and his research team, as a subcontract to this project.

\section{E1. Accident and Damage Prevention Modeling and Concepts}

\section{E1.1 Current Model and Problems}

A corporate employee of the Public Utility Service (City of Raleigh) was interviewed regarding the current underground utility installation practice and process. The interviewee's work is directly related to water and sewer line installation and maintenance. However, the summary of the interview is not statistically studied. The purpose of the interview is to allow true understanding on the practices and aids the new idea on proposed model. The practice according to the One-Call center document has been implemented as shown in the early chapter.

Several problems may cause subsurface utility accidents. First of all, the utility companies normally have the as-built plan, but not inside the residential property. For example, the public utilities department has as-built water lines on public property only as far as the water meter. The water line patch beyond the meter is unknown.

Second, data management is also a key problem. Each utility company may have their utility database and use a different format. Therefore, efficiently organizing all utilities information and databases is impossible. For example, the Public Utility Service has its water and sewer as-built plan in paper format. On the other hand, other utility companies may use electronic file format. However, different software always uses different file formats. Although some software has fileformat-converting features, the converted file may lose some information. 
Third, even if all companies keep their data in the same format, a problem still occurs because the data formats and layers agreement must be understood among all companies. Therefore, the format of organizing information must be set, and one party or department should be responsible for maintaining and gathering all information in one place.

\section{E1.2 Proposed Model}

All stages in subsurface utility installation are Proactive Prevention stage, Prevention stage, and Reactive Litigation stage as described in Figure E1.1. The Proactive Prevention stage is defined as the prevention stage as practiced before starting the field operation. The Prevention stage is defined as the prevention stage as practiced during field operation. The Reactive Litigation stage is defined as the practice of investigation as the consequence of accident or damage, if occurring. The examples of accident and damage prevention practices are also shown in each stage in Figure E1.1.

An as-built plan is a key element in Figure E1.1 model. After field operation is finished, the asbuilt has to be generated and maintained in order to aid the design stage when installing a new utility. Because there are a number of underground utilities without the as built or record as described in the early chapter, the Proactive stage is still required in the model. The full records of subsurface utilities locations will be gained after the first underground utility installation. Therefore, the Proactive stage will not be necessary and can be disregarded in several years.

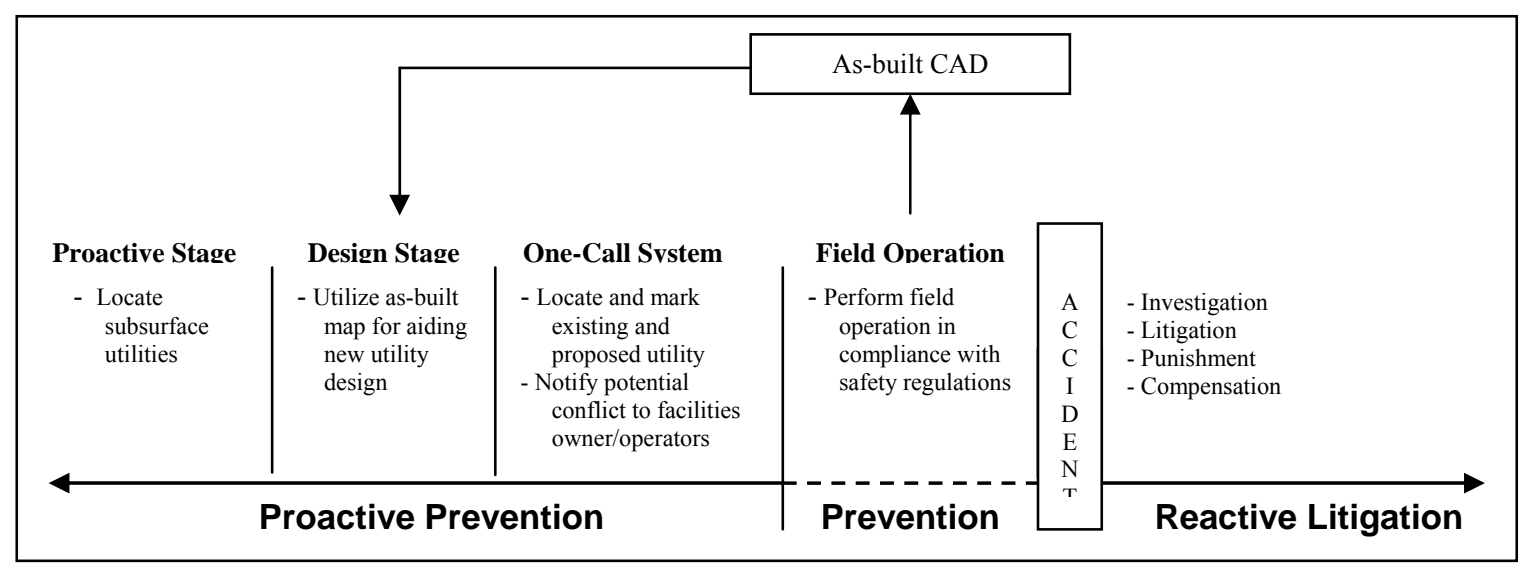

Figure E1.1 Proactive Accident Preventions Model, Prevention stage, and Reactive Litigation stage 
Instead of receiving only subsurface utilities information during the design stage and field operation, if the subsurface engineer receives one GIS or CAD file containing all matters information: topography, physical objects on ground, and underground utilities in separate layers, the information will be much more useful and easier to organize. Figure E1.2 shows the information management in AMM, All Matters Map.

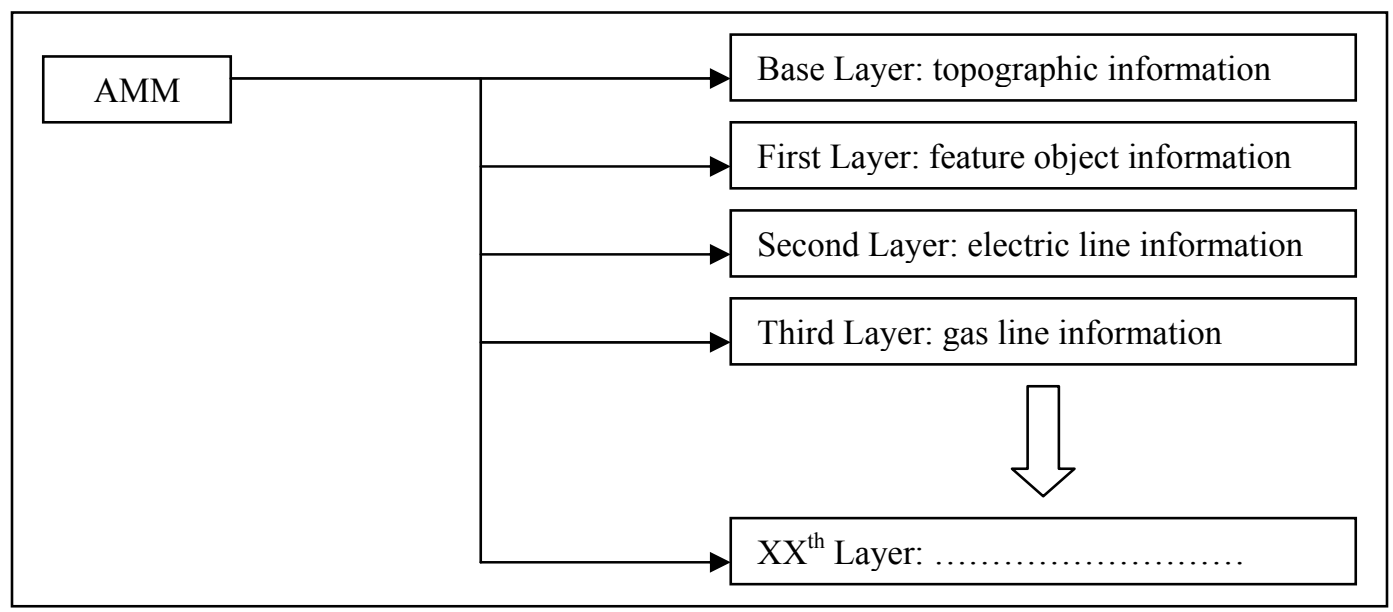

Figure E1.2 AMM Information and Layers

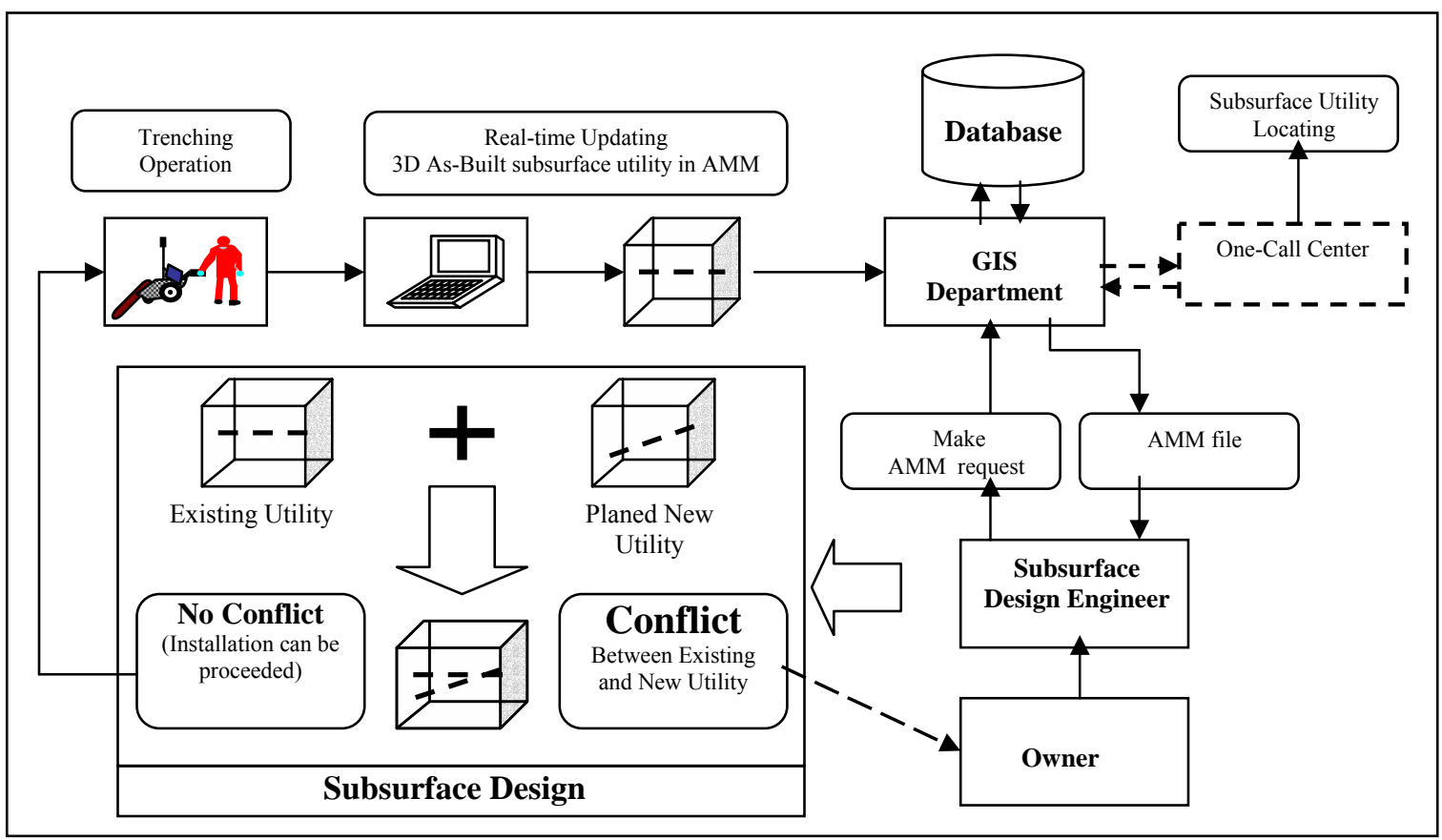

Figure E1.3 The Proactive Damage Prevention Concept 
The model in Figure E1.1 and AMM in Figure E1.2 can be implemented in Figure E1.3 diagram. The diagram shows all stages from Figure E1.1 except Reactive Litigation. The AMM, which is the key element, will be real-time updated during field operation and then solely maintained by the GIS department. The GIS department needs to establish connection to the One-Call center database because the One-Call center currently has all subsurface utilities information and conducts the subsurface utilities locating process. The subsurface engineer will also play a key role by requesting AMM from the utility department. By doing so, the engineer will be able to safely design a new utility path.

\section{E2. System Prototype Design}

The chapter explains that creation and appearance of the prototype. Next, the method is explained for determining the location and coordinates of the trench bottom will be explained. Thereafter, because there are many types of positioning systems, the possible prototypes are presented as the integration between a particular positioning system, tilt sensors and the platform.

\section{E2.1 Utility Location Assessment}

\section{E2.1.1 System Platform}

The system platform functions as the house of the tilt sensors and the positioning receiver units. Two receivers are required at the platform because one measures the location of the platform, and the other provides the direction of the platform which is mounted on the machine. Two oneaxis tilt sensors or one bi-axis tilt sensor are required to measure the angle of the platform with respect to gravity. The platform protype is shown in Figure E2.1. 


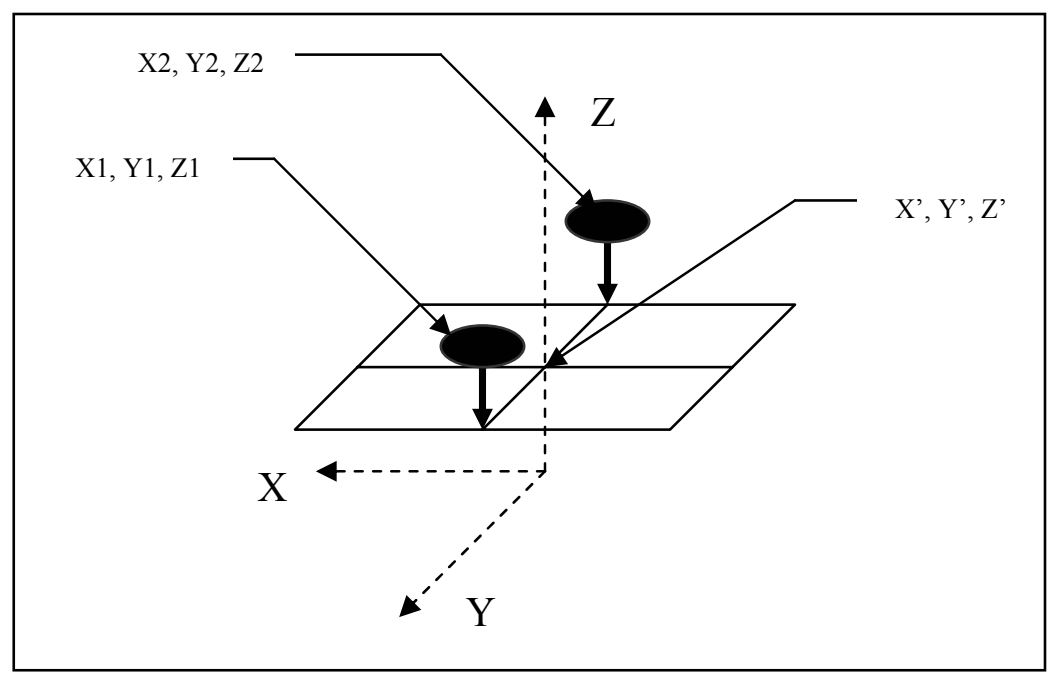

Figure E2.1 System Platform

By setting two receivers on the $\mathrm{Y}$ axis, the $\mathrm{Y}$ angle can be measured by simple calculation. However, the positioning systems always contain error, so the $\mathrm{Y}$ angle should not be calculated from the different elevations of two receviers. The error is truly significant because only one degree of error can produce an error at the trench bottom more than five centimeters in the $\mathrm{X}-\mathrm{Y}$ plane depending on the the length between the platform and the trench bottom. Therefore, the Y angle will not be calculated from the two receivers but from a tilt sensor.

Figure E2.2 shows the physical model of a trencher. The A, S, H lengths have to be measured. Moreover, the $\theta_{\mathbf{Z}}$ is known as the trencher arm angle. The $\theta_{\mathbf{Z}}$ is adjustable and can be measured by using an another tilt sensor. The following figures, E2.3 - E2.5, show the 3D analysis to find the location of the trench bottom with respect to the platform. In Figure E2.3, the analysis is based on the $\theta_{\mathrm{X}}=0$ and $\theta_{\mathrm{Y}}=0$ situation. The $\mathrm{D}$ length and $\theta_{\mathrm{D}}$ will be the products and aid the further analysis. In Figure E2.4, the analysis is based on the $\theta_{\mathrm{X}}=0$ and $\theta_{\mathrm{Y}} \neq 0$ situation, and its product will also aid the further analysis. In Figure E2.5, the analysis is based on the $\theta_{X} \neq 0$ and $\theta_{\mathrm{Y}} \neq 0$ situation, or the general situation, in the other words. 


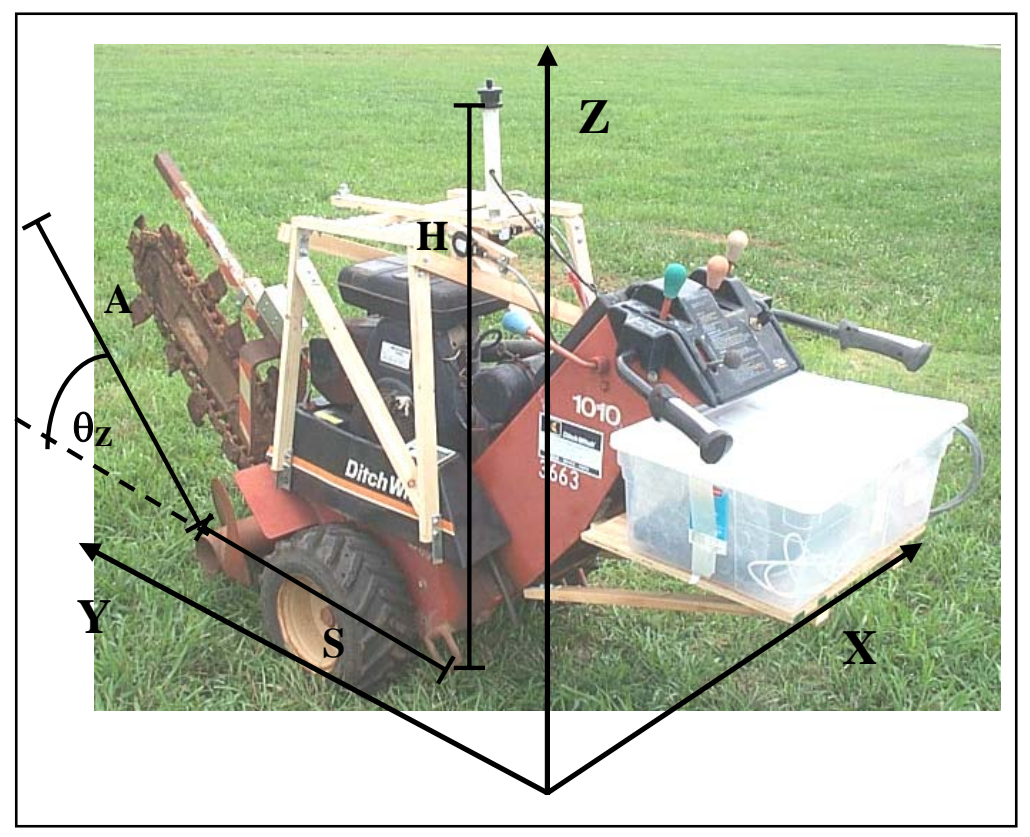

Figure E2.2. Trencher with Dimensions

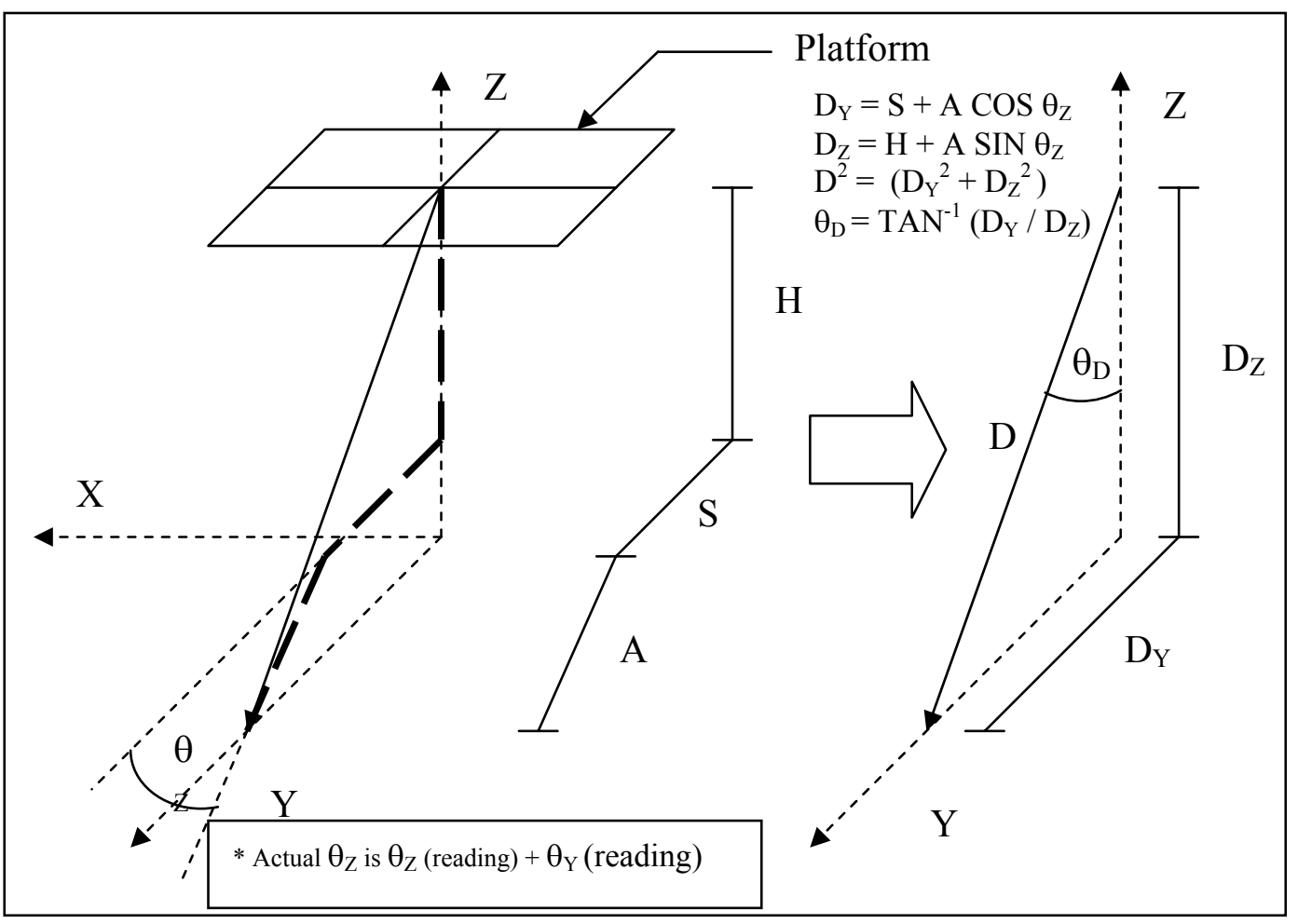

Figure E2.3 Simplifying Diagram for Determining Utility Location When $\theta_{X}=0$

$$
\theta_{\mathbf{Y}}=\mathbf{0}
$$




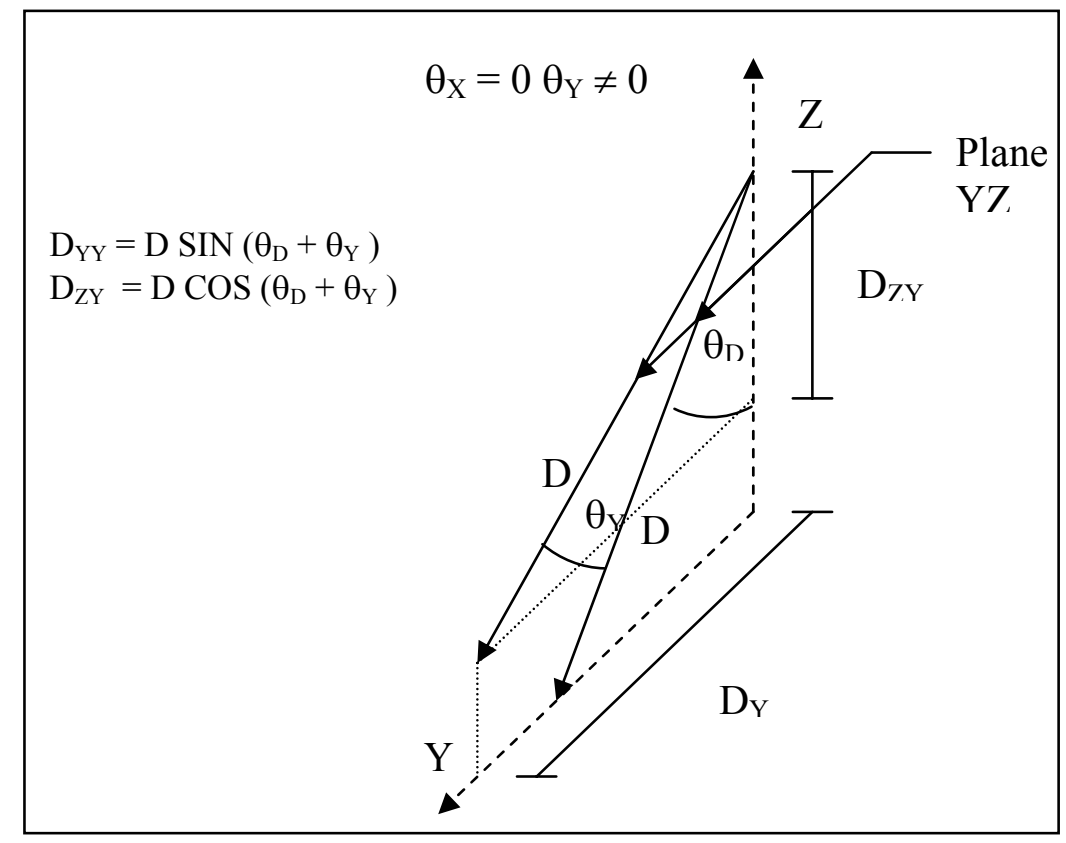

Figure E2.4 Simplifying Diagram for Determining Utility Location When $\theta_{X}=0$ $\theta_{\mathbf{Y}} \neq \mathbf{0}$

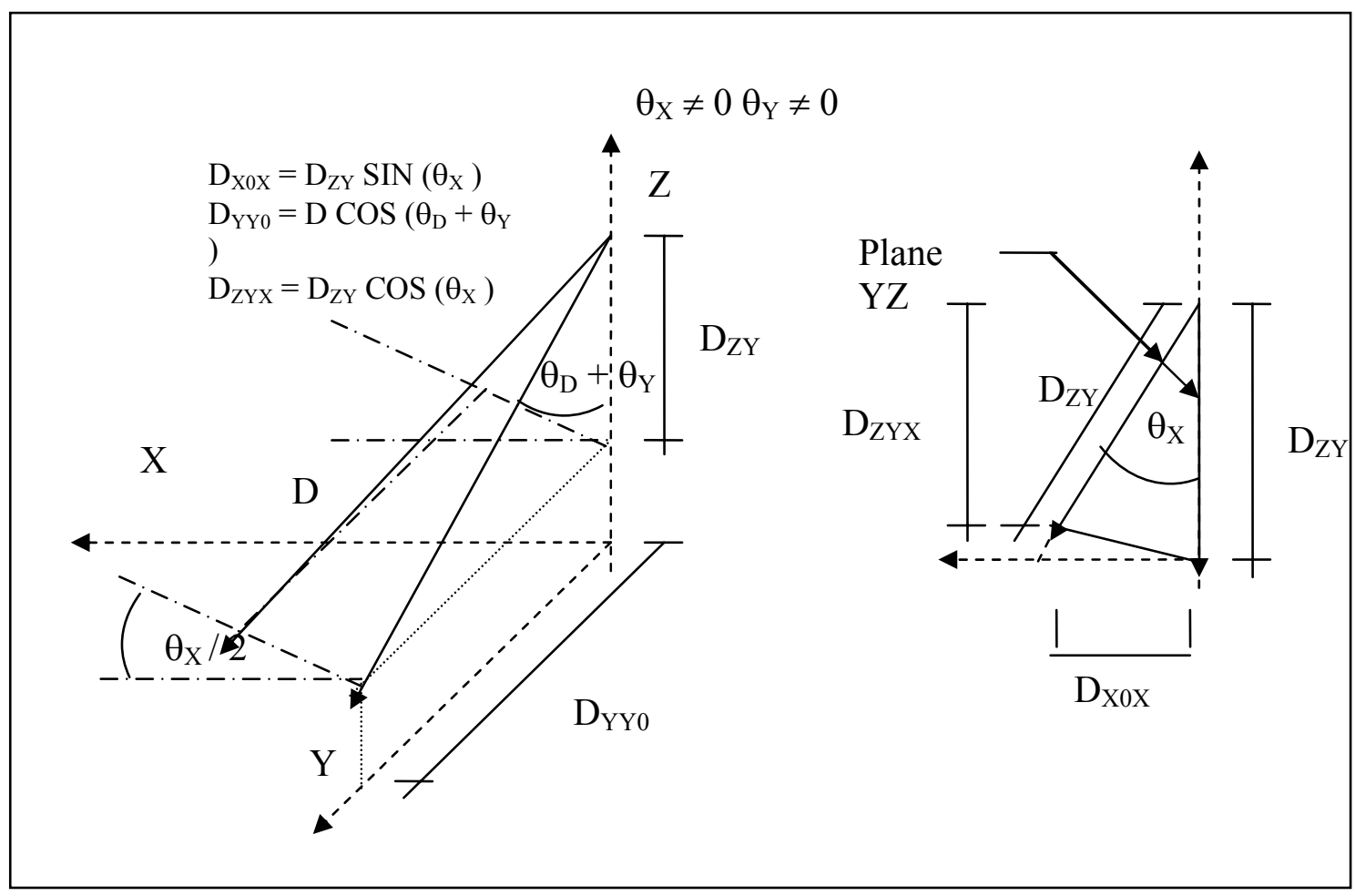

Figure E2.5 Simplifying Diagram for Determining Utility Location When $\theta_{X} \neq 0$ $\theta_{\mathbf{Y}} \neq \mathbf{0}$ 


\section{E2.2 Proposed Prototypes}

Several instruments measure the position of the platform and lead to the location of the trench bottom. Total Station is the typical surveying method and has been used for surveying control points that are the most accurate. GPS, Global Positioning System, is the newcomer that can measure any position with lines of sight to the satellites. However, GPS is still questioned as to accuracy. Moreover, the newest technology in position measurement is a laser-based positioning system. There are two laser based instruments as described in the early chapter: CAPSY and SPSI. CAPSY is still not practical for three-dimensional position measurement because it allows only two-dimensional location that is $\mathrm{X}$ and $\mathrm{Y}$ or $\mathrm{N}$ and $\mathrm{E}$ in geodetic coordinates. On the other hand SPSI or Odyssey, its trademark, allows three-dimensional position measurement. Features of these instruments are summarized in Table E2.1.

Table E2.1 Position-Measuring Instruments and Their Compared Features

\begin{tabular}{|c|c|c|c|c|c|}
\hline Instruments & $\begin{array}{c}\text { 3D } \\
\text { Measurement }\end{array}$ & Reading Time & Accuracy & $\begin{array}{l}\text { One-man } \\
\text { Operation }\end{array}$ & References \\
\hline Total Station & Yes & $\begin{array}{l}\text { Fine: } 3 \mathrm{sec} \\
\text { Coarse: } 0.7 \mathrm{sec}\end{array}$ & $\begin{array}{l}1 "(\text { Angle }) \\
2 \mathrm{~mm}+2 \mathrm{ppm} \text { (Distance) }\end{array}$ & $\begin{array}{l}\text { Yes } \\
\text { (Some Models) }\end{array}$ & $\begin{array}{l}\text { Topcon } \\
\text { AP-L1A }\end{array}$ \\
\hline GPS & Yes & Real time & $\begin{array}{l}1 \mathrm{~cm}+2 \mathrm{ppm} \text { (Horizontal) } \\
2 \mathrm{~cm}+2 \mathrm{ppm} \text { (Vertical) }\end{array}$ & Yes & $\begin{array}{l}\text { Trimble } \\
5700 \text { Receiver }\end{array}$ \\
\hline CAPSY & No & Real time & $+/-3.2 \mathrm{~mm}$ (Horizontal) & Yes & (Chapter 2) \\
\hline Odyssey & Yes & Real time & $2 \mathrm{~mm}-5 \mathrm{~mm}$ & Yes & $\begin{array}{l}\text { Arcsecond } \\
\text { Vulcan }\end{array}$ \\
\hline
\end{tabular}

Total station, GPS, and Odyssey have the possibility to locate the platform in three-dimensional coordinates. However, the use of total station in real-time control of operations and equipment is limited to operations that require position update rates (Table E2.1). 


\section{E2.2.1 Prototype 1 implementing auto-tracking total station}

Currently, a one-person total station has been developed whereby the total station can track a user with a reflector. The system utilizes servomotors to control the horizontal and vertical rotations of the total station. The ultimate accuracy of information generated by a total station relies heavily on the skills of the crew and the physical limits of users (Beliveau, 1995). To perform the surveying practice, the prism or receiver holder must firmly hold the pole in order to achieve the most accuracy. However, the tilt sensors mounted platform can reduce that problem because no human is involved in the field operations. With tilt sensors, the platform does not have to be perpendicular to gravity. The system prototype is shown in Figure E2.6.

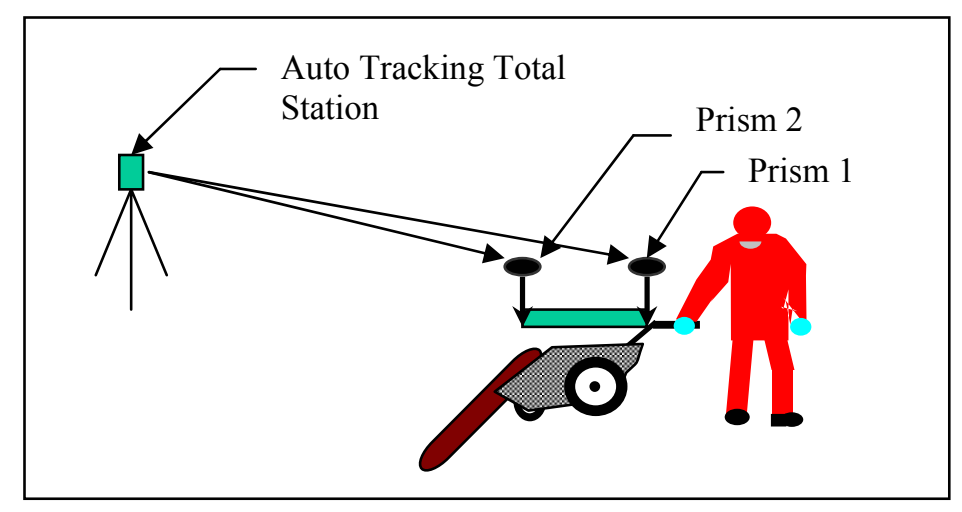

Figure E2.6 Prototype 1 Implementing Auto-Tracking Total Station

The system reading strategy also has a great impact on productivity because an auto-tracking total station is not a pure real-time data collecting system. Two strategies have been reviewed. First is to read Prism 1 and then Prism 2, and second is to read Prism 2 and then Prism 1. The diagram in Figure E2.7 depicts two strategies, their moving distances, and the numbers of stops. 


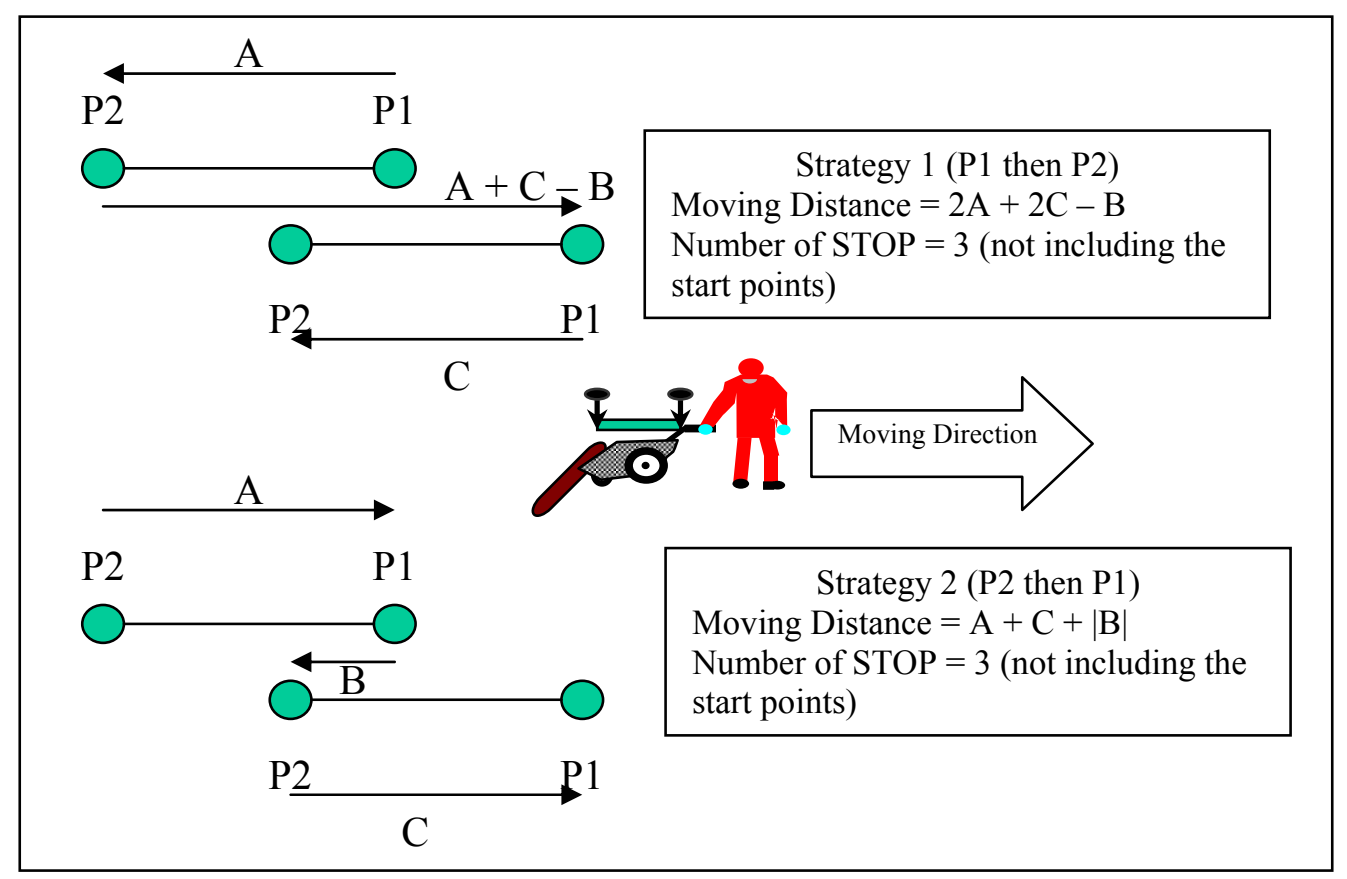

Figure E2.7 Analysis of Two Strategies in the Prototype 1

From Figure E2.8, Strategy 2 is always better than strategy 1; even B is a negative number (B will be negative number, when the platform in the second position does not lap with the first position).

\section{E2.2.2 Prototype 2 implementing GPS}

GPS performance is a function of the mode of operation. Absolute point positioning and differential point positioning are the two common modes of operation (Yvan et al. 1995). Absolute point positioning refers to the positioning of a point by a single receiver. Relative survey method or differential point positioning is normally called differential GPS surveying (DGPS). Relative positioning is achieved by setting up satellite receiver antenna sets on at least two points and obtaining satellite data simultaneously (Yvan et al. 1995). One receiver, called a base station, stands on the point with a known coordinate, so that the true ranges to the satellites are known. Using true ranges will allow the base station system to determine corrections and send out radio signals to other receivers in limited areas. When another receiver occupies a point with unknown coordinates, the reading coordinates will be adjusted by corrections on radio 
signals transmitted from the base station. By doing so, the accuracy of the computed position will be improved. Moreover, DGPS can be also applied to both a static mode and a mobile mode.

Differential corrections can be obtained from several sources: onsite based station, the worldwide network of DGPS radio beacons, or a satellite differential service provider. The network of DGPS radiobeacons throughout the world is rapidly expanding, and the signals that most radiobeacons transmit are free. There are also a number of satellite differential service provider options including commercial service that users have to pay for. Now WAAS, Wide Area Augmentation System or EGNOS satellite systems for the US and Europe respectively promise to improve integrity, accuracy, and availability of GPS for users.

However, DGPS can only achieve submeter accuracy in the horizontal position. RTK, Real-Time Kinematic, allows better accuracy at centimeter-level. With RTK, a base station is needed and placed on the known point. A base station transmits a correction-data-containing radio signal in the UHF, VHF, or spread spectrum radio band. Ranges from satellites to a computed point will be calculated and then adjusted by the correction data.

In Table E2.1, RTK can achieve 1 centimeter and 2 centimeters accuracy horizontally and vertically, respectively. RTK can be the answer for the Prototype 2. The following sentences will be some facts of RTK (Trimble, 2002).

- RTK needs a minimum of five satellites to get initialized. After initialization, only four satellites are needed.

- A dual frequency GPS receiver is required.

- A GPS receiver must be capable of On-the-Fly initialization.

- Initialization takes one minute.

- A based station is required, and the coverage area is no more than 10 kilometers. 


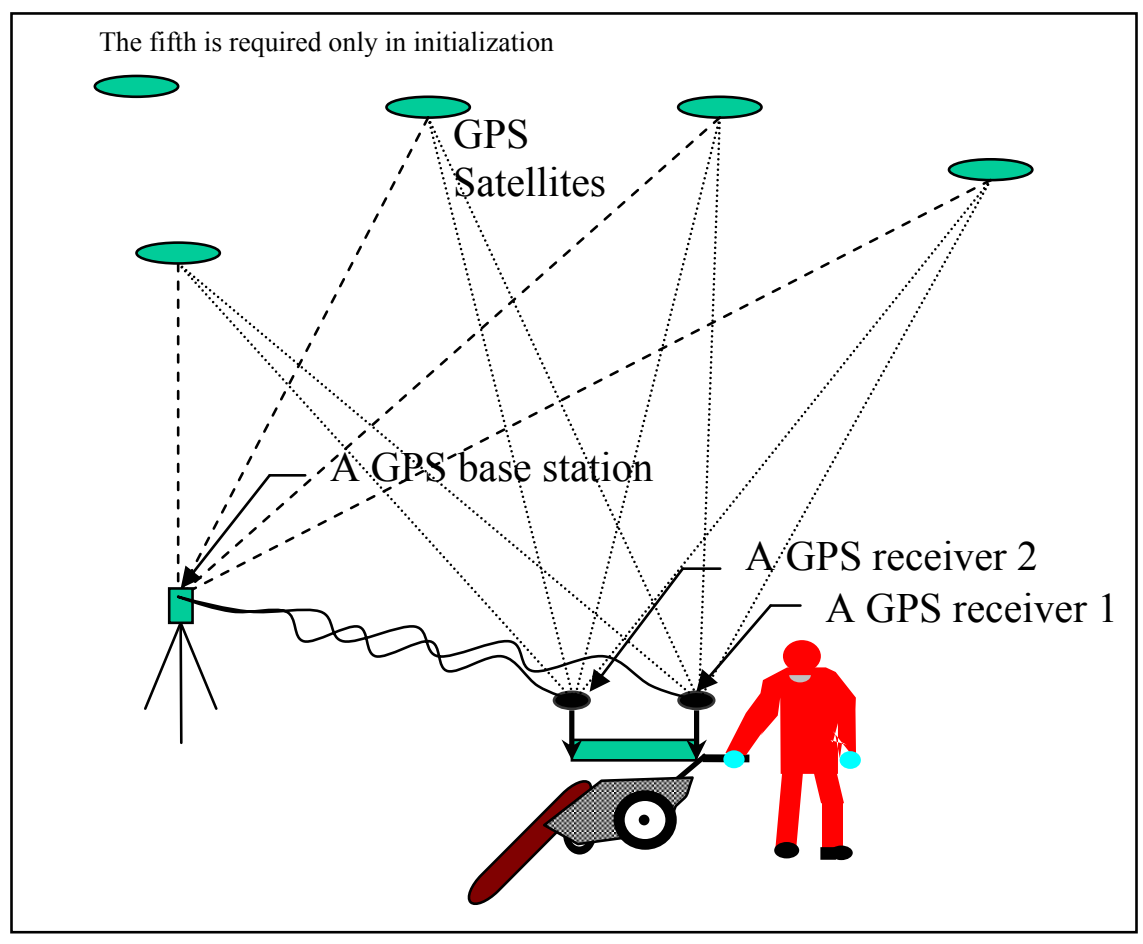

Figure E2.8 Prototype 2 Implementing GPS (RTK)

The Prototype 2 can be set up as shown in Figure E2.8. The data collection strategy is not required, since both receivers can collect data from satellites and receive radio signals from a base station at the same time.

\section{E2.2.3 Prototype 3 Implementing a Laser Based Positioning System}

Both Odyssey and Vulcan are laser based positioning systems that provide accurate real-time 3D position measurements. The theory and details are described in chapter 2. The systems' performance characteristics are accuracy and update rates that cannot be achieved by other systems.

The accuracy of all subsequent measurements depends on the accuracy of the calibration and cannot achieve the accuracy of reference points. However, the maximum achieved accuracy is one part of 100,000. For example, at the distance of 250 meters, the theoretical accuracy will be $250 / 100,000$ or 2.5 millimeters. If the distance decreases to 100 meters, the accuracy would be 1 millimeter. 
The data rate or the frequency at which the system can provide position measurements is five to ten times per second. It can be considered a real-time data collection. The Prototype 3 can be set up as shown in Figure E2.9 and the top view in Figure E2.10.

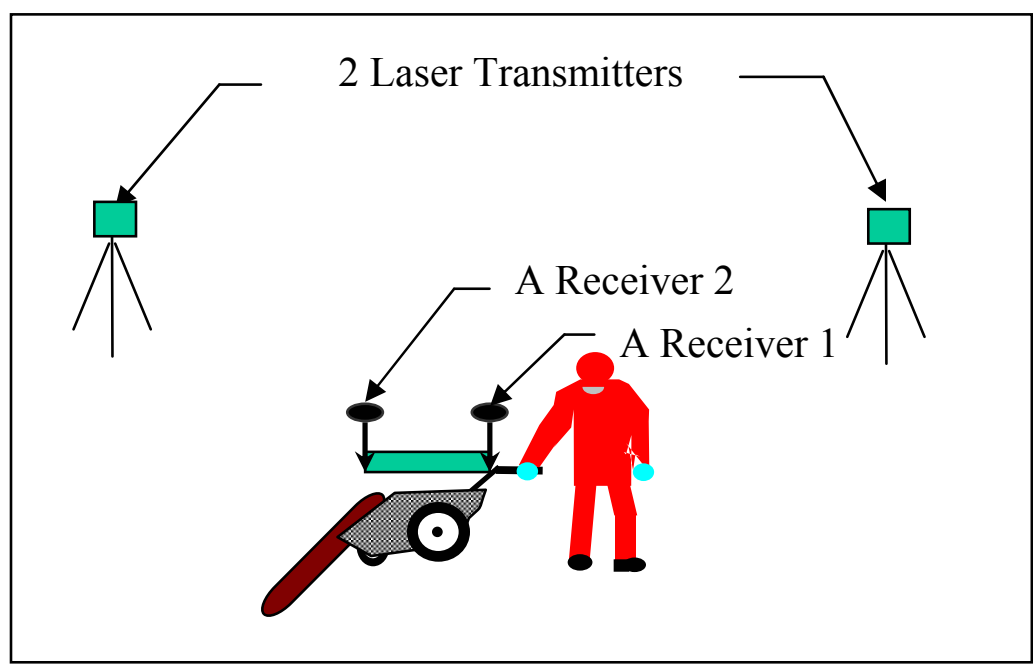

Figure E2.9 The Prototype 3 Implementing a Laser Based Positioning

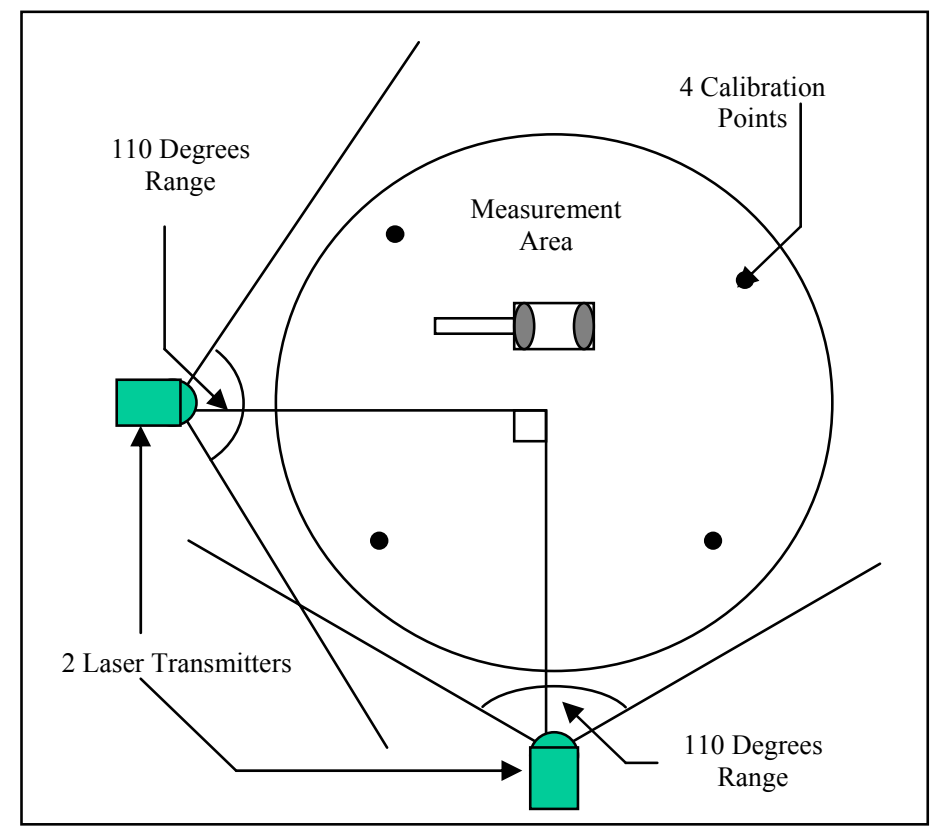

Figure E2.10 The Top View Picture of The Prototype 3 Set-up 


\section{E3. Field Experiments and the Analysis of Field Data}

This chapter presents the design of an integration application, called SPS-CAD. SPS-CAD stands for Spatial Positioning System Integrated CAD. Additional formula and algorithm are provided in order to achieve more accuracy. The algorithm for TCAP provides the direction correction algorithm when only one receiver is used, and the depth adjustment formula can reduce elevation error for around 6 to 8 centimeters depending on the angle of a trencher arm.

The initial and final field experiments were run in the Annex West campus of North Carolina State University. This chapter provides the analysis and commends of experimental results

\section{E3.1 SPS-CAD and Additional Calculation Formula}

\section{E3.1.1 SPS-CAD}

From the previous chapter, Odyssey has been chosen for real-time positioning assessment because it allows real-time positioning measurement and requires no skilled surveyor or extra labor. SPS-CAD, Spatial Positioning System integrated CAD, requires only one trencher operator, and he or she is able to read the coordinates of the trencher from the Odyssey screen, shown in Figure E3.1.

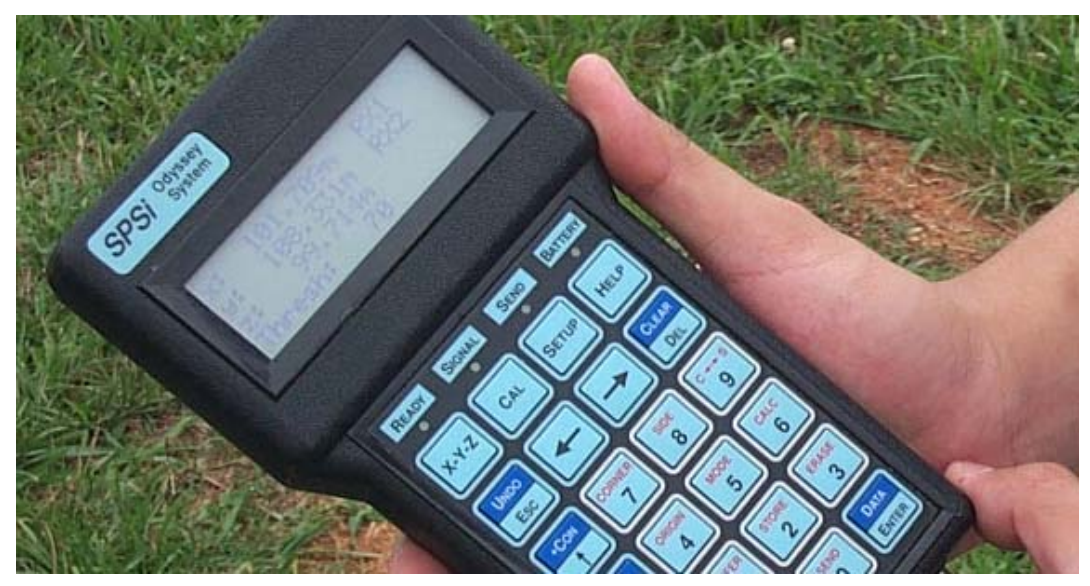

Figure E3.1. The Reading Screen of SPSi or Odyssey 

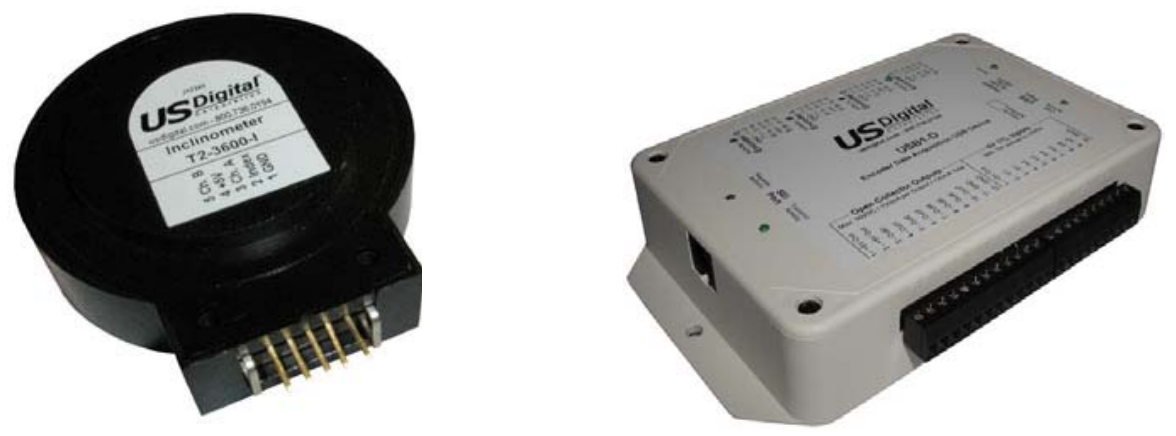

Figure E3.2. T2-7200 Inclinometer and USB1 Data Acquisition from US Digital

In order to assess the accurate location of the trench bottom by knowing the location of the receiver, tilt meters or inclinometers are used to measure the angles $\mathrm{X}, \mathrm{Y}$ and $\mathrm{Z}$ (the details are in the previous chapter). SPS-CAD uses 3 T2-7200 inclinometers from U.S. Digital Inc. The T27200 inclinometer displays 0.05 degree-change reading that allows SPS-CAD to get a more accurate position. Figure E3.2 presents the T2-7200 inclinometers and USB1 data acquisition, and Figure E3.3 shows the location of the mounted inclinometers. Figure E3.4 presents the full photograph of SPS-CAD and a trencher.

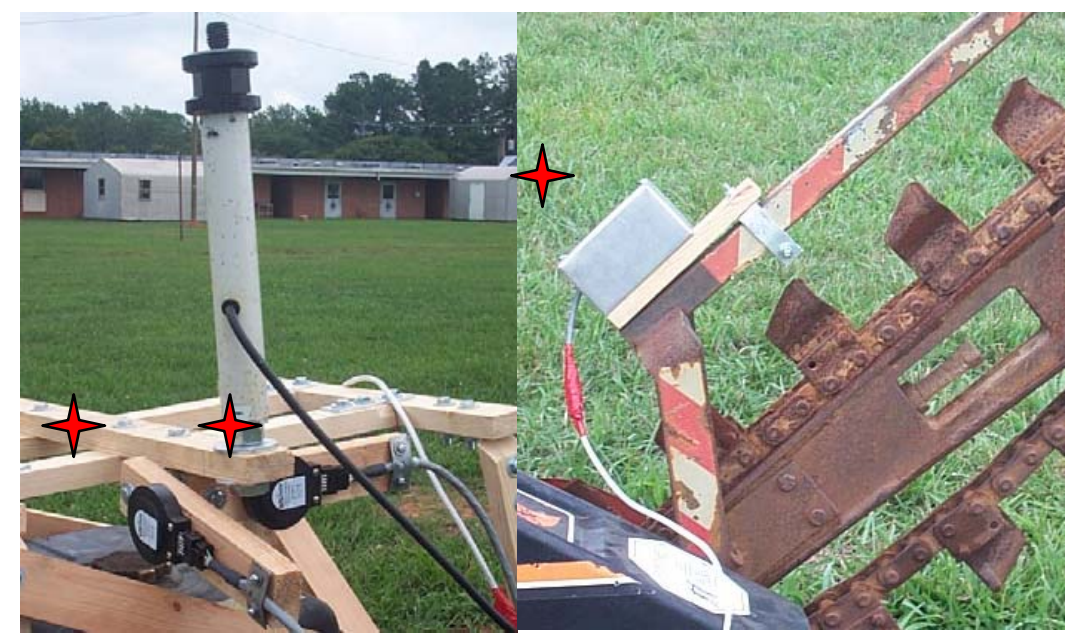

Figure E3.3. The Locations of Three Inclinometers on the Trencher 


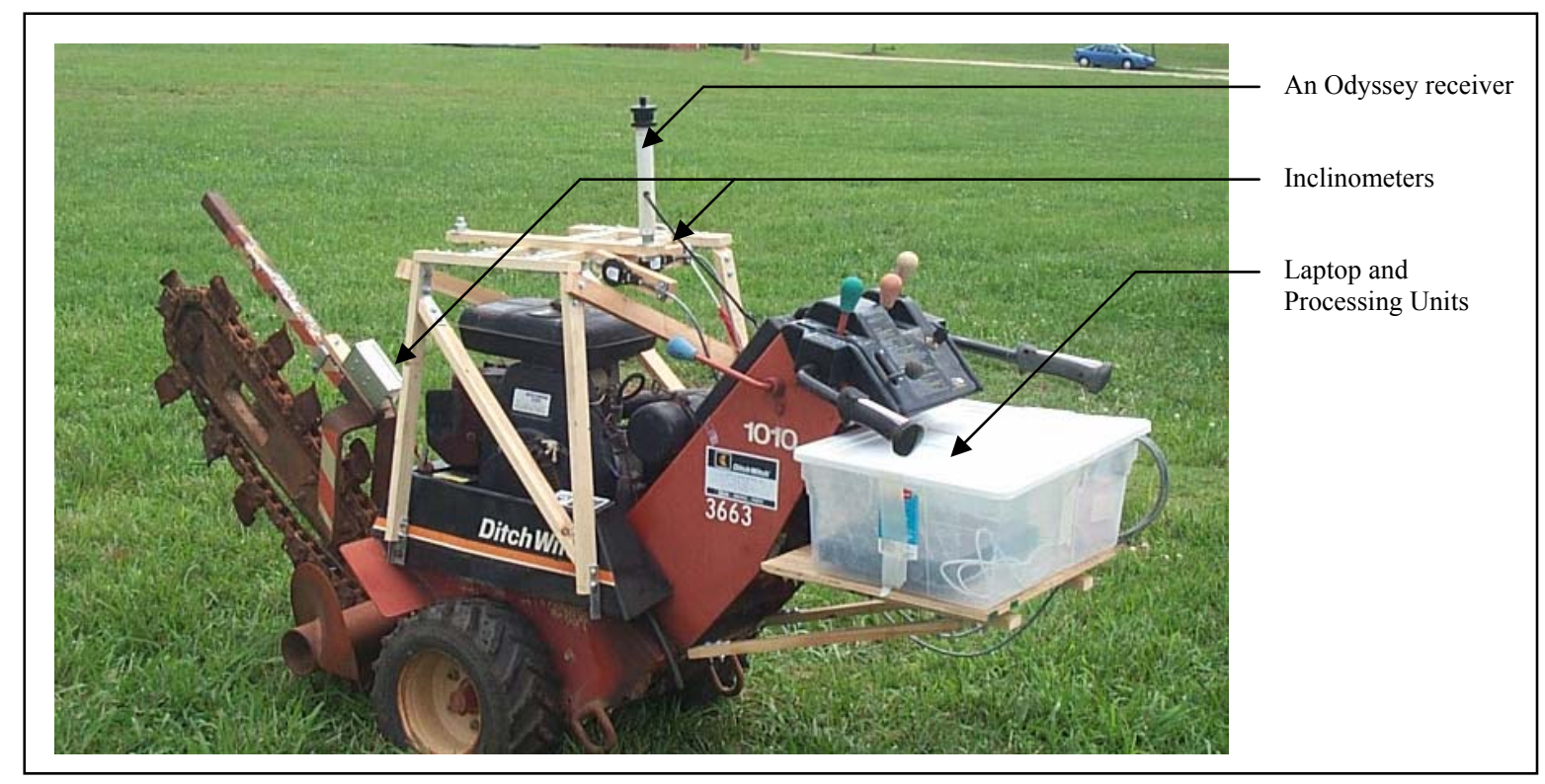

Figure E3.4. A trencher and SPS-CAD

\section{E3.1.2 Algorithm for TCAP (Trench Calculated Point)}

TCAP takes the product of the previous point for correcting the direction of the current calculation. The algorithm is shown in Figure E3.5. From the algorithm, the first calculation of TCAP will obtain the direction from the surveyed point. Only $\mathrm{X}$ and $\mathrm{Y}$ values from the survey point are used for direction correction. Thereafter, the coordinates of the first point and its direction allow acceptable accurate vectors projecting to the trench bottom. Trencher CAL product from point 1 will be used to correct the direction for point 2, and so on. An example in Figure E2.5 explains that an error occurs because the current calculation takes the previous calculation product that normally contains an error. 


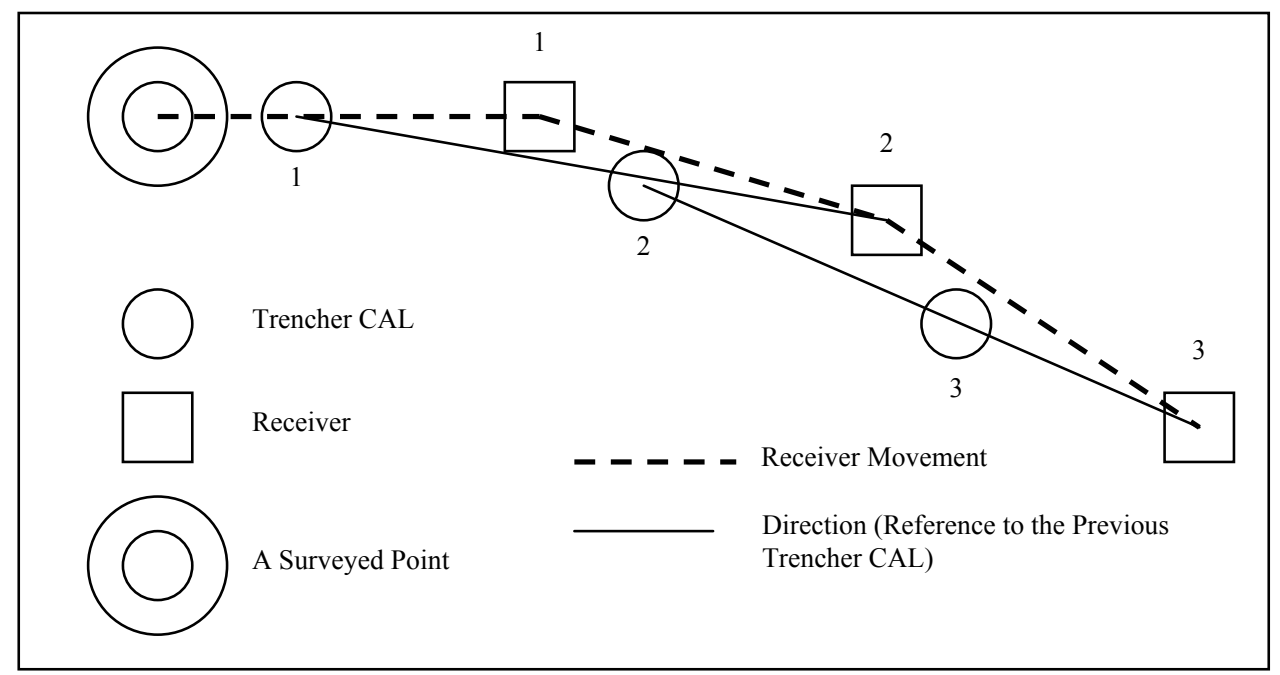

Figure E3.5. The Algorithm of Direction Correction

\section{E3.1.3 TCAP Depth Adjustment}

From the formula in Section E2.1, TCAP is the center point and tip of the trencher arm. A center point and tip of the arm, however, is not the point that exactly tangents a trench bottom. Therefore, one formula must be applied to the elevation of TCAP. Figure E3.6 depicts the existence of a semicircle tip and solution.

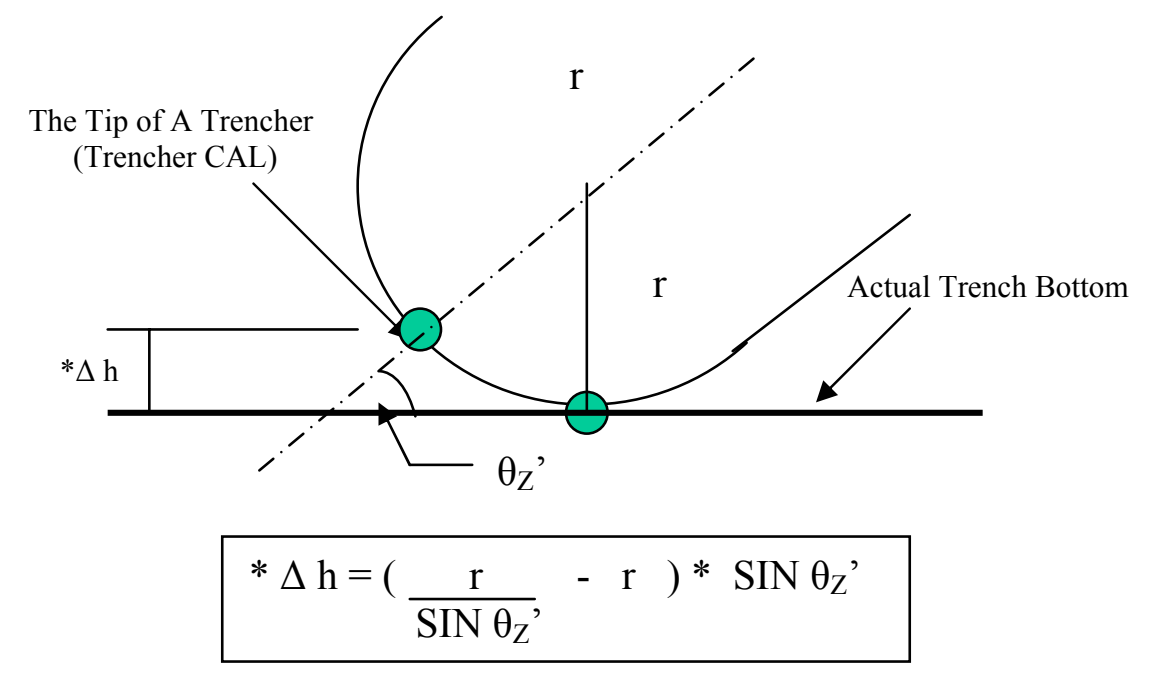

Figure E3.6. Depth Adjustment of TCAP 


\section{E3.2 The Initial Field Experiment}

\section{E3.2.1 Setting up the reference points and Odyssey}

The initial field experiment was conducted in the Annex West campus of North Carolina State University. First of all, four reference points were surveyed by assuming the first point coordinates to be $(100,100,100)$. Thereafter, the Odyssey system was set up and calibrated by using those four reference points. The reference points are located as shown in Figure E3.7, and Table E3.1 shows the coordinates of reference points.

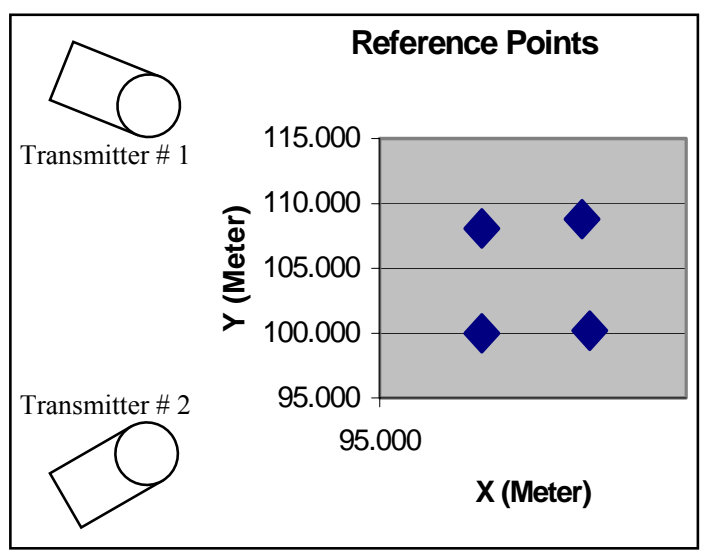

Figure E3.7. Reference Points and Transmitters Location

Table E3.1. Coordinates of Four Reference Points

\begin{tabular}{|l|l|l|l|}
\hline RF Point & $X$ & $Y$ & $Z$ \\
\hline 1 & 100.000 & 100.000 & 100.000 \\
\hline 2 & 99.993 & 108.074 & 100.064 \\
\hline 3 & 104.902 & 108.796 & 100.035 \\
\hline 4 & 105.277 & 100.195 & 100.023 \\
\hline
\end{tabular}

After the calibration was successful, a receiver was attached on SPS-CAD that was on a trencher from Figure E3.4. The leveling-calibration of SPS-CAD is also important and needs to be done before using a trencher. Applying the leveling bulb tool on the platform can simply perform the leveling-calibration. The $\mathrm{X}$ and, then, $\mathrm{Y}$ inclinometers were set to zero when each level is 
perpendicular to gravity along the $\mathrm{X}$-axis and $\mathrm{Y}$-axis, respectively. Finally, $\mathrm{Z}$ angle was also set to zero by turning the trencher arm parallel to Y-axis, aided by using the leveling bulb tool.

After the calibrations were finished, the experiment was started. Two trenches were created and connected to each other. Three sets of information were collected from field: first, coordinates of actual trench point (ATP): second, coordinates of cut trench point (CTP): third, coordinates of trench calculated point (TCAP). ATP and CTP are measured directly from the positioning system (Odyssey). TCAP is calculated from the position of the receiver, changing angles, and the projection vector from a receiver to the tip of trencher blade.

\section{E3.2.2 Data Collection}

To determine TCAP, two sets of information are needed. First, the coordinates of a receiver can be saved on the flash memory in the Odyssey processing units. The elevation of the receiver that is shown on the screen is not a true value because the height of the carriers is different from the calibration rod. Therefore, the formula to calculate the true elevation of the receiver is shown below.

Actual Elevation $=\mathrm{Rh}+\mathrm{H}$

when $\quad \mathrm{H}=$ the height of a calibration rod

$\mathrm{Rh}=$ the elevation reading from the instrument

Second, 3 changing-angles reading from inclinometers can be obtained by using manufacturer's software. Fifty samples were generated at each point that the receiver coordinates were measured. The average or mean will be the representative of the whole samples. The coordinates of the trench bottom were calculated by using these angles plugged in formulas in Section E2.1 (Utility Location Assessment) and all adjustments in Section E3.1. By doing so, TCAP can be assessed and thereafter compared to ATP and CTP.

To measure CTP and ATP, Odyssey system on its calibration rod is a very simple and productive way. Correction on actual elevation is not required. Measuring CTP and ATP is required because 
a trencher creates an error itself by spilling dirt back into a trench. Figure E3.8 shows how the trench measurement was set up. Measuring coordinates on a plastic glass does not disturb soil condition because of a sharp tip of the calibration rod. Examples of receiver coordinates, ATP, and CTP, and Angles data are shown in Table E3.2 and Table E3.3.All raw data are in Appendix A: The Initial Field Experiment data.

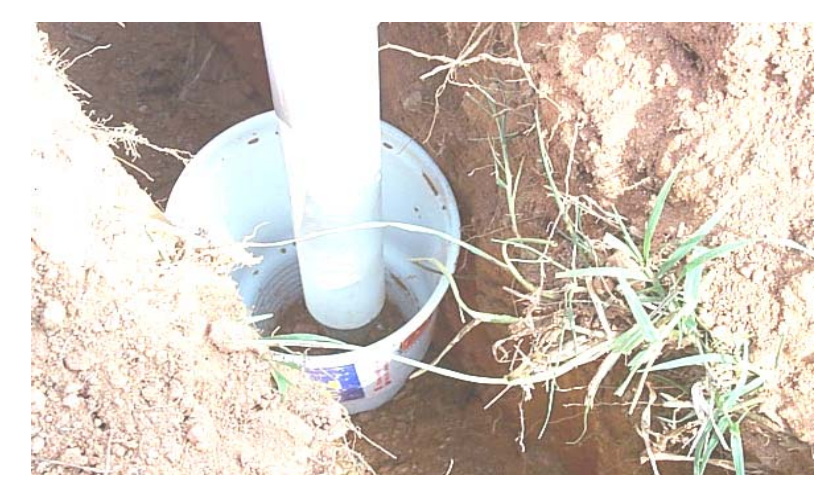

Figure E3.8. Trench Measurement Set-up

Table E3.2 Receiver Position, ATP, and CTP Data

\begin{tabular}{|l|l|l|l|l|l|l|l|l|l|}
\hline \multirow{2}{*}{ Point } & \multicolumn{4}{|l}{ Receiver Position } & \multicolumn{2}{l|}{ ATP } & \multicolumn{2}{l|}{ CTP } \\
\cline { 2 - 10 } & X (meter) & Y (meter) & Z (meter) & X (meter) & Y (meter) & Z (meter) & X (meter) & Y (meter) & Z (meter) \\
\hline 1 & 101.659 & 107.390 & 99.743 & 101.980 & 109.699 & 99.658 & 101.970 & 109.545 & 99.561 \\
\hline 2 & 101.603 & 106.947 & 99.745 & 101.936 & 109.219 & 99.636 & 101.909 & 109.176 & 99.565 \\
\hline 3 & 101.577 & 106.256 & 99.733 & 101.870 & 108.780 & 99.637 & 101.869 & 108.843 & 99.559 \\
\hline
\end{tabular}

Table E3.3 Angles Data

\begin{tabular}{|c|c|c|c|c|c|c|c|}
\hline \multirow{4}{*}{$\begin{array}{l}\text { Point } \\
\# 1\end{array}$} & $\theta \mathrm{x}$ & $\theta \mathrm{y}$ & $\theta z^{\prime}$ & \multirow{4}{*}{$\begin{array}{l}\text { Point } \\
\# 2\end{array}$} & $\theta \mathrm{x}$ & $\theta \mathrm{y}$ & $\theta \mathrm{z}^{\prime}$ \\
\hline & 79 & 7177 & 6625 & & 87 & 7195 & 6611 \\
\hline & 82 & 7179 & 6629 & & 88 & 7197 & 6609 \\
\hline & 84 & 7176 & 6629 & & 90 & 7191 & 6611 \\
\hline
\end{tabular}




\section{E3.2.3 Analysis of Initial Field Experiment}

Figure E3.9 depicts that when a trencher is making a curve, the TCAP curve is inside the ATP curve. Figure E3.9 also shows the locations of TCAP and ATP including the photograph of the cut trench. Figure E3.10 shows an error in the X-Y plane.From the photograph of Trench \# 1 in Figure E3.8, the Trench \# 1 was a straight line in the first half and then turned to a curve. The accuracy of TCAP is very good while the trench was a straight line. On the other hand, when the trench is a curve, TCAP curve is at the left side or inner curve of the ATP curve.

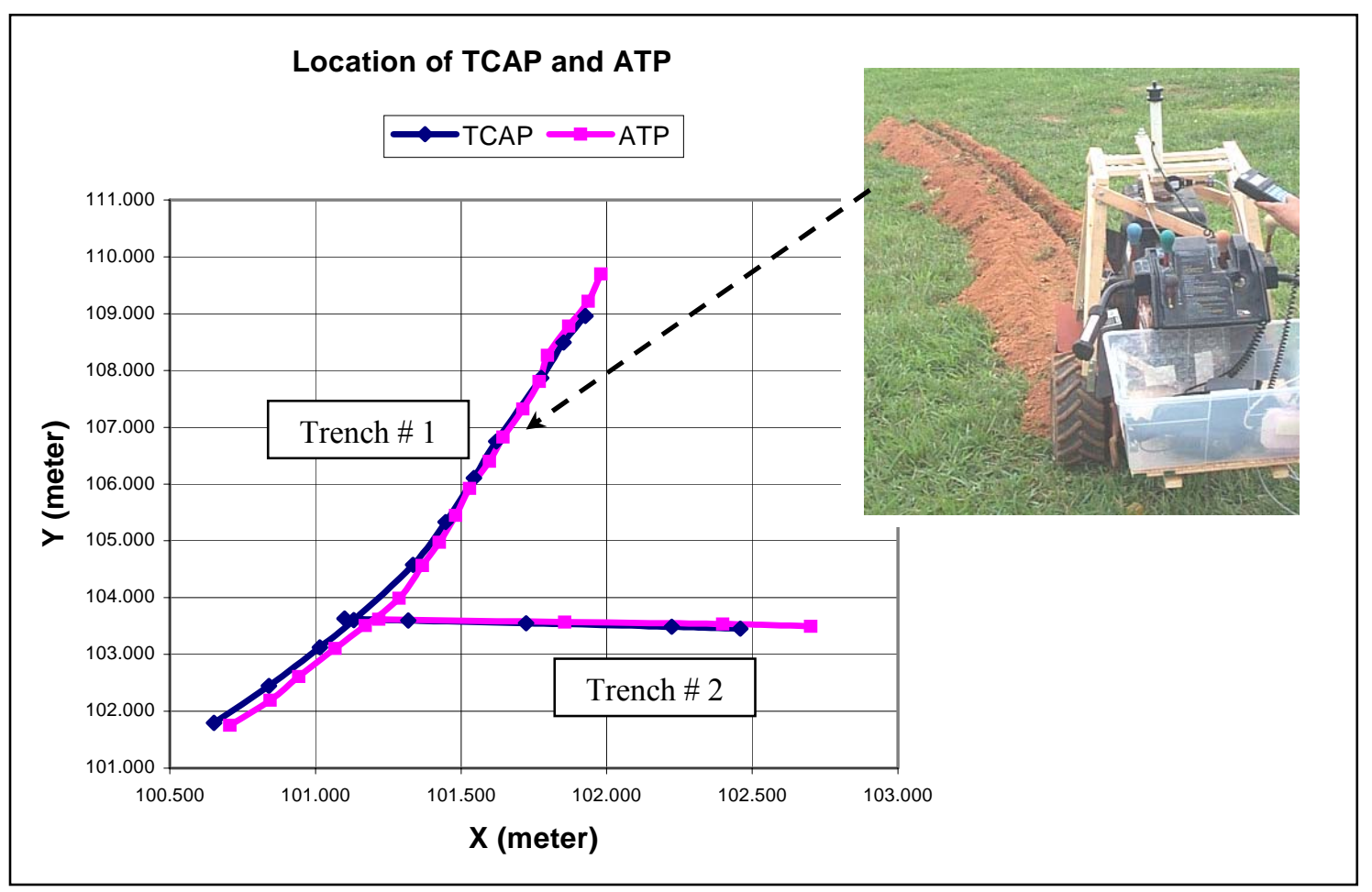

Figure E3.9 The Top View of TCAP and ATP

From Figure E3.10, a maximum error in the X-Y plane is quantified from the perpendicular distance between the ATP curve and TCAP curve. The error is approximately 7.5 centimeters. Figure E3.11 presents the profiles of Trench \#1 along the Y-axis and elevation. A maximum error in $\mathrm{Z}$ direction or an elevation error from ATP is 12 centimeters for Trench \#1 and 7.5 centimeters for Trench \#2. A maximum error in $\mathrm{Z}$ direction from CTP is 5 centimeters for Trench \#1 and 8 centimeters for Trench \#2. The ATP profile is the true utilities-placement 
elevation, but the CTP profile is not the true. Moreover, ATP profile is normally above CTP profile, and TCAP profile runs between those profiles.

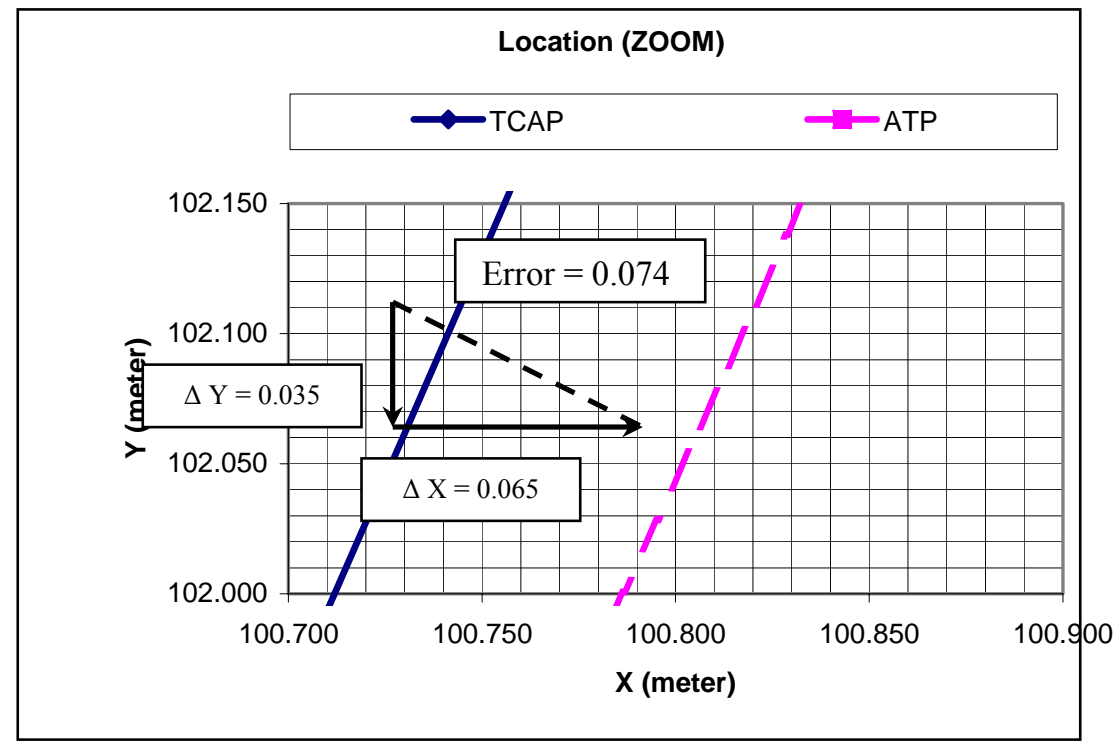

Figure E3.10. An Error in X-Y Plane

From Figure E3.11, TCAP profile should have given the CTP profile according to the calculation. An error, however, can cause slightly different shapes between the CTP and the TCAP. Unfortunately, the ATP profile is unpredictable because it depends on the characteristics of a trencher and an operator.

Even though the shape of TCAP profile is similar to the CTP, some part of the TCAP profile is below that of CTP. In reality, that is impossible. The problem can result from stopping a trencher to gather data in a long distance interval. Figure E3.12 depicts why shorter intervals create less error. The thick lines represent the trench profiles that are collected from the system. 


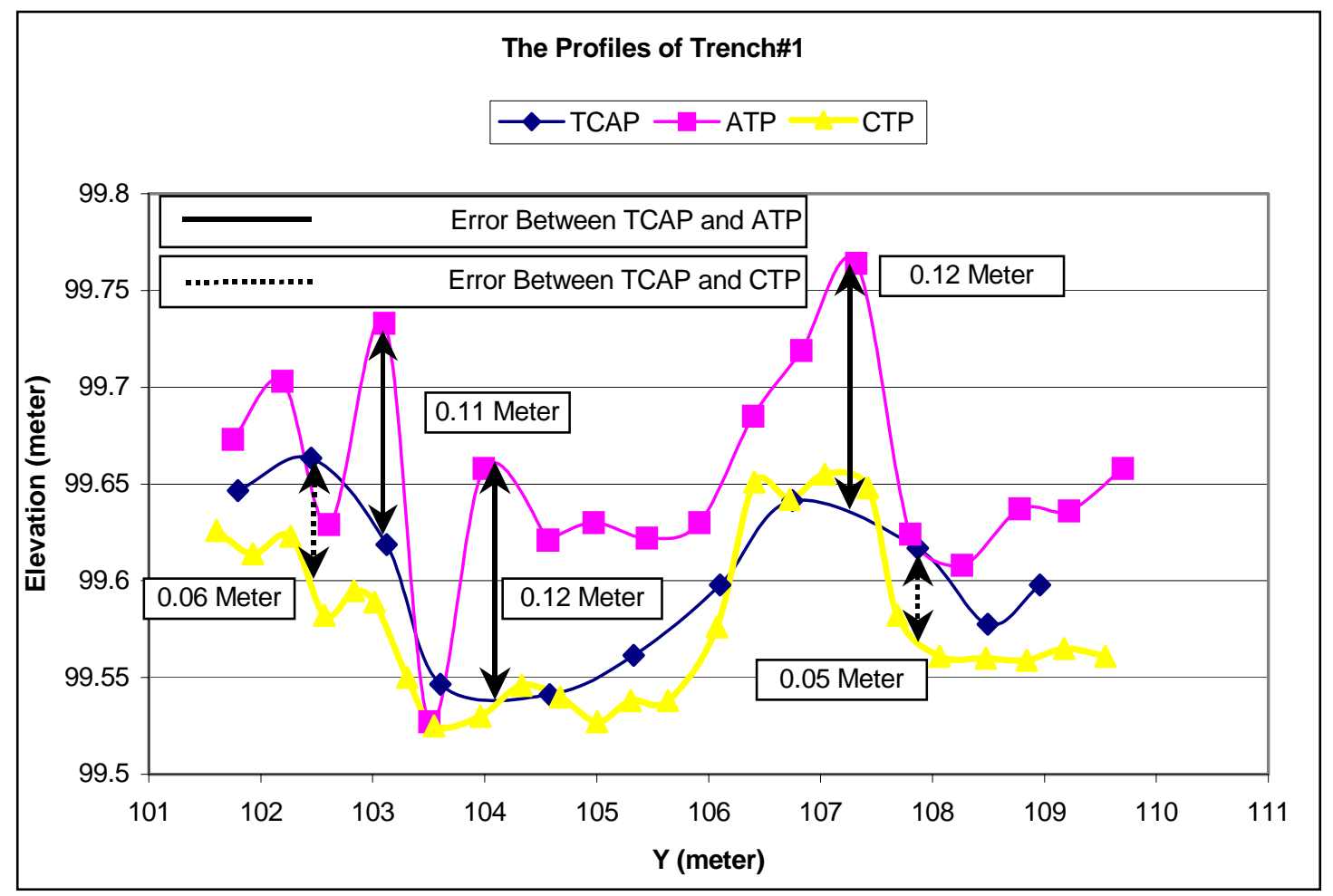

Figure E3.11. The Profiles of Trench \#1

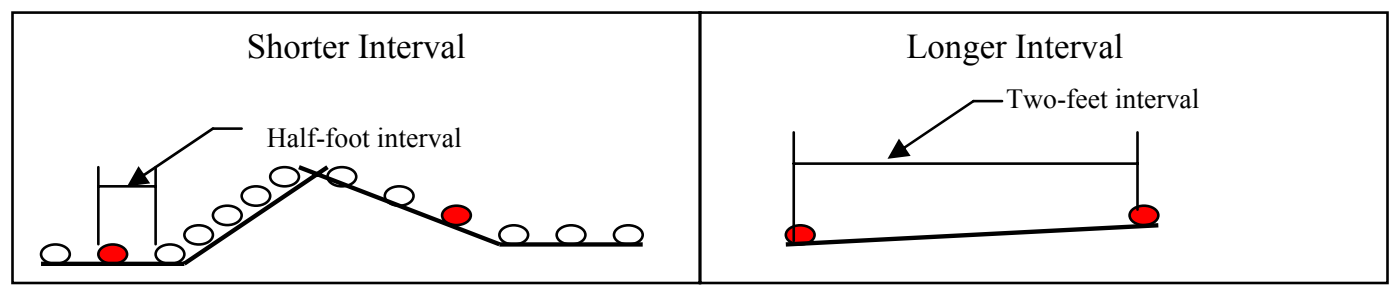

Figure E3.12. The Advantages of Real-time Data Collection

\section{E3.2.4 Questions to the Final Experiment}

Overall, the initial field experiment favorably provides a significant amount of data and information. In particular, it demonstrated the validity of collecting the spatial data while trenching.

- How does the TCAP profile compare to the ATP profile if a trencher faces an immediate side slope such as a bump?

- Can the calibration of a trencher, instead of calibrating only a platform, improve an accuracy of Trencher CAL? 
- Is the measurement of trencher dimensions in figure 6.2 accurate, and if it is not, what are the correction values?

\section{E3.3 Final Field Experiment}

\section{E3.3.1 Setting up the Reference Points and Odyssey}

First of all, four reference points has been surveyed by assuming the first point coordinate to $(10,10,10)$. Thereafter, the Odyssey system was set up and calibrated by using the reference points. The reference points are located as shown in Figure E3.13, and Table E3.4 shows the coordinates of reference points.

Experience from the initial field experiment is that only prototype calibration may not be able to accurately set up zero-angles. Even though the SPS-CAD is leveled, a trencher may not be leveled. Therefore, in the final field experiment, the "whole" system was calibrated at one time.

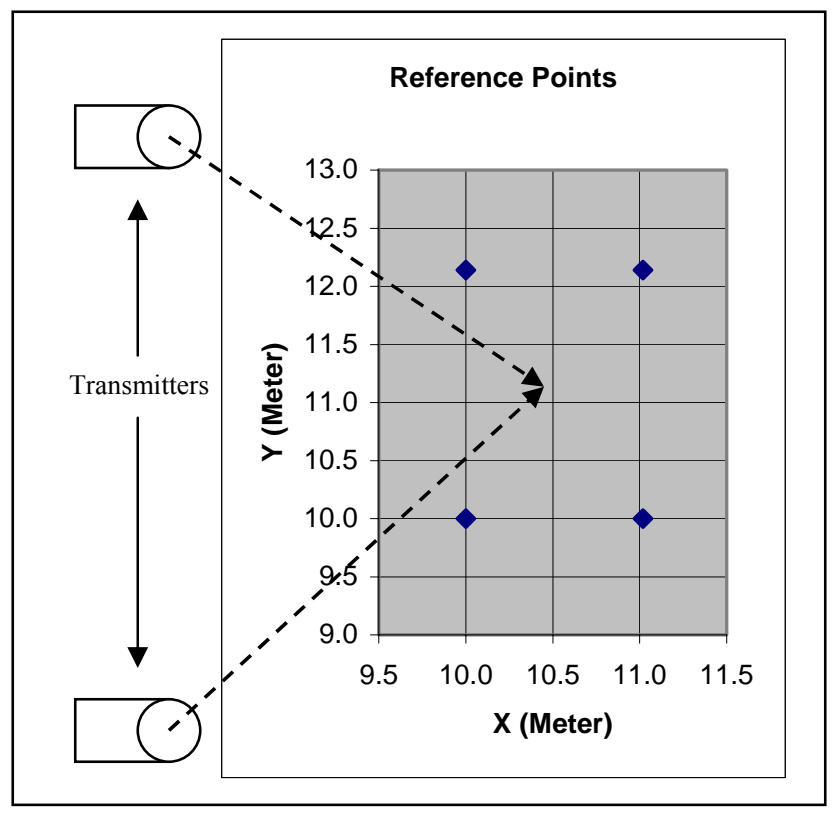

Figure E3.13. Reference Points and Transmitters Location 
Table E3.4 Coordinates of Four Reference Points

\begin{tabular}{|l|l|l|l|}
\hline RF Point & X & $Y$ & $Z$ \\
\hline 1 & 10.000 & 10.000 & 10.071 \\
\hline 2 & 10.000 & 12.141 & 10.000 \\
\hline 3 & 11.018 & 12.141 & 10.000 \\
\hline 4 & 11.018 & 10.000 & 10.070 \\
\hline
\end{tabular}

The calibration was simply done by placing a trencher on a flat and level floor, and then all inclinometers were set to zero. Figure E3.14 shows the "whole" system calibration. Using a measuring tape to measure the trencher dimensions can possibly cause a considerable error. From Figure E2.2, the $\mathrm{H}$ and $\mathrm{S}$ distances from the measuring tape may not be perpendicular and parallel, respectively, to $\mathrm{X}$-axis and $\mathrm{Y}$-axis, even though the "whole" system calibration was successful. Therefore, coordinate-correction values can possibly improve accuracy. After the final field experiment was finished, the tip of a trencher was measured by using the Odyssey calibration rod. Figure E3.15 presents the coordinate-correction values.

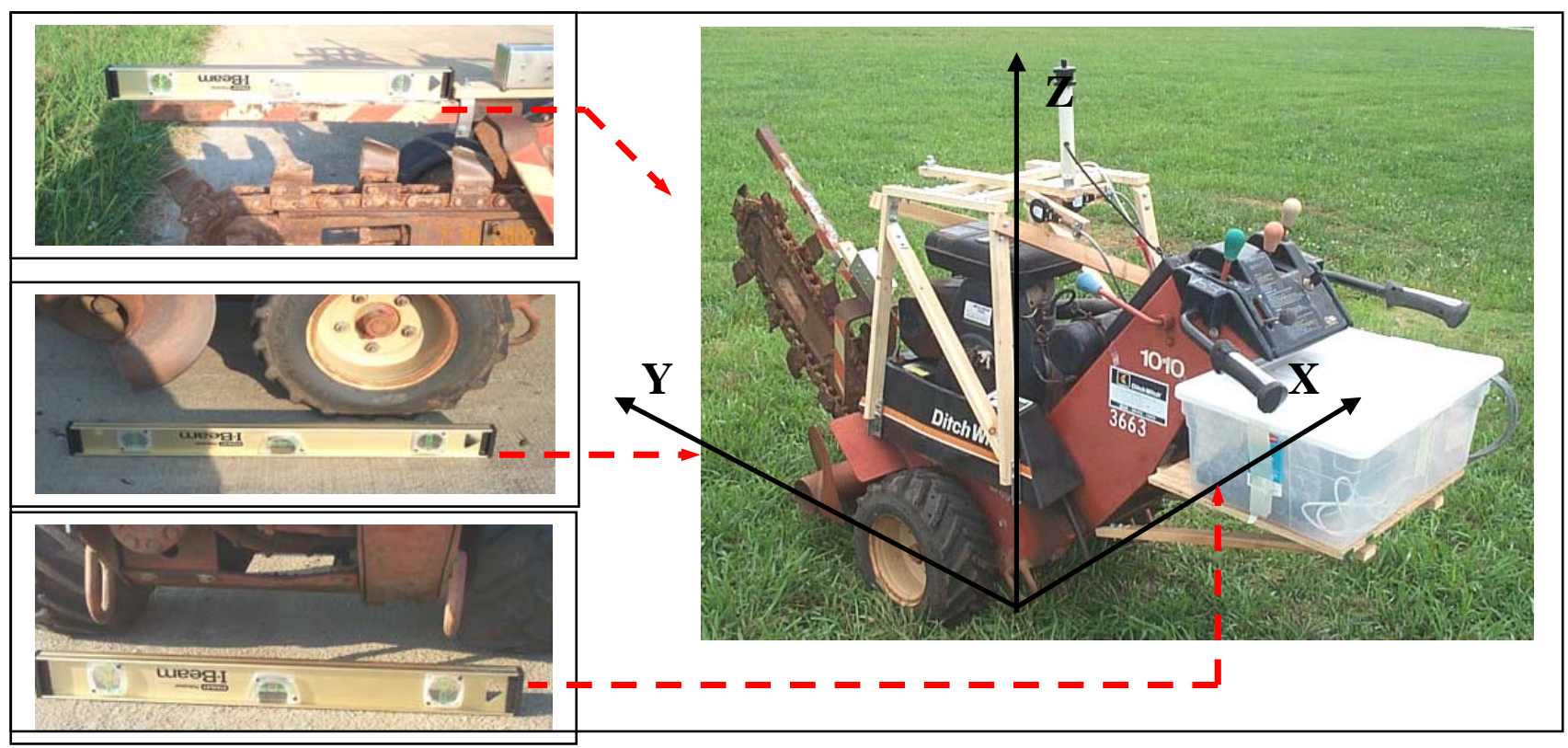

Figure E3.14. “Whole” System Calibration 


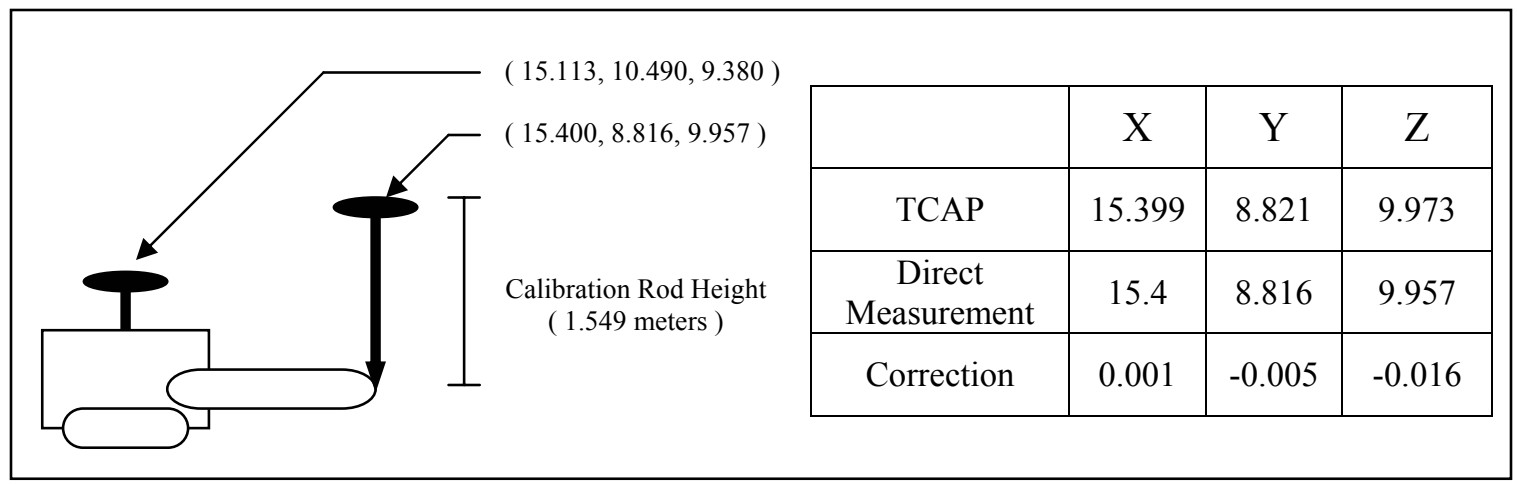

Figure E3.15. Coordinate-Correction Values

\section{E3.3.2 Data Collection and Analysis of the Final Field Experiment}

In the final field experiment, an object was placed under the right wheel and then the left wheel of the trencher. Figure E3.16 shows the positions of a receiver, TCAP and ATP. The positions and photograph of the object are provided in Figure E3.16.

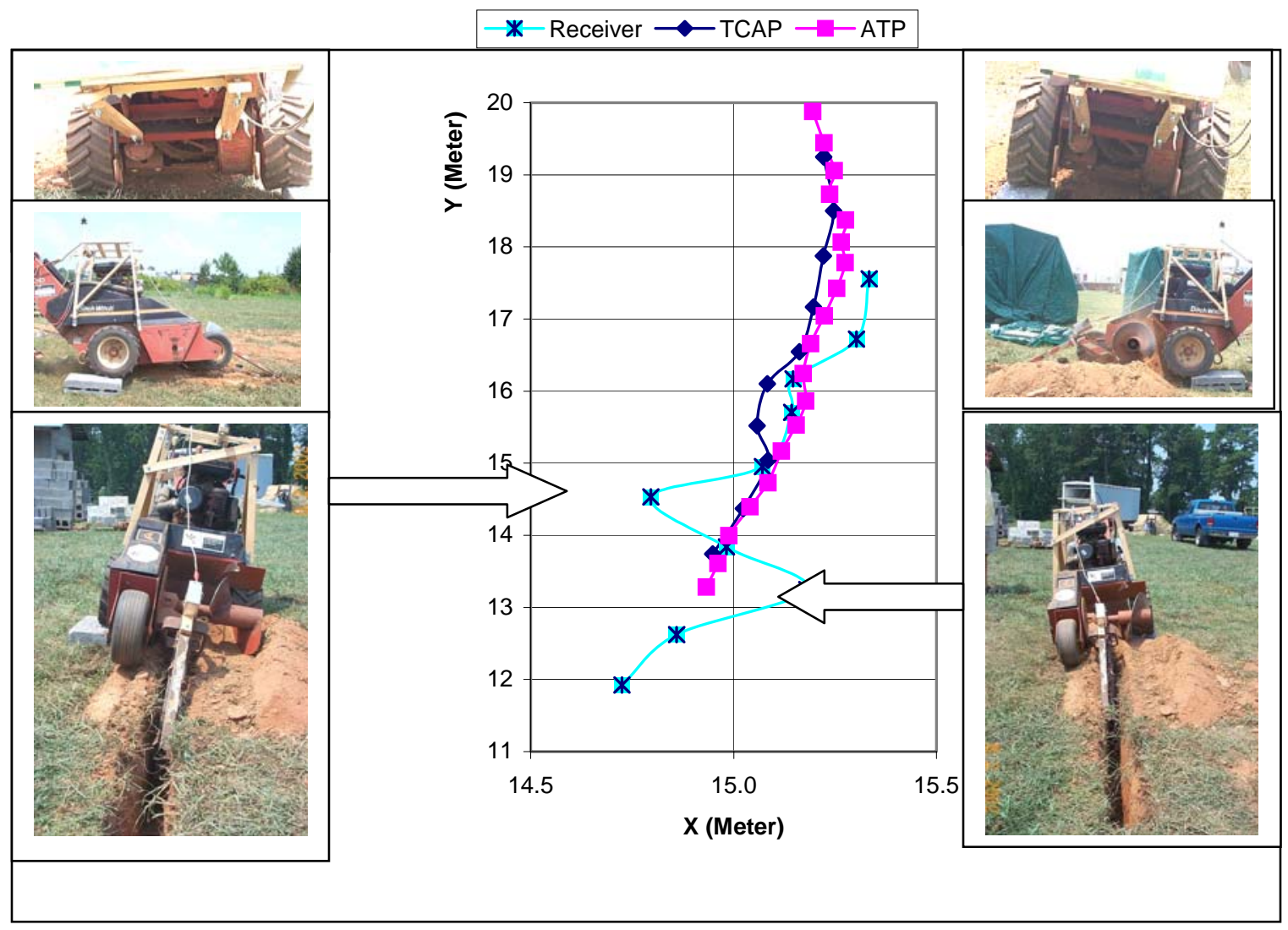

Figure E3.16. Locations of a Receiver, TCAP, and ATP 
When a trencher encountered an object under its wheel, the receiver swayed to the opposite direction to ATP. For example, if an object were under the left wheel, the receiver would sway to the right of ATP. From the experiment, when a trencher hit an object under the right wheel, TCAP created the largest error. After that when a trencher faced an object under the left wheel, TCAP also created an enormous error but in the opposite direction from the first time with approximate same size. Therefore, an error that was created by first hitting an object was taken out by the second hitting an object. Figure E3.17 depicts locations while a trencher faced objects, and Figure E3.18 presents the maximum error in X-Y plane. The error is approximately 11 centimeters.

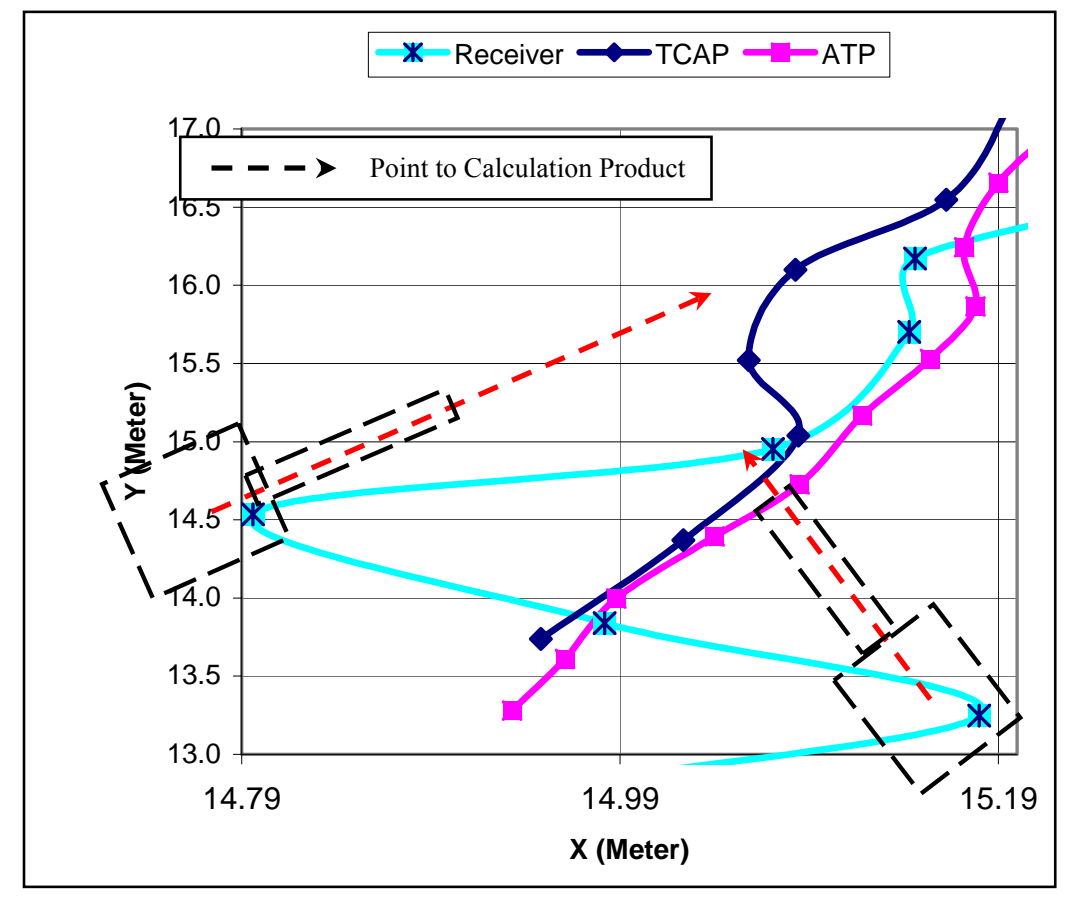

Figure E3.17. Locations While Hitting Objects

An error obviously occurs if a trencher tilts along $\mathrm{X}$-axis. However-

- What happens if a trencher only encounters an object under the right wheel, and then moves straight and level?

From the algorithm for TCAP in Figure E3.5, the scenario in Figure E3.19 is that a trencher faces an object under the right wheel at point \#2. Then, the trencher moves on the level ground at point 
\#3 and point \#4. Therefore, TCAP \#2 has the greatest error. The scenario can lead to two assumptions regarding a maximum error caused by hitting an object or side tilting.

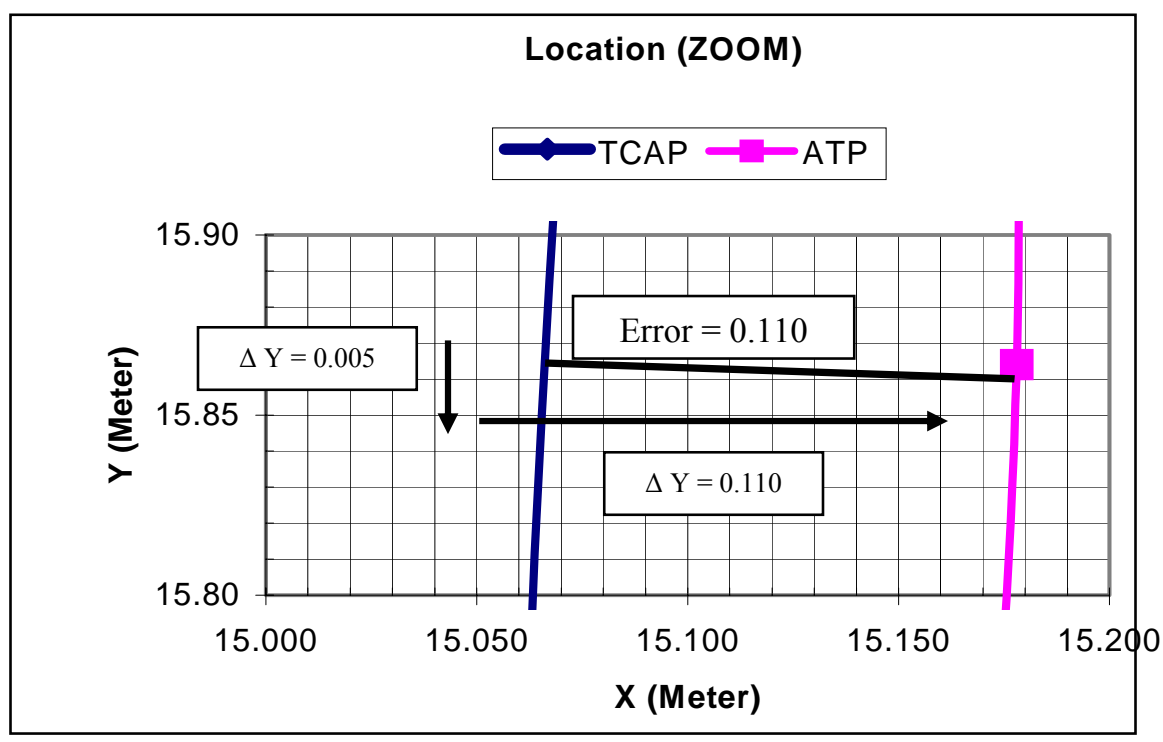

Figure E3.18. An Error in XY Plane

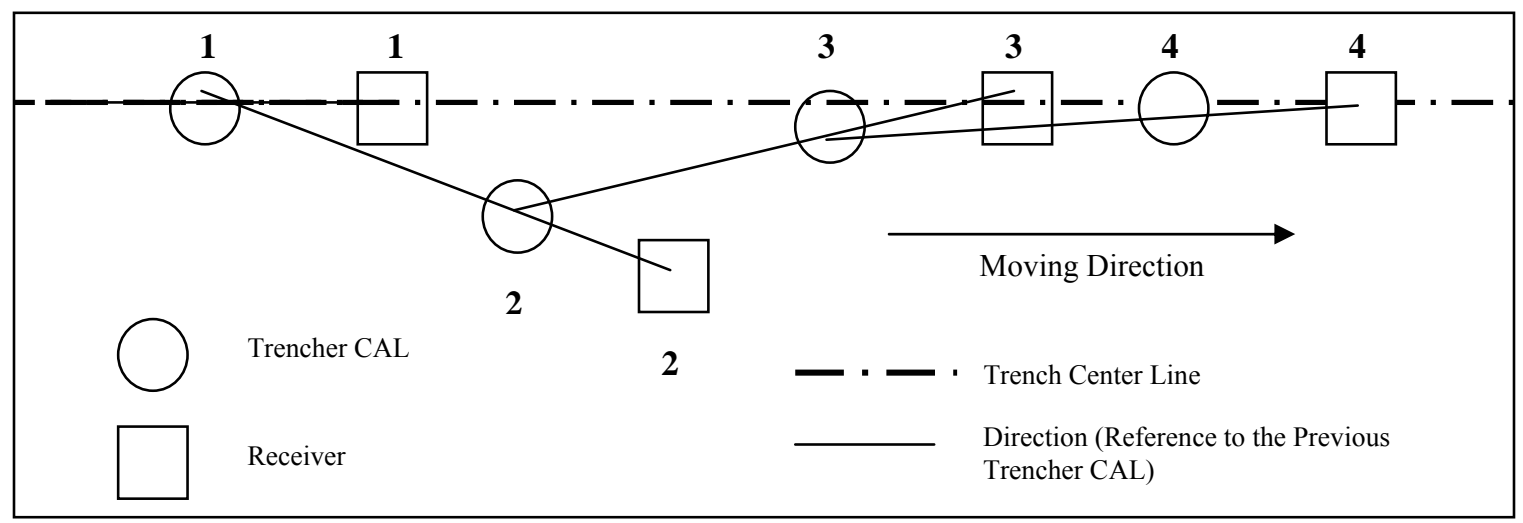

Figure E3.19. The Scenario Showing Self-Correcting Direction

- The greatest side tilting that can occur to a trencher while it is operating creates the largest error in X-Y plane.

- There is no accumulative error if a trencher moves over objects at the same side more than one time. 
From Figure E3.20, trench profiles results are almost similar to the first experiment. An error between TCAP and ATP is about 12 centimeters. An error between TCAP and CTP is 12 centimeters.

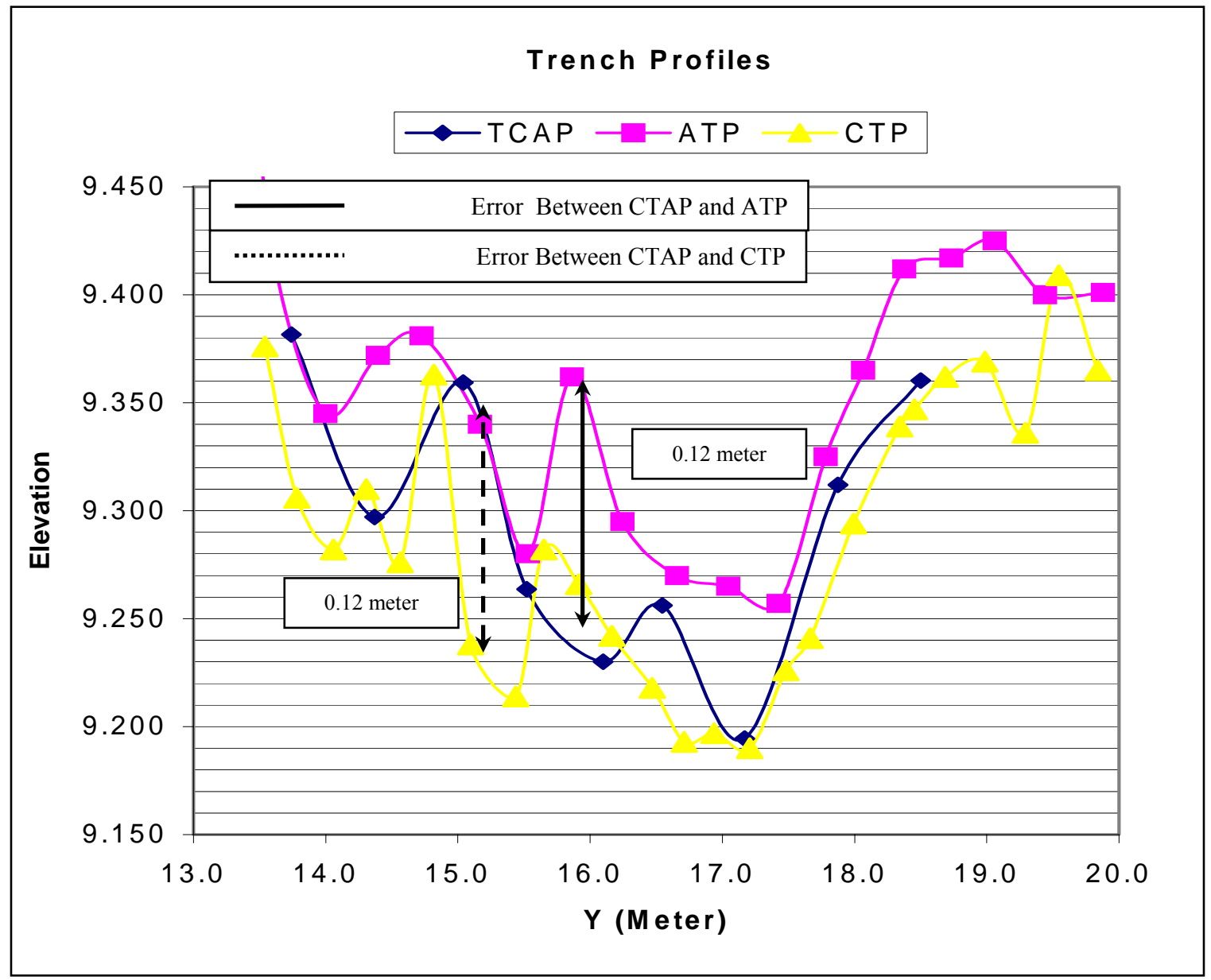

Figure E3.20. The Trench Profiles

\section{E3.4 SPS-CAD Software}

The integrated software is introduced. SPS-CAD software comprises two elements: TCAP.exe and DRAW.lisp. TCAP.exe is written in C-language to execute the calculations by taking a receiver coordinates file and angles files as the inputs. TCAP.txt, the output, will later be an input file for DRAW.lisp. DRAW.lisp, LISP- language, finally outputs As-built.dwg that is compatible with commercial spatial analysis software in the market such as Arcview GIS. All source codes are in Appendix: C. The diagram in Figure E3.21 shows the flow. 


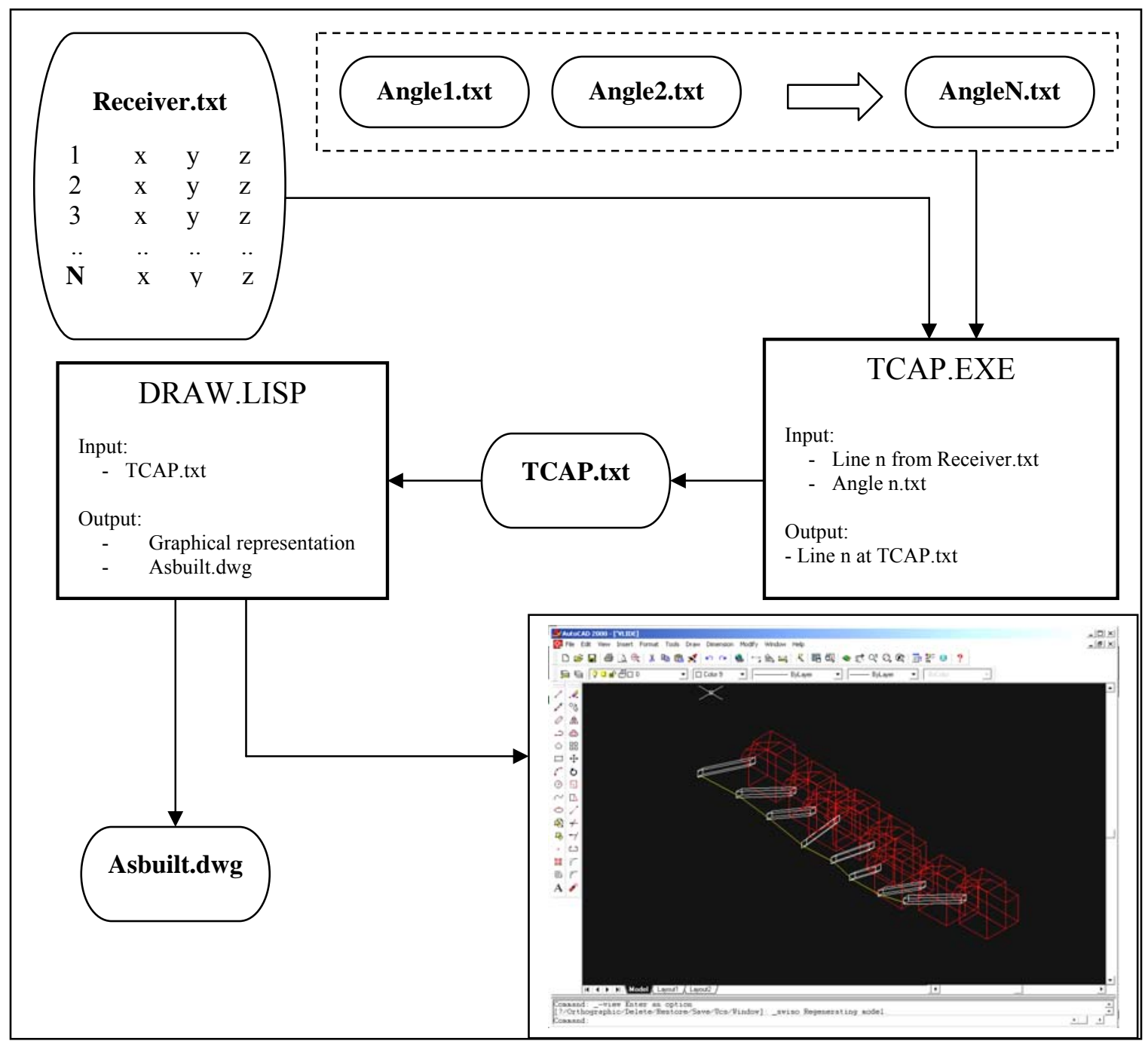

Figure E3.21 Data Flow Diagram of SPS-CAD Software

\section{References for Appendix E}

Trimble (2002), <http://www.trimble.com/gps/> (Mar. 11, 2002)

Yvan, J., Beliveau, J., Williams, M., King, M.G. and Niles, A.R. "Real-Time Position Measurement Integrated with CAD: Technologies and Their Protocols." journal of construction engineering and management, Vol. 121, Issue 4, November/December 1995 $346-354$ 